Balázs Vaszkun

\title{
One Hundred Years of Management
}

American Paradigms and the Japanese Management "Reloaded" 
Institute of Management

Department of Management and Organization

Supervisor: Prof. Miklós Dobák

(C) Balázs Vaszkun, 2012 
Corvinus University of Budapest

Management and Business Administration

Doctoral School

\section{ONE HUNDRED YEARS OF MANAGEMENT AMERICAN PARADIGMS AND THE JAPANESE MANAGEMENT "RELOADED"}

Doctoral Thesis

Vaszkun Balázs György

Budapest 2012 



\section{Table of contents}

Foreword

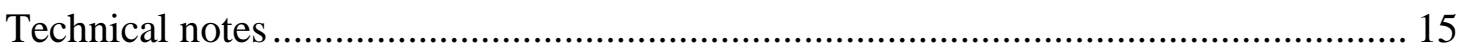

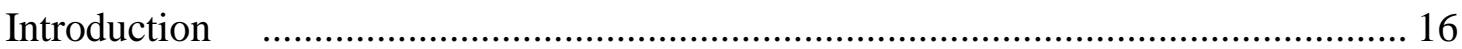

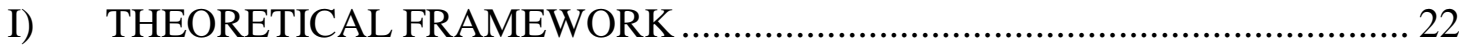

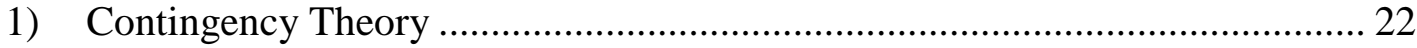

2) Organizational economics: the agency and transaction cost theories.............. 26

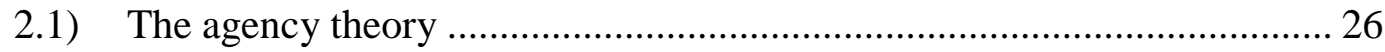

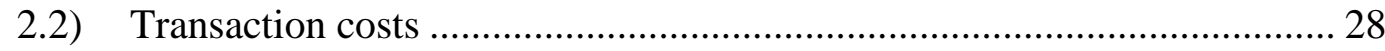

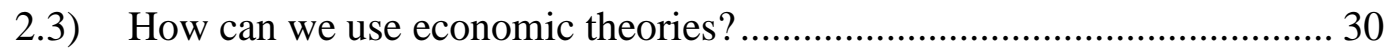

3) The theoretical framework of change for national management patterns ........ 31

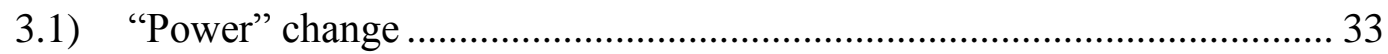

3.2) "Generational" change: the sociological perspective .............................. 34

3.3) Institutional or evolutionary change: decisive but invisible ..................... 34

3.4) Long-term partnership: a socialization process .................................... 35

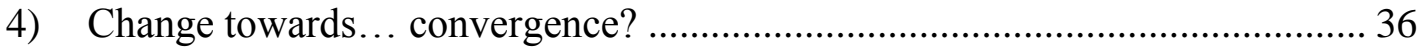

II) THE EVOLUTION OF AMERICAN MANAGEMENT ................................... 39

1) Scientific Management: engineered production .......................................... 40

2) Human Relations: the "awakening" employee ............................................ 44

3) Structural Revision and Open Systems......................................................... 51

4) Strategies for Global Competition .......................................................... 56

5) Making sense of the world of paradigms: summary and implications .............6 64

III) THE EVOLUTION OF JAPANESE MANAGEMENT .................................. 70

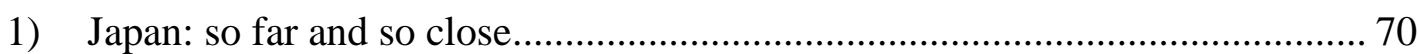

2) From feudalism to modern business in Japan................................................ 75

3) Taylorism, the efficiency movement, and Scientific Management ................. 79

4) Human Relations: a lack of raison d'être?................................................... 83 
5) Structural Revision and the export of the Japanese Production System........... 85

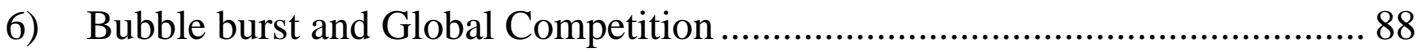

7) Summary of management paradigms in Japan ........................................... 92

IV) THE CHARACTERISTICS OF JAPANESE MANAGEMENT ....................... 93

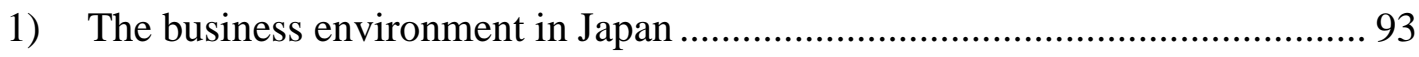

1.1) A small living area with frequent catastrophes .................................... 94

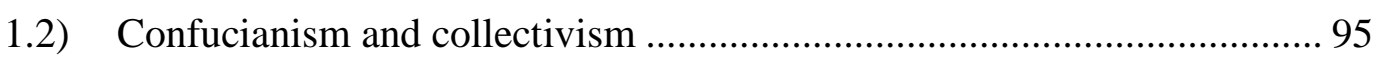

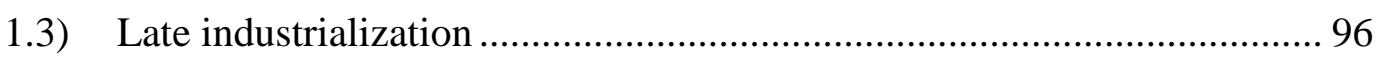

1.4) Developmental state and protected markets ......................................... 97

1.5) An economy with continuous growth.................................................. 102

1.6) An ambiguous and rigid labor market ............................................ 103

2) Corporate assets in the past and present ................................................. 105

2.1) Easy-to-train and devoted employees.................................................. 106

2.2) Superiors are more managers than leaders .......................................... 107

2.3) Homogeneity and male dominance ................................................... 108

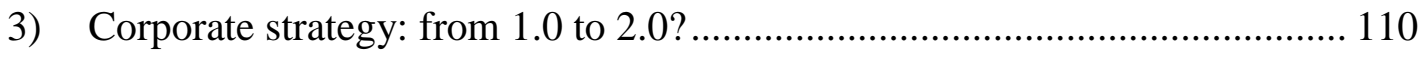

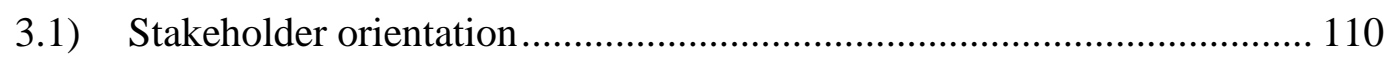

3.2) Cost and quality leadership (vs. product differentiation) ..................... 112

3.3) Diversified portfolios, spin-offs and start-ups ................................... 113

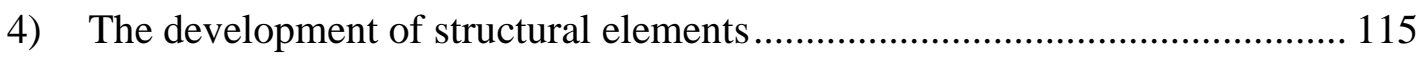

4.1) Big and complex, U-form based group hierarchy .............................. 115

4.2) Large boards dominated by insiders ................................................. 119

4.3) Central HRM prevails over Finance _................................................... 121

4.4) Processes of decision making: a consensual approach ......................... 123

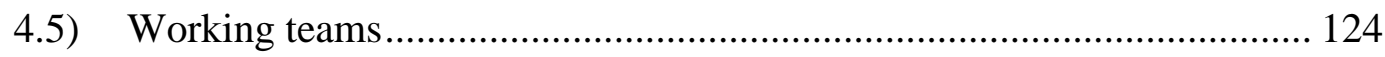

5) Organizational Behavior and employment philosophy .............................. 125

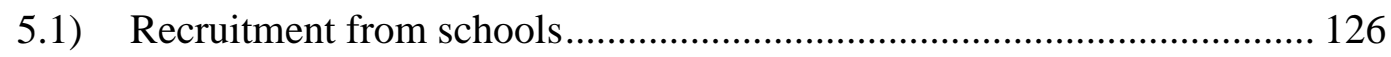

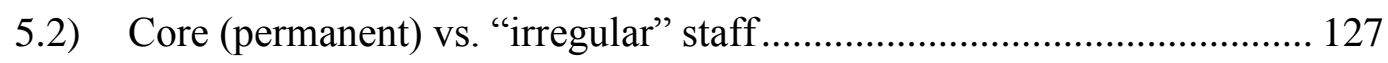




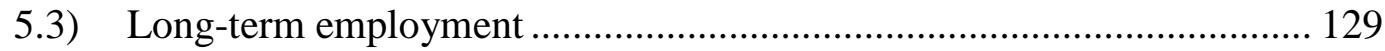

5.4) Formal induction with the chairman: creating a family ....................... 131

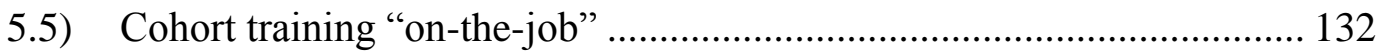

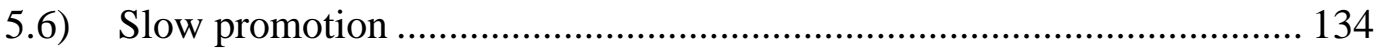

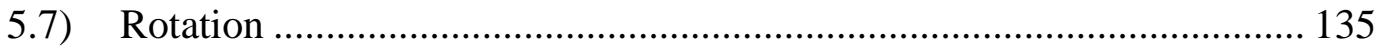

5.8) Tenure-based compensation or "Seniority pay" .................................... 136

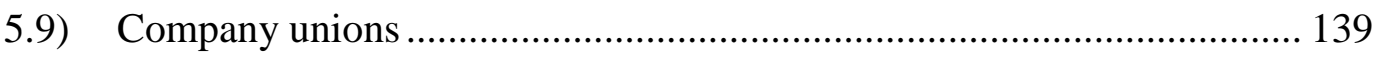

6) Control and performance measurement............................................... 143

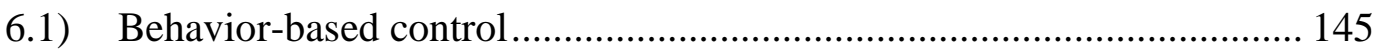

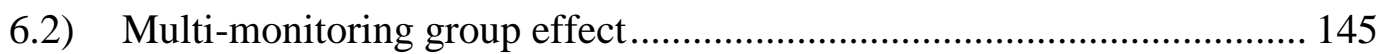

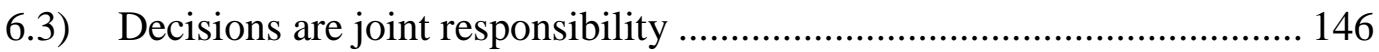

6.4) Good performance means increasing market share and harmony ........... 148

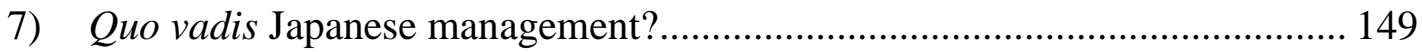

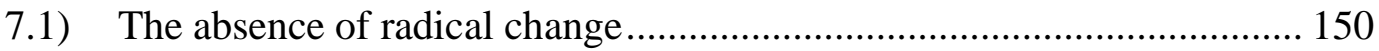

7.2) A questionable change led by new generations .................................... 151

7.3) The step-by-step process of institutional change.................................... 153

7.4) The incremental effects of foreign ownership and international trade .... 154

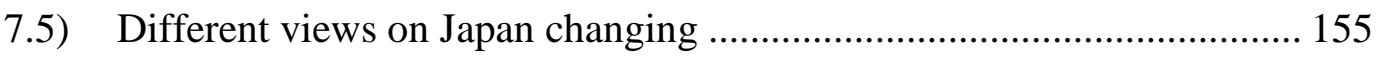

8) Summary of the Japanese management literature ..................................... 159

V) UNDERSTANDING THE INTERNAL PRESSURES IN SOCIETY............. 162

1) Preparing the field: Research Design ......................................................... 163

1.1) Research question for the survey..................................................... 163

1.2) Hypothesis (1) on the link between observed trends and attitudes.......... 164

1.3) Hypothesis (2) on internal support .................................................. 164

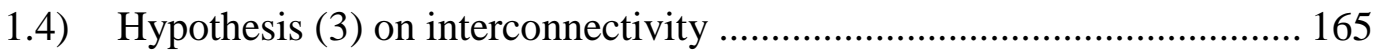

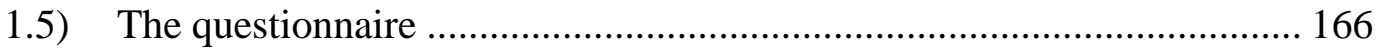

1.6) Panel, methodology and relevance ................................................... 168

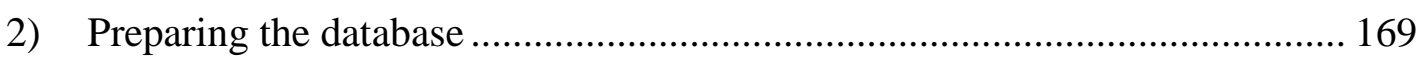


2.1) Risk factors, possible errors: data reliability ........................................ 169

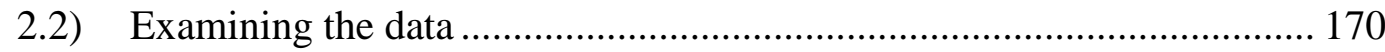

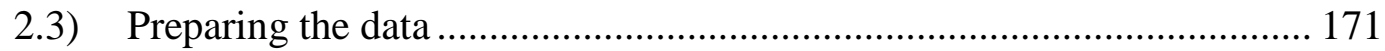

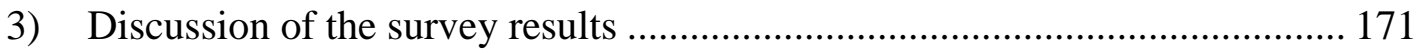

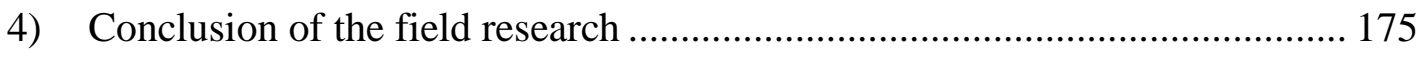

VI) THESIS SUMMARY: PARADIGM CHANGES IN MANAGEMENT ......... 177

ANNEX I: A parallel between contingency theory and management history ...... 183

ANNEX II: Further potential paradigms - recent trends and models .................... 186

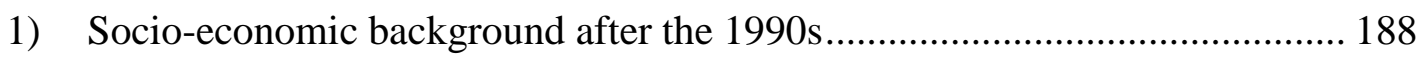

2) More emphasis on finance, more power to shareholders ............................. 190

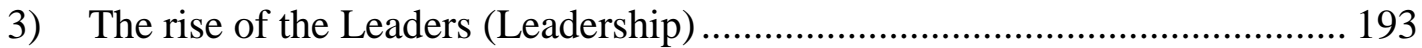

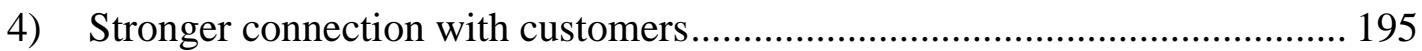

5) Creating networks: Groupings, partnerships and alliances.......................... 197

6) The contingency logic behind the content analysis of the HBR .................... 200

ANNEX III: Content analysis at Waseda's main library ......................................... 201

ANNEX IV: The "MS Word" format of the questionnaire .................................... 203

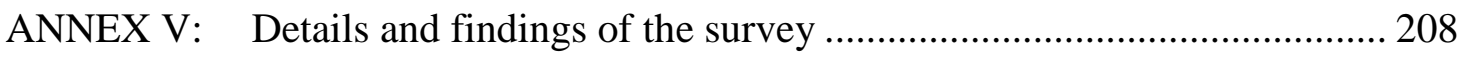

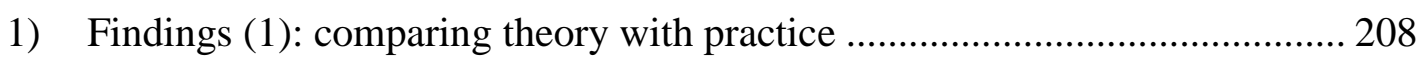

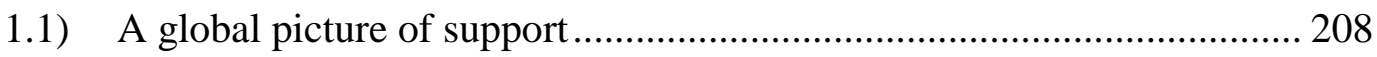

1.2) Looking at the variables: a general picture .......................................... 211

1.3) Looking at the variables: detailed feedback ........................................ 215

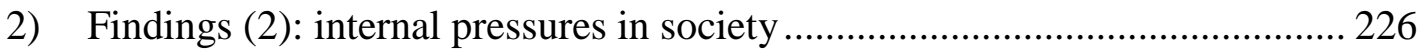

2.1) Attempting cluster analysis with 4 clusters .......................................... 226

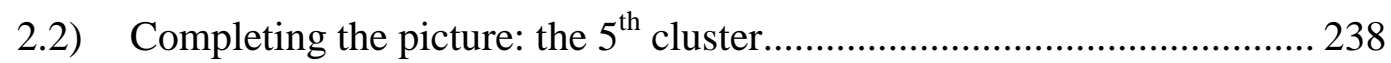

2.3) Turning back to the map of clusters ................................................... 247

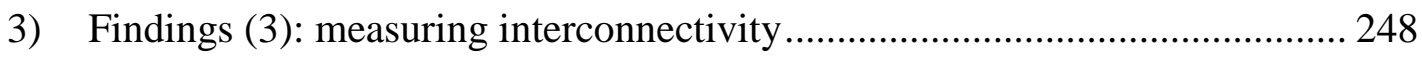

3.1) Recreating the management elements .............................................. 248

3.2) Reinterpreting the management elements.......................................... 250 
3.3) The main indicators of Japanese Management ...................................... 253

3.4) The clusters and the main indicators: a discriminant analysis................ 256

ANNEX VI: Suspected origins of the management elements ............................... 258

ANNEX VII: Cluster mean values of all variables (4 clusters) .............................. 259

ANNEX VIII: Grouping of the empirical elements................................................ 262

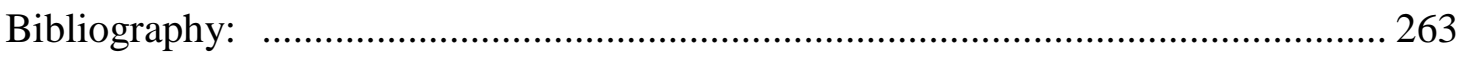

List of the author's relevant publications ............................................................. 287

\section{List of Figures and Tables}

Figure 1: Working method on management paradigms …................................... 17

Figure 2: A representative model for contingency theory ........................................ 19

Figure 3: The interconnectivity of contingency elements: a modern approach .......... 20

Figure 4: U.S. Direct Investment Position Abroad on a Historical-Cost Basis............ 48

Figure 5: Theoretical impact of the new competition: articles on Japan ..................... 55

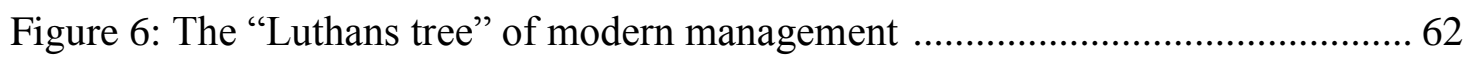

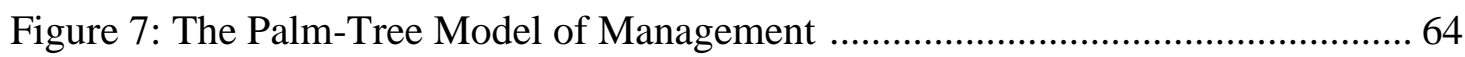

Figure 8: The demographic development of the Japanese markets............................. 73

Figure 9: Outward Foreign Direct Investment in Japan compared to the US ............. 80

Figure 10: Japan's Stock Price Index from 1989 to 1991 .......................................... 84

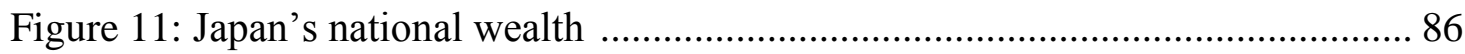

Figure 12: The revenue-based decline of Japanese multinationals ............................. 86

Figure 13: An illustration of economic policies in Japan .......................................... 94

Figure 14: Japanese real GNP, CPI and real wage increases (1966-1999) ................ 98

Figure 15: Labor turnover in Japan, 1995-2010 …............................................. 101

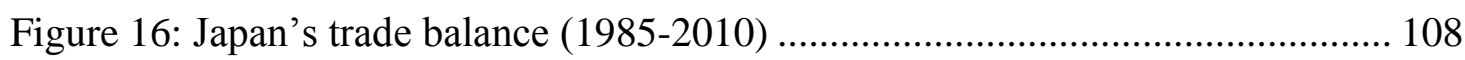

Figure 17: Survey results for vocational training ............................................. 128

Figure 18: Opinions on employee training policies .......................................... 128

Figure 19: Unionization ratio in Japan with comparative data for the 2000s ............ 137 
Figure 20: The Japanese real GDP growth, 1990-2011 _......................................... 138

Figure 21: A convergence model for management systems ................................... 149

Figure 22: Hypothetical scheme of the Japanese management system ..................... 160

Figure 23: The contingency model of Scientific Management .............................. 177

Figure 24: The contingency model of Human Relations ....................................... 178

Figure 25: The contingency model of Structural Revision ................................. 178

Figure 26: The contingency model of Global Competition ................................... 179

Figure 27: Theoretical importance of finance from 1991 ..................................... 184

Figure 28: Theoretical importance of leadership from 1991 ................................. 187

Figure 29: Theoretical importance of marketing issues from 1991 ......................... 189

Figure 30: Theoretical importance of consolidation, alliances and partnerships ...... 191

Figure 31: Redesigned model for the contingency theory of management ............... 193

Figure 32: General support of traditional management ....................................... 203

Figure 33: MDS Proxscal map of 4 clusters in two dimensions ............................ 221

Figure 34: MDS Proxscal map of 5 clusters in two dimensions ............................ 232

Figure 35: MDS Alscal map with dimension labels .......................................... 242

Figure 36: The correlation matrix of the recreated elements …............................ 243

Figure 37: Empirical connections between management elements ......................... 245

Figure 38: The strongest correlations between the empirical elements ................... 246

Figure 39: The main indicators and their connections (correlations) ........................ 247

Figure 40: The MINISSA model of the eight main indicators in 3D ...................... 249

Table 1: Theories of contingency change as affecting national management patterns 28

Table 2: A synthesis of modern management paradigms ....................................... 61

Table 3: Management practices as in the 80s-90s in Japan and in the US ..................69

Table 4: The structure of the Japanese Labor Market ............................................ 99

Table 5: The wage gap between full-time and part-time workers........................... 123

Table 6: Labor Disputes in Japan (1975-2002) .................................................. 137 
Table 7: An attempt to classify major works on Japanese Management 150

Table 8: The 30 elements of Japanese management as observed in literature 154

Table 9: Paradigms and the evolution of the management system 172

Table 10: Paradigm changes in the US and in Japan ........................................... 173

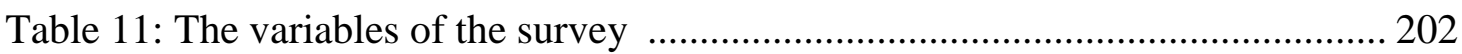

Table 12: Crosstab on the general support of Japanese management ....................... 204

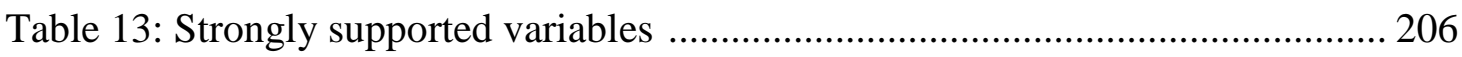

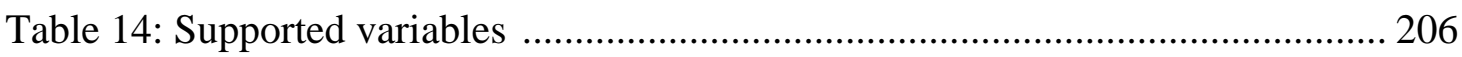

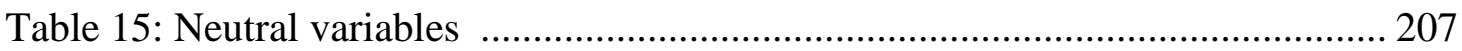

Table 16: Not supported / rejected variables ........................................................... 207

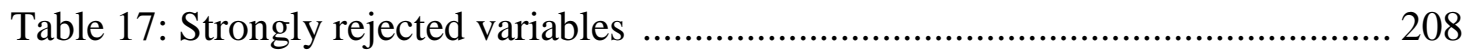

Table 18: The 30 elements of Japanese management in literature and practice ....... 219

Table 19: Cluster 1 mean values compared to total means ..................................... 221

Table 20: Cluster 2 mean values compared to total means .................................... 224

Table 21: Cluster 3 mean values compared to total means ....................................... 227

Table 22: Cluster 4 mean values compared to total means ..................................... 230

Table 23: Cluster 2 mean values compared to total means ................................... 234

Table 24: Cluster 2 - the two extremes of cluster mean values ............................... 236

Table 25: Cluster 3 mean values compared to total means ................................... 237

Table 26: Cluster 3 - the two extremes of cluster mean values …........................... 238

Table 27: The new labels for the management elements ........................................ 244

Table 28: Classification results: match of the predicted cluster memberships ......... 251

Table 29: Structure matrix of the discriminant functions ....................................... 251 


\section{Foreword}

I have always been fascinated both by history and the professional way in which large multinational firms operate. So I feel very happy, that I could combine the two topics in this thesis. It reviews approximately the last hundred years (basically the time since mass production) in American and Japanese business history, with a focus on the evolving management of large firms, and attempts to give a background on why Japanese management did not profoundly change after the bubble burst crisis. Its logic, as detailed in the following chapters, is summarized in the table below:

\section{Research area/question No. 1:}

How do national patterns of systematic, conscious and planned management evolve with time?

\section{Theoretical framework:}

Contingency Theory \& Change theories $\rightarrow$ Evolution is mainly due to a process of adaptation to changing external conditions $\rightarrow$ It may be radical or incremental, driven by internal and/or external factors

\section{Historical Analysis}

of American and Japanese Management Thinking

$\rightarrow$ In American Management History, we witness major transformations at a regular pace $\rightarrow$ In Japan this seems not to be the case

\section{Assumption:}

Japan's reluctance to change can be (at least partially) explained by institutional, agency and transaction cost theory.

\section{Research area/question No. 2:}

What does Japan's society think of its traditional management and how would they like it to be?

\section{Hypothesis 1:}

Attitudes in society must match the recent trends of management practices.

Hypothesis 2:

Important groups in society still support the old ways Japanese firms have been governed.

\section{The Japanese management system} in detail

- What is Japanese Management?

- What are its main characteristics?

- How did they emerge/evolve?

\section{Hypothesis 3:}

The Japanese management system is so embedded with so many interconnections that partial adaptations are made very difficult without ructions to the whole system.

\section{Field research study}

- Verification of H1, H2 and H3

- Clear picture of post-bubble attitudes

- Towards a new management system?

Summary and conclusion

This thesis is structured as follows: the introduction will include further clarifications on what I could or could not deal with in this thesis and what I mean precisely by certain terms. After a description of how different theories will frame and guide my work in Chapter 1, Chapter 2 reviews American management history from about the 1900s until the early 90s (later, Annex 2 sets out visible post-1990 directions in which business in the US recently seems to be moving). Chapter 3 contrasts Japanese management theories and their evolution with the American history, and Chapter 4 expounds in detail 
each major practice of the so-called Japanese management system, examining its past and present. Finally, the field research study, carried out in Japan, attempts to analyze the current change potential of still existing traditional management practices and estimates the extent to which Japanese society and business is ready to change if pressure increases.

The subjects and questions which this thesis deals with are not new: for almost every separate part, several books have already been written-sometimes more than several. However, the unique way of summarizing and presenting old ideas, and the way in which the field study and the analysis was carried out, are new in this thesis. Even some of the old facts gain here a new significance. Every day we live in slightly new circumstances, important changes happen, and every day may lead us to new experiences or deeper understanding of our life. Therefore, I believe that it is always possible to invent a new interpretation of historical roots. I feel that writing this thesis has helped me not only to improve myself as a teacher and manager, but also to acquire a deeper understanding of our contemporary society. I hope that I will be able to convey both that happy feeling and the experience.

In this regard, I would like to acknowledge each person who gave me a helping hand or advice in my work. Prime acknowledgement is due to my research director, Miklós Dobák, for reviewing my thesis so many times and for helping me to get to the right places for my research, and the Japan Foundation whose funding made it possible for me to stay in Japan. This thesis was also partly supported by the TÁMOP-4.2.1/B09/1/KMR-2010-005 project. Many thanks to Christina Ahmadjian, Chris Pokarier, Takashi Saito, Hireyoshi Umezu, Masaaki Sugiura, Glenda Roberts and my colleagues at Corvinus University whose support and advice contributed to my improving the thesis. A special mention must be made of Aiko Watanabe for translating my questionnaire, Gyula Bakacsi and Sándor Takács for revising the HR paradigm, Erzsébet Czakó and Károly Balaton for revising the parts on structure and global competition respectively, Bill Tsutsui for his corrections, József Móczár for his overall feedback, and László Füstös for his help in the data analysis. Richard Robinson helped to revise my imperfect English. Earlier work from Mauro F. Guillén and Daniel Wren on the evolution of management had a special influence on mine. The Business History Society of Japan also made a special impact on my orientation and I appreciated meeting such distinguished scholars as Hideaki Miyajima, Geoffrey Jones and Howard Gospel. The forum notes of Minoru Mochizuki, Scott Urista, George Olcott and others greatly helped me to understand the nuances of Japan's recent corporate activity. And 
like every book, this one could not have been finished without the patience and support of my wife Réka and my family.

Finally, it would be impossible to name here every friend who supported me with some good words or advice, or the few hundreds of respondents who spent their time answering my long questionnaire with no recompense. Such a vast project is simply not possible to accomplish alone-thank you all.

The following pages bear the traces of the contributions of many, but all responsibility for errors or misprints is my own.

your student

Balázs Vaszkun

21 March, 2012 


\section{Technical notes}

I did not plan to start with such a message when I began writing this thesis but I feel that one word must go to commemorate the victims of the devastating and unprecedented 9.0-magnitude Tohoku Earthquake which struck Japan on March 11, 2011. I was deeply moved by witnessing both the disaster with all the casualties and the sorrow it left behind, and the relief operations which helped the victims to keep their dignity and react in a calm and organized manner, in the bitter cold and despite the shortages in drinking water, food and fuel. I would like to convey all my respect to the ones who made a sacrifice for a less painful and quicker recovery.

As for the writing of Japanese words, the original kanji or kana characters were transcribed into roman ones using the Hepburn system. The custom in both Japan and Hungary is to give personal names with the family name first followed by the given name. However, to facilitate the reading of this thesis outside of these countries, personal names are given here in the order customary in the international academic environment, with the given name first. For the same reason, macrons have been used only in cases when their absence could possibly lead to the misunderstanding of the given term. In personal names and in names of places such as Osaka or Kyoto, the long vowels of Japanese have been kept short. Books and/or articles published in Hungarian have been supplemented by an unofficial translation in parentheses.

For the analysis of GDP series, the reader must be aware that in 2000, Japan changed the GDP measure and switched to the Organization for Economic Cooperation and Development's benchmark, the so-called SNA 93 standard from the SNA 68. The change, thought to increase Japan's reported growth rate, ensures more detail on the components of GDP as well as greater comparability with the statistics of other OECD members. 


\section{Introduction}

The goal of this introduction is to define our subject, timeframe and geographical focus, and raise the main questions of this thesis. That will enable us to design a theoretical framework necessary for further analysis. One hundred years is a long time to survey, and for this reason it seemed better to synthesize the main characteristics of corporate management into "paradigms": dilemmas, answers, and communication channels of managers specific for each main period in our 100-year timeframe.

It is important to remember that "management" is much older than 100 years. Some "management activity" or functions of what we call management today (planning, organizing, coordinating, etc.) already existed from the very beginning of human history, before being revolutionized by industrialization and mass production. The need for such central functions came with the rise of the early civilizations where parallel to farmers, different castes or occupational groups emerged in society. Great achievements such as the pyramids, the Roman road network, or the organized religions required central planning and coordination. Although these societies developed many important management principles, the elements that would have made these administrators "managers" in a modern sense were not yet all present.

Although these early times are indeed fascinating, we will focus here on management in the last 100 years "only" (starting with mass-production), especially in large companies. There are several reasons for this restriction, detailed here below.

Some of the most important keywords in management studies are systematic, conscious, and planned. Without these terms, it is certainly not possible to talk about science or theory. ${ }^{1}$

Systematic, because when following some routine or specific process, in similar conditions we must expect similar reactions or answers in order to seriously study something. Because humans are different from one another, achieving systematic reaction therefore means eliminating the human factor as much as possible.

Conscious means that ways of behavior and processes are thought out with regards to their possible consequences, and they follow the rationale of a certain formal knowledge. Our research is conscious because we analyze reactions or results and build

\footnotetext{
1 "Theory attempts to bring together what is known in a discipline, to explain the relationship between these knowns, and to predict likely outcomes given certain causes and relationships." (Wren, 1994: 350)
} 
up some knowledge based on this experience. To achieve conscious managerial behavior supposes either huge personal experience or an efficient knowledge management in which experience is transferred and accumulated so as to be used by other members. Achieving consciousness in science is basically possible for organizations with long life which are capable of accumulating that knowledge.

In addition, to plan something with a good probability of success presupposes some understanding and control of the environment as well as power and resources to act with. I believe that these three are all key factors in academic study and can be met by rather large organizations because their managers are obviously in a better position to become systematic, conscious and planned. For this thesis, the era when big business emerged is an important turning point.

It is also clear that our society has created different types of organization of considerable size where such systematic, conscious and planned management can be found. Basically armies, the administrative bodies of states, global religious organizations, and later large companies all come into this category. One may ask: why is the evolution of companies different from that of other types of organization? It is because their goals or sense of existence have evolved with time. Armies were all set up in order to settle conflicts and ensure the supremacy of one over another. State administration is a technical body developed for making sure that the desires of the (political) leaders are realized. Religions have an important social function by reducing the negative effects of incertitude and they can ensure their own survival, but have no legitimate reason for further use of their power. Thus, the most controversial organizations are large companies, where even the most basic questions, such as "Who is the owner?", "Why does the company exist?", or "What gives managers the right to control employees' lives?" may lead to confusion.

We know, then, that we should look at large companies but it is not clear where and when management became conscious, systematic and planned.

Common sense would suggest that it has been so since the creation of big factories where the daily work of hundreds or thousands of employees must have been organized. What lead us to the development of those factories?

According to Wren (1994), the Renaissance and Protestantism brought a sort of cultural rebirth to European civilization, a "new environment that would lead to the need for the formal study of management." (23) As an important element of capitalism, 
he highlights the role of individualism and the transforming value of work, developed by and through Protestantism - also described by Max Weber in 1905 (Weber, 1930). Why is this idea essential for the development of management? Because initiative and entrepreneurship, brought by this rebirth, would create a bigger business sector with more players and more intense competition. Another element is the division of labor, first promoted by Adam Smith in 1776 (Smith, 1937) or by Henri Fayol in 1916 (Fayol, 1956). Specialization resulted both in rising productivity and the need for coordination between specialized bodies of production. Writing on systematic management, others asserted that growing market demand (bigger population and new trade routes), faster and cheaper production, and enhanced specialization, which must be coordinated and supervised by "professional" management, was the background of the developing factories and the raison d'être for the formalization of management studies (Litterer, 1963).

In spite of its European roots, management, as a field of study or science, was born in the United States of America. "Management is an American term and an American creation", writes Locke (1996: 1). Therefore, we must start our investigation for the evolution of management in the "New World". But in order to study change, it seems logical to direct special attention to Japan as well, the country which heavily impacted American management. Japan is even more interesting due to her fascinating story of rising to the "second biggest" position after World War II, and then fading with the bubble burst. How has management evolved in the States and how could Japan take over such a great share of the global trade? Was it just an inevitable "paradigm shift"? For somebody familiar with Taylor, Mayo, Fayol, Drucker and other "gurus" of management, the U.S. seems to evolve through distinctive phases or paradigms somehow separate from each other. How was this once powerful Japanese management system created and why could it not retain its supremacy? Did those evolutionary changes follow a logical pattern and can they be explained? These questions will serve as a structure for the following chapters.

Management and paradigm are two notions still to be clarified here.

The word "management" is used in everyday conversation, sometimes meaning things as simple as achieving something or succeeding in something ("I've managed to..."). In academia, different concepts have been developed through whole books on 
what managers do, and these concepts continue to coexist. Short definitions, attempting to provide a synthesis, are rather simplistic and abstract. A few examples are:

"Management refers to the process of getting activities completed efficiently with and through other people." (Robbins, 1991: 5) ${ }^{2}$

Management is "the function of getting things done through others." (Koontz \& O’Donnell, 1955: 3$)^{3}$

"Management is the use of people and other resources to accomplish objectives.” (Boone \& Kurtz, 1987: 3)

Management is "the activity which performs certain functions in order to obtain the effective acquisition, allocation, and utilization of human efforts and physical resources in order to accomplish some goal.” (Wren, 2005: 9)

In this thesis management is generally defined as the activity of the top manager (CEO, general director, etc.) or the top management (board, executives) of a rather large firm, with a focus on only strategic questions which concern the organization as a whole: business policies, employment systems, or, in general, tools which the top management has in order to set rules, design systems and attain desirable performance.

Having stated that, we try to ignore the human or face-to-face factor of management. When speaking about motivation for instance, we may consider the effect of a bonus system but less so the personal impact of a leader or the efficiency of his or her speeches (rhetoric). This understanding of management raises questions like "how to deal with complexity", or "how to build and organize a company to reach optimum results". With terms used by Kotter (1990) or Zaleznik (1992), our focus is on the role of the "manager" in contrast to the "leader".

The second point to clarify about management is the notion of result or performance. It seems that in different ages and places performance might have had a radically different meaning and what might have been a good achievement in, for example, Texas at the beginning of the twentieth century may have been considered bad in Germany for instance in the same period of time, or even in the same place but some decades later or earlier. Therefore, the question of what is considered good performance usually remains open and is therefore decided case by case.

\footnotetext{
${ }^{2}$ Cited by Dobák \& Antal (2010).

${ }^{3}$ Cited by Wren (1994).
} 
Very much related to management, the person of the manager can also be an interesting question. For our study of paradigms, it would be useful to adopt a distinction made by Guillén in 1994. He identified two groups of managers: the management intellectuals and the management practitioners. Practitioners are people in charge of governing a company, whereas intellectuals form a restricted elite of opinion leaders, philosophers, and spokespeople, who would typically work for the largest, most prominent companies, consulting or research firms, business schools, universities, or agencies. They are the knowledge creators and diffusers on managerial and organizational issues. In this thesis, both groups will represent an important input to help us differentiate management paradigms.

When using the term "paradigm", it is not necessary to enter into the full details described by Kuhn in 1962 and then in 1970. This perspective would mean paradigms with distinct sets of ideas, in different languages, which would make them incommensurable with each other. Yet what we need is to compare starkly different ideas and management patterns within the same framework. Thus, in order to follow the logic of this thesis, we will define a "paradigm" in management to be a set of ideas, questions and answers, which form the dominant business practices and thinking for a certain period of time and geographical area. Guillén (1994a), who also used this term, noted that paradigms ought to have a normative approach, complete arguments and impact in more than one country. In this thesis we will describe paradigms by answering the following questions: What kind of business and social environment characterized the specific era? What were the main managerial questions and challenges? What were the answers and solutions, and how were they diffused? In our model, the description of different paradigms can be summarized in the manner shown by Figure 1.

We will make a difference between "paradigms" and the management practices of any specific company which are only a sort of mirror or layout of the actually dominant paradigm. 
Figure 1: Working method on management paradigms

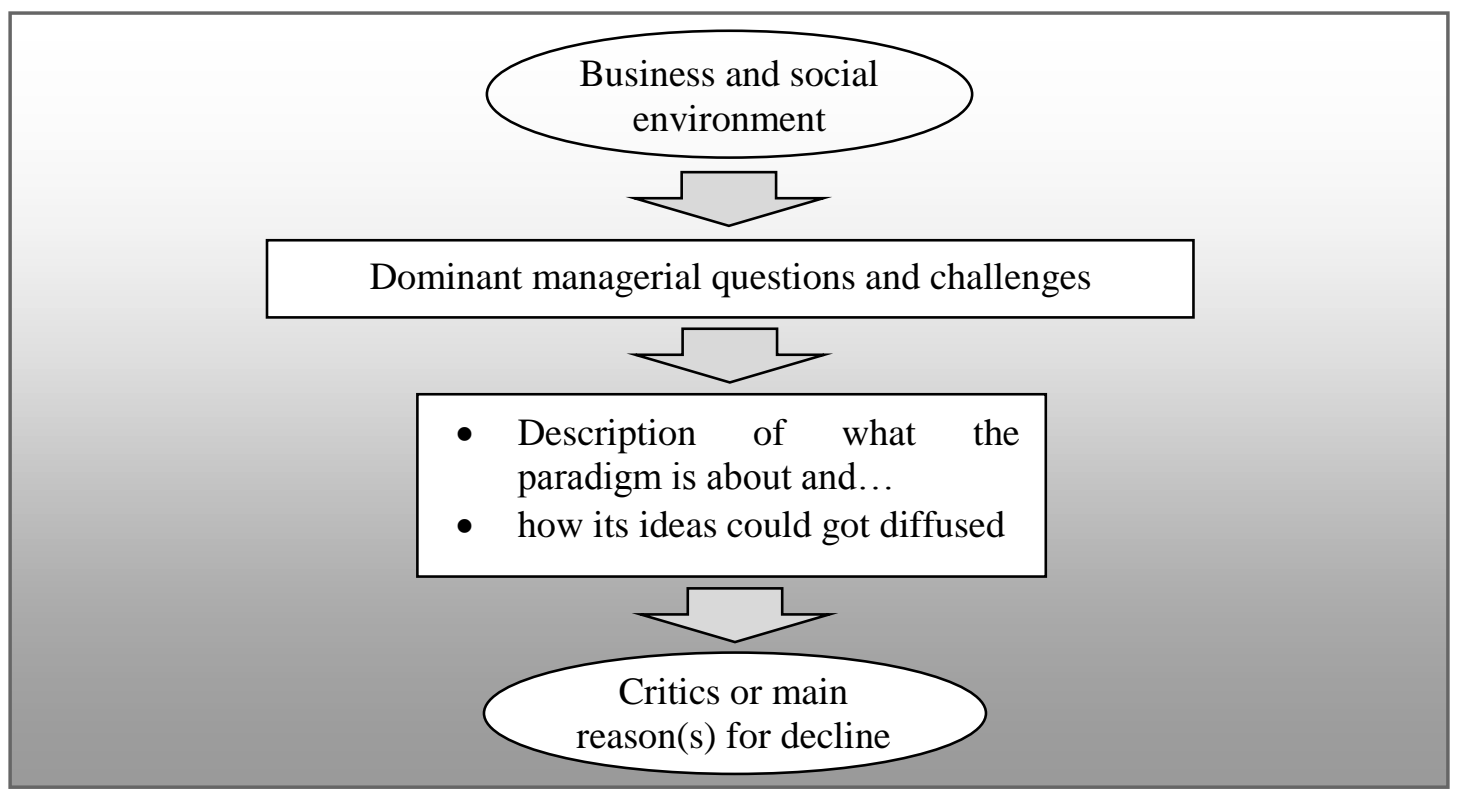

Source: author 


\section{I) THEORETICAL FRAMEWORK}

In this chapter we build a foundation for the analysis of management paradigms and their evolution. The framework of contingency, transaction cost and agency theories with our change theory will provide us a solid base to understand how and why historical changes occurred in corporate management.

Understanding change requires a comparison between the past and the present, which involves history. But history is broad and apart from the revision of the main events of the past, we need a more precise framework with the aim of not only following the evolution but of understanding recent transformations ${ }^{4}$ as well.

The use of classical economic theories has troubled management specialists and business historians for a long time, because these theories preferred to stay outside the companies and usually treated them as a "black box" (Lamoreaux, Raff, \& Temin, 2007). Yet in recent decades, several good solutions have emerged for looking inside corporate structures, which is very useful for our historical approach.

Contingency theory is especially helpful for providing an analytical framework for the evolution of management in a given area, and for identifying which elements change in what circumstances. Also, the same framework will help us to question the current managerial evolution in Japan.

The use of the transactional cost and agency theories is rather to look deeper inside the corporation and to understand how the internal characteristics of a company can make change easier to happen or jeopardize it. As stated before, we are not dealing here with change management ${ }^{5}$ or any tactical analysis of what a leader may do to reform the company. Our focus is on how the environment impacts the other elements of the management system.

\section{1) Contingency Theory}

The framework of contingency theory is well known and has been widely used in academia since the 1960s. Moreover, it became the dominant way to study organizations in the 1970s (Child, 1977). In spite of its decreasing popularity later on,

\footnotetext{
${ }^{4}$ The term transformation will be used in this thesis as a synonym for radical change.

${ }^{5}$ Change management ("How to make change happen and lead it?") is not the same as management change (the change or transformation of a given management system).
} 
its assumptions do still form the mainstream ideology in describing how systems interact with their environment (Morgan, 1997). Apart from the historical origins of contingency theory, here we will expound the main characteristics and focus on detailing what the use of contingency logic is for this thesis.

Until the late 1950s, management theories were mostly concerned with finding "the best way" to manage an organization (for instance, the most effective organizational form, production methods, or personality traits and working styles of managers). These theories were deficient in that they formally ignored the implications of the different objectives and environmental pressures on organizations (Bowey, 1976). As for management studies in general, the biggest contribution of contingency theory was to state in the 1960s that there was no "one best way" in management, no tool or method which would always work to solve certain types of problem. Researchers in contingency found that the optimal solution for every dilemma or situation had to be found according both to the external and internal environment of the company: managers would adapt their organizations until the best fit with the environment was achieved. The process of the increasing sophistication of these environmental elements reflects the development of the theory.

\section{Figure 2: A representative model for contingency theory}

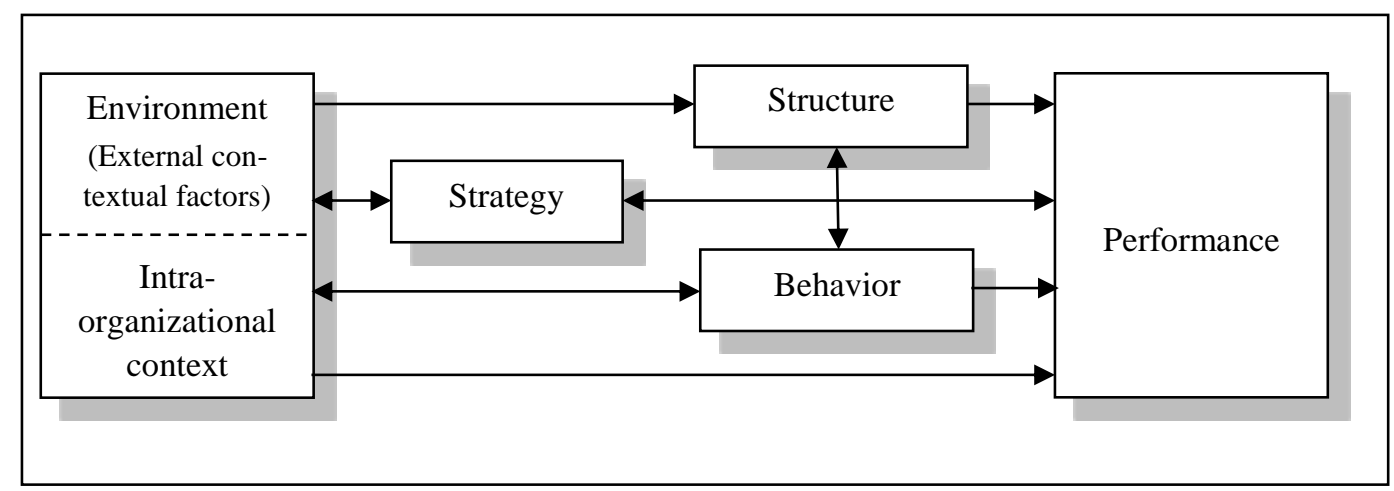

Source: Dobák (1988)

Based on Figure 2, we can sum up the main ideas of the "matured" contingency theory as follows.

(1) Organizational efficiency and therefore the output depend heavily on the structure.

(2) There is no structure valid for every kind of environment and organization. This basic assumption was subjected to scrutiny in the earliest studies.

(3) Contingencies can be manipulated by elite groups (“dominant coalitions"). 
(4) Strategy interacts with both contingencies and performance, it is sensitive to them, and affects both. Basically all elements are connected.

(5) With appropriate information on the organizational context and environment, managers are facilitated in choosing the adequate form (structure) and strategy for any company, developing adequate behavioral characteristics, and therefore optimizing performance.

Figure 2 has to date proved to be a good way of summarizing the findings of contingency theory. However, some connections may still be missing from the chart. Since the 1990s, big organizations have developed skills and the power to modify any contingency elements, at least theoretically. The environment can be changed by lobbying, PR, marketing, R\&D, and so on. Multinationals have several options to deploy headquarters or build other types of location and their human resources are regularly trained. Behavioral elements can be enhanced by organization development, strategy adapted to the changing contingencies: all these affect performance and performance affects all. Thus, for the twenty-first century, it could be simpler and also more realistic to represent elements as in Figure 3. Through the inner circle, all elements are interconnected: any elements paired in the model might possibly affect each other.

Figure 3: The interconnectivity of contingency elements: a modern approach

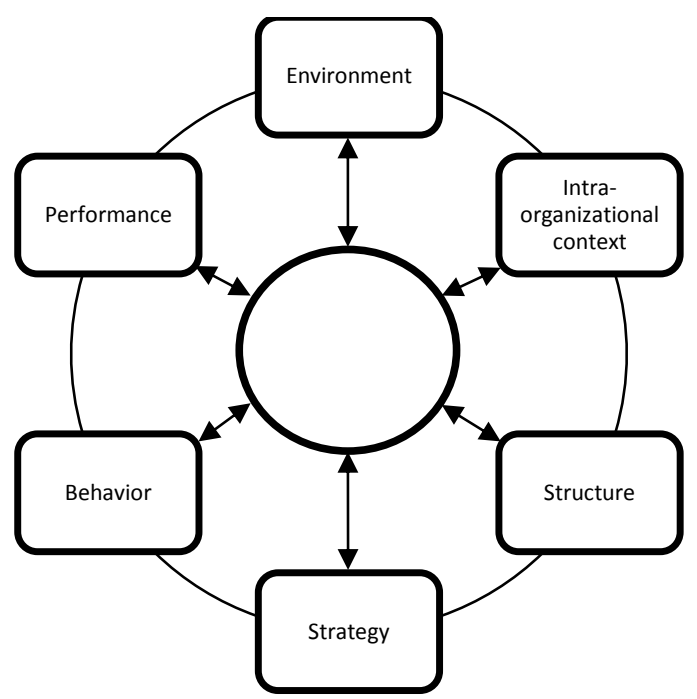

Source: author

For this thesis, it is important to note that we do not attempt to fully explain or analyze change by contingency theory. This model would be far too complex to work with. 
Neither is contingency theory adequate to compare different cultures or countries. The theory will merely help us as a tool to evaluate the same management system in different time periods and different environmental conditions.

In order to compare different paradigms efficiently, contingency theory is used as a means to identify relevant characteristics for the analysis. The main contingency elements from the previous point will be retained and applied to the next chapter: seeking to identify different characteristics for each management paradigm, we will use these figures as support to explain the evolution.

The environment as a category will cover all external factors to companies, e.g. market (economic) characteristics, technical, legal, cultural background, or relations with and positioning to other organizations essential for daily operations (partners, suppliers, etc.).

By intra-organizational context, we shall mean the size, the origin, the operational technology, the location, the material or human resources and the nature of operations of a given company.

Strategy stands originally for decisions like keeping a linear production line or moving towards diversification, but we can supplement that with modern strategic management ideas and concepts, covering how the organization will make money in the middle or long run (cost advantages, ways of differentiation from competitors, etc.).

Structure covers all structural elements of companies (division of work, authority, coordination) making a certain configuration in each company (functional or unitary "U-form", multidivisional or "M-form", matrix, virtual...).

Behavior stands for interpersonal relations within the company, issues related to morale, motivation, or team efficiency. As formulated by Luthans (1973a): "organizational behavior is the result of the interaction between the human being and the formal organization." (69)

Performance includes the means of control and the measurement of output, even the definition of performance itself as the expected outcome in distinct cases may be drastically different.

We can grasp a certain logic through the evolution of management described in the next chapter, and form an idea of what type of environmental change affects what, predominantly, in the corporate system. Contingency theory is widely used for this sort of purpose. What is new in this study, however, is the historic parallel linking the evolution of management directly with the contingency framework. In the following 
chapter, this parallelism will be emphasized by repeating modified versions of Figures 2 and 3.

\section{2) Organizational economics: the agency and transaction cost theories}

Contingency theory, as Donaldson (2001) argues, tends to remain a framework isolated from economics. However, due to its traditional concern with performance, it is or should be consistent with economics. To resolve this contradiction, some attempts have been already made to import elements of economics into organizational theory, mostly using agency theory and transaction costs economics. Without trying to combine all these theories, in this thesis we will use the economic approach as a complementary to contingency theory. Agency and transaction cost theories introduce the personal interests of managers and do enter more into the black box of organizations, compared to classical economic theories. Our choice of theories is also supported by Lamoreaux, Raff \& Temin (2007), for whom agency theory, transaction costs and game theory are the most useful among economic theories for business history.

\section{1) The agency theory}

Agency theory, developed mainly from the 1970s, puts focus on a "contract": a situation with information asymmetry where an owner delegates his rights or power onto somebody else to make the best use of his or her belonging. The owner is called a "principal", and the operator an "agent" (Kieser, 1995).

We assume that principals, in order to have their interests better represented, delegate tasks, decisions and power to the agent, who is supposedly well compensated for these services. The benefit for the principal is the time, the competencies and the experience of the agent. Yet there is a risk as well, because the agent may use the property for his or her own benefit. The less information the principal has on the agent's daily activity, the bigger is this risk. This risk and the incentives which can be used to limit this risk are the main concerns of agency theory (Eisenhardt, 1989).

Its contractors can be the employer and employee, the salesman and the customer; but in business, this situation is typically translated into the relationship between the owners or shareholders, and the managers of a given company. The main 
goal of shareholders in traditional theory is to maximize their profit. This is then also the contracted objective of the managers, but they may have other, personal goals in parallel which may harm the contracted one: maximizing their own compensation, or establishing a reputation which would enable them to gain more important positions in other companies. Even if the owner (principal) wanted to reduce risk and control the manager's activity more strictly, the situation is by default asymmetric and managers do always know more about what they are doing than the principals (e.g. the real stake of the manager's effort in a given result, compared to external factors, or the real performance of the manager).

The problem has existed since the separation of ownership and management or control, and it became even more complicated with the emergence of stock markets: today's corporations have an unlimited number of owners, holding small fractions of the total shares. Individually, they cannot have either the tools or the competencies to supervise the management of the company. To resolve that contradiction, they elect trustees, directors, who would represent their interests before the executive management. The result is a doubled risk with two contracts and three parties.

"In a corporation, the shareholders elect a group, the board of directors, who in turn, are expected to employ others as managers to oversee day-to-day operations. In theory and legally, the board and these senior managers are agents of the shareholders and are expected to maximize the wealth of these investors. In practice, this is not always the case, raising the vital question of corporate governance." (Wren, 2005: 415)

Another big question is the motivation of the board to really evaluate the performance of the president and executives, ask discerning questions, blow the whistle, or perform other uncomfortable corrective actions. Their motivation is attenuated strongly by human nature, conformism, or simply the fact that they are selected by the president of the firm and are CEOs themselves elsewhere (Angyal, 2001).

Agency theory deals with relations and interactions as contracts in any kind of organization. Being limited when written, contracts cannot provide regulation for every possible situation. This lack of regulation can lead to the basic problem of asymmetrical relations: opportunism (Williamson, 1985).

The seeking of self-interest over common gain can be reduced by pay for performance (stock options, for example), careful selection and socialization, 
monitoring of behavior at work, and so on. Issues of corporate governance mentioned by Wren include the selection, compensation and control of CEOs by the board of directors. Theoretically, stock options ought to solve the problem of information asymmetry and allow the manager's performance to be evaluated by market mechanisms (stock prices). We will see however how from an external (Japanese) perspective, stock options can have biased effects and lead to merely short-term goals, often harmful for the organization in the long run.

\section{2) Transaction costs}

We can find transactions as the "smallest unit of analysis in the transfer of property rights" in the work of Commons (1934). ${ }^{6}$ The ownership and transfer of these rights were much in the focus of Commons' thinking and he finally separated them into two groups: some inside and others outside the firm.

After studying vertical and horizontal integrations in the US, Ronald H. Coase reexamined the principle of transactions and questioned whether the market (i.e. price mechanism) is efficient enough to fulfill human needs without any firm. His question became the basic dilemma for theories of transaction cost.

He found that it was much cheaper not to consider the market mechanism for every production process, since money transactions, introducing an artificial institution, were also cheaper than bartering (Coase, 1937). The level of success with which firms were able to replace market mechanisms will be further discussed in the next chapter.

Building on Coase, Williamson (1996) supplemented his view of the firm with explanations of bounded rationality (discussed also later) and opportunism (the seeking of individual gains in transactions). His aim was to find institutional solutions to deal with transaction for the lowest cost possible.

In transaction cost theory, efficiency means to use less of the limited resources both for producing products and services, and for making the related transactions happen. The former covers production costs, and the second transaction costs. With a closer look at transaction costs, we arrive again at the level of contracts: ex-ante transaction costs cover the preparation of the contract (the transaction), while ex-post costs include securing and controlling transactions as set down in the contract. This latter also means

${ }^{6}$ Quoted by Wren (2005). 
solving potential conflicts in regard to the different interpretation of the contract by the different parties, or renegotiating it when transactions cannot happen as foreseen because of a change in contextual factors for instance. The main added value of the theory for Williamson is to explain better these ex-post transactional costs, as we can never foresee all potential problems and our contracts are by default imperfect (Kieser, 1995).

Transaction costs can be greatly reduced when these agreements and their implementation can be achieved at low cost. The three main elements of this are transaction-specific investments, and the uncertainty and the frequency of transactions. When important, transaction-specific investments are made in a contractual relation, their result is usually lower production cost, but also the opportunity cost of the broken relationship is increased by the cost of the investment. As a consequence, transaction costs also rise. The investment ties the parties more closely together, but there is also a reluctance to make specific investments, unless the long-term perspective of the relationship is secured. Accordingly, these costs are lower within a company than between independent players on the market (see below).

Uncertainty regarding the contextual elements or the other party's behavior can also cause transaction costs to rise. Controlling the other's opportunistic behavior is costly, and uncertainty or mistrust would make the investment by default necessary: in the same manner, we pay for insurance in order to avoid a bigger potential loss.

By contrast, a higher frequency of transactions results in lower transaction costs due to economies of scale, synergies, lower production cost, and a (ceteris paribus) naturally secured long-term perspective.

Williamson (1985) describes three possible institutional forms for these transactions: market transactions, long-term contracts (such as franchise partnerships) as hybrid solutions, and organizations. An analysis of transaction costs would define which form is more adapted to a certain type of transaction: organizations are better for reducing uncertainty and opportunism but at higher costs as markets are typically more efficient. Markets seem to be more adapted for transactions without uncertainty or a need for specific investments.

To sum up, transaction cost theory also deals with contractual relationships but here, the focus is on bounded rationality and opportunism, rather than the information asymmetry described by agency theory. Also, the former typically describes ex-post and the latter ex-ante transaction costs. None of the contracting parties have perfect information on 
the transactions or on the other's behavior, which may be opportunistic and include selfbenefit seeking tricks and traps. ${ }^{7}$ The solution is provided by institutions controlling the opportunistic behaviors of the contracting parties.

\section{3) How can we use economic theories?}

The main point of the two economic theories for this thesis is not simply the opportunistic side of individual managers but the control systems which consequently need to be established.

Building on Jensen \& Meckling (1976), Donaldson (1995) criticized agency and transaction cost theories as economic models, because they commonly presuppose that human actors in organizations follow their self-interests, even "to the detriment of the organizational collective" (3). In the agency theory, this is the agent who would misuse the power and trust delegated to him or her by the principal; and for transaction cost theories market discipline would fail in large corporations and managers would "selfaggrandize" through excessive compensation. For this example, Williamson (1970) promotes an M-form structure to limit this opportunistic behavior and closely monitor the performance of the various divisions from the center.

We will find different degrees of uncertainty, mistrust, time-horizons and therefore different institutional solutions in Japan and in the US. For the US, the basic assumption is that market transactions gained a more important role and broader acceptance, compared to Japan where the production cost is so much valued that central actions can be better explained by transaction costs. Her hierarchical approach will also shed a different light on transaction-specific investments even in "market" relations. Kester (1996) also argues that Japan is more determined to reduce transaction costs, build stable relationships, and shareholders may bear substantial agency costs as a consequence. The focus for the US, on the other hand, is the reduction of agency costs (associated with the separation of ownership and control), formal mechanisms and commercial relationships, which causes higher transaction costs.

Therefore, the US, offering more typically a shareholder-oriented context, is also more preoccupied with regulating its shareholders' position rather than with providing a central care for lower production costs. Japan however, targeting international

\footnotetext{
${ }^{7}$ We have similar assumptions in game theory but the actors' behavioral impact on the output is not the focus of this thesis.
} 
competitiveness as a means to recover from World War II, makes less effort to reduce information asymmetry than to reduce production and transaction costs at a national level. We will discover these differences more in detail in the following chapters.

\section{3) The theoretical framework of change for national management patterns}

According to our conclusions for the contingency theory, all contingency elements are interconnected and can affect each other. One element changing would cause a misfit in the system, so presumably others would move into fit with the changed contingency again. Our next step here is to design a model explaining how this change will occur.

To avoid getting lost in related theories and ideas, we needed to further refine what type of change this thesis ought to be about. In the introduction an important clarification was made concerning the roles of managers versus leaders. As a consequence, we are not interested here in techniques and practices of how to lead change, how to make it happen, and whether the company has enough resources or the manager enough power to implement change. Our goal is rather to identify the reasons which cause corporate changes at a national scale, and the characteristics of those changes (e.g. pace). In addition to the contingency filter mentioned above, and the managerial approach, the paradigms of the next chapter will also help us to keep a restricted focus.

Donaldson (1987) distinguished three theories for organizational change: contingency determinism, strategic choice and "structural adjustment to regain fit", and argued that the latter was the most accurate. His point, originally made in 1984, brings us closer to an appropriate picture of contingency change: for this thesis, we will assume that change (in structure, for example) is not directly caused by contingency. It is rather the lack of fit, or the mismatch between the contingency elements, as in Figure 3 , which leads to change. This contingency approach is further explained by Wood (1979) as follows:

"The contingency theorist neither ignores nor is unable to deal with change, as so many of the crude critics of functionalism presume, but rather treats it as largely unproblematic. Change reflects above all else the evolution of ideas, i.e. progress. ... Where problems of gaining support are recognized, then writers assume that participants can be encouraged, especially with the aid of social scientists qua change agents and catalysts, to see the appropriate design as the 
'ultimate reality'. In this way contingency theory models and open systems concepts are used both theoretically and as heuristic devices." (337)

We have agreed above that in this thesis we will deal with changes as "structural adjustments" aiming to regain fit with the socio-economic and socio-demographic contingencies. In order to answer our research question and understand how corporate changes occur on a national scale, we can further refine our model examining two characteristics: the source of pressure for change and the pace of the resulting adjustment.

By change, we often mean a significant achievement in a relatively short time. This approach can be identified as "radical" change or transformation, but we must also acknowledge the importance of other, slower types of change ("incremental" change). This distinction is commonly used in research and education. ${ }^{8}$ Radical change also implies that change occurs on several elements of a given management system at the same time. Also, change can be a result of both internal and external factors ${ }^{9}$ and can have various groups as supporters. Table 1 summarizes our model before we go into further details.

Table 1: Theories of contingency change as affecting national management patterns

\begin{tabular}{|c|c|c|c|}
\hline & $\begin{array}{c}\text { Internal source of } \\
\text { pressure }\end{array}$ & $\begin{array}{c}\text { External source of } \\
\text { pressure }\end{array}$ & \\
\hline $\begin{array}{l}\text { Incremental pace } \\
\text { (and scale) }\end{array}$ & $\begin{array}{c}\text { Institutional or } \\
\text { Evolutionary } \\
\text { approach }\end{array}$ & $\begin{array}{l}\text { Long-term } \\
\text { partnership }\end{array}$ & $\begin{array}{l}\text { (Transactional cost- } \\
\text { driven economies) }\end{array}$ \\
\hline $\begin{array}{l}\text { Radical pace (and } \\
\text { scale) }\end{array}$ & $\begin{array}{l}\text { Generational } \\
\text { approach }\end{array}$ & $\begin{array}{l}\text { Power } \\
\text { approach }\end{array}$ & $\begin{array}{l}\text { (Economies regulated } \\
\text { by agency theory) }\end{array}$ \\
\hline
\end{tabular}

Source: author

It may be that the dominance of agency theory in regulation versus transaction cost reinforces the aptitude of a given system for radical change driven by internal agents and the prevailing transactional cost-orientation helps current institutions to remain. This assumption will also be examined later in the thesis. In the following paragraphs of this point these four approaches will be expounded. After having been supplemented

\footnotetext{
${ }^{8}$ See for instance Tushman \& Romanelli (1985), or Dobák (1988).

${ }^{9}$ E.g. coercive vs. mimetic change by DiMaggio and Powell (1983).
} 
with the two axes of source and pace, our framework will be ready for further use in the next two chapters.

\section{1) "Power" change}

Kotter (2008) mentions eight important steps for any change process: (1) the sense of urgency; (2) building teams; (3) creating vision; (4) communication; (5) empowerment; (6) short term wins; (7) never letting up; and (8) making change prevail. Among these, the most important phases, common in nearly all books, are: raising attention and the will to change, building a powerful and active coalition as main protagonists, reinforcing the ongoing process as much as possible, and freezing the result at the end. Out of the eight steps, Kotter especially emphasizes the very first one: the sense of urgency, the sense of crisis. We will understand later how important this stage is when looking at the contemporary evolution of Japanese management.

In most countries we can find "revolutions" which radically changed the socioeconomic status quo and transformed main institutions. Some of these revolutions are initiated or forced by external powers. For the US, we can mention the era of lean management which happened partly due to the poor trade balance with Japan and revolutionized American production (Guillén, 1994a). Japan's history is certainly not a "laboratory of revolutions" but still we can find some radical transformations such as the opening pushed by Commodore Perry in 1853, putting an end to feudalism, or the total reconstruction of the country after World War II. In those cases the status quo had been drastically challenged by a new power which was certainly stronger than the previously dominant elite. This type of transformation has been well described by Marie-Laure Djelic (1998), who analyzed the transmission of the American business system to other countries. She summarized three basic conditions for such a transformation: (1) an intensive sense of internal crisis (similar to Kotter), (2) a power imbalance (geopolitical dependence) of the country or the group in question, given that this dependence includes a model to copy, and (3) a cross-national network of changeprotagonists. Her theory provides a very neat explanation of important chapters in Japan's modern economic history and in America's diplomatic relations. 


\section{2) "Generational" change: the sociological perspective}

There are cases where major reforms are carried out in organizations only by internal players, without the impact of any dominant external power. In some cases these players have been previously managing the organization and introduce reforms due to specific circumstances but more often, internally driven changes are led by a "new generation" of corporate actors (Voordeckers et al. 2007, Gomez 2007). The term originally relates to family-owned firms although the same circumstance can also be observed in large corporations (especially when several managerial positions are filled at the same time) or even at a national scale. In terms of radical change, the sense of crisis mentioned earlier has a similar significance in the case of internally driven reforms.

In the history of the US, the era of the Civil War can be identified as a "generational change". For Japan, we mentioned earlier the role of Perry in the Meiji Restoration. In parallel, the generational nature of the revolution must also be highlighted: as the two driving factors met in the second half of the nineteenth century, the modernization and transformation of the Japanese business system was able to take place relatively smoothly. Moreover, in the evolution of American management thinking from the 1910s, important changes can be found approximately every twenty years (see later). This idea gives a potential role to young generations in leading change.

\section{3) Institutional or evolutionary change: decisive but invisible}

Institutionalism has been greatly promoted by the economist and Nobel laureate Douglas North and will be used in this thesis to explain internally led incremental change. Olcott (2009) described the institutional environment as a key determinant of organizational form and behavior. According to institutional theorists, organizational structures are indeed shaped by the need for fit with preconceived notions of society about forms of organization which are effective and legitimate (Powell \& DiMaggio, 1991). As Jacoby (2007) explains, managers' reactions are shaped by power contest and social norms, which involves a non-rational decision-making process. This perspective differs slightly from that of contingency theory, because the final form does not especially reflect operational efficiency. But sooner or later, contingency or institutional approaches all move along the same line of fitting with the environment. 
The term evolutionary fits very well with the institutionalist approach but refers more clearly to the biological background of organizational change. Van de Ven and Poole (1995) relates this approach to the theories of Lamarck, Darwin, Mendel, Gould and Eldridge. According to evolutional theorists, change proceeds through a continuous cycle of variation, selection, and retention. In the title of this paragraph we combined institutionalism and evolutionism in order to focus on incremental change. In this perspective, we accept that the customs, institutions, and "culture" of a nation are a force strong enough to ensure continuity in social or economic evolution but at the same time there is a constant adaptation to new variables in the environment.

The internal focus puts great emphasis on the top management in the firms of a given economy and on the distinction between managers and leaders as formulated by Kotter (1990). According to the managerial roles defined by him, some executives ("leaders") are more inclined to corporate reforms than others ("managers").

\section{4) Long-term partnership: a socialization process}

It may happen that a country establishes a strong, long-term partnership with another one, for instance in trade, or receives a significant FDI inflow from a major external partner. That was the case of several small Asian economies such as the four "little dragons" during the last decades of the twentieth century: as their trade was mainly with Japan for a relatively long time and direct investments came from the same origin, it left a strong mark on these Asian companies involved (Zhu 2009, Marosi 2003). This type of change may have no actual significance for the management systems of the US and Japan can be counted among the protectionist economies where any foreign influence is controlled. We will see later, however, that in this second case the picture today is biased and the foreign presence is strengthening day by day.

Using all these change theories, our aim has been simply to find out how we will be able to differentiate change throughout this thesis, which will help us to understand how national patterns of management can adapt to the environment. We shall apply these theories in the historical study of such management patterns, first in the case of the US, and then in Japan. Again, due to the long timeframe analyzed, our challenge will be to identify the types of change that we are looking for. Therefore, we start our historical analysis with an assumption. 
We assume in this thesis that if we can define distinct sets of characteristics for successive periods of time, which can be clearly differentiated due to the significant differences between them, then we can speak about radical change.

Our hypothesis is indeed that in the management history observed in the US, distinct management paradigms can be identified, and this will be used as proof of radical change or transformation.

\section{4) Change towards... convergence?}

Before closing this theoretical chapter, mention must be made of the huge debate between those who argue that national patterns are weakening and the world is moving towards global trends, and those for whom path dependency and local characteristics will continue to make the difference in business as in other areas in our life. These are the theories of convergence versus path-dependency. Berger synthesized the basic assumption of convergence as follows.

"Competition, imitation, diffusion of best practice, trade, and capital mobility naturally operate to produce convergence across nations in the structures of production and in the relations among economy, society, and state. Variations may be found from country to country, because of different historical legacies. But such distinctions fade over time..." (Berger \& Dore, 1996: 1)

Berger set the historical origin of the debate to the $1950 \mathrm{~s}$ and $60 \mathrm{~s}$, the decades of growth, when the engine of convergence was technology. From the 1970s, the focus shifted to successful companies producing the same product with the same technologies but organizing production in fundamentally different ways. ${ }^{10}$ By the 1990 s, the view that technology dictates a single optimal way of organizing production apparently vanished but analysts continue to expect that structures of production and economy are and must be converging, which is certainly facilitated by the deregulation of domestic economies. The collapse of the Soviet economy also gave new energy to the convergence theory (Boyer, 1996).

\footnotetext{
${ }^{10}$ Resulting books are, for instance, the British Factory - Japanese Factory (Dore, 1973), or The machine that changed the world (Womack, Jones, \& Roos, 1990).
} 
According to Wren (2005), the basic question of why firms differ was first asked by Edith Penrose who noted in 1959 that a firm's resources (location, equipment, pool of managerial talent, knowledge, etc.) were "inherited" via prior decisions and therefore limited the decisions about the future direction of the firm. Organizational character as defined by Philip Selznick (1957) can also be understood as part of this heritance, potentially serving as a competitive advantage (see later with the Global Competition paradigm). Given the main idea of this theory and the biological laws of competition (Gause \& Witt, 1935), it does not even make sense to consider the idea of total convergence of competing firms. Moreover, as they were impressed by devoted Japanese employees, American scholars in the 1980s tended to point out that internal resources can be strengths, and therefore become a strategic advantage. It was precisely this idea which was the focus of the emerging resource-based theory, as promoted by Wernerfelt (1984), or an "introduction" to the core competencies concept of Prahalad and Hamel (1990).

In their classic work on structural isomorphism, DiMaggio and Powell (1983) asserted that organizations tend to become isomorphic through three types of processes: coercive (external pressure), mimetic (internal drives) and normative (along best practices). Ohmae (1989) agreed that both managers and consumers tend to speak a common language all over the world. But, as he argued, this increasingly borderless world does not automatically lead to global products that are the same everywhere and firms will continue to make "local" products, and become an "insider" in each market. For him, uniformity cannot provide a solution even for global companies. That might explain why in American and Japanese companies, several authors find evidence of both convergence and divergence (Jacoby 2007, Abo 2007).

There is a strong temptation to think that the world is becoming like the US, moving along dominant best-practice lines in each industry. ${ }^{11}$ Bartlett and Beamish (2011) argued that for a certain period of time, this idea seemed to be well grounded and useful in practice. But that time seems to have passed and Guillén (2001) denies that globalization encourages economic convergence across national borders: his point is that it rather leads to economic diversity. While acknowledging the driving force of best practices in each industry, we can conclude though that an ultimate convergence would

${ }^{11}$ Or along best-practices found in different countries: in the automotive industry for instance, the Japanese model might be such a dominant model, while financial firms move rather towards American practices (Jacoby, 2007). 
be contradictory to the current logic of business practices and therefore its impact has no actual strategic relevance for this thesis. We must note however, that some forces of convergence may lead to both incremental and radical corporate changes as described in the previous point. Thus, international comparisons are especially helpful in finding new ways and adapting to new circumstances. Tsuneyoshi (2001) formulates this for Japan as follows:

"The belief that the adoption of a certain model, such as the Western model, will solve all of one's problems has always been an illusion, but circumstances in our world today make it difficult to maintain such illusions. Yet cross-cultural comparisons do illuminate, albeit vaguely, what societies have to face in common, what alternatives might be possible, and where those alternatives might lead us." (190) 


\section{II) THE EVOLUTION OF AMERICAN MANAGEMENT}

This chapter seeks to answer the question "Why and how have management practices and ideas changed over time?" We assume that the history of management can be defined by several "paradigms" and that the study of their evolution can provide us an answer. We will focus our attention on the impact of the environment, which we will examine later in the case of Japan as well.

The birth of modern factories is largely due to the construction of the railways which brought the "revolution" of transportation, bigger markets, separating ownership and management (as few were able to finance alone a complete railway line), and growing companies with more hierarchical levels. By the time of the Civil War, the interchangeability of parts in production (first in weaponry) was established, and so standardization with less skilled labor became reality. In addition, from the 1870s, a growing quantity of continuous-process machinery was introduced in American factories in order to increase the volume of production (Locke, 1996). The industrializing world entered an era dominated by the power of economies of scale, where the first priority of the firms was growth. ${ }^{12}$ Steam power made mechanized production cheaper, so prices could be lowered as well. Lower prices meant higher demand, which pushed factories to employ more workers, and buy more machines; this race could be won only by those who achieved the cheapest prices through larger-scale production. By the 1900s, the aspect of scale in the US turned out to be a great advantage over the hitherto relatively more developed Western European economies. Consequently, Litterer (1961) argues that in America technical skills and innovation were not used to make products, as in Europe, but to make production lines. To sum up, the key drivers behind the rise of Big Business in the late 1880s were technology, management, mass markets, and economies of scale and scope (Koehn, 2009).

However, management of those ever-growing companies presented a serious challenge, because their owners lacked professional training or any kind of education about how to organize and coordinate the work of so many at the same time. In addition, a significant proportion of workers were illiterate or, due to immigration, could not even speak English. The given responses included using the "stick" (punishment) and the "carrot"

\footnotetext{
${ }^{12}$ Skaggs and Leicht (2005) call this period (1860-1910) Entrepreneurialism.
} 
(rewards, bonuses), and building a sort of "factory ethos", often linked to religious morals and values, in order to stabilize hierarchy (Wren, 1994).

People were learning from their co-workers, production did not have standardized methods, and innovation was often blocked or resisted by labor. Employers promoted low wages because when a worker got enough money to survive for a few days, he or she simply did not return to work for that time. Workers did not make long term plans, or save money; and management also operated in the same, ad-hoc way, without serious experience-transfer or conscious methods. The general belief was that a good manager is made merely by personality, and owners recruited mainly family members to managerial positions, simply as a matter of trust.

Standardized mass-production required more professional management, different to the previous manufacturing systems supervised by family owners. Large firms reached a size where their owners could not directly supervise work and train workers by themselves. This new management style emerged under the name of "Scientific Management", which we will examine as our first paradigm.

\section{1) Scientific Management: engineered production}

"The conservation of our natural resources is only preliminary to the larger question of national efficiency." (Franklin D. Roosevelt $)^{13}$

Management literature abounds with studies confirming Taylor's Scientific Management from the 1910s to be the first management "model" or "paradigm" (Pindur, Rogers, \& Kim, 1995). ${ }^{14}$ The difference compared to previously described practices was that a systematic, conscious and planned approach appeared in management. Why then, and why there? Were the 1900s clearly different for the working population from the nineteenth century? We can argue that they were, first because factories grew to much larger sizes than ever before. ${ }^{15}$ Size can be an advantage in terms of scale economy on the one hand, but on the other, it represented a big challenge for the managerial society which at that time lacked professional training. Organizing the work of such masses often turned into violence and created clear tension

\footnotetext{
${ }^{13}$ Cited by Taylor (1911).

${ }^{14}$ See also in other works: (Guillén, 1994a), (Wren, 1994), (Waring, 1991), or (Levie, 1993).

${ }^{15}$ Ford, for instance, employed 53,000 workers by 1919 (Wren, 1994).
} 
between blue- and white-collars. In addition, those masses were generally uneducated, which seriously hindered complex work with machines.

In addition, the twentieth century was clearly different for the workers because a new professional group appeared in the increasingly complex American companies: engineers. Breaking the European dominance, the US became top-ranking country in terms of the number of engineers in 1900-with Germany as second (Guillén, 1994a). Familiar with numbers, they quickly became the business elite, often combining the professions of businessman and engineer. Both skills were important, as there was an urgent need for methods of dealing with labor unrest, with growing complexity in factories, and helping managers to gain further economies of scale (productivity).

Charles Babbage (1791-1871), an English mathematician and engineer was among the first in Europe to develop a rational, systematic approach to management, but his thinking was not widely disseminated. Guillén (1994a) states that both in leading business literature and in practitioners' writings, issues specific to Scientific Management appeared in the 1880s, and became dominant mainly in the 1910s and the early 1920s. Parallel to publications, techniques and ideas of Scientific Management were taught in the curriculum of leading business schools as Wharton, Harvard, and Dartmouth. Although the authors of those articles and books were numerous, the most cited apostle of the scientific approach to management was Frederick Winslow Taylor (1856-1915). In spite of government investigations due to strikes in military factories, ${ }^{16}$ and a general resistance from blue-collars, by 1915 his main ideas had been introduced or at least tried in 140 establishments totaling 63,000 workers. The original appeal was important: Taylor proposed a system which could use unskilled workers instead of unionized, expensive and rare skilled workers, raise productivity and reduce organized resistance through pay rises.

Was he the only creator of these new ideas? Certainly not. James Watt and Matthew Robinson Boulton from Soho Engineering Foundry, Great Britain, introduced systematic and planned management techniques as early as in the late 1790s (Pindur, Rogers, \& Kim, 1995). Babbage also established a systematic approach in Britain. These, however, lacked the power of economies of scale to effect a sufficient increase in production. The New World was waiting for a scientific man from large-scale industrial production who could create universally applicable managerial methods, solving all

\footnotetext{
${ }^{16}$ Taylor had several hearings from 1911 to 1912, especially due to strikes in the Watertown Arsenal.
} 
major labor problems of that time. It happened to be Taylor, with his Scientific Management, which gave an appropriate answer on how to deal with uneducated labor, workers' resistance towards piece-rate pay, underperformance, and tense managerworker communication at the same time. He called it scientific because, for the first time, he calculated piece-rates using precise measurements: their base became facts instead of whims, estimation, or even past performance. Also, he designed a proper and sustainable way of performing each task through time study and calculation. His management philosophy was new, because he wanted to recognize and pay "first-class" workers, instead of positions. As the result of several years of experiment, Taylor designed a system based on time study, performance standards, selection of workers, careful assignment to the right job, separation of planning from performance, task management and functional foremen (Taylor, 1911).

Taylor's concept as a whole apparently failed in widespread practice as managerial tasks proved to be too complex for uneducated clerks (Wren, 1994). Also, organized labor caused much trouble. His system ensured total and objective control both on workers and on clerks for the first time - he certainly gained enemies. This happened in spite of his widely read books ${ }^{17}$ and the efficiency of his system, ${ }^{18}$ on which he was giving classes at Harvard from 1909. Statistical evidence also shows that manufacturing output per working hour counted as 100 in 1958 went from 21.2 in 1890 up to 52.0 in 1929 (U.S. Dept. of Commerce, Bureau of the Census, 1975). ${ }^{19}$

Taylor's work was finally continued, polished and disseminated worldwide by his followers: Gantt, Barth, the Gilbreths, Brandeis, Le Chatelier, Emerson, and others. Henry Laurence Gantt in particular (1861-1919) was successful in this quest as one of the first management consultants and lecturer at numerous universities, with over 150 titles published, and more than a dozen inventions patented. By way of example, the basis for the Soviet central planners to control their five-year plans was Gantt's work: his famous chart designed for project planning (Wren, 1994). Also, Frank and Lillian Gilbreth improved the methodology of time-and-motion studies and Emerson further clarified efficiency (Luthans, 1969). Due to these improvements, more and more managers and engineers came to accept Scientific Management. World War I and the

\footnotetext{
${ }^{17}$ Taylor's most famous writings are his book 'Shop Management' from 1903, and 'The Principles of Scientific Management' from 1911.

18 After Midvale, Taylor worked as a consultant for several companies where he could achieve spectacular raises in performance for lower labor cost.

${ }^{19}$ Cited by Wren (1994).
} 
resource efficiency promoted by Roosevelt also played an important role in its popularization. Beyond that, the biggest effect made by one single person was perhaps that of Brandeis in the Eastern Rate Case, who successfully proposed that Scientific Management could help the railways to gain efficiency, and cut costs without raising fare prices (Aldrich, 2010). New disciplines such as industrial psychology with Hugo Münsterberg, Social Gospel or industrial sociology also supported the efficiency movement, although already paving the way for more "human" solutions (Wren, 1994).

Staying with the practical impact, mention must also be made of the names of Ford and Bedaux. Henry Ford (1863-1947) made extensive use of Scientific Management techniques and improved his production process with gravity slides, automatic and endless-chain conveyors and other technological innovations. While speeding up the production line, Ford also increased the pay of his workers as Taylor proposed, although he disagreed with a few of Taylor's ideas. Charles Eugene Bedaux (1887-1944) also played an important role due to his popularity as a business consultant. He worked to increase efficiency using Scientific Management methods, for instance through the standardization of the time spent on a specific task. Between 1918 and 1942, over 700 American companies with 675,000 workers were advised by Bedaux (Guillén, 1994a).

At the same time, organized protest of workers came close to triggering civil war: in the US it reached a higher level and was more savage than in any other industrialized country, especially between 1900 and 1920. Not only companies but also government and the courts were becoming increasingly hostile to unionism and accordingly, union membership declined from around 5 million in 1920 to 3.5 million in 1921 (Wren, 1994).

In addition, critics pointed out that some research data described by Taylor were simply not true, that he promoted exploitation, ignored the human nature of workers, and some observers even questioned to what extent Scientific Management was scientific (Gibson et al. 1997, Marosi 1983). The shift to the HR movement could be seen as a failure of the paradigm, though both the ideas and practices of Scientific Management survived the era, and can be found at work even today. 


\section{2) Human Relations: the "awakening" employee}

"Psychology shows apparently that people produce more if happy, if they would produce more when furious, we would make them so." (Comments of a corporation's vice president $)^{20}$

In the previous point we listed some problems caused by the rise of large-scale industry; labor unrest appears to be at the top of that list. Scientific Management attempted though to give a technical solution to "soldiering" by increasing the size of the pie which could be divided between the owner(s) and the workers. But wage appeal itself proved to be insufficient as strikes worsened and endangered profit. Continuous problems caused a shift in general attention away from the technical towards the socialpsychological aspects of work: thus a new paradigm arose from the "uncooperative" and "individualistic" background of the Scientific Management (Wren, 1994).

What was different in the 1920 s, compared to thirty or twenty years earlier? Slower immigration, the electrification of industry, and urbanization certainly had an important effect on society (Guillén, 1994a). American labor prospered, too, witnessing real wages double between 1865 and 1890, and once more from 1890 to 1921. In parallel life expectancy increased, and the average industrial working week decreased from 60 hours in 1890 to 55 hours in 1910, and then to 50 hours in 1920 (Wren, 1994).

Psychology gained broader acceptance as early as during the Scientific Management era for its role in supporting selection at the workplace. Also, corporate care of personnel was not a new idea: before industrialization business was more family-sized with paternalistic management. Early factory owners, such as Robert Owen (1771-1858) and Benjamin Seebohm Rowntree (1871-1954) provided a large range of company benefits to workers, such as meals, housing, education, health care, recreation, or dancing lessons. Owen also set up cheap company stores and raised the minimum age for working children (Pindur et al., 1995).

Welfare services were developed in large companies from the 1900s, and here women played a growing role: it may be that it was at this point they had managerial career opportunities for the first time in business. After World War I, many companies

\footnotetext{
${ }^{20}$ Originally cited in Pierre Fraisse, 'Les perspectives des relations humaines', Revue de psychologie appliquée, Revue trimestrielle, 4:1 (Jan. 1953), special issue devoted to report of the French Psychotechnique mission to the U.S.A. (Oct.-Nov., 1952: 144). Source for this thesis: Locke, 1996: 256.
} 
launched programs, such as health and accident insurance services or old-age provisions. The departments concerned were in charge of selection, training, performance-tracking and nursing of the workers, as well as providing welfare services. In 1914, Ford had an employment department called the Sociological Department; he cut the working day from nine to eight hours and raised the minimum wage from 2.5 to 5 dollars per day (Ford, 1922). Employers clearly sought to develop a certain sense of belonging and to integrate workers more than before, and this growing interest in the human side of enterprise was fertile soil for two professions rising in parallel: sociology and psychology.

Lillian Gilbreth appears on the borderline between two paradigms, as the Gilbreths are usually referred to as Taylor's followers and ambassadors of Scientific Management. However, this view can be considered an overgeneralization, because Lillian Moller Gilbreth (1878-1972), the wife of Frank certainly went beyond the mechanization of work. She not only enhanced the "motion study" and analyzed industrial fatigue with her husband, but was among the first to emphasize the importance of psychology in industrial activities. As Wren wrote: "She was not the originator of industrial psychology, but she brought a human element into scientific management through her training, insight, and understanding” (1994: 148). Known also as "The First Lady of Management", she was a psychologist, who, parallel to her maternal role with twelve children wrote several titles with rather "soft" contents.

The somewhat symbolic beginning of the Human Relations paradigm is usually associated with the Hawthorne studies, although Hawthorne began as a Scientific Management-inspired experiment in 1924. It was conducted by a professor of electrical engineering from MIT, who was looking for enhanced productivity while bettering light conditions (Gillespie, 1991).

By the end (in the early 1930s), the Hawthorne research had made it clear that pure technical skills were not enough for the successful management of people. There was a need for a good sense of diagnosis to understand human behavior, and interpersonal skills to be able to motivate, engage with, lead and communicate with workers, or somehow deal with the shock of the 1929 stock market crash and the following economic depression. ${ }^{21}$ But first-line supervisors with both technicaleconomic and human relation skills were rather rare in the early 1930s.

\footnotetext{
${ }^{21}$ Unemployment rate rose to about $25 \%$ and the Norris-La Guardia Act of 1932 protected unions and supported the unionization of workers (Skaggs \& Leicht, 2005).
} 
The new paradigm, called HR (Human Relations) movement, emerged as a response to this need. For some management theorists, this behavioral movement is composed of two different sets of ideas: human relations and modern behaviorism or organizational behavior (Pindur et al., 1995). From his perspective, Bakacsi (2011) identifies each of these as a "paradigm", to emphasize the different degrees of workers" "skill" and "will", and the different social circumstances giving rise to both HR and OB.

For others, the paradigm known as Human Relations simply came in two waves (from the 30s to the mid-40s, and then again from the late-1940s), with ambassadors mainly from the social and psychological sciences. Those sciences apparently developed as a means to give a more scientific basis to practical ideas, like Lawrence $\mathrm{J}$. Henderson with Paretian sociology, or Elton Mayo with Hawthorne. This thesis relies more on the second approach: we deal with the subject as one paradigm, because the basic, "paradigm-forming" dilemma remains the same: in an environment of tense industrial relations, how to influence our human resources with "soft" tools for producing more (productivity) with lower costs (efficiency). The "soft" simply becomes "softer" with time.

For Levie (1993), the first true representative of the first wave, in the 1920s, was Mary Parker Follett, followed by Mayo and Roethlisberger. Wren adds Chester I. Barnard, Jacob L. Moreno and Henderson to the list.

As early as the 20s, managerial tools have been developed in order to reduce absenteeism, labor turnover, or strikes. Follett based her management on individual and group motivation and "constructive conflicts"; she emphasized coordination rather than orders (authority); and group dynamics rather than formal structures (Follett, 1941). For Mayo, too much emphasis on technical variables and overreliance on them decreases production, and so, he argued, technical progress can jeopardize previous achievements in society. He greatly promoted "soft" methods increasing productivity, although at the institutional level, the American Management Association founded in 1923 proved to be the major disseminator of HR ideas (Guillén, 1994a). Strong messages also came from Hawthorne, where the greatest lesson of the experiments may be that enhanced satisfaction of workers leads to higher productivity (Levie, 1993). Efficiency and productivity remained first target for the HR advocates, as it was for Scientific Management: the only difference between them was in the methods used to achieve it. When McGregor first wrote about it, he could only hope that a more positive attitude 
towards workers (the "Y-view") would be developed and would improve management, although the reality of the late 50s was still not that bright (McGregor, 1960).

Mayo's toolbox for managerial problems was more about listening, using group pressure for at least standard performance and initiating worker participation. Thus, the early stage of HR can be called a closed system, where workers perform predefined tasks, and the later phase an open system, were people have the skills to solve problems in connection with their work environment (Bakacsi, 2011).

The second wave of Human Relations started with the emerging motivation and decision-making theories, and with the increasing involvement of employees in decision-making. The leading scientists of this second wave were Chris Argyris, F. L. W. Richardson, Jr., C. R. Walker, Arthur N. Turner, Rensis Likert, Kurt Z. Lewin, Abraham H. Maslow, Frederick I. Herzberg, Douglas McGregor, Alex F. Osborn, Robert R. Blake and Jane Mouton. ${ }^{22}$ By the 40s, their interest had turned more towards job enlargement and enrichment, work design, rotation, motivation, leadership, group dynamics, and participative management. Finally in the late 1950s, Keith Davis redefined HR and wrote an important book with a modern approach of it, differentiating the terms "organizational behavior" for the understanding of human behavior, and "human relations" for the application of this understanding to operational situations (Davis, 1957). ${ }^{23}$ Edward Wight Bakke wrote explicitly about "human resources" at about the same time, still putting the focus on productive work rather than personal happiness (Bakke, 1958). ${ }^{24}$ The start and development of "human resources management" was also an important step towards enhanced administration of personnel and for building administrative support for the increasingly bureaucratized firms of the postwar period. $^{25}$

Equipped with more knowledge on motivation, the second wave of HR went further in transforming jobs and interpersonal relations. Organizational Behavior and decision-making theories delegated more power than had hitherto been the case to employees (now decision makers), who also became better educated (skilled) and better socialized at work (motivated) from the 1950s.

\footnotetext{
${ }^{22}$ For more information on the first vs. the second HR waves, see Waring (1991).

${ }^{23}$ Cited by Wren (1994).

${ }^{24}$ Cited by Wren (1994: 377).

${ }^{25}$ See, for instance, French (1964).
} 
Up to this point of the thesis, two of the main authors of the Human Relations paradigm have been ignored because of the difficulty of categorizing them as either the first or the second wave. Considered as transitional figures, their work created a link, as it were, between the two waves. Yet regardless to their category, Barnard and Simon merit our special attention.

A scholar from Harvard ${ }^{26}$ but primarily a management practitioner, Chester Barnard (1886-1961) made great theoretical contributions to the field of management study. He is credited with being the creator of numerous theories, including the acceptance theory of authority, the role of the informal organization, the functional and dysfunctional aspects of status systems, the importance and nature of decision processes, and the role of the executive organization as a communications system. Denying the validity of economic models for the rationality of human beings, and in opposition to transaction cost theory, he stated that organizations come into existence simply when there are people who are able to communicate with each other, willing to contribute to action, and who do this for a common purpose. This system, called an organization, can be maintained if equilibrium is created between the system and its environment on one hand, and within the system itself on the other (Witzel, 2005).

Another breakthrough theory from Barnard deals with the acceptance of authority based on free will and outside forces: he identified a "level of acceptance" under which employees would accept orders from managers automatically, without any questioning process. This level was determined by non-written norms and an understanding of cooperation and trust. Accordingly, the employee would accept a directive if he understood it, was able to follow it, and he believed it was appropriate regarding the organizational goals, at least as the employee understood them (Barnard, 1938).

Under this new light, managers were no longer giving orders but rather gaining the cooperation of their employees (increasingly capable of making decisions by themselves, a point further developed by Simon). But Barnard not only redefined theories on authority, cooperation and communication: he was also able to describe organizations in a wider sense than given by their formal structures, and identify them by their investors, suppliers, customers, or other contributors as well (Barnard, 1948). This point will be important later on while describing Japanese management and the stakeholder view of firms.

\footnotetext{
${ }^{26}$ He had not actually completed his degree when he left Harvard in 1909 (Witzel, 2005).
} 
Herbert A. Simon (1916-2001) was greatly influenced by Barnard in developing his theory about "bounded rationality". In his classic Administrative Behavior, he criticized the idea that management is based on principles, as in the work of Gulick, Urwick, or even Fayol, and called for a new theoretical framework able to deal with the real causes of bureaucratic disease, not only symptoms. As a key to this new framework, he described the psychology of decision-making in organizations. He stated that rationally behaving individuals do not optimize their situation but make decisions, based on the environmental constraints, which are good enough rather than optimal (Simon, 1947). This emphasis on the "open system" (in connection with the environment), which he acquired with James March, will be also mentioned in the next point.

Contrary to previous studies, such as that of Bendix (1974) which claimed HR was merely an ideology, Guillén (1994a) affirms that there was a significant practical impact of HR techniques. Adoption of HR techniques was often associated with the creation of personnel departments but also concrete techniques were implemented in corporate practice. New institutes and research groups were formed, especially in the US and the UK. Their basis was often Gestalt psychology and Social Gospel.

The work of Jacob L. Moreno (1892-1974) must be highlighted, since it was he who developed sociometry, an analytical technique for representing interpersonal relationships on a so-called sociogram, but also psychodrama and sociodrama, serving rather therapeutic purposes (Moreno, 1953). Another important construct for analyzing behavior was group dynamics, credited generally to Kurt Lewin (1890-1947) and his famous leadership studies. Company practice was later to benefit from Lewin's finding that changes in behavior were more easily induced through group participation and involvement than through simple orders (Lewin, 1948). According to Wren (1994), this also led to his unfreezing-refreezing theory on change. Other techniques from this era included human relations training or sensitivity training (increasing interpersonal awareness), suggestion systems, magazines \& newspapers targeting employees, brainstorming and group discussion methods, job enlargement and enrichment, psychological testing of personality traits, morale surveys, etc. Knowing themselves better in relationship to others apparently fostered the workers' emotional and moral well-being, essential to group cohesion (Locke, 1996).

Just as Scientific Management had its corporate flagships, written records prove that these HR techniques also greatly contributed to corporate success, and could even save companies from bankruptcy, like the Scanlon Plan (group-based incentives 
combined with a suggestion system) in 1938 at the La Pointe Steel Company. Incentives at Lincoln Electric were based on individual performance but James F. Lincoln earned his success by paying particular attention to recognition and self-management of employees. IBM introduced job enlargement in 1944, first at its Endicott (New York) plant, in order to ease the monotony of mechanical work at the assembly line (Wren, 1994).

Organizations tended to become flatter to maximize administrative decentralization and encourage individual responsibility, initiative, and involvement. This gave birth to bottom-up management and an earlier identification of young talents. Lewin's work, as we have seen, could be used in industry to lower resistance to change and stimulate group participation.

For a complete picture of the Human Relations paradigm, we must also look at its ambiguous impact on the labor soldiering problem. It goes without saying that HR was not made to represent workers, but it did not attack unions directly either. Mayoists looked at the worker from the management's perspective and accepted the need to "use" them as a means to higher productivity and lower costs. In addition, the paradigm brought no alternative for the resolution of industrial conflict (e.g. collective bargaining). Briefly, HR proponents did not really take unions into account in building social solidarity. Moreover, unions raised their voices when such techniques as "moral surveys" were introduced, creating direct communication between workers and management, and by-passing labor leaders (Guillén, 1994a). These strong lines of "power games" may provide some of the reasons that unions are usually neglected in developing main management ideas. Labor seemed to gain substantial power through legislation in the 30s (i.e. the Norris-La Guardia Act of 1932), which made resistance stronger than it was in the 20s. However, from the mid-1930s, strikes and tension decreased again and organized labor henceforth caused less trouble for companies.

Other critics of HR state that rather than defining a new ideology, it was just a revival of earlier humanist thinking driven by the prestige of Harvard and MIT to build a "conflict-free dream" although conflicts are necessary (Wren, 1994). Authors also question the credibility of Mayo as evidence proves that his desire was to show that material incentives play only a secondary role in productivity. Focusing on his goal, he may have been biased or ignored signs indicating the importance of money. In fact, there were so many variables and control groups by the end of the experiments that separating the effects of material incentives from other variables would be a tough task even today. Bell (1956) argued that the idea of a contented worker being equal with 
productive worker was simplistic and too general. His critique became well known under the term "cow sociology” (Guillén, 1994a).

To sum up, the HR paradigm, with all of its merits and valuable contributions, was not wrong: it may simply have become exaggerated compared to its scientific content. Certainly, after the 1940s, it no longer provided appropriate answers for several new managerial challenges. By that time companies were internationalizing on a massive scale, which certainly still required good communication, interpersonal and intercultural skills. However, skills alone were not enough, as inadequate structures often blocked further growth and international development. Thus, as concluded by Wren (1994): "after World War II, the search for a general management theory would emerge as a solution to the complexities of managing in the modern era." (342)

\section{3) Structural Revision and Open Systems}

"I see too many academics forgetting what I think our job is in management, and that is to organize available knowledge; develop new knowledge, of course, but organize it in such a way that it can be useful to practicing managers to underpin management." (Harold Koontz) ${ }^{27}$

The United States enjoyed nearly unlimited markets until the 1950s when it arrived at saturation point. In parallel, the international environment had only limited impact on the development of American capitalism, except for the two wars (Guillén, 1994a). Then, the Marshall Plan and the postwar period brought new international opportunities for the hitherto stagnating USA: the end of World War II meant economic recovery due to new markets, new products, and new technologies, and ever since, American outward FDI has shown constant growth (see Figure 4).

\footnotetext{
${ }^{27}$ Cited by Ronald G. Greenwood in "Harold Kontz: A Reminiscence", presented at the meeting of the
} Academy of Management, Boston, August 14, 1984 (source: Wren, 1994). 
Figure 4: U.S. Direct Investment Position Abroad on a Historical-Cost Basis, aggregate totals (millions of dollars)

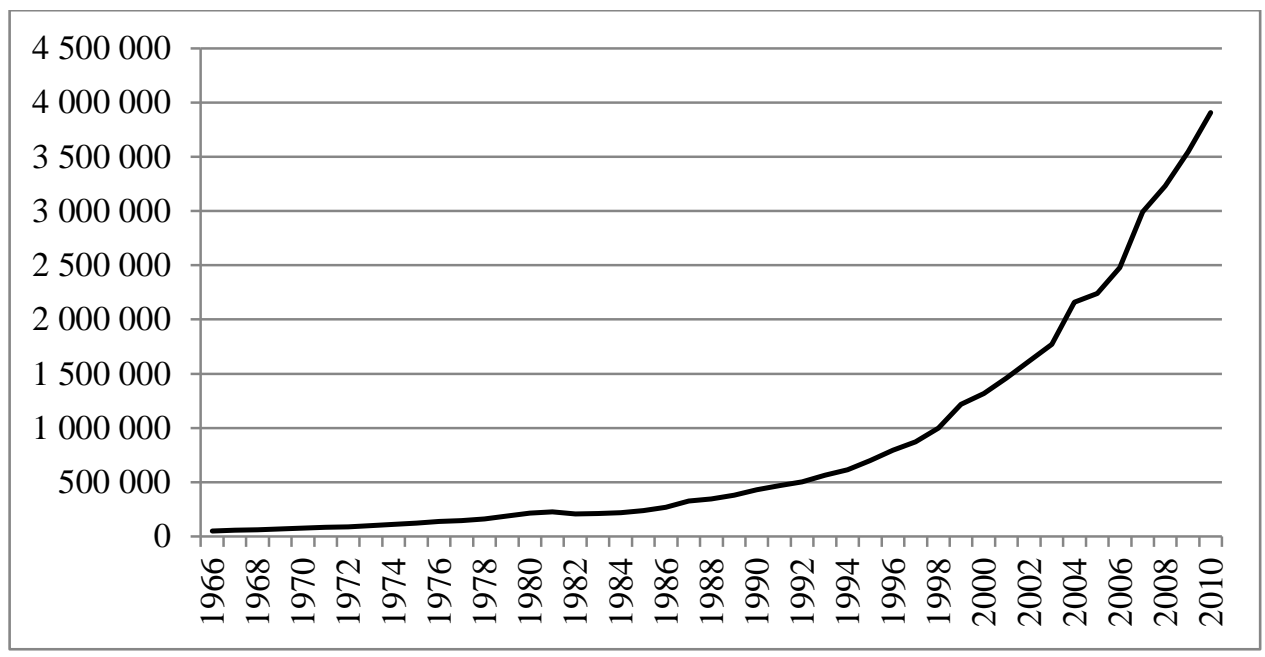

Source: U.S. Bureau of Economic Analysis (methodology and presentation of data changed in 1977, 1982, and 1994).

This opening also brought a greater need for coordinating product development, manufacturing, and marketing on a global scale with adequate corporate structures.

Scientific Management ideas, which had faded in the Great Depression, witnessed a resurrection with the wartime production and the development of Operations Research, Management Science, Management Information Systems and Cybernetics (Wren, 1994). Thus, management had to shift from the prewar productionoriented practices to a new, "top-management" perspective coping with a growing need for coordination, larger-scale enterprises and markets, and a better-educated workforce. In terms of specialization, managers had to grow into generalists able to manage specialists. A new era came with business expansion and diversification.

Ownership and management became definitively separated but a widespread stakeholder view "protected" management from the shareholders. According to dominant values, owners could earn only a "fair" share of profit, and literature dealt rather with the managers' rights than the shareholders' ones (Jacoby, 2007). This philosophy continued in the $1970 \mathrm{~s}$ as well. The 50s and $60 \mathrm{~s}$ were the era of "organization men" with tremendous opportunities for management careers in internationalizing companies. Along with increasing size, complexity and decentralization, corporations massively adopted M-form structures and therefore expanded middle-management ranks. In parallel, the inefficiencies in the bureaucracy attracted more attention (see Crozier, 1964). By the mid-1950s half of the largest American manufacturing firms were operating under a multidivisional structure (Fruin, 
1992). Chandler in 1962 and Palmer et al. in 1987 claimed that the multidivisional form replaced the unitary (functional) form as the prevalent administrative structure among large American corporations. Palmer et al. introduced the M-form structure as a practical way to "regulate the nature and extent of territorial growth both within and between nations" (25). Yet in the 1960s, the financial perspective gained emphasis as a managerial career perspective due to the mushrooming in mergers and acquisitions (M\&A). This foreshadowed the coming conflict between stakeholder and shareholder values.

Also in the early 1950s, a new system theory was developed by Bertalanffy, followed by the development of the contingency theory. Herbert Simon, with his colleague James March, stated that the classical principles of organization were incompatible with their actual contexts and therefore predicted the birth of new ideas, new frameworks, or perhaps a new paradigm. The diversification of firms, as well as the mergers and acquisitions (M\&A), increased the role of controllers and financial experts, who were able to provide accurate information on the performance of different parts. ${ }^{28}$

With the development of contingency theory, authors sought to identify all valid elements of the environment and build a model leading towards "organizational fit" or a better match between their structure and the environment. Examples are the studies by Chandler (1962), Galbraith and Nathanson (1978) or Mintzberg (1980). The conclusion, which led to a wave of new books and practices, was: "the adequate way to organize was contingent upon certain strategic and/or technological choices made by the management" (Guillén, 1994a: 85).

Needless to say, there are not many managers who would not manage according to the situation or circumstances. But we must not underestimate the power of focus on the environment in management research, consulting and education, in a world where the business elite is accustomed to seeking to enhance performance mainly by looking into the organization (production process, employee welfare, etc.). Parallel to its impact on organizational structure, the situational approach also gained terrain in leadership (Fiedler, Hersey \& Blanchard, Vroom \& Yetton), ${ }^{29}$ and, especially from the 1970s, in Strategic Management (e.g. SWOT analysis). Thus, in this quest for organizational fit, a robust organization theory had to be developed so as to provide a framework for researchers.

\footnotetext{
${ }^{28}$ Mainly through ROI (Return-On-Investment) and other similar indicators.

${ }^{29}$ For more information, see Bakacsi (1996).
} 
The first general theory in management is usually attributed to Henri Fayol, who defined the main elements of managers' activity and the general principles guiding them in $1916 .{ }^{30}$ Another forerunner worthy of mention was Donham, editor of Harvard Business Review, who launched the journal in 1922 with the claim for a broad executive theory in business. Despite these first attempts, their era proved to be too early for a topmanagement approach to organizations, because practitioners were busy with improving field efficiency and productivity. Big structures remained mainly functional as this was believed to be the best way for large-scale operations (see Weber on bureaucracy).

With the massive internationalization of large companies, markets became wider, technology more advanced, organizational forms more intricate and people more specialized. These elements, as we have stated previously, led to the need both for a more precise manner of handling organizational problems, and for a more sophisticated management education-based on a solid (and if possible integrated ${ }^{31}$ ) theory. Although this integrated general theory was never able to emerge,${ }^{32}$ research greatly enriched our understanding and tends to be confirmed by the fact that Fayol's ideas continue to be valid today. His book was published in English in 1949 and became highly popular, ${ }^{33}$ and was quickly followed by others on general management: for instance, William $\mathrm{H}$. Newman, George Terry, Harold Koontz and Cyril O'Donnell, or even the US Department of the Air Force (Wren, 1994). In addition, the management "guru" Peter F. Drucker published his widely read book The Practice of Management in 1954.

Their writings were greatly popularized by business schools and the development of management education: the number of undergraduates studying management grew each year after the 1950s, from already 370,000 in 1950 (nearly double the number studying engineering). A real breakthrough was brought by the graduate business schools and the MBA programs: these turned out 4,814 graduates in 1960, 23,400 in 1970, 49,000 in 1980, and 70,000 in 1990 (Locke, 1996). All of these schools dealt with general management theories: Fayol, Drucker, and so forth.

\footnotetext{
${ }^{30}$ Published in the Bulletin de la Société de l'industrie minérale (first version) then reprinted (Fayol, 1956).

${ }^{31}$ On the diverse management approaches, see Koontz (1961) and (1980).

${ }^{32}$ Fred Luthans (1973a) proposed the contingency theory of management as the way out of the theory jungle, but for Koontz, theories had become more numerous by 1980.

${ }^{33}$ Henri Fayol, General and Industrial Management, trans. Constance Storrs, London: Sir Isaac Pitman \& Sons Ltd., 1949.
} 
Guillén (1994a) gave the framework of the internationalizing and bureaucratizing firms, with more emphasis on general theories on management and organizational structure, the name "Structural Analysis". Here we shall use this term with some modification to illustrate the emergence of a new paradigm. Completing the work of Henri Fayol and Max Weber, the forerunners of the Structural Revision paradigm felt that efficient structures and operation of organizations were an alternative to the Mayoist school in solving the misery of the economic holocaust of 1929. They attempted to develop the "right" management functions and structures, stressing these as a means to both employee satisfaction and productivity. In a sense, especially compared to HR ideas, the toolbox of Structural Revision meant a return to the "hard" side of management. Among these early advocates we can count for example James D. Mooney (a General Motors executive), C. Canby Balderston, Charles L. Jamison and William N. Mitchell (professors who initiated the founding of the Academy of Management), Luther Gulick and Lyndall F. Urwick, and Ralph C. Davis. ${ }^{34}$

The early works generally had a "one-best-way" approach which could only satisfy practitioners as long as organizations kept their relative homogeneity. That was an adequate answer for the age of depression, when organizations fought for survival rather than internationalization. Moreover, it was a good means to raise management thinking from an operative level to a broader viewpoint, and thus prepare the way for more complex corporate designs.

These early ideas were then followed by more sophisticated approaches, promoted for instance by Alfred P. Sloan, Peter Drucker, Dale, Chandler and other "gurus", or the numerous consultants from McKinsey, BCG, and Delta. Curiously, the flavor of one-best-way approaches remained in the air due to the mushrooming "management by..." concepts, the most famous being management by objectives, credited to Drucker. Indeed, an easy-looking solution is always more appealing than a complex model, hard to understand, with plenty of variables and much uncertainty.

We do not have precise measurements or any representative survey indicating to what extent managers took into account these writings, but the practical impact of the Structural Revision paradigm is hard to overestimate, mainly due to the rise of the consultancy business. Consultants and the mainstream literature all popularized the contingency approach. It was logical, easy to understand, and close to the needs of

\footnotetext{
${ }^{34}$ For more details on these authors, see Wren (1994: 295-313).
} 
internationalizing companies, so managers just followed the trend. McKinsey; Robert Heller \& Associates; Cresap; McCormick and Paget; Booz, Allen and Hamilton; A. T. Kearney and others assisted countless structural reorganizations in the US, seeking for a better adapted organization with a better fit (Guillén, 1994a).

Structural Revision, with the context of open systems, certainly showed the way and sewed the seed of many new ideas, but it had its critics as well. On the one hand, several researchers in the social sciences deplored the analogy with plants and animals. They claimed that success in human organizations was more complex than adaptation and survival and that congruency or fit theories could help to explain the past but not to "predict what fits will lead to high performance in the future" (Wren, 1994: 392). Indeed, compared to the Scientific Management and HR movements which promised a better world in a utopian way, the paradigm of Structural Revision remained rather vague about the future.

On the other hand, criticisms from the 1970s denied what the early findings suggested: that a change in contingency would directly cause a move within the organization in order to reset the best possible fit. These debates eased however, and the contingency theory of organizational structure, the basic theory of the Structural Revision, continues to be a mainstream theory for organizations.

\section{4) Strategies for Global Competition}

"Chasing market share is almost as productive as chasing the pot of gold at the end of the rainbow. ... If you are in business, you already have 100\% of your own market. So do your competitors. Your real goal is to expand the size of your market. But you will always have 100\% of your market, whether it grows or shrinks." (Henderson, 1989: 141)

In the previous point, we focused on the internationalizing and growing corporations, with their operations being greatly restructured. The year 1969 witnessed a huge drop in US stock prices, which caused finance departments to lose their relative importance, compared to other functions like human resources management (Jacoby, 2007). In the 1970s, blue-collar jobs were reorganized (inspired by examples from Japan and Sweden), more psychologists were engaged by companies, Organizational Behavior and 
Human Resources (formerly Employee Relations) gained prestige and even more importance than before. There was a trend for companies to expand their headquarters adding considerable HRM departments, and to centralize their activities. Between 1965 and 1980, for Schwarz \& Volgy (1985), the declining American economy was indeed “overtaxed, overregulated, and overburdened by excessive government spending" (98).

The modest (1.5-4\%) rate of growth of American companies was shadowed by the spectacular rise of other countries. Whereas in 1950, the US provided half of the world's industrial output, this had fallen to only 21 percent by the mid-1980s. The same figure went up to 19 percent for a new competitor challenging US hegemony: Japan (Locke, 1996). Moreover, for the first time in the history of developed nations, the trade balance of the US and then many other Western countries had been broken by this “developing" country. This trade deficit kept growing even after the Plaza accord and in 1986 , despite the dollar's plunge, reached a record $\$ 148$ billion; in contrast to the Japanese $\$ 56$ billion trade surplus with the US (Tsurumi, 1987). This emerging, new "competition" had huge impact on the status quo of developed countries: both on the economy and on society as a whole.

Consequently, between 1970 and 1990, the average American worker added an extra 164 hours to his or her working year (Schor, 1992). This means that they worked one month more in the beginning of the 90s than 20 years before. In most of the manufacturing industries, companies encountered slowdowns and new risks for their survival. The shrinking economy led organizations to implement massive lay-offs and restructuring. During the decline of the American manufacturing, the Big Three carmakers alone eliminated 250,000 jobs by closing many of their plants, and another 250,000 workers lost their jobs in related industries (Kenney \& Florida, 1993). The workplace became more demanding, with accelerated speed and higher stress. Employment uncertainty made workers feel anxious about the future and work each day harder and longer than before (Hochschild, 1997). ${ }^{35}$ Additionally, the two oil shocks shaken the whole world and it became clear that oil and energy prices play a significant role in the competitiveness of countries-as do raw materials and natural resources (Hoványi, 1982).

In the 1980s, the US (Carter and Reagan) initiated a huge deregulation campaign to free the economy. From the 70s, strategic planning and forecasting emerged as a new-old corporate function in order to help companies to improve competitiveness. The

\footnotetext{
${ }^{35}$ See also in other works: (Kunda, 1992); (Perlow, 1997); (Schor, 1992)
} 
1980s could also be called the era of hostile takeovers, which as a consequence brought growing power to shareholders.

Thus, parallel to deregulation, the 70 s and 80 s opened up an enlarged, global competition for the American firms, never before experienced. This competition made the business sector rethink efficiency, productivity, and competitiveness. New functions were needed in order to find ways to survive and to compete, and genuine strategic thinking which simple strategic planning could not provide (Mintzberg, 1994). New, instant solutions had to be found.

Locke (1996) recounts America's economic realities after 1980 as three-sided: (1) "an inability to compete with Japanese imports in many important industrial sectors"; (2) "an unprecedented invasion of Japanese transplants"; and (3) "a diminished American influence in Europe" (166).

Hamel and Prahalad (1985) speak about a "Japanese attack in the 1970s". An increasing number of books suggested that "management in U.S. firms was failing to remain competitive" (Wren 1994: 360, Kenney \& Florida 1993) or even confirmed the "collapse of the American management mystique" (Locke, 1996). Theorists and practitioners tended to look abroad for best practices in order to find remedies for the flagging productivity. This research led to Japan and made her a management example not only to the US, but to the whole industrialized world.

Prominent books soon appeared on the managers' bookshelves on rising Japan, particularly those by Vogel (1979), Pascale \& Athos (1981), Ouchi (1981), and Ohmae (1982). This list can be topped by the broadcast (June 24, 1980) of the NBC White Paper ("If Japan Can, Why Can't We"), the 1980 Special Issue of Business Week ("The Reindustrialization of America"), and the countless articles throughout the 1980s in Quality Progress, The Harvard Business Review, Fortune, and other specialized journals. Deming Societies were founded in every region; the Association for Manufacturing Excellence was created, to name only a few events highlighting the theoretical impact of the new competition. "For the first time, beginning in the late 1970s, American management found itself singled out for its shortcomings in terms of efficiency among capitalist forms of management" (Locke, 1996: 5). This entire echo gave to the Japan focus a huge theoretical impact, fueled by the Nippon economic success. 
To evaluate this impact more precisely and better grasp its scale, we can turn to the method used by Guillén (1994a) and carry out a content analysis of the Harvard Business Review (HBR) articles. ${ }^{36}$ Our assumption is that it is an especially good way for measuring impact as the HBR, as an influential business journal, is widely read by prominent figures of both business and academia. As shown by Figure 9, the 1970s already witnessed a number of articles related to Japanese manufacturing techniques, Japan's competitive advantage and falling back of US industry, but the real rise happened with the 80 s, perhaps partly linked to the books mentioned above.

Figure 5: Theoretical impact of the new competition: articles on Japan in the Harvard Business Review

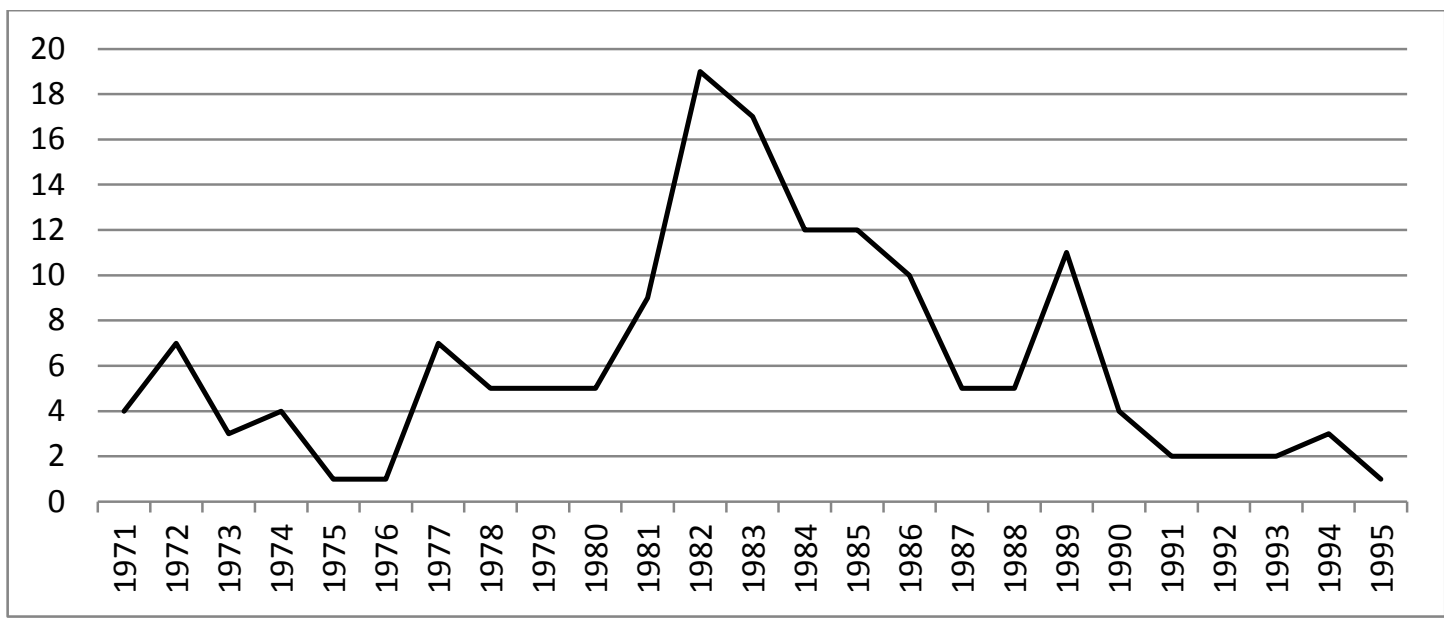

Source: content analysis carried out by the author

After a similar content analysis of the California Management Review, Locke (1996) confirmed that during the decade of the 80s the topic of Japan rose spectacularly, leading to 1985-86 when the journal indexed Japan as a "special" category. In parallel, the popular business weekly Fortune assigned 2.4 percent of its article content in 1980 to Japanese business and manufacturing, or American subjects related to the Japanese challenge. The same figure rose to 9-15 percent for the following years.

To sum up, the theoretical impact of Japan rising and redesigning global competition was undoubtedly heavy in the USA. Beyond that however, we must understand its general significance for American management history and the paradigm framework of this thesis.

\footnotetext{
${ }^{36}$ The author slightly modified the method originally used by Guillén.
} 
The "Lean management trend" was partly created by the new need for international competitiveness, and by the external pressure from Japan and other emerging markets. American managers were seen as merely short-term oriented and corrupt. Many American firms (or at least their manufacturing systems) were characterized by poor quality, high cost, and slow product launches (Putnam, 1985). Although very few in the US could offer all advantages out of price, quality and speed, the Japanese appeared to satisfy all three elements at the same time. Japan apparently offered answers to competitiveness with both "hard" tools (production systems, mechanization of work) and "soft" ones (interpersonal relations, social aspects of work). However, Japan is not important here merely as a new management model but also as a new global competitor questioning American dominance in world trade. I believe that the focus in the 70 s and 80 s should not be on Japan itself but rather on its role in opening a new era, a new paradigm: the one of the global competition. Competition had existed for millions of years already (as Darwin pointed out), but the context of this new paradigm added two important elements to it.

One is the emergence of strategy and strategic thinking in business, due to the hostile environment. In Darwinian competition, as in trade and commerce, random chance is the main factor. As Henderson pointed out: "In fact, business and biological competition would follow the same pattern of gradual evolutionary change except for one thing" -which was for him strategy (1989: 140). Peter Drucker stated in 1954 that decisions that really matter were "strategic". Chandler described strategy as influencing the organizational structure of firms (1962). From issues concerning planning and forecasting in the 1960s and 70s, strategy evolved in common American business press as well. ${ }^{37}$ Following up previous ideas, and based on the thinking of Drucker and Chandler, Igor Ansoff (1918-2002) wrote his book on corporate strategy (1965) and built a comprehensive framework for further contributions. The contribution of Ansoff, also called the father of strategic management, cannot be overestimated: his strategic product-market matrix, his contingency view of strategic management and strategic decision-making are known and taught worldwide. Even the term strategic management can be credited to him: at one point in his writings, he actually renamed the action of formulating objectives and plans on an analysis of the environment "strategic management" (Ansoff, 1976).

\footnotetext{
${ }^{37}$ As observed during the content analysis of Harvard Business Review articles.
} 
The other important element leading to the new paradigm was globalization, the extreme widening of the arena of competition. According to the findings of Gause and Witt $(1935)^{38}$ from the University of Moscow, two small living creatures can survive and continue to exist together, given a certain amount of food in a bottle if different species, but two of the same species could not. When competing for the same essential resource or food, one of the two sooner or later displaced the other. The bottle in this experiment represents the area of competition whereas the food is the living basis (income) of firms. According to the example taken from biology, ${ }^{39}$ companies which are "perfectly" identical, making a living in the same way, cannot in the long run coexist in the same area. Thus, through globalization and the development of information and transportation technologies, this competition area is widened to encompass almost the whole planet. The widening arena became a matter of fact with the rising Japan and other emerging economies in Asia, while the economies of Latin America and Africa will soon take their stakes as well.

We may conclude from the biological experience that only competitive strengths, unique skills can ensure that a living entity or firm have a unique advantage in obtaining the resources it requires, and therefore maintaining certain equilibrium in the area of competition. The same conclusion led Porter to write his famous book series on competitive advantage. ${ }^{40}$ The idea that strategies such as product differentiation or focus on niche are necessary alternatives to cost leadership, in order for companies to successfully compete and survive, became a key for American business in recovering from the competitive crisis of the 1970s and early 80s. "Each must be different enough to have a unique advantage", argued Henderson (1989: 140), and in this way they can survive. This idea proved to be true even with the cheaper Asian competitors and, as just one example, saved Harley Davidson after its bankruptcy (Porter, Takeuchi, \& Sakakibara, 2000). Moreover, with Japan becoming number two economy in terms of GDP, American companies needed to differentiate themselves from their competitors more than before, and create a stronger sense of belonging through corporate culture: a clearer identification of "us versus our competitors". The force of difference or culture encouraged employees to put in more effort for the same price, and customers to pay more for a near-identical product closer to their "heart".

\footnotetext{
${ }^{38}$ Cited by Henderson (1989).

${ }^{39}$ The example is obviously an exaggeration as we have seen with the critics of Structural Revision, but serves as a good illustration on the globalizing competition in business.

${ }^{40}$ His most famous ideas are the five forces of profitability or the "diamond model"; the value chain of firms; or the generic strategies cited above (low cost, product differentiation, and focus). For more details, see Porter (1980 or 1985).
} 
One is tempted to conclude that the Japanese success was indeed the main cause leading to the rise of strategic management. However, the argument of this thesis is that the Global Competition paradigm is far beyond Japan's influence. It is true that the answers and tools for the competitiveness challenge came basically from there in the 1980s. But if Japan did not exist, the same wave would have arrived a few years later from China or Korea.

Thus, we believe that the practical impact is credited more to the competition with emerging economies than simply to the uniqueness of the Japanese production systems. Beyond real success stories in some cases, the adoption itself of these techniques, the difficulties of transplantation and cooperation with the Japanese managers, the cultural differences actually caused serious problems in many American corporations. By Japanese standards, workers in the US lacked loyalty to the company, had too high salary claims, and were still commanded in a bad, Taylorist manner. The Japanese typically criticized American managers for their lack of commitment, and abuse of power, whereas Americans resisted assimilation and sometimes cooperation (Locke, 1996). As a possible solution, Ouchi was for a long time looking for a hybrid type of organization, combining advantages from both the American and the Japanese side, but with limited proven impact on practice (Ouchi \& Jaeger, 1978).

As a practical impact parallel to the reorganization of production lines, many of the American production facilities had to be outsourced: this drop in manufacturing was an inevitable step toward a more competitive and more service-centered economy. Ideas on quality, believed to be essential for successfully copying Japanese competitiveness, were reinvented in American corporations. The American Society for Quality Control, founded in 1946 with 1,000 members, saw its membership grow to 24,000 in 1970, 32,000 in 1979, and to the spectacular 57,000 in 1988. The year 1978 witnessed the birth of another quality control organization as well: that of the International Association of Quality Control, whose budget grow in merely nine years from $\$ 100,000$ to $\$ 1.5$ million (Locke, 1996). This society put heavy emphasis on small-group activity and quality circles, ${ }^{41}$ for instance. To be fair, this popularity was greatly supported by Japanese investment of over $\$ 25$ billion in heavy industry only, and the related 100,000 jobs (Kenney \& Florida, 1993).

\footnotetext{
${ }^{41}$ The quality circle was a kind of suggestion group with the aim of enhancing quality and making the production process more effective (Lawler III \& Mohrman, 1985).
} 
But new jobs created by foreign investments, or rising industries like information technology and other forms of knowledge work were likewise unprotected from downsizing, and inequalities rose significantly in society (Koehn, 2009). This led to the growing power of a small but rich part of the population, typically possessing most of the shares and resources. According to Wolff (2007), in 2004, the top 1 percent of households held roughly 34 percent of the nation's wealth, and the top 20 percent controlled nearly 85 percent of this wealth. ${ }^{42}$ The opposite was true for Japan, described in the 1980s and $90 \mathrm{~s}$ as a middle-class society. However, in spite of growing inequalities, the US economy reached an upswing by the early 1990s: analysts praised again low inflation, high profits, and a skyrocketing stock market (Roach, 1996).

Partly due to the cultural differences previously mentioned, the Global Competition paradigm also had its critics. Like Scientific Management, the lean production concept could not be implemented as a whole in different organizations and was not easily transferable (Guillén, 1994b). The paradigm of Global Competition is the first one channeled by external pressure, and here we suddenly encounter the real drawback of travelling management techniques. Up to now we have been focusing on the internal evolution of American management. Looking back at the "change schools" described in Chapter 1, we may conclude that the major factor leading to Scientific Management or the Human Relations movement was a generational change, whereas Global Competition can represent the "power school" due to the forced change and the strong external model. As a consequence of the external pressure, natural resistance and criticism is also the greatest in this case.

Strategic planning was also widely criticized because for many authors strategy is not about plans but about "insights". That at least is the point for Campbell \& Alexander (1997) who argue that "strategy development is the process of discovering and understanding insights and should not be confused with planning, which is about turning insights into action" (42). The message that firms should separate strategy development from implementation is also confirmed by Mintzberg (1994). Others even added that the future cannot be predicted anyway and so completely new ways are needed to think about strategy in uncertainty (Courtney, Kirkland, \& Viguerie, 1997).

These criticisms do not mean, however, that strategic management did not have brought appropriate answers to the challenge set by Japan and other newly emerging

\footnotetext{
${ }^{42}$ Cited by Koehn (2009)
} 
countries. In the early 1990s, the US could finally march towards the twenty-first century with stronger, more reactive firms and better economic indicators. As a sign of good corporate performance, in the late 90s, the US had the lowest unemployment rate since the 60s. At the same time, it became much more shareholder-oriented than before, and American firms have been following typically short-term financial goals based on stock market information. Consequently, except for employee ownership cases, the full stakeholder approach remains extremely rare in the US (Jacoby, 2007).

\section{5) Making sense of the world of paradigms: summary and implications}

Writers usually attempt to approach management history in one of five different ways. These different approaches are: (1) discussing management developments of a given time period; (2) using the "schools" way; (3) the institutional approach with a focus on events; (4) the biography-based study of famous people; and (5) the combining of ideas and biographies (Gibson, Hodgetts, \& Blackwell, 1999).

The previous points of this chapter essentially described a time-based model, but our theoretical framework made it possible to use this time-line approach to define paradigms, categorize schools, and to better understand the life of management gurus or events at the same time.

The aim of Chapter 2 was to identify typical managerial dilemmas, philosophy and practices characterizing each period of time since mass production has been in use. These paradigms were certainly adequate for the socio-economic circumstances of each given period, but their proposed solutions did not expire with the emergence of a new paradigm.

Scientific Management was resurrected with the name of automation, management science, operations research, or management information systems, described as quantitative management movement by Pindur et al. (1995), or as the mathematical school by Koontz (1961 or 1980). Human Relations also covers latter organization behavior, personnel management, human resources management, and empowerment-named "Human behavior" by Koontz, or "Behavioral schools" by Luthans. Structural Revision was based first on the contingency theory of structure, but also initiated general management theories and management education, theories of international firms, the study of matrix and virtual structures, and so on. Accordingly, it contains references to the Management process school, and even to the Empirical school 
(by Koontz), and the System approach (see Pindur et al., 1995). Global Competition stands for the study of Japanese business but also for competition in general, strategic planning or strategic management, and corresponds to the strategic management and Japanese-style management and even the excellence approaches described by Pindur et al. Table 2 summarizes briefly what we have identified as paradigms in this chapter.

\section{Table 2: $\quad$ A synthesis of modern management paradigms}

\begin{tabular}{|c|c|c|c|c|}
\hline Paradigm & $\mathbf{S M}$ & HR & SR & GC \\
\hline Beginning & 1910s (1880s) & $1930 \mathrm{~s}$ & $1950 \mathrm{~s}$ & $1970 \mathrm{~s}$ \\
\hline Aim & $\begin{array}{l}\text { Reach productivity } \\
\text { and gain in effi- } \\
\text { ciency through the } \\
\text { automatization of } \\
\text { work and counte- } \\
\text { ring the unstable } \\
\text { and inefficient } \\
\text { human side of work }\end{array}$ & $\begin{array}{l}\text { The study of } \\
\text { competence (skill) } \\
\text { and motivation } \\
\text { (will) of workers as } \\
\text { individuals or team } \\
\text { members, in order } \\
\text { to enhance produc- } \\
\text { tivity and profit }\end{array}$ & $\begin{array}{l}\text { The study of } \\
\text { organizational } \\
\text { structure as a way } \\
\text { to create cohesive- } \\
\text { ness and help ma- } \\
\text { nagers to govern } \\
\text { diverse and hectic } \\
\text { business contexts }\end{array}$ & $\begin{array}{l}\text { Fight global } \\
\text { competitors with } \\
\text { strategies } \\
\text { (positioning, etc.) } \\
\text { adapted to the } \\
\text { contingencies and } \\
\text { with better } \\
\text { customer relations }\end{array}$ \\
\hline Basic idea & $\begin{array}{l}\text { Routines of best } \\
\text { practice speed up } \\
\text { work, useless } \\
\text { thoughts are } \\
\text { avoided }\end{array}$ & $\begin{array}{l}\text { If somebody is } \\
\text { happier at work, } \\
\text { he/she will bring } \\
\text { more profit }\end{array}$ & $\begin{array}{l}\text { Efficiency or } \\
\text { productivity is to be } \\
\text { reached by adapted } \\
\text { corporate structure } \\
\text { and institutions }\end{array}$ & $\begin{array}{l}\text { Production needs to } \\
\text { be "Japanized"; } \\
\text { need for more value } \\
\text { added products and } \\
\text { services }\end{array}$ \\
\hline Focus & $\begin{array}{l}\text { Production system } \\
\text { and internal } \\
\text { efficiency }\end{array}$ & $\begin{array}{l}\text { Employees, } \\
\text { interpersonal } \\
\text { relations }\end{array}$ & $\begin{array}{l}\text { Organizational } \\
\text { structure and fit of } \\
\text { system elements }\end{array}$ & $\begin{array}{l}\text { Strategic manage- } \\
\text { ment, comparative } \\
\text { advantages }\end{array}$ \\
\hline
\end{tabular}

Source: author

After this summary on the paradigms studied in Chapter 2, the last idea of this part attempts to draw a general conclusion from it. To begin with, an illustration can always help to grasp the meaning of the ideas.

Some decades ago, Dobák (based on Luthans, 1973b) attempted to design a model able to represent modern management history with the help of Corvinus University ${ }^{43}$ Ph.D. student Demjén (see Figure 6). His image was a perfect method to contrast soft and hard elements (the two-sided roots and trunk of a tree) with the open system perspective (the branches and the leaves).

\footnotetext{
${ }^{43}$ At the time the university was Karl Marx University of Economic Sciences.
} 
Figure 6: The "Luthans tree" of modern management

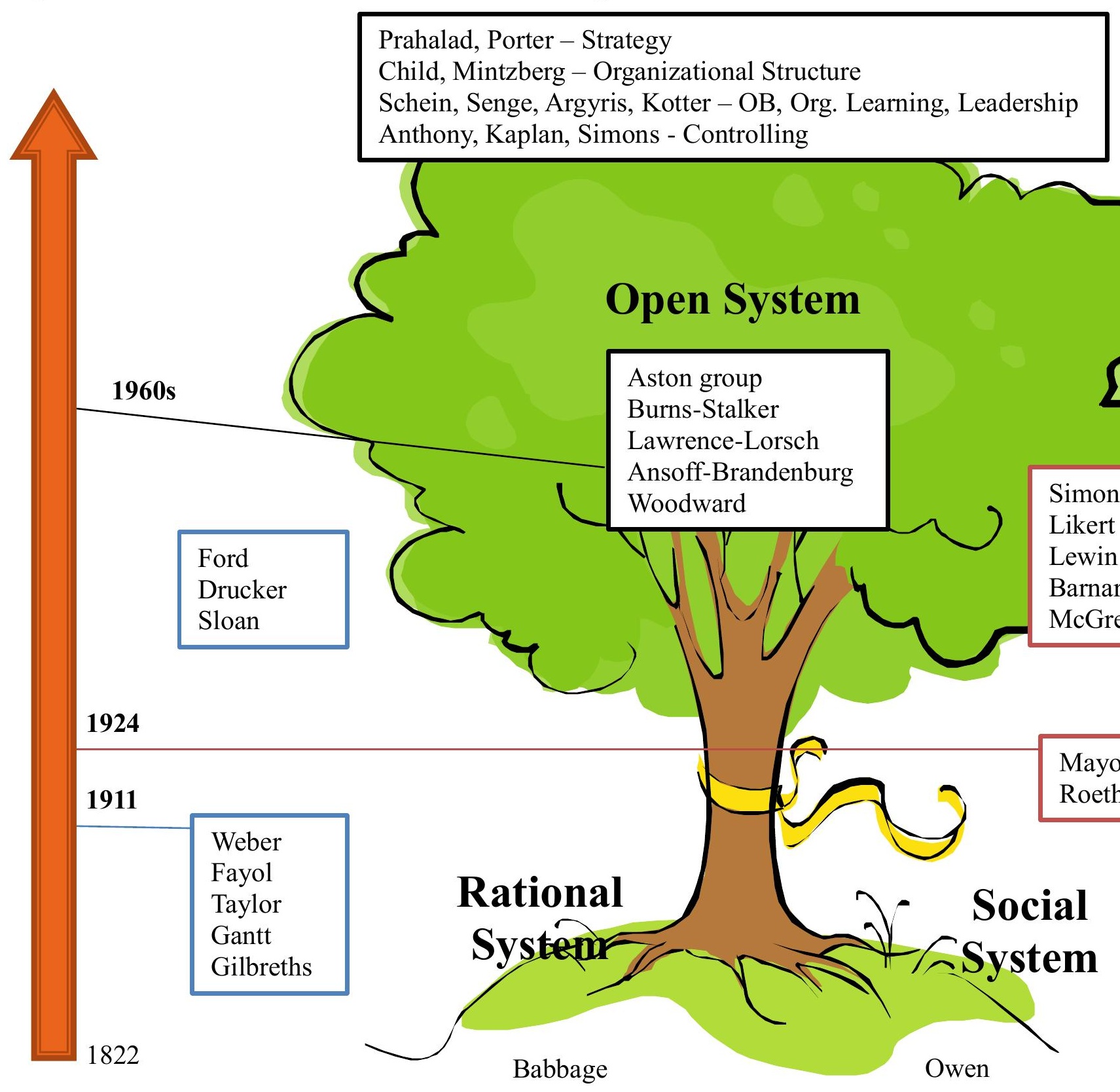

Follett

Source: Dobák (2009), based on Fred Luthans

Indeed, several researchers sought to find some logic in the nature of managerial practices and found it in the oscillation of dichotomy variables. The two extremes are often identified as "hard and soft"; or "rational and natural"; "rational and social"; or even "mechanistic and organic solidarity". ${ }^{44}$ Yet in this thesis, we argue that these dichotomies, although their categories matter, do not represent the whole evolution. In a sense, Chapter 2 described this historical development as the evolution of the main

\footnotetext{
${ }^{44}$ For more details, see Levie (1993), Luthans (1973b), Guillén (1994b); “The change masters" by Kanter, or the "Management gurus" by Huczynski.
} 
different business areas or functions of today's corporations (see Annex 1). Each paradigm had a specific function (production, personnel management, organizing, strategy, and so forth) which was more in focus than the others and has been greatly developed. In some respects, paradigms are a bit like "management by" ideas: we know that they cannot cover the entire reality, but we humans cannot cover it either (bounded rationality). Thus, we pick up focus points in regards to the actual contingencies to work with, and this usually brings satisfactory results.

The closed vs. open systems is another perspective of note. Presumably, managers have always governed according to the contextual situation. What this chapter has shown is that a century ago, it meant little compared to what it means today. We studied the time when managers had to step out of the boundaries of their firms, and match different organizational elements with the environment. The idea is not new, but the unique framework aligning management history and contingency theory has proved to be of good use to understand parallelisms.

Beyond their closedness or openness, the first set of paradigms was based on productivity and efficiency: the focus was put first on production process, then on the worker, and the adequate organizational form. Their dominant control mechanism is the transaction cost. The latest (second set of) paradigms and trends are based on competition and efficiency, and the dominant control mechanism becomes agency theory. The evolution is mainly due to the increasing size and complexity of firms until the 1960s, and to the competition for markets and the sophistication of consumer culture thereafter.

Our paradigms were likely to merge into the current of history and changing socio-economic conditions. Old views were not wrong and people were not less intelligent in older times; with the exception of a few prophets, they just found solutions to their contemporary problems without anticipating unnecessary things. We are often reminded that Scientific Management sought to find "one best way" adequate to all organizations in management. But even nowadays, we hope to find magic recipes suitable for every kind of problem, despite knowing there is no such way. Representatives of Scientific Management also knew this, they just did not need more sophisticated management for their time, because companies were not as complex or diversified as today and they did not need to face multiple environments.

In Table 2, paradigms are represented with a beginning date while the end is missing. This is not an error; as stated previously, these paradigms do not really end: they don't "die". They are more than fashions or fads. They are principles in a sense, 
rather than eras: the guiding principles of business, each having one specific period when it used to be the leading idea, the "mainstream".

Like the palm tree, where the earlier leaves build up the trunk and serve as a support to the new leaves, ${ }^{45}$ former management ideas also continuously give birth to new approaches which are sometimes simple modernized versions of the old, but still valid thoughts. In this manner, a palm tree can represent for us the evolution of management (see Figure 7).

${ }^{45}$ More precisely, see Wikipedia on the Palmae or Arecaceae: "The trunk will develop an axillary bud at a leaf node, usually near the base, from which a new shoot emerges. The new shoot, in turn, produces an axillary bud and a clustering habit results." (http://en.wikipedia.org/wiki/Arecaceae, accessed on June 24, 2011) 


\section{Figure 7: $\quad$ The Palm-Tree Model of Management}
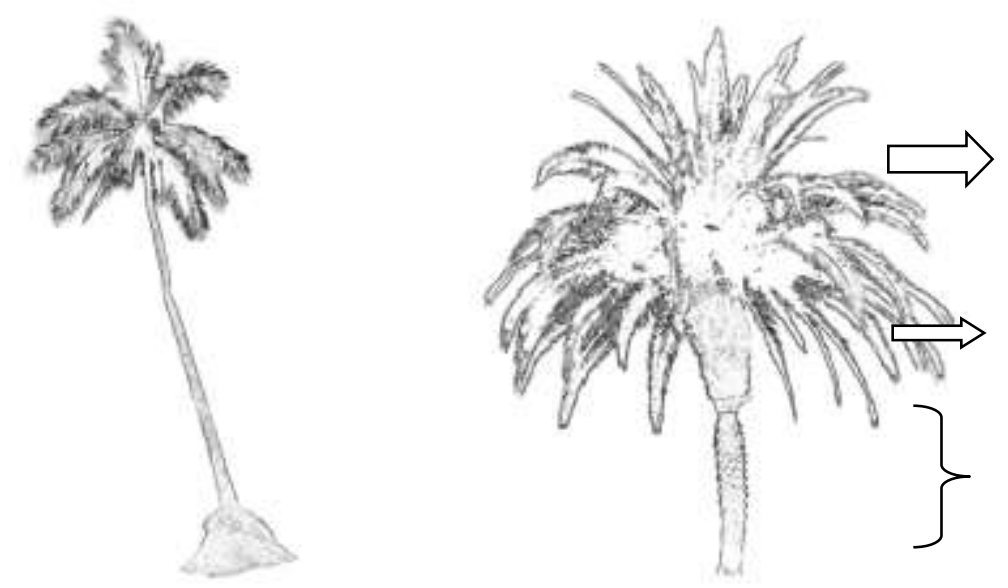

Recent "big leaves":

(financial management,

marketing 2.0, networks)

"Theory jungle"

Paradigms

(SM, HR, SR, GC...)

Source: author

In human history, entire civilizations and empires have risen and fallen for different reasons: climate change for Mesopotamia, closing itself off from the outside world for China (Diamond, 1999), and Epicureanism for Greece and Rome (Wren, 2005). By the same token, one may conclude that size was the major reason why Western Europe lost its technological advantage: after the industrial revolution, the United States was able to emerge and defeat the European economies on their own markets due to mass production and the resulting cheaper prices, despite expensive labor and transportation. Early paradigms reflected the rule of scale economy.

The big change happened in the 80 s, with the challenge of the high quality goods produced by cheaper labor in emerging industrialized economies. The recent paradigms find new ways to compete beside scale economies and price: differentiation, communication of values, and the establishment of emotionally driven consumer behavior. Global competition is making this new model, which we can call Paradigms 2.0, a must for other economies as well (Porter et al., 2000). Curiuously, Japan, formerly the main competitor, is taking a longer time than expected to adopt a "2.0 paradigm"-and this is the next important issue raised in this thesis.

We cannot answer here the question of why and how Japan managed to rise to a point of impacting US business practices: this question is answered by many other books revolving around the "Japanese miracle". But we can turn to the recent problems of Japan: look at its economic and managerial crisis, study the question whether during its managerial evolution Japan went along the same path as the US did, and try to find explanations on recent stagnation. 


\section{III) THE EVOLUTION OF JAPANESE MANAGEMENT}

We have seen how the Japanese influence affected the United States; in this chapter we shall look at how the pressure for change returned to Japan. We will contrast the four American paradigms with Japan's evolution and national business patterns.

The story of the same paradigms raises questions related to Japan's deep crisis, which will be answered with a field study later on.

Japan and the US have many common historical traits. Both were created or at least modernized by more developed external powers; many of their institutions still bear the mark of this. They went along more or less the same path regarding the evolution of management, except that Japan was about three decades late since the creation of massproduction. Greatly affecting each other, these countries are so close and so far at the same time, with ambiguous question marks on their recent evolution: the US seems to have found a solution to the challenge of Global Competition. Will Japan do the same?

\section{1) Japan: so far and so close}

There are numerous reasons to think that Japanese management is, or at least should be similar to the American model. In literature and field studies however, one often finds the opposite.

We have argued in this thesis that modern management was created by industrialization and the rise of mass production in the United States from the 1880s. During that era, the US used to have quite an intensive relationship with Japan. In 1853 Commodore Perry opened up the hitherto closed empire for trade and diplomatic contact. Other European powers followed the US in signing agreements with Japan but the Americans had the privilege to be her first partner. Before Scientific Management was born, the Europeans were more advanced in many industries and technologies, and therefore most of the Japanese industries were initially modeled on European examples. From the 1910s however, when the Japanese conquered markets large enough to develop mass production and Taylor's principles were accorded worldwide attention, American business captured Japan's attention again. Within two years of its being published, Taylor's book on Scientific Management was translated into Japanese and mass 
production was initiated based on his ideas, influenced later also by the German "Rationalisierung" (Tsutsui, 2001).

From 1945 to 1952, Japan was occupied by the American army under the command of General MacArthur. MacArthur, also called the SCAP (Supreme Commander of the Allied Powers), initiated major reforms in order to transform the militarized, nationalist country into a peaceful island, based on the American values of liberal democracy. The Japanese proved to be rather cooperative and obedient regarding these reforms and the General seemed satisfied with their advancement (MacArthur, 1964). In parallel, American business was exported in different phases after the war and Japan was under tight enough control to be fully receptive to this influence. ${ }^{46}$ Since the use of military is prohibited by the Japanese constitution, the American forces remained in Japan and do so even today. The continuous presence of the military was paralleled by the American management experts who travelled to Japan in order to modernize the industry and attain more exacting levels of quality control. Most sources highlight the role of Deming, Juran and Crosby in this respect (Pindur, Rogers, \& Kim, 1995).

We can assume that the Japanese growth was based on American technology, know-how and markets, but it was not only Japan to adapt American principles and practices: the process was two-way. The US was transformed by Japanese manufacturing as described in Chapter 2, after Japan emerged as the number one exporter to the American markets. The American business literature and consulting industry became the local advocates of TQM, lean management, Just-in-Time and other Japanese practices in the 1980s. This short story would suggest that the American and the Japanese management model must have been similar by the early 1990s.

However, that was not the case. As Alan Webber, a Japan Society fellow wrote in 1990: "The United States and Japan are fundamentally different countries: indeed, they are virtually mirror images of one another. Moreover, the one area in which they are more the same-their economic success-is a source of increasing conflict rather than cooperation." (209) In addition, regarding the Nippon success, Ohmae (1995) argued that "it was not Japan that was so stunningly competitive but a handful of industries within Japan and, more to the point, only a handful of companies within each of those industries" (155). All the rest was apparently "addicted to government support". A

${ }^{46}$ According to Locke (1996), the worldwide "Americanization" of management systems occurred in three (overlapping) phases: (1) the Marshall Plan; (2) the NATO phase intensified by the Cold War; and (3) the management education phase. 
"handful" may be an exaggeration but others also confirm that there is an enormous competitive gap between the elite companies and the rest of the country. Others claim that the two systems have been fundamentally different since the beginning of industrialization (Ohtsu, 2002). At this point the only certainty is that we must go deeper than the surface in order to understand both Japanese management as a whole and its differences when compared with the American model.

One (still generalized) way with strong argumentation to summarize the American-Japanese differences is the shareholder-stakeholder categorization (Ahmadjian \& Robbins, 2005). We will expound this point later in the next chapter, but Japan is typically represented as a stakeholder-oriented nation whereas in the US shareholders' rights prevail over the other interest groups in corporate life.

To sum up, technology, shareholder and stakeholder orientation, and other cultural differences may all be means to emphasize the differences between American and Japanese management. Cultural analysis may include both country studies made by sociologists for instance, and comparative research focusing on national characteristics such as individualism vs. collectivism, hierarchical distances, etc. ${ }^{47}$ It is clear that production techniques or cultural differences alone can do little to describe different management systems and give appropriate answers to understand the relationship between two countries. History mostly adds great value to the previously mentioned comparisons. In the case of Japan and the US, for instance, some analysts argue that their difference is mainly due to Japan's late industrialization and ensuing progress to modernity in Japan (Dore, 1973). One wonders however, what would stop a country which made a century's-worth advancement in a few decades to jump again and fill the gap in case of another crisis.

Thus, with the aim of unveiling the surprising differences, we will build on history and geography, and sometimes on culture at the same time. Based on local contingencies (geography) and given a certain timeframe (history), every society creates institutions framing the citizens' life and business. The longevity of Japanese institutions seems to be greater than that of Western countries.

As a first step towards the detailed analysis of the Japanese model, we will define the basic question: what is in fact Japanese management? Many are tempted to say it is the

${ }^{47}$ See Ouchi \& Jaeger (1978) or Hofstede (1983). 
kanban, just-in-time, zero-defect lean and so-on production systems invented by Toyota. It is certainly not.

As we stated in the introduction, this thesis is not restricted to production techniques. Liker, Fruin and Adler (1999) defined the Japanese management system as composed of four layers: (1) Shop floor production systems; (2) Factory organization and management; (3) Corporate structure and systems; and (4) Institutional environment. The first one is clearly the easiest to copy and emulate as indeed was the Toyota Production System from the 1980s. ${ }^{48}$

We found that this may be a good approach to see Japanese management in its complexity but it is difficult to clearly distinguish the content of the layers. For instance, layer 2 contains human resource practices whereas human resource policies are said to be at layer 3. Also, it is not clear whether we can categorize supplier networks as layer 2 or 3 .

It is rather difficult however to find comprehensive models on the Japanese system, while many works provide analysis from one specific point of view (finance, employment, etc.). Some conceptualizing attempts were made by Hatvany and Pucik (1981b), or Richard Pascale and Anthony Athos (1981). According to the latter, executives can influence complex organizations with seven levers of management functions: superordinate goals, strategy, structure, systems, staff, skills, and style. Their concept is rather similar to the one of the contingency theory which we presented in Chapter 1 and finally chosen as a framework to analyze management systems. The approach of Nakagawa (1983) also has some merit: he indeed confirmed that the term "Japanese management" does not have any explicit and precise meaning: for him, it is a "general term for many practices which seem unique to Japanese business management, but which are-taken one by one-not necessarily unique to this country at all." (1)

Here, we attempt to consider the "Japanese management system" as a whole and define its meaning accordingly. Thus, its main characteristics (30 elements in total) were filtered out from various items of literature on Japan. For the rest of this thesis, we will understand Japanese management to be the integrated mixture of these elements, ordered below according to the main categories of the contingency model. The advantage of this method is that it makes Japanese management comparable to the previously designed paradigms. Table 3 lists all 30 of these elements, and contrasts them with the characteristics of the American system as known in the early 1990s.

\footnotetext{
${ }^{48}$ The same authors claim that high-performing Japanese firms did not necessarily practice TPS, either in the auto industry, or in other business areas.
} 
Table 3: $\quad$ Management practices as in the 80s-90s in Japan and in the US

\begin{tabular}{|c|c|}
\hline Japan & The United States (US) \\
\hline \multicolumn{2}{|c|}{ Environment } \\
\hline 1. A small living area with frequent catastrophes & "Unlimited" land and resources \\
\hline 2. Collectivist culture, Confucianism & Individualist culture, values based on Christianity \\
\hline 3. Historical isolation, late industrialization & "Brain drain", (rel.) early industrialization \\
\hline 4. Developmental State and protected markets & Open, liberal state, anti-trust policy \\
\hline 5. An economy with continuous growth & Unstable economic growth \\
\hline 6. An ambiguous and rigid labor market & Competitive external labor market \\
\hline \multicolumn{2}{|c|}{ Intra-organizational context } \\
\hline 7. Easy-to-train and devoted employees & Professionals with generally valuable skills \\
\hline 8. Superiors are more managers than leaders & Strong leadership culture (along with management) \\
\hline 9. Male dominance, homogeneity & Diverse society and corporations \\
\hline \multicolumn{2}{|r|}{ Strategy } \\
\hline 10. Stakeholder orientation & Shareholders are above all \\
\hline 11. Cost leadership (vs. product differentiation) & Differentiation, competitive distinction \\
\hline 12. Spin-offs, start-ups, diversified portfolios & Divestment, outsourcing, core competence \\
\hline \multicolumn{2}{|c|}{ Structure } \\
\hline 13. Big and complex, U-form based group hierarchy & Anti-trust culture, M-form structures, market rules \\
\hline 14. Large boards dominated by insiders & Small boards with outsiders, even at CEO level \\
\hline 15. Central HRM, prevails over finance & Finance dominance \\
\hline $\begin{array}{l}\text { 16. Processes of decision making: a consensual } \\
\text { approach }\end{array}$ & Top down or convincing/voting \\
\hline 17. Working teams (open office, group seating...) & $\begin{array}{l}\text { Competition encouraged, cubicles, individual } \\
\text { performances }\end{array}$ \\
\hline \multicolumn{2}{|c|}{ HR / OB / Employment philosophy } \\
\hline 18. Recruitment from schools & Entry and exit at any age \\
\hline 19. Core (permanent) vs. "irregular" staff & Internal mobility \\
\hline 20. Long-term employment & Share price is more important than job security \\
\hline 21. Formal induction, creating a family & Informal, individual induction and career \\
\hline 22. Cohort training "on-the-job" & Training is an individual option \\
\hline 23. Slow promotion & Fast promotion of high performers \\
\hline 24. Rotation & Specialization \\
\hline 25. Seniority pay (tenure-based compensation) & Mainly performance-based pay \\
\hline 26. Enterprise-based or company unions & Industry-wide (trade) unions \\
\hline \multicolumn{2}{|c|}{ Control \& Performance } \\
\hline 27. Behavior-based control & MBO, priorities, targets \\
\hline 28. No direct control, multi-monitoring & Utilitarian control of workers \\
\hline 29. Decisions are joint responsibility & Decisions are the individual's responsibility \\
\hline 30. Good performance: market share, harmony... & Stock price, dividend, ROA, ROI = performance \\
\hline
\end{tabular}

Source: compiled by the author, based on references in Chapters 2, 3 and 4 .

It seems that Webber was right and the two sides are total opposite of each other. The question: "why?" requires further analysis. On the other hand, what Webber could not see in 1990 is the economic crisis: the bursting of the bubble makes a contrast with the Japanese success and certainly casts a shadow over its glory. Was this glory merely an illusion? Or is the fact simply that it could not change when it had to, which brought a sudden end to the golden age? 
In the following points we will gain a deeper understanding of how the Japanese management system evolved from feudalism and how the previously described paradigms occurred in Japan. Performing this parallelism, our approach can be compared to the French "Régulation approach" as described by Théret (2000). Then, in the next chapter, we will attempt to gain a deeper insight into each element of the Japanese managements system summarized in Table 3 using mainly geographical, historical and sociological data. This knowledge ought to help us in formulating some research questions with the aim of understanding how Japanese management is linked to the crisis and the need for change.

\section{2) From feudalism to modern business in Japan}

Observers often note that Japan's industrialization occurred relatively late in the nineteenth century. As a matter of fact, in 1867, Japan was still a feudalistic country with an archaic governance system centered on agriculture while the nations of Western Europe and the United States were marching towards mass production and the second industrial revolution. In what follows, we will deal briefly with how the industrialization and the development of a modern management system took place in Japan, and to what extent the American management paradigms are valid in the Japanese case. We will start with the analysis of these paradigms and then go into details of specific corporate practices.

By way of introduction, as we did in the case of the US, we will briefly survey how mass production and industrialization emerged in Japan: from the forced opening of the feudal system, through the reforms after the Meiji revolution, until the first big factories were created.

In terms of business, the Edo period (1603-1868) was characterized by a huge agricultural sector and a relatively small and low-status group of merchants and artisans. Given the hereditary nature of society, these activities were organized and maintained by the families through the so-called ie (household) system in form of independent urban and rural companies. The Tokugawa recognized four social statuses based on Confucianism: the warriors (samurai), the peasants, the artisans and the merchants; in the order of their social reputation. Somebody belonging to a certain status was forced to follow the related strict rules, defining business and career possibilities, social habits: 
literally their entire life. As a consequence, economies of scope could be reached along the same sort of product line, but significant diversification or merging of production with distribution was not possible (Totman, 2006).

After the unification of Japan, stability was a key element the Tokugawa sought to achieve in order to seize and keep power. Shoguns from 1603 to 1868 , the Tokugawa family opted for the isolation of the country in order to reinforce their reign: foreign trade became a state monopoly and contact between foreigners and Japanese was strictly controlled. The isolation had various consequences: not only was feudalism lengthened but it also boosted local industries such as silk weaving or contributed to the development of big cities and castle towns (Pyle, 1996).

The forced opening of two Japanese ports by Commodore Perry and the following unequal treaties created an external pressure strong enough to explode the already tense Japanese governance and its hereditary, anti-merit system. The revolting samurai forced the shogun to give back his power to the emperor, and from 1868, a new regime begun called Meiji. The new government, composed of former samurai, initiated major reforms reframing the entire political, business and social system. The first modern corporations, named zaibatsu, appeared from about 1885. This is certainly late compared to the West, but they grew fast and matured rapidly (Fruin, 1992).

The term zaibatsu literally means "financial group" which certainly refers to their financial or banking activities such as landing or money-changing, and to the fact that they contained several firms with diverse activities. Although many of the zaibatsu had centuries-old origins, they really arose from the 1880s with the purchase and integration of government-owned ventures when finance minister Matsukata initiated their privatization (Pyle, 1996). Besides the biggest ones (Mitsui, Mitsubishi, Sumitomo, Yasuda), there were a handful of others such as Okura, Furukawa, Asano, or Fujita, able to develop Japan's first industries. Their early strategies were primarily based on interfirm transactions and economies of scope (through diversification) rather than scale, because the development of large-scale production was still hindered at the end of the nineteenth century.

One reason for this lack of scale was technology, which needed to be imported from the already industrialized Western countries (about 100 years late compared to Western Europe). The Meiji government did indeed organize several study tours for the administrative body, invited foreign experts and distributed scholarships to encourage students going abroad. Many of the industrial activities were redesigned and based on 
Western technology from the 1900s but curiously, the produced goods continued to be distributed through the centuries-old wholesale and retail networks (Fruin, 1992). As a result, production and distribution is often separated even today, this latter being ensured by specialized trading companies, the sogo shosha. The technology-based argument is formulated by Fruin as follows:

"An overwhelming reliance on Western technology has meant that far more effort has gone into experimental, limited, and prototype manufacturing than high-volume manufacturing. Acquiring technology, fiddling with it, producing a limited run of prototypes, selecting from among them, and then fine-tuning products for the market-place has captured the attention of far more workers, technicians, engineers, and managers than high-volume manufacturing. [...] Japanese and other latecomers to industrial development are not really able to leapfrog the production technologies and product lines of already industrialized nations. But neither are they required to repeat their entire industrial history. What they can and must do instead is to produce far fewer, perhaps only a handful, of the key transition products linking immature and mature technologies. This interim period is low volume but absolutely necessary." (1992: 215)

Beyond pure technology, skilled workers were also scarce and in that respect, the Japanese and American factories before Taylorism emerged were remarkably similar. The owners of the means of production often lacked the technical and managerial competences and contracted with skilled foremen (oyakata). As in the US, they held authority over recruitment, training and dismissals, but also over the work process and the employment conditions (Dore 1973, Tsutsui 2001). Early production depended on the individual skills and abilities of these oyakata.

The other obstacle to mass production was the small size of markets (see Figure 8). The feudalistic Japanese market was not big enough to support a high level of production when the first industrial firms were created but demand grew quickly with the wartime period. In 1894-95, Japan had a spectacular victory over China, establishing a dominant role in the region. Then, in 1904-5, the Japanese army defeated Russia as well, annexed Korea in 1910, and acquired important markets during World War I when the Western powers' attention was held by the European conflict (Pyle, 1996). Smaller-scale "mass production" was able to start from the 1910s in Japan, three decades later than in the US. At the dawn of American mass production in the 1880s, the size of its population 
was about 50 million, growing to over 90 million by the 1910 s, the approximate start of Scientific Management. Japan reached a population of 50 million in the 1910s, and 90 million by the mid-1950s.

Accordingly, the Fordist reorganization of the factory and excessive mechanization of work came also with a relative delay of three decades, although the Japanese saw it as an advance on Scientific Management and even as an inevitable stage in the industrial progress. In the words of Tsutsui, "under conditions of scarce capital, abundant labor, and uncertain markets, the high-volume, high-technology assembly line was acknowledged as an inappropriate model for most Japanese firms" (2001: 67).

Figure 8: Demographic development of the Japanese markets, compared to the USA (number of people in thousands)

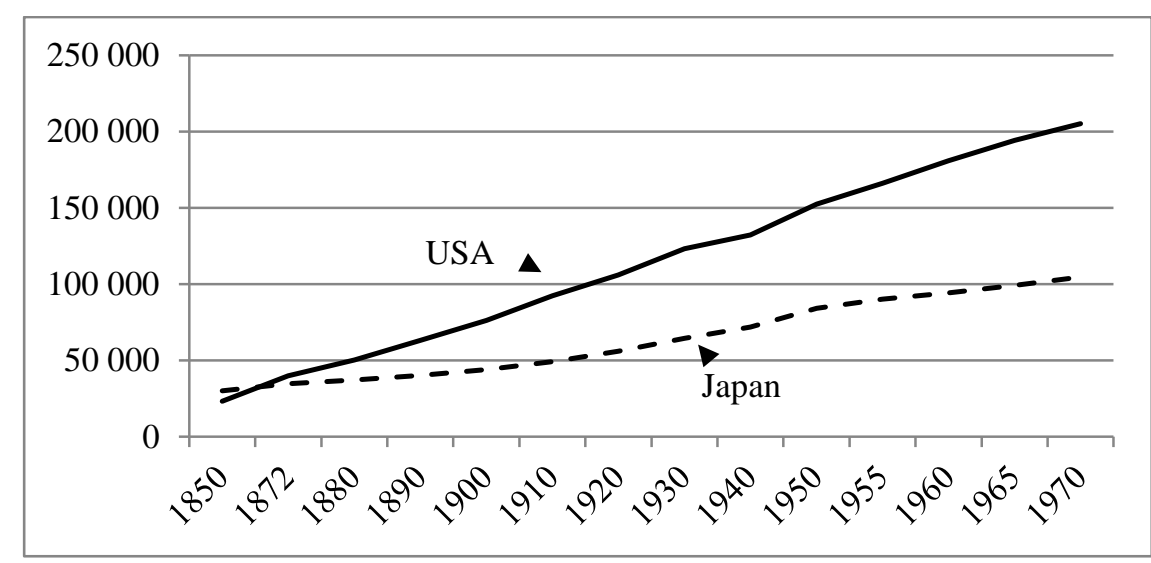

Source: Ministry of Internal Affairs and Communications, Japan (Statistics Bureau); U.S. Department of Commerce (Bureau of Census)

As in the US, mass production in Japan brought important reductions in production costs. Fruin (1992) described this reduction as an impact composed of four factors: (1) economies of scale due to the bigger volumes produced; (2) economies of learning, due to the long-term employment especially and the eagerness of the Japanese to improve; (3) the economies of scope where related products and services can be run through the same institutional facilities; ${ }^{49}$ and (4) transaction-cost economies explained by less $e x$ post adjustment of contracts or agreements. Typical results of these economies are efficiency, rationality, causality, and optimality.

After this introduction on the development of mass-production and the creation of large companies from the Meiji Restoration (the latter multinationals), we can now

\footnotetext{
49 This point is especially interesting in Japan because of the strong inter-firm networks and broad cooperation as well.
} 
turn back to our paradigms which these firms have been subjects of, in the US just as, potentially, they are in Japan.

\section{3) Taylorism, the efficiency movement, and Scientific Management}

Taylorism, although extremely popular in the 1910s, was banned in Japan in the late 1920s and attention turned towards Germany and rationalization. This point recalls the story of Taylor's impact on Japanese Management and its later evolution. Tsutsui (2001) indeed suggests that Taylorism in Japan paralleled that in the United States in many ways and was reshaped by several adaptations. These can be systematized, according to Tsutsui, as the total quality control concept of the 1960s, which "allowed firms to exploit the technical benefits of Taylorism while avoiding the determined opposition of workers and labor unions" (11).

We have already seen that large-scale production was not attainable in Japan until the 1910s and in actual fact, Japan achieved a comparable output with the US in the 1940s or 50s only. In contrast to American history, the lack of mass immigration is another difference, but the scarcity of skilled workers and the available cheap but unskilled masses both represent similarities. The exaggerated power of the skilled foremen hindered the improvement of production systems and standardized, homogeneous quality which urged managers to find alternative ways. Labor unrest was also a common phenomenon: following the Sino-Japanese War, but especially from the 1910s, the organized labor movement put pressure on factory managers to find a systematic response (Tsutsui, 2001). So Japan was certainly late with industrialization and mass production, but once Western technologies had been adopted and the adequate market size reached, the development of the Scientific Management paradigm happened relatively fast. That may have been due to the Meiji study tours supported by the government and the openness of the Nippon students and delegations who mostly visited the US after the 1900s.

Taylor's book The Principles of Scientific Management was translated and published in Japanese as early as in 1913, but even before this, Taylor's press was highly significant. Yukinori Hoshino, who was in the US in 1911 when The Principles was published, introduced Scientific Management in his own book when arrived home in 1912. Toshiro 
Ikeda's book (Secrets for Eliminating Futile Work and Increasing Production ${ }^{50}$ ), also on Scientific Management and published in 1911, sold more than a million copies in 10 years. There was a story of some company chairmen who gave thousands of copies of this book to their employees (i.e. twenty thousand copies distributed at Mitsubishi, or fifty thousand at Kawasaki), and ideas from the book were instantly adopted in several large firms. Another book by Koichi Kanda (from 1912) ${ }^{51}$ spent nearly 600 pages discussing ideas such as Taylor's piece-rate system or Gantt's bonus system. Practical case studies were published on factories which could be improved and made more efficient using Scientific Management, and lectures on related topics were held at the most prestigious Tokyo University. The Japanese Taylor Society was founded in 1925 (Nakase, 1979).

Several of Taylorism's proponents came from the field of psychology, notably Yoichi Ueno, called also "the father of efficiency" or the "Taylor of Japan" (Tsutsui, 2001). During the 1910s and the 20s, he may have been Japan's most insistent advocate of Taylorism, developing the idea into a wide-ranging, structured and long-lasting movement. Interestingly, there was little direct support from the state parallel to this private publicity, although government-owned enterprises were among the first to implement Scientific Management and its practices such as work study, standardization, or systematic planning for example.

Such an early success cannot be simply explained by the general openness of Japanese society to Western ideas and technologies. On the eve of World War I, the general public in Japan was asking for cutbacks in military and government expenditures and Scientific Management offered a good deal in suppressing inefficient practices. Similar to what happened in the US, the labor movement and the socialist movement developed vigorously after the Russo-Japanese War and encouraged the implementation of a rational wage system and other modern management techniques (Tsutsui, 2001). Organizational structure also supported large-scale production and the development of Scientific Management: just as Ford had chosen the U-form, it proved to be the ideal structure for Japanese firms as well.

After its early success, Taylorism developed further and continued to exist under different terms and names. In 1917, the year of the Russian Revolution, Toshiro Ikeda and his colleagues launched a new magazine called Efficiency, which marked the

\footnotetext{
${ }^{50}$ The original title was Noritsu Zoshin Mueki no Tema wo Habuku Hiketsu.

${ }^{51}$ Titled Jissen Konjyo Kanri (Practical Factory Management).
} 
beginning of the "efficiency movement" (Nakase, 1979). In Sumitomo and other companies, the time clock and identification signs such as a company badge were introduced, "in an effort to stipulate [sic] employees' pride" (180). This movement sought to bring and implement Taylor's ideas in a much broader sense than the creator himself imagined. "It goes without saying that the principles of Scientific Management should be spread widely, into individual households and through all areas of national society", wrote the above-mentioned Yoichi Ueno, one of their leaders (Tsutsui, 2001: 23). So the Japanese created "the most efficient arrangement for kitchens", "the most efficient golf swing", or the "one-best-way" in pearl diving.

Then, the late 1920 s were marked by rising nationalism and an intensifying diplomatic relationship with Germany. Accordingly, Scientific Management evolved into the German Rationalisierung movement, introduced in Japan by Kaichiro Imaizumi in 1927, the year of the third meeting of the International Scientific Management Conference (Nakase, 1979). Among the catalysts which led to the wide coverage of the movement in the press, we must note the Showa financial crisis in 1927, "a sobering panic in the banking system that foreshadowed the Great Depression in Japan” (Tsutsui, 2001: 59). Rationalization was an imported concept from Germany but well integrated into the Japanese mentality-specifically the use of state-sponsored cartels to restrain competition in many cases and encourage cooperation. Trust and cartels, first banned by Americans in the late-40s, were current practice in Japan, and aimed to reduce transaction costs, and increase efficiency and productivity. After Taylorism, which concentrated on the firm and shop-floor reforms, the rationalization movement used as its basis a whole industry or the entire national economy. As early as 1930, one-third of the major manufacturing companies had already shifted from light to heavy industry, growing to more than half by 1954. The same figure was $63 \%$ in 1973 (Fruin, 1992).

In 1931 the Manchurian Incident broke out, and government regulations multiplied. The promulgated Major Industry Control Act reinforced the power of big business. The government body for industrial rationalization was reorganized into the Control Bureau.

"Thus, the scientific management movement developed by stages from an efficiency improvement and retrenchment movement into the industrial rationalization movement, and further underwent a transformation from industry and company control to government control. In this way, the scientific management movement changed into a device for fascist rule." (Nakase, 1979: 188-89.) 
As for the labor unions, management broke them up and transformed them into patriotic associations. Scientific Management was no longer considered as a respectful means for industrial organization but the enemy's ideology and way of management.

Needless to say, however, that these deep-rooted practices and efficiency philosophy can be found later, in the post-war era as well. For instance, the methods and practices of TQC (Total Quality Control) were introduced in Japan in 1957 from the US (Fruin, 1992). In each company and in every way possible, new methods and ideas were continuously tested and then adopted or discarded in order to improve efficiency and competitiveness.

Despite the fact that there were only a few documented cases of direct labor opposition to Taylorist management (Tsutsui, 2001), it would be a serious oversight to ignore criticism of Taylorism. Most labor complaints centered on the new wage system ideas, and in some cases skilled workers protested vehemently about losing much of their previous power. Scientific Management's detractors also argued that its techniques led to the degradation of work, to increasing individualism, to capitalist exploitation, and that overwork became the norm, or that the gap between labor and capitalists became wider. Nakatsumi ${ }^{52}$ noted that "wage systems appeal to the profit motive of workers, consequently undermining their moral values as well as their sense of mutual solidarity, and giving rise to antagonisms and jealousy among them." (41)

Other opponents warned that the increase in industrial efficiency caused by the implementation of Taylorism would in the longer run provoke exaggerated production output and subsequent unemployment. Their criticisms were emphasized by the effects of the Depression: the excess capacity of the industry persisted until 1936 and "the lingering pool of unemployed workers" also provided a strong disincentive for managerial improvement schemes (Tsutsui, 2001: 86). Although the organized resistance to Taylorism was not that strong as in the US, all this criticism and its consequent alternations led to an enhanced Taylorism enriched by the aspects of the American Human Relations paradigm.

\footnotetext{
${ }^{52}$ Cited by Tsutsui (2001).
} 


\section{4) Human Relations: a lack of raison d'être?}

In the American history of management, we find the roots of the Human Relations paradigm in industrial welfare, then the Hawthorne studies demonstrated that group performance can be higher than the sum of individuals (contrary to what Taylor thought), and finally different techniques were developed in order to enhance the interpersonal skills of workers and managers. Japanese managers were aware of these ideas due to the occupation: the Americans introduced HR with the help of some Japanese scholars after World War II (Tsutsui, 2001). The new management philosophy certainly aroused the interest of the general public in Japan, particularly due to the efficiency gain created by the enthusiasm of the workers and to the calming of labor relations. Moreover, some HR practices such as suggestions systems or attitude surveys were indeed implemented in firms. The overall impact of HR however was minuscule compared to the revolution raised in the US, and its detractors for the most part claimed that Japanese industry had no need of American teachings on communication or teamwork (Tsutsui, 2001). In our understanding, there are multiple reasons explaining the reluctance of the Japanese to the HR movement.

Firstly, welfare never appeared as a shortcoming in Japanese companies as it did in the US: indeed, the first industrial enterprises started with national or even political purposes. Partly as a consequence of late industrialization, several functions and responsibilities that governments had in the West were instantly deployed at private firms in Japan which became "vehicles of public progress" (Fruin, 1992: 308). These functions included in-company training, housing, medical coverage and retirement assistance, commuting subsidies or cost of living supplements-all welfare that could not be financed by the local and national governments due to a lack in adequate resources. In addition, several laws ensuring the social security system, old age pensions, unemployment benefits, accident compensation and a minimum wage were passed relatively early, from the 1920s (Cole, 1971). The system also implies that employees in Japan are called "company-men" whose entire living (and that of their families) is provided by the company, in which they would spend (and for which they would sometimes sacrifice) their life (Marosi, 1985). Consequently, the lives of the wives were also taken care of and schooling and common activities were often provided for them (Abegglen, 1960). 
Secondly, given the collectivist culture, ${ }^{53}$ not a single manager would have thought at the dawn of industrialization in Japan that workers are better managed as individuals than as members of a workgroup. Group thinking was banned by Taylorism while in a collectivist culture like Japan the group has always been in the center. It is precisely this very aspect of Scientific Management which the Japanese have denied and refused ever since they came into contact with Taylor's ideas (Tsutsui, 2001). For instance, shop floor workers who are allowed or even encouraged to design their own working methods are in direct contrast to those of Taylorism, who could only operate according to techniques predefined by engineering experts. However, with the HR movement and the concept of "empowerment" from the 60s or 70s, American firms tended to bypass shop floor supervisors and empower their production workers to choose their own projects or design their work. Compared to Japanese standards, Americans went even too far because this activity in Japan involved a great amount of top-down direction and kept focus on the management's priorities and goals (Liker, Fruin, \& Adler, 1999).

Finally, interpersonal skills were never in short supply in Japan. Both the intensely hierarchized Japanese language and the Confucian spirit are poor vehicles for the direct and verbal transmission of emotions such as friendship, love or tenderness, but movies made in Japan are clear indicators of a society in which these emotions abound. After the theories of organizational behavior were developed in the US by Barnard, Likert, McGregor, Argyris and others, the Japanese borrowed and adapted them and "it appears that the Japanese found their organizations more receptive to this form of participation than have American managers" (Keys \& Miller, 1984: 343). Japanese managers apparently accepted more fully that employees are capable and ready to participate in the organization of work and contribute to a supportive supervisory climate. One in-depth application of the participation concept could be the quality circles, discussed in detail later on.

"The concept of empowerment is that each employee acts voluntarily through an understanding of the company mission based on the corporation's ideology. That is, empowerment may be interpreted as the employees' commitment towards their company and working towards common values. Thus, voluntary improvement is promoted by employee empowerment. Although both common values and employees' commitment

\footnotetext{
${ }^{53}$ See Point 2 for more details.
} 
towards their company, as characteristics of empowerment, differ from nation to nation, in Japanese companies, empowerment is strongly encouraged and built up by Japanese management and culture.” (Lee, 2000:

To sum up, the mainstream of management thinking affirmed the HR approach as a useful and necessary component of corporate administration but did not consider it to be a replacement for Scientific Management. According to Tsutsui (2001), HR techniques and rhetoric proved in application "remarkably compatible with mass production and Taylorite methods" not only in Japan, but also in the US-contrary to the theoretical stance of HR proponents. (158) As evidence of this, the Japan Efficiency Association published within a single year both a Japanese version of Mayo's The Human Problems of an Industrial Civilization and a new translation of Frank Gilbreth's book Cheaper by the Dozen.

\section{5) Structural Revision and the export of the Japanese Production System}

We saw in the previous chapter how in the 1950s American firms became internationalized and, as a consequence, divisionalized, and how this structural evolution led to a greater need for management theories and globally competent managers. Basically, this new paradigm was generated by an important outflow of American Foreign Direct Investment to the European countries.

Figure 9: Outward Foreign Direct Investment in Japan compared to the US (1970-2010, billion dollars)

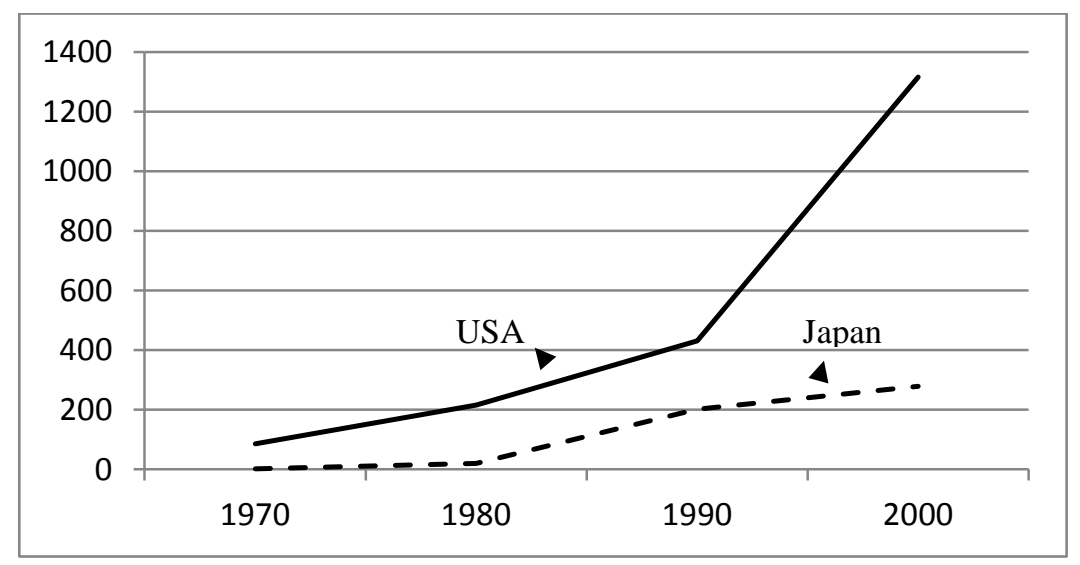

Source: UNCTAD 2006 Statistical Annex, cited by Shinpo (2008: 111) 
As shown in Figure 9, the same wave of investment abroad came to Japan in the 80s, when the high yen catalyzed the hollowing out of the Japanese industry. We might say that once again, the new paradigm emerged 30-40 years later compared to the US: only after 1985 would Japan experience diverse markets, although a few leading companies (mentioned by Ohmae) had already accumulated a great amount of knowledge of foreign markets and workforces. Until the end of the 80s export from a few trading houses predominated over deployed production.

In this point we shall argue that the paradigm of Structural Revision arrived late and only partially in Japan, which certainly muted the strength of economic transformation. The organizational structure plays a central role in our arguments-with strategy, because since Chandler (1962), it has been known that the product range strategy is directly linked to the organizational form. Large companies have two basic ways to organize their operations: the functional logic (U-form) and the divisional one (Mform). ${ }^{54}$ In the former model, production is organized at local level in factories but marketing, sales, financial, logistic or research functions are divided between factory and head-office organizations, or remain under the authority of the headquarters. Central decision-making predominates and top management remains involved in the operational coordination. In the multidivisional structure, the full range of operational responsibilities is delegated to divisional management, which enables top management to save time for strategic planning (Dobák, 1988). Since the functional structure is designed to reach the lowest production cost through large-scale production, we can also draw a link between the transaction cost orientation and the U-form, whereas the dilemmas of M-form organizations are better dealt with in agency theory.

We saw in the previous chapter that although M-form organizations already existed from the 1920s in the US, the multidivisional structure spread mainly with the Structural Revision paradigm during the $1950 \mathrm{~s}$ and $60 \mathrm{~s} .^{55}$ Then, it was imported to Japan as well but without massive adoption. Each business unit as individual company in Japan was not especially large or complex anyway, by American standards. Among the 200 largest industrial firms in Japan, 77 were diversified (had at least three different, major product lines) in 1954 and 80 in 1987. Also, of the largest 200 Japanese industrial firms, only $40 \%$ engaged in a limited diversification in 1987 and no major Japanese

\footnotetext{
${ }^{54}$ Matrix, virtual structures and other alternative forms can be seen as further refinements of the basic organizational questions dealt with by the $\mathrm{U}$ and $\mathrm{M}$-forms.

${ }^{55}$ By the same token, the profit center approach was introduced by Matsushita as early as 1932, but failed to gain widespread adoption (Miyamoto, 2008).
} 
firms were highly diversified, having more than three different product lines with at least $20 \%$ of sales each (Fruin, 1992).

Before a massive export to the Western markets could begin (after the late 1950s), the domestic and proximate East Asian markets available for Japanese companies were not that large, so competing on the basis of scale economies could be extremely risky. Accordingly, the core industries of pre-war Japan such as shipbuilding, railroad or telegraph-equipment industries were not especially geared to volume manufacturing, even though some economies of scale could be achieved in textiles, paper, metals or food. Thus, the zaibatsu mainly competed on economies of scope, and even later, instead of diversification, Japanese firms benefited mainly from simple scale and scope economies. As Fruin stated, they "stuck" with the traditional U-form organization but instead of divisionalisation created "product-focused, functional units within their organizations", so product management could be delegated to factories (177).

But even beyond size, there were several factors hindering the divisionalization of Japanese firms. First, we have already mentioned the separated production and distribution functions. The distribution of products, based on traditional networks, ensured primarily economies of scope by using the same institutions for different products. Therefore, splitting marketing, sales, R\&D, production and logistics and reorganizing them by product types into divisions appeared to be completely opposed to the Japanese model. But also, the hierarchical way of thinking of Japanese employees supported the U-form rather than the multidivisional structure. The keiretsu were not that large and bureaucratized when looking at the single units: it was the group structure, even if virtual, which made them large. Accordingly, the strategies of these distinct units were based on a specific and complete product line, rather than multiproduct range choices. Japanese human resource policies also played a role in keeping the system as centralized as possible.

To sum up, even large Japanese corporations were relatively small and simple compared to American ones, and most of them operated typically with a centralized, functional structure. Around the time of World War II, there were still no truly global, multinational companies in Japan. When, during the American occupation between 1945 and 1952, the zaibatsu holdings were split up into small companies, it was logical that those entities form inter-firm and supplier networks, cooperate in research \& development, marketing or selling to export markets. But in fact, according to Fruin 
(1992), even before the end of the 1930s, "a structure of product-based supplier network was in place", creating from 5 up to 65 percent of the product value (134). A clear benefit for large firms by using smaller suppliers came from their lower wages, technical strengths, and underemployed workers, and from the flexibility of the smaller structures. The same author summarizes the structural development of Japanese companies as follows:

"In Japan, with a few notable exceptions like Matsushita Electric Industrial, multidivisionalization was not the answer to the increasing complexity of modern business. Instead,[...] the strategy was to form constellations of interdependent firms, joined by financial ties and integrated through business interactions. Indeed, in the absence of anti-trust legislation which prohibited such interlocking business alliances, a strategy of structured interdependence had much to recommend it. Individual business units did not become overly large and bureaucratic, the financial necessity of diluting ownership by recourse to public offerings was avoided, and firms could remain focused in energies and resources." (152)

\section{6) Bubble burst and Global Competition}

We argued in the previous point that the internationalization and hollowing out of Japanese industry somehow transformed corporate life in Japan, but it was not accompanied by the multidivisionalization of large firms. Therefore, the managerial context did not change drastically either. Yet the consequences of this high yen period went much further than the question of divisionalization in Japan and therefore, the following paragraphs will be dedicated to a brief review of this history.

In September 1985, the finance ministers of the five major industrial nations met in the Plaza Hotel in New York to deal with the huge trade deficits with Japan, and they agreed on joint action to drive down the value of the US dollar. This agreement was called the Plaza Accord and as its consequence within a year, the dollar dropped from over 240 to 160 against the yen (Ohtsu, 2002). The American objective was to counterbalance the artificial competitiveness of the Japanese export supposedly caused by the under-valued yen and so to attenuate Japan's extreme trade surpluses. The strategy seemed to work out better than expected, because the dollar fell sharply against the yen, indeed damaging Japanese exports. As a remedy, the Nippon government 
loosened its monetary policy and lowered the discount rate to a historical low of $2.5 \%$ (Graham 2004, Abegglen 2006). Credit became cheap and easy to obtain, leading to a new corporate "fashion" in Japanese firms called zaitech, where managers could often make more money on investing and speculating in land and shares than from their traditional business. They certainly accumulated significant capital and acquired foreign firms, especially in the US and in Europe. But at the same time, by the end of the 80s, real industrial activities in Japan had deteriorated compared to financial speculation. Companies hollowed out a significant part of their production to other Asian countries, which helped to avoid the negative effects of the endaka (the high yen period).

The overall result was a financial bubble: the rise of both stock and land prices in a seemingly endless spiral, with bank loans obtained using these lands and stocks as collateral rather than future earnings prospects. At its height, the Tokyo stock market was worth more than $40 \%$ of the total capitalization of the world's stock markets (Graham, 2004).

The Bank of Japan realized that this bubble economy had got out of control and doubled its interest rate from 1989 to 1990-once again with dramatic effects. In January of 1990, the Tokyo Stock Exchange plummeted drastically. The effects of the bubble burst in Japan are well known in the world: within not even a year, Japan lost 30-60\% of her "business value". The losses of companies (shares, real estate), families (land, houses), banks and other financial institutions (with liabilities greater than assets) became greater almost day by day until the lowest point was reached in October.

\section{Figure 10: Stock Price Index from December 1, 1989 to December 1, 1991}

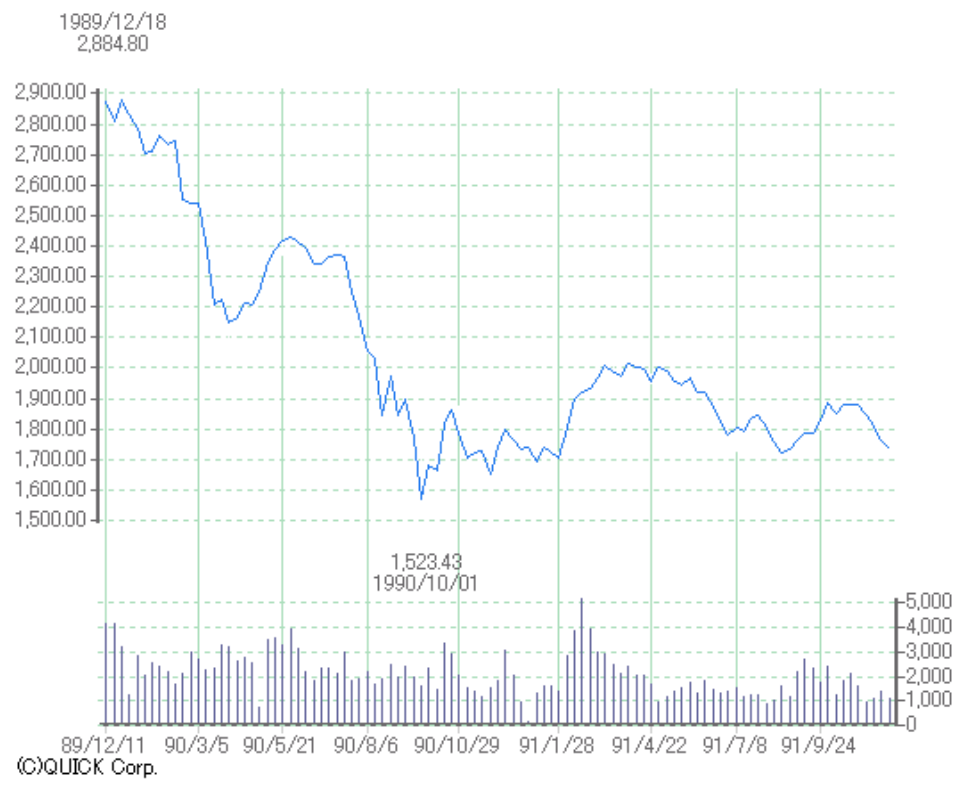




\section{Source: Tokyo Stock Exchange}

Though not immediately, the bursting of Japan's financial bubble brought evidence that the country had lost its hegemony both in trade and in industrial production and new challengers offered alternatives to the world looking for cheap labor and high-quality products, such as South Korea, Taiwan, Hong Kong and China, etc. When something similar happened to the US in the 1970s and 80s, its answer was massive deregulation and strategic paradigm change. Whether the same happened or is happening in Japan remains doubtful.

The curious fact about the Nippon bubble burst is the lack of immediate reaction. In the leading American business journal Harvard Business Review for instance, there was no article on the burst until 1993 and the first one with criticism related to Japanese manufacturing appeared in May, 1993 with the modest title "Japanese Manufacturing". The first article specifically on the bubble burst with the lingering recession was also published as late as November, 1993 in the same journal by a Japanese author, questioning Nippon long-term competitiveness (Hori, 1993). The first article on the failure of Japanese banks dates back to July, $1994 .^{56}$

How can we explain the slow pace of reactions here? On the one hand, nearly every expert in US-Japan relations advocated the supremacy of the Japanese model until the 1990s. Even later, all wanted to believe that they were right. On the other hand, the previous dominance was so spectacular, that some economic indicators expressing Japan's strength still prevailed in the first half of the 1990s, while the American trade deficit continued to decline.

In 1995 for instance, \$22 billion of foreign direct investment went from Japan to the US (\$7 billion in manufacturing). As explained by Liker, Fruin and Adler (1999), this figure represented accumulated investment in opening or expanding about 1,700 manufacturing plants across the US. With such widespread activity and investment within one year, it is hard to claim "this country is in deep crisis". Looking at Figure 11, and considering that the economic activity got out of its normal course between 1985 and 1990 , the situation clearly seems not so bad.

Thus, the bubble burst dulled the enthusiastic acclamation about Japan's success but failed to establish a general sense of crisis within or even outside the country. This fact slowed down both the reactions and the corrective actions, and the usual post-crisis process of recognizing bad loans, writing down capital and (if possible) getting

\footnotetext{
${ }^{56}$ In contrast, the first article triggered by the Lehman shock was published in January 2009, four months after the beginning of the financial crisis.
} 
recapitalized by private investors or government started effectively only in the late $90 \mathrm{~s}$ or early 2000s. During that time, the cost of managing the crisis probably went up as well.

\section{Figure 11: Japan's national wealth (trillion yen)}

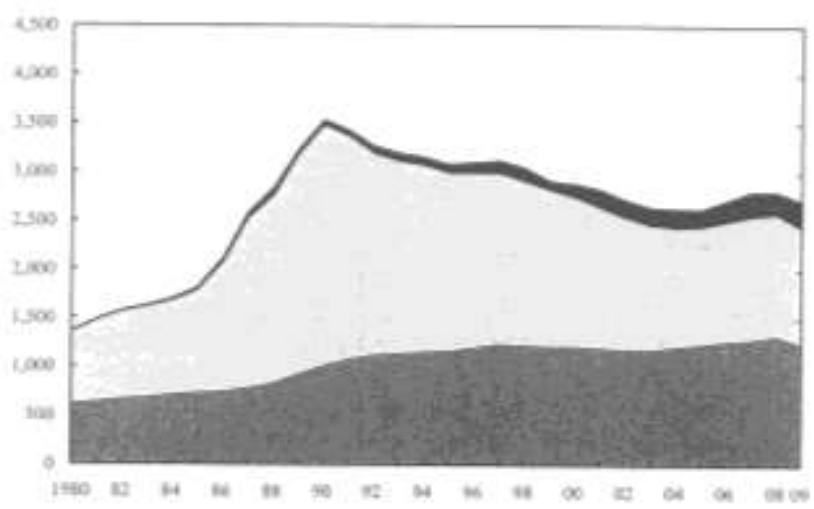

Net external assets

口Tangible non-produced assets

GFixed assets and inventories

Source: Cabinet Office (Facts and Figures of Japan, 2004)

Since 1990, Japan has been witnessing the same circumstances and apparent loss of competitiveness as the US had from the 1970s. The environment is becoming more global and newly industrialized developing countries have successfully conquered parts of the Japanese export. Japan's labor has become relatively expensive, its companies slow and rigid, and again, with a delay of about three decades, the country encountered the potential need for paradigm change (Black \& Morrison, 2010). The same claims for deregulation appear as was the case in the US previously (Imai, 2011). The following figures represent this declining competitiveness.

Figure 12: The revenue-based decline of Japanese multinationals in the Fortune Global 100 (left) and 500 (right) ranking
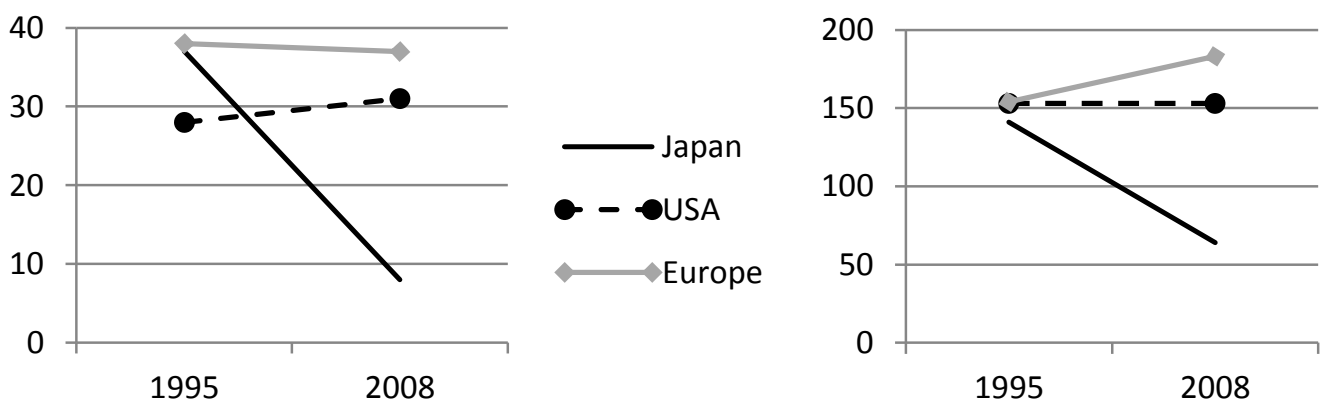

Source: Fortune Global 500 List 1995, 2008, cited by Black \& Morrison (2010: 3) 


\section{7) Summary of management paradigms in Japan}

When Masao Hanaoka (1997b) analyzed changing management systems, he used the following explanation to describe management conceptualization as being infinite or unlimited: "While management conceptualization capability is based upon the prevailing management conditions and entrepreneurs' experience, it is the ability to create an entirely new form of management behavior. There have been already examples identified in history of entirely new forms of management behavior being introduced as a result of management conceptualization capability. Management revolutions have resulted from breaking out of existing routines, in some cases affecting not only the company environment, but also development trends." (156)

We have attempted to show in this chapter that those management revolutions are rather rare in Japan, compared to the US where we were able to identify paradigm changes in a regular pace of about every 20 or 30 years. In Japan, those changes were apparently belated or muted by the strength of the institutional environment.

Scientific Management as a new paradigm occurred relatively early (in the 1910s) in Japan, almost at the same time as in the US, but without the same potential for large-scale production. Taylorism and Scientific Management provided tools for badly needed growth in Japanese industry, which the Japanese then developed to the point of perfection in every area of their life: the country, the company, and the household. Even though the label changed, the same ideas prevailed for a century in Japan: Taylorism, the efficiency movement, rationalization, wartime expansion of production capacity, lean and quality management all served to cut waste and increase efficiency. As a consequence, Scientific Management became embedded in Japanese society, and the Japanese finished by naturally accepting its methods as something intuitive, rather than imported or artificial. By the 1930s, Scientific Management had established firm roots in Japan and remained the dominant paradigm henceforth: later paradigm changes proved to be difficult. Adjustments in the original Taylorist ideas fulfilled the same needs as did the American HR movement, and no radical transformation but structural adaptations happened when Japanese firms grew larger and became internationalized. Traditional management and old strategies have been the target of more criticism since the 1990s, with the fading competitiveness of Japanese industry, but old ways still seem to prevail without radical transformation. In the next chapter, we will examine this recent evolution in greater detail. 


\title{
IV)THE CHARACTERISTICS OF JAPANESE MANAGEMENT
}

\begin{abstract}
After the overview of management paradigms in both the US and Japan, we concluded that the Japanese system appeared to be less flexible. In this chapter we will take a deeper look at this perceived rigidity and its possible origins. In doing so, we will provide a more detailed analysis of the previously identified elements of the Japanese management system with a focus on geographical and historical facts.
\end{abstract}

Analysts often claim that crude attempts to compare and contrast the Japanese management system with that of the West can be seriously misleading, simply because the two are different in nature. Among experts in Western countries, Japanese practices may seem particularly distant from American ones. Chapter 3 showed that, if we imagine the American, the European, and the Japanese systems on a continuum, the American and the Japanese could be the polar opposites of each other. Indeed, to academic commentators, both systems represent an extreme (Cole 1979, Koike 1983).

To avoid the pitfall of a superficial comparison such as Table 3 could be in itself, we shall here enter into the details and make an attempt to understand the Japanese system as a whole: precisely what each characteristic of the traditional system $^{57}$ means, how they emerged and evolved, under what circumstances, what the historical origins are if any, and the extent to which they are still valid today. Our analysis only goes for Japanese firms operating in Japan, because foreign subsidiaries may be compromised by the host country's characteristics.

\section{1) The business environment in Japan}

We will begin this point with the contextual elements which assumingly have conditioned the evolution of Japanese management practices from the Meiji industrialization. These "contingencies" represent the external environment of the Japanese companies. For each element, we will clarify how they affected corporate life both in the past and in the present day.

\footnotetext{
${ }^{57}$ We concluded earlier that the "traditional" system was certainly valid until the 1990s. Although most of the elements survived in some form, we will talk about the period from the mid-90s as the "recent evolution" of the system.
} 


\section{1) A small living area with frequent catastrophes}

The Japanese islands were created by the collision of two tectonic plates, which explains both the archipelago's frequent seismic activity and its mountainous terrain (Totman, 2006). With three quarters of the country covered with mountains, Japan's arable, inhabitable land area is very limited and the population density is high. In addition, the main islands' location places them in the path of strong typhoons every autumn.

As a result of this unique geography, natural disasters are common in Japan, as the recent Tohoku earthquake (with its attendant tsunami and the nuclear tragedy of Fukushima) reminds us. Throughout their history, the Japanese have had to face a high risk of destruction for nearly all of their material achievements. This may have contributed to Japan's resilient, practical mindset, as well as the nation's tradition of innovation. Crises ensure renewal and reflection in every society, and for that reason Japan's frequent natural disasters, despite their devastating physical consequences, have had the advantage of keeping Japanese infrastructure and technology regularly refreshed. According to government statistics, Japan suffered disaster damage amounting to just $0.05 \%$ of her GDP in 2009 , but in 1995, the year of the destructive Kobe earthquake, the total came to about 2\%. In 2011 the figure will probably be even higher due to the triple disasters of earthquake, tsunami, and nuclear crisis.

Also noteworthy in Japan's geography is the scarcity of many critical natural resources, especially those most in demand in industrial societies. The relative dearth of land has hindered large-scale agriculture and made cities extremely compact, and the limited natural resources has often forced people and companies to self-restriction, in terms of product range for instance (Marosi 2003, Vaszkun 2010). Japan's natural limitations can even cause surprising consequences when their impact reaches beyond individual lifestyles or some corporate affairs (such as location, import dependence, etc.). Transportation is one such example. The Japanese road network has remained largely unchanged for centuries. Even during the transport revolution brought by railway construction in the nineteenth and twentieth centuries, the rail lines were generally laid along the pre-existing routes, thus reinforcing traditional distribution

systems. So although railway construction frequently challenged established business forms in the United States, this was not the case in modernizing Japan (Fruin, 1992). 


\section{2) Confucianism and collectivism}

The philosophy and political economy of Confucianism were vigorously promoted in Japan by the Tokugawa Shogunate and later by the Meiji state. Their aim was to solidify the basis of social and political development. Originating in China, Confucianism is a world-view and a coherent set of values which can be considered as an excellent means of strengthening citizens' sense of hierarchy and building a positive attitude to hard work and study. Indeed, according to Bellah (1957), Confucianism marked the development of Japanese business institutions more than any other system of thought, although the impact of Buddhism is also considerable. Confucianism was strongly supported not only by the Tokugawa, but also by the Meiji government and, according to Ohtsu (2002), it still affects business performance today through the values of harmony, hierarchy, benevolence, loyalty and learning. Yet its historical role is apparently slightly different:

"Confucianism, according to Weber, is a this-worldly religion but without the strong ascetic values or activism found in Calvinism. The central virtue under Confucianism is harmonious adjustment of the individual to the established order of things. This passive nature of Confucianism did not generate a moral dynamism in economic activity. Thus, Weber apparently considered religion as the principal force either for stimulating (as in the case of Protestantism) or retarding (as in the case of Catholicism, Hinduism, or Confucianism) economic activity." (Ohtsu, 2002: 5)

Collectivism can be seen as an integration of the values of equality and group membership. The effects of globalization push societies towards individualistic values and some scholars have already denied that the Japanese are a collectivist nation (Matsumoto, 2002). Comparing Japanese and Western societies however, it is apparent that in the latter, individuals are integrated into society through their functions, which are mostly based on contracts, but in Japan people identify themselves with society through groups, such as corporations, and based on a sense of belonging (Maruyama, 1997).

The collectivist nature of the Japanese and the people of East Asian countries is sometimes linked back to the cultivation of rice fields, practiced in this region since the fifth century B.C.E. (Diamond 1999, Marosi 1985). 
Today, however, rice cultivation is no longer a dominant feature of life, and other coordination mechanisms seem to have taken its place in order to keep people cooperating. If we accept the assumptions of transaction cost theory about the risks of moral hazard, hold-up, and the cost of opportunism, cooperation and interdependence are meant to be more effective than individualism. Opportunism may infect interorganizational relations in Japan as elsewhere, but the "opportunism with guile" described by Williamson may be less pronounced (Fruin, 1992). The phenomenon of multi-monitoring described later goes not only for workers but for firms as well, and misleading, distorting, disguised behaviors are forced out of inter-firm networks due to the excessive monitoring costs and the social shame. Even beyond honesty, group members must try to match the best buys available on the market and be responsive in their dealings with other members, or their membership will be questioned. By the same token, investment in interdependence is not only recognized but even valued by the firms and sustains a "creative tension” (Itami \& Roehl, 1987).

The consequences of this group culture in companies are wide-ranging. In the case of a mistake at work for instance, even in serious cases, the group would protect the person with group power and (sometimes irrational) justifications. It is not because they believe that the culprit is right, but because the person is a member of the group. On the other hand, once somebody has been labeled as one whose opinion runs against those of the group, that person would find themselves opposed on any issue and ruled out by majority opinion: no one in the group would defend them in any circumstance (Nakane, 1972).

The important feature in Japan is that the egalitarian group thinking of collectivism is combined with the hierarchical order of Confucianism, making all differences of age, gender or education matter.

\section{3) Late industrialization}

We have seen above how the Tokugawa isolated the country from the 1600s to 1853 for matters of control of the daimyo (feudal landlords) and how industrialization suddenly began at the end of the nineteenth century. Clearly, there was a sense of inferiority towards the Western powers, whose technological advancement was spectacular compared to the Japanese. 
Alexander Gerschenkron's (1962) thesis about the effects of late development can be considered to be valid for Japan as well: he claims that late developers have to be more calculating and organized in the process of industrialization and this leads to higher levels of political, economic, and social interdependence. We will find this basic idea again while formulating our third hypothesis.

Japan's relatively late development has had several consequences for its industries, the financial markets and institutions, on the organizational structure and strategy of firms, and so on. Dore (1973) highlights for instance the predominant role of the state, the quicker industrialization and bureaucratization of firms, and the greater recognition of unions and of the workers as human beings. Jacoby (2007) emphasizes also that after World War I, Japan moved for rapid industrialization but strongly wanted to avoid the labor movements seen abroad, which led to the adoption of Scientific Management and welfare capitalism at the same time.

Indeed, the aim to learn as quickly as possible from the West marked the corporations from the top to the bottom and gave the central government another legitimate reason to be firm with its policies and reforms.

Fruin (1992) associates late development with the necessity of organizational learning as well. Western knowledge represented a risk and uncertainty for Japan in achieving its developmental aims because Japanese entrepreneurs had limited capabilities to identify, implement, and evaluate Western learning. Thus, "it was strategically sound to focus enterprise efforts in well-defined spheres of activity" (Fruin, 1992: 214). This conclusion leads us to the later detailed structural and strategic characteristics.

\section{4) Developmental state and protected markets}

This point deals with the consequences of a strong interventionist political elite on business in Japan. First, we will look at elements reinforcing the role of the state in corporate life inside the country, and then we will examine the international effects of this on world trade and the exporting position of Japanese firms.

In the historical context of the Meiji Restoration, Japan ran a high risk of being colonized by the Western powers. The young samurai seizing power after 1867 had a genuine intention to transform and modernize the Japanese political, economic and social regimes with the assistance of Western experts, but they also had the terrifying example of colonized China right in front of them, which made the new political elite 
strongly nationalist and protectionist, as far as possible. The idea was not utterly alien to them: the Japanese were still used to the centralist governance and extremely strong regulations of the Tokugawa. During feudalism, citizens' life in Japan was unusually highly regulated: each cast had its own permitted clothing, hairstyle, meals, and occupations. Being used to centralization, even when foreign experts were invited to help the Japanese carry out reforms and acquire new technologies, Japanese authorities had as their final goal to send them back home as soon as the locals learned what they had to, and then continue to build everything at their own.

After the hierarchical rule of feudalism and the rising to power of bureaucrats, justified by the rush for parity with Western countries, the Japanese central government eventually moved to militarization and increasing self-reliance, until the end of World War II. The preparation for war only emphasized the weight of central power in Japan. "During those cataclysmic years, the bureaucrats invaded every conceivable area of people's lives, justifying their actions as wartime necessities. The powers nominally vested in the Diet and in political parties evaporated, as the Emperor's bureaucrats assumed virtually dictatorial control" (Miyamoto, 1995: 10). The prevailing power of bureaucrats over the Diet in the legislative process and over local affairs apparently remained after the war as well, despite the intentions of American occupation.

The classical post-war example for strong regulation is the history of the Ministry of International Trade and Industry (MITI), established in 1949 to formalize the cooperation of the Japanese government and the private sector and ensure economic development. The activity of MITI is a good illustration of the "Developmental State" playing an active role in economic regulation and development, with tools such as large subsidies and redistribution, five-year development plans, investment "advice" to private firms ("window guidance"), low-cost financing to industrials through the Japan Development Bank, import substitution, science-based innovation and export subsidies (Black \& Morrison 2010, Fruin 1992, Móczár 1987, Johnson 1982). ${ }^{58}$ Such plans are not peculiar to Japan; similar ones have come into existence at a global level, but their scope of influence and action are different. ${ }^{59}$

\footnotetext{
${ }^{58}$ Needless to say, other ministries played the same active role in "guiding" their respective sectors. Another example is the "convoy system" protecting banks from bankruptcy, headed by the Ministry of Finance.

${ }^{59}$ See for instance the 2015 target of the Millennium Development Goals (MDGs) for United Nation member states, the global framework aimed at eradicating both extreme poverty and its adverse effects which emerged from the 2000 adoption of the UN Millennium Declaration (http://www.un.org/millennium/declaration/ares552e.pdf).
} 
As an illustration of the strength of recent economic policies in Japan, see Figure 13 below. Through the extra spending, Japan managed to keep its GDP above the bubble peak for the cost of 460 trillion yen between 1990 and 2005. Koo's (2011) comment on this is rather positive: "If we assume, rather optimistically, that without government action Japanese GDP would have returned to the pre-bubble level of 1985, the difference between this hypothetical GDP and actual GDP would be over 2,000 trillion yen for the 15-year period. In other words, Japan spent 460 trillion yen to buy 2,000 trillion yen of GDP, making it a tremendous bargain." (23)

\section{Figure 13: An illustration of economic policies in Japan}

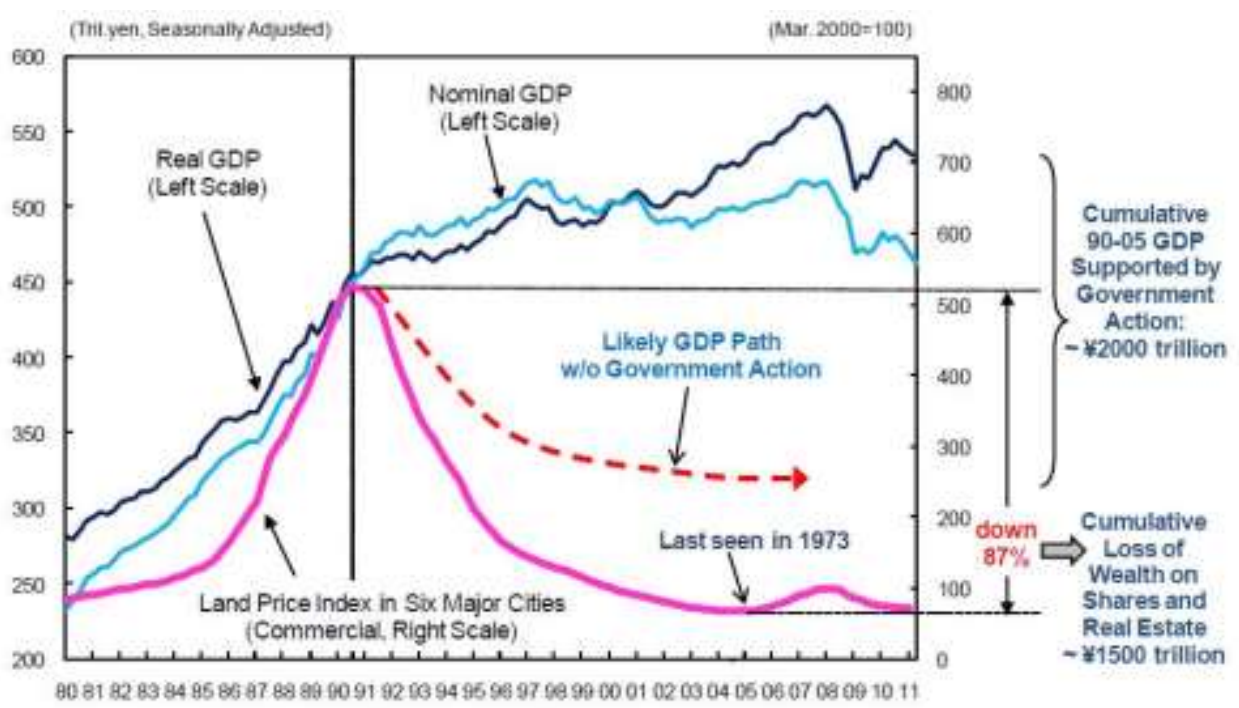

Source: Koo, 2011

Ministries have not only been powerful "advisers" for business in Japan, but also a pool for would-be managers. Because of the favors one could receive from ministries and regulatory bodies, the Japanese firms became interested in employing former bureaucrats directly and using their personal networks for their own benefit. In a practice known as "amakudari", freshly retired bureaucrats land jobs at organizations related to the sectors which they formerly supervised.

Needless to say, the amakudari are a rich source of corruption. But such postretirement careers have been officially banned for years now: the government approved an ordinance on March 30, 2009 to abolish the "watari" 60 system and the practice of amakudari. "The 2007 amendment to the national public servant law bans ministries

\footnotetext{
${ }^{60}$ The watari system encourages retired bureaucrats to take a succession of jobs at entities connected to their former ministries, i.e. special and chartered corporations (Carpenter, 2008). It implies also that they receive considerable retirement packages at each of these jobs.
} 
and agencies from playing a mediatory role in finding jobs for retiring officials. During a three-year transition period to 2011 , however, both entities would be able to continue to engage in such arrangements"-commented a journalist in Japan Times (Kyodo, 2009). Yet even if the further supply of retired bureaucrats dried up in 2011, the ones already in position still remain.

Concerning world trade and international business, the framework today is given by Japan's WTO membership. Although it still has important exemptions and selfprotecting measures such as duties on imports, these are apparently more and more difficult to maintain. After the Lehman shock however, even the US may move back towards a more centralized business system (Bremmer \& Pujadas, 2009). In Japan, this centralization basically meant control on foreign investment and on import, in addition to the planning system detailed above.

Central protection was at its highest during the wartime economy and during postwar reconstruction (the MITI era). With the foreign trade lobby and Japan's OECD membership, the liberalization movement unfolded slowly, in five waves (Hamada, 1991). Foreign investment was finally allowed in 1980 by the Foreign Exchange Control Law. In 1984, Prime Minister Nakasone explicitely encouraged inward FDI.

The share of foreign capital in Japanese companies developed markedly after the 1990s. In 1976, there were 1,101 foreign firms operating in Japan, and the number grew to 1,421 by $1996-$ an increase of 320 , or $29 \%$, in 20 years (Black \& Morrison 2010). The Japanese External Trade Organization (JETRO) found in 2002 that there were 4,190 foreign-owned or affiliated head-offices and 1,464 other places of foreign business established in Japan. ${ }^{61}$ Ahmadjian and Robbins (2005) argued that foreign investors contributed to the weakening of traditional stakeholder capitalism. Olcott (2009) found several examples of the rules of foreign capital prevailing over Japanese traditions, although he was unable to entirely confirm his hypothesis that firms with Western capital abandoned the old management practices described in this chapter.

According to Tokyo Stock Exchange data, there were 2,280 listed companies on the TSE in 2010, of which $12(0.5 \%)$ were of foreign origin. In the same year on the Euronext, there were $141(14.4 \%)$ foreign listed companies out of a total of 980 (New York Stock Exchange Euronext, 2011). The same source states that nearly $45 \%$ of

${ }^{61}$ Cited by Schulz (2006: 170). 
shareowners on the NYSE had some exposure to shares in companies headquartered outside the United States in 1998.

Thus, the trend is an increasing weight of foreign capital, but Japan might opt for further internationalization in the hope of increasing exports, rather than closing again. In the post-war period, Japan greatly benefited from the liberal trade policies of the Western world due to her membership of the GATT and then the WTO. Japanese industry has been producing a trade surplus since 1981, and this has contributed to a massive accumulation of foreign funds (see later in Figure 16). The time may have come when the other parties oppose these benefits, as has become apparent since the problems with the WTO Doha agenda and the multilateral trade negotiations on agricultural trade reform. The current negotiation on the Trans-Pacific Partnership is another striking example.

Today, Japan imposes trade barriers and heavy duties especially in the food sector, for instance on wheat and rice (currently $778 \%$ on this latter), or on pharmaceuticals, in order to protect her industry. According to estimates by the agriculture ministry, Japan would lose $¥ 7.9$ trillion in GDP due to a drop in farm production, if free trade created overwhelming competition. This scenario would be highly probable, because due to geography and a lack of natural resources, the cost of production of nearly all agricultural commodities is extremely high. For instance, the rice produced in Japan (Japonica rice) costs six times more than the same amount produced in China. This holds for milk too, with a multiplier of four. Manufacturing and services may gain something from a free trade context, but the agriculture remains the Achilles heel. Japan's food self-sufficiency rate is already incredibly low at $39 \%$, but this rate is estimated to plummet to $13 \%$ if trade barriers are lifted. And the price is not only the human cost of lost employment, but the country's food security and the high food-trade prisoner risk as well: food channels become too easy to block. For reference, the target for China in the recently enacted Twelfth Five-Year Plan (2011-2015) is to be more than 95\% self-sufficient in food needs. (Simpson \& Schoenbaum, 2011)

On the other hand, the natural efficiency of liberal markets can be seriously hindered by extensive protection. On protected markets, most products tend to be more expensive, because producers enjoy monopolistic or oligopolistic situations and regulations sustain unviable companies. Also, protected markets tend to be inefficient as they usually hinder innovation and can even contribute to wars or conflicts, destroying the markets the protection was trying to sustain (Kornai, 2011). The dilemma is tricky, since Japan's food safety certainly becomes questionable if free trade widens. 


\section{5) An economy with continuous growth}

The Japanese economy has been notably marked by the remarkable pace of recovery following the catastrophe of World War II. Real national income grew at an average of $10.8 \%$ from 1946 to 1954 . This achievement helped Japan to reach the prewar levels of productivity, national income, and personal consumption. For the next fifteen years from 1955, the rate of growth was maintained at an astonishing level: 9.1\% for 19551960, 9.8\% for 1960-1965, and 12.1\% for 1966-1970 (Pyle, 1996). The first oil crisis slowed down even the Japanese economy, but between 1950 and 1973 its real growth averaged more than $10 \%$-nearly $300 \%$ of the American growth during the same period.

The context of growth (rapid until 1973, then slower, but still stable, until 1990) has made its impact on Japan's firms and management philosophy. In the following points we will go into more detail on this impact but it is clear that growing wealth represents resources to subvent export and extra means of redistribution among employees and society in general.

Before analyzing the end of this rapid economic growth, we shall briefly review the reasons for it and its dynamics. Pyle (1996) highlights five main elements which helped Japan to gain such an impetus. The first was extensive technological innovation with the focus on replacing Japan's destroyed industrial capacity. It involved a massive introduction of technologies from foreign companies but "as usual", the Japanese took great care to avoid foreign control of their businesses. The second driving force behind growth was the high rate of investment, especially in export industries. The high rate of savings achieved by the Japanese played a major role in contributing to this unusual amount of investment. Third, sources mention the highly motivated and well educated workforce which we will see evidence of later in this chapter. The fourth factor includes the overall growth of international trade, mainly due to the postwar reduction of trade restrictions and to the export subsidies. Finally, the role of government (described previously) is generally highlighted as a causal factor of rapid growth.

It is no surprise that continuous growth cannot be maintained forever. As soon as Japanese labor became more expensive compared to neighboring countries, and restrictions were set up on the main export markets, the impetus of growth was broken, and ever since we have been witness to a rather stagnant economy (see Figure 14). Evidently, the five reasons for vigorous growth listed above have lost much of their validity. 
Figure 14: Japanese real GNP, CPI and real wage increases (1966-1999)

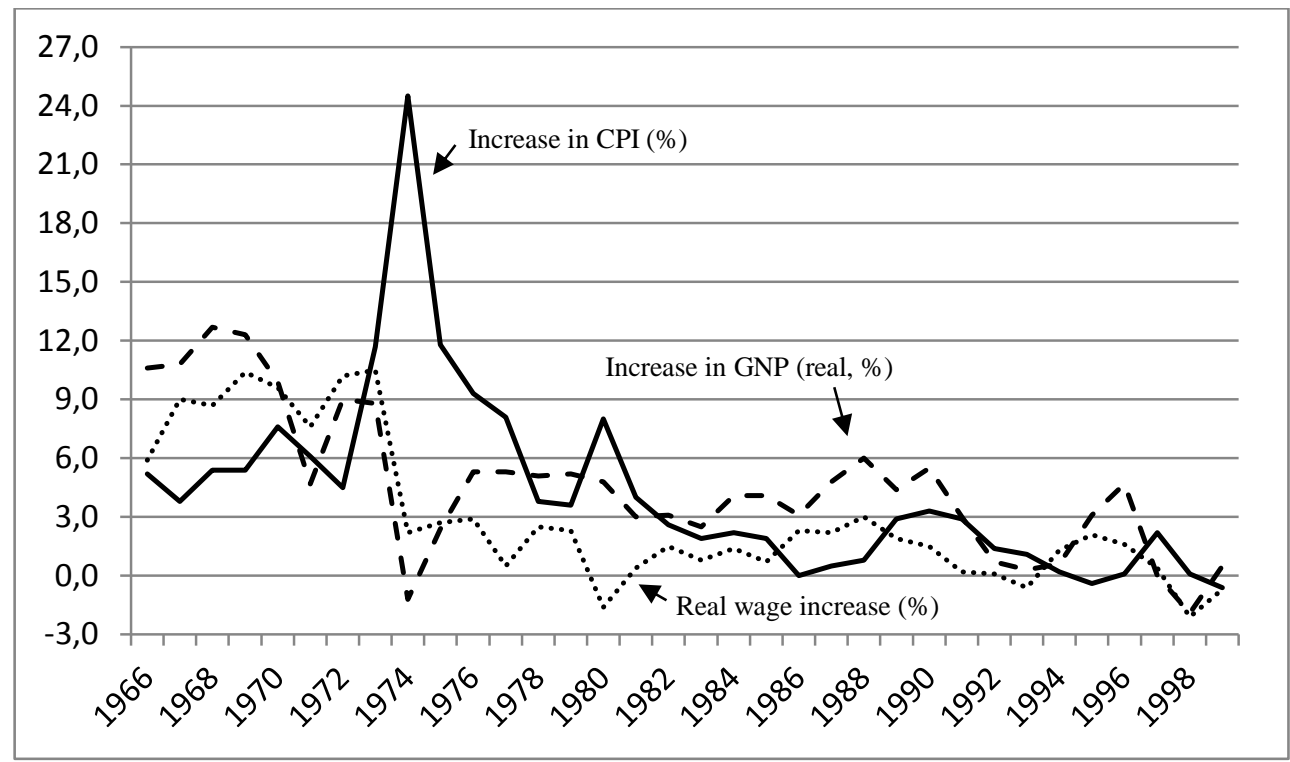

Source: Economic Planning Agency and Ministry of Labor (collected by Ohtsu 2002, compiled by the author)

Since the bubble burst, economic performance has hardly reached the 1989 level in many areas. Real GDP growth has fallen to 1-2\% after 1990. Unemployment has risen from $2.1 \%$ to a peak of $5.4 \%$ in 2002 . Both land and stock prices have plummeted: the Nikkei 225 index fell from 38,916 in 1989 to 8,579 in 2002, and the index number of land prices in the six major cities dropped from 100 in 1990 to 30.4 in 2002 (Keizer, 2010). The outstanding GNP growth for the year 1996 is mainly due to substantial government spending, not the natural dynamics of the economy itself (Benson, 2006). Thus, it is clear that a major circumstance for Japanese business changed: growth is no longer the default mode, and the organization of the economy must reflect that change.

\section{6) An ambiguous and rigid labor market}

Traditionally, the Japanese external labor market, at least the mid-career labor market, is almost non-existent for regular workers: it deals only with non-regulars. We will investigate later the practice of recruiting directly from school, and confine ourselves to noting that the Japanese are typically hired before their graduation. In that practical sense, the institution of the labor market in Japan is much weaker than in the West.

Apart from the age of the fresh recruits, gender also plays a major role in traditional Japanese business. Boys and girls can both be recruited, but according to 
Japanese customs, these latter would soon leave the firm, once married or before their first baby is born. They will return to the labor market as middle-aged housewives, depending on the age of the children, because kindergartens, elementary schools and junior high schools represent a significant maternal workload in parallel to regular housekeeping and the finances of the family. Thus, as a consequence of the long-term employment of males recruited from schools and universities, the Japanese labor market is composed of these returning housewives, and some youngsters who failed school or could not find a job immediately afterwards. In the growing economy, dismissals were few and temporary.

The business history of Japan provides evidence why the labor market developed in that way: the main reasons seem to be related to the late industrialization of the country. Once the first big factories with machine power started operating, skilled labor became extremely scarce and the challenge was how to keep workers in-house once they had been hired. For various reasons, the practice of long-term employment (see later) grew significantly in scale in most of the large firms, and this worked against the development of an external labor market (Pucik \& Hatvany, 1982). By the same token, the fact that young graduates, especially from engineering, found jobs very easily at the dawn of industrialization also hindered the development of an external labor market. In addition, individuals' private social capital (tenure, etc.) is typically not transferable to other groups, which makes any changing of employer a great social loss for the Japanese, even with a nominal raise in salary (Nakane, 1972).

After the bubble burst, when firms had to dismiss workers in larger numbers due to economic difficulties, this traditional picture was redrawn by the growing number of unemployed mid-career workers (see Table 4 below).

Table 4: $\quad$ The structure of the Japanese Labor Market (rounded figures in millions, percentages in brackets)

\begin{tabular}{|c|c|c|c|c|}
\hline & 1987 & 1992 & 2002 & 2007 \\
\hline Total workforce & $46.2(100)$ & $52.6(100)$ & $54.7(100)$ & $57.2(100)$ \\
\hline "Regular", full time employees, total & 37.7 (81.6) & $42.0(80.0)$ & $38.5(70.3)$ & $38.3(67.1)$ \\
\hline Part-time workers, total (paato, arubaito) & $6.6 \quad(14.2)$ & $8.5 \quad(16.1)$ & $12.1(22.1)$ & $12.9(22.6)$ \\
\hline Temporary or dispatched workers (haken) & $0.01(0.2)$ & $0.2 \quad(0.3)$ & $0.7 \quad(1.3)$ & $1.6 \quad(2.8)$ \\
\hline Total of "non-regulars" & $8.5(18.4)$ & $10.5(20.0)$ & $16.2(29.7)$ & $18.9(33.0)$ \\
\hline
\end{tabular}

Source: Hanami (2006), Imai \& Shire (2006: 84), Employment Status Survey: Statistics Bureau 1988, 1993, 2004, $2009^{62}$

${ }^{62}$ Cited by Imai (2011: 65). 
To adapt to the new circumstances, meet demand for flexible employment and deregulate the labor market, several measures were taken to legalize temporary employment between 1990 and 2003. Temporary work and personnel placement in particular were deregulated in 1999 and 2003. Used hitherto as a source of unskilled labor, successive revisions of state regulations opened this path to a larger number of jobs, with the aim of expanding this market for skilled male workers as well (Imai \& Shire, 2006).

The growing market size of the personnel service firms is an obvious sign of the changing business patterns and contextual factors. The American market for staffing and temp agencies represented about $\$ 89$ billion in annual revenue in 2011, which is $1.9 \%$ less than five years ago, according to the Market Research Report of Ibisworld. ${ }^{63}$ That means that around 2006-07, the American market provided a share of $\$ 90$ billion to those agencies compared to the nearly $\$ 340$ billion worth global market (Coe, Johns, \& Ward, 2009). In Japan, according to the Ministry of Health, Labour and Welfare, in 2004 there were 6,794 enterprises providing general temporary staffing, and 5,927 special worker dispatch firms. There was an explosion in the number of firm start-ups and international firm entries especially after the mid-1980s. The estimated value of the Japanese market was about $\$ 23$ billion in 2004, significantly more than 10 years earlier, which made the sector rather attractive to both international and Japanese firms (Coe, Johns, \& Ward, 2006a).

In short, we can say there was significant transformation of the labor market in Japan, such as the increasing weight of non-regulars and females, and an urgent need for more mid-career opportunities. However, the large Japanese firms apparently keep focusing on the recruitment of young graduates, and recent trends may lead more to a reshuffle than to a restructuring of labor markets (Dedoussis, 2001).

\section{2) Corporate assets in the past and present}

In the "golden era" of the Japanese economy, Japanese management was praised for the motivated, devoted employees who made no issue of the time and effort taken in doing their job, managers who cared for the good reputation of the company and the wellbeing of their employees not in exchange for high bonuses but due to a positively seen

\footnotetext{
${ }^{63}$ See http://www.ibisworld.com/industry/default.aspx?indid=1464, downloaded on December 15, 2011.
} 
paternalism, the state-of-the-art production technologies continuously improved by the workers, and so on. Even though some authors such as Luthans et al. (1985) denied that Japanese workers were more committed than Americans, we have seen earlier that the Japanese success even encouraged the proliferation of the resource-based view of firms in the 1980s. Historically, it is asserted that attitudes such as "maintenance of communal discipline, dedication to hard work, desire for learning, respect for seniority and hierarchy, loyalty to communal groups, submission to authority and adherence to tradition" are all associated with the Tokugawa period of Japan (Hirschmeier \& Yui, 1981: 11). This point attempts to focus on these "resources" in Japan.

\section{1) Easy-to-train and devoted employees}

With the emerging Global Competition paradigm and fading American competitiveness, management experts in the US turned towards Japan in order to identify elements ensuring its commercial strengths. Among other things, they noted the devoted, motivated Japanese employees with company-related knowledge and skills; employees who were eager to make personal sacrifice for the glory of the company at any time (Mouer \& Kawanishi, 2005). Figure 15 shows the Japanese average labor turnover for the past fifteen years. For reference, general turnover rate in the US was $8.5 \%$ in December 2011, according to the Bureau of Labor Statistics (United States Department of Labor).

Figure 15: Labor turnover in Japan (separation rate), 1995-2010 (\%)

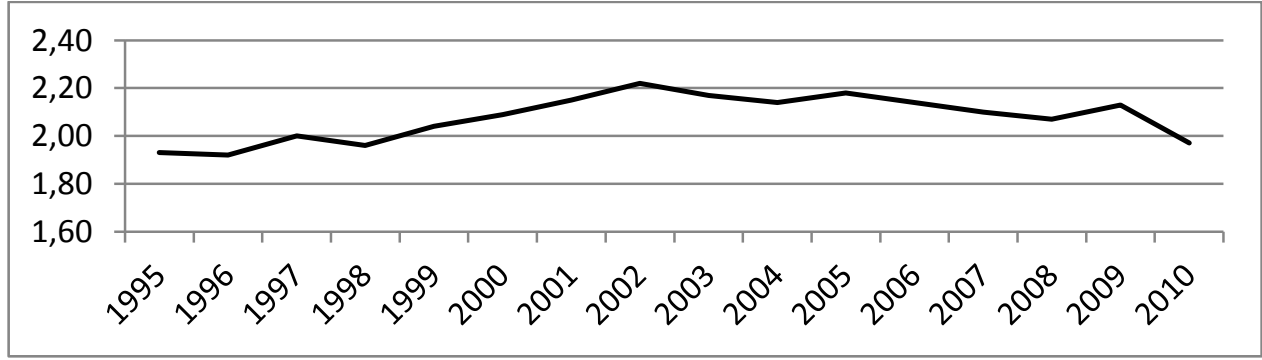

Source: Ministry of Health, Labor and Welfare

Long-term employment, on-the-job and uniform cohort training programs seemed to lead to "the development of a very strong corporate identity and loyalty in the work force, a wide range of experience and responsibilities via job rotation for the employees and good will on the part of the job applicants especially among university graduates." 
(Schulz, 2006: 171) This observation contributed greatly to the rise of the resourcebased view of firms in the West.

On one hand, this phenomenon concerns people's attitude to hard work. We have seen how hard work and study has been valued by Confucianism for thousands of years in Japan. Evidence is ample even today, suggesting that Japanese work harder than Westerners. Mouer and Kawanishi (2005) found that, in terms of weekly hours of work in manufacturing, the Japanese workers reached higher levels than the US, UK, France or Germany in the 1950s, and the mid-80s. By the end of the 90s however, the difference had become miniscule. Yet, there are other figures indicating their intense workload. Absenteeism is historically low in Japan, compared to other countries, as well as the number of lost days due to industrial disputes.

On the other hand, the image of devoted workers can hide unveiled details on their relations with the workplace. First of all, although reluctant (or incapable?) to change job, these workers are among the most unsatisfied by global standards (Marosi, 1985). There are historical reasons for recruitment at a young age (see later), but part of it is easier integration and management in a paternalistic manner.

The employment system today has proved to have remarkable economic disadvantages, such as the poorly developed external employment market, or the external and internal mismatch of the supply and demand of qualified workers (Schulz, 2006). Job seekers in Japan (whether they actually have a job or not) actually have extremely limited prospects to find new employment which might better match their actual needs.

In addition, even if they could change their workplace, the loss as a consequence would be probably bigger than the benefit. Japanese employees spend long years in an organization, they tend to move up with time, being rotated between different departments, and acquire highly firm-specific skills and knowledge. As a consequence of the non-transferable skills, their wage would naturally decrease when moving to a new organization and workers become dependent on the success of their current workplace.

\section{2) Superiors are more managers than leaders}

In the US, when catastrophes happen like a natural disaster, 9/11, economic recession or financial crisis, media tends to highlight the role of great leaders, "heroes", who gather suffering people, turn them into one direction and lead them towards recovery, success, and reconstruction, reinforcing the basic American values (Berinato, 2010). 
Hirschmeier and Yui (1981) assume that war is indeed something which produces great generals (heroes). By the same token, we may think that competition (i.e. the war between companies) is the best way to select and produce good leaders in business. It is interesting to note that since the Tokugawa, there has basically been no war in Japan, and competition is severely controlled, if it exists at all (see Point 1.4).

In Japan, to achieve synchronized moves, there is usually no need for leaders: the system is built up in a way that people know their role in advance and act accordingly, given that this action was foreseen by the administrative elite and prepared beforehand. Post-disaster plans are well-prepared in advance and do not need strong leaders. The goal is not to develop outstanding creativity or build inspiration but make the system work. We have seen this in Taylor's ideas: planning and action are separated. Therefore, traditional managers in Japan have shown a relative aversion to risks and change-all basic elements for leaders to Kotter (1990). According to a largescale questionnaire survey carried out by MITI in 1996, most presidents (69\%) in Japanese firms make their decisions involving other committee members at a point when consensus is achieved under their leadership (Kono \& Clegg, 2001).

However, since the 1990s, change is becoming a routine in Japan as well. Schulz (2006) writes about a "new generation" of managers who witness the daily dismissals of their superiors or even managers of their own age whose companies are being shut down. Managers of this new generation are apparently "more interested in their own careers, in success-related pay and quality of life" (169) and they also accept change more easily. The ones affirming that Japan is in crisis today will probably think that there is a need for leaders. It is just that the Japanese firms do not seem to have a demand for them. It is apparently the same in politics, where Japan is marked by its short-lived prime ministers.

\section{3) Homogeneity and male dominance}

Even in the 1980s, when Japanese business practices were praised and copied globally, the Americans refrained from fully implementing the Japanese system for several reasons. One of them was the different social context, namely that Japanese society was said to be strongly homogeneous compared to the diversity found in the US (Tsuneyoshi, 2001). Immigration has been historically low and for a long time 
forbidden, or strongly controlled by government. ${ }^{64}$ For the first time in 1996, the number of registered foreigners exceeded $1,400,000$-about $1 \%$ of society. ${ }^{65}$ This figure may seem meager compared to most of the developed countries, especially the US where whites represent about $80 \%$ of society and, in fact, they are all "immigrants".

In addition, Japan, as most of the Confucian countries, offers more leadership positions to men as opposed to women than the global norms. Favoring men for managerial positions is widespread in corporate life but also in other areas of life such as bureaucracy or politics. For instance, the influence that Japanese women wield over political decision-making processes is $7.2 \%$ of the level of their male counterparts, although the world average is $18.5 \%$, according to the Global Gender Gap Report 2011 of the World Economic Forum. ${ }^{66}$ With this, Japan ranks 101 out of the 135 countries covered by the report.

As a possible origin of this male dominance, we mentioned Confucianism, in which the vertical relationship between husband and wife is regulated in favor of the husband, who would therefore make the major decisions. Confucianism played the role of the dominant ideology in the Edo period when the ie system of Japan was created. In that system the smallest administrative unit of the country was the household, with the husband at its top, fully representing the whole family. ${ }^{67}$

With the Meiji period and after, the ie system was gradually abolished and the administration was hitherto based on the citizens. However, the leading role of males was restored in the womanly ideal of "good wife, wise mother" policy during the Meiji, Taisho and Showa periods, which took hold as the organizing principle of female gender (Faison, 2007). Then, the role of women has recently become a hot topic again because of the estimated challenges related to the ageing society. In order to face the dwindling population of young males and to make the Japanese system more flexible, women will apparently need to occupy a more active role in business (Abegglen, 2006).

Beyond male dominance, the Japanese companies suffer from an extreme homogeneity in their membership: they all tend to be alumni of the same schools or universities, they

\footnotetext{
${ }^{64}$ See for example the Tokugawa's foreign policy or the Alien Registration Act from 1947.

${ }^{65}$ The figure has doubled since the founding of the registration system in 1952 (100\% growth in 44 years). Today, the "official" proportion of foreigners in Japan is between 2 and 3 percent. In reality, there are probably more, for instance if some Chinese and Korean residents did not apply for citizenship.

${ }^{66}$ Cited in the article "Japanese female political empowerment below curve" in The Japan Times Online, on November 3, 2011, downloaded from http://www.japantimes.co.jp/text/nn20111103b2.html

${ }^{67}$ The term household is more precise because adopted family members or servants were also parts of the ie.
} 
have the same values and professional skills due to their homogeneous trainings, and they use the same ways and logic in approaching problems. This homogeneity often leads to enhanced efficiency when operations are standard, but also represents a risk when unforeseen changes occur and the members are not used to diversity. Authors on Japan tend to highlight the people's avoidance of sudden changes, with "the compatibility of maintaining stability while avoiding stagnation” (Maruyama, 1997: 117).

Building on considerable empirical evidence, Pudelko (2006) affirms that foreigners are still scarce in Japanese company boardrooms, and even in foreign subsidiaries the main decisions tend to be made by the Japanese. This is confirmed by Olcott (2011), who stated that in the Japanese boards, the number of foreign directors is miniscule.

\section{3) Corporate strategy: from 1.0 to $2.0 ?$}

In our evaluation of the American management history we found that one of the most significant contextual changes for firms arose in the 1970s, with the emergence of cheaper but high quality products from Asia. The US responded with severe deregulation and a greater emphasis on PR and marketing versus less attention on production cost or consumer price. It represented a paradigm change in business strategy with such striking consequences that the whole business context seemed to move with it. We concluded that with this answer the US was leapfrogging from Paradigm 1.0 to 2.0. Before the 1980s, most of the current Japanese management characteristics could be found in the USA as well, so the two systems were more similar (Inagami \& Whittaker, 2005). That was before Paradigm 2.0 took root in the US. The same challenge of cheap competitors obviously came to Japan after 1990 and the aim of this point is to examine the Japanese reactions compared to our findings in the US.

\section{1) Stakeholder orientation}

The stakeholder approach emerged in the mid-1980s and is credited to Edward Freeman. Freeman stated in 1984 that managers must develop strategies which lead the company in a satisfactory way for all its stakeholders: shareholders, employees, customers, suppliers, and communities. In terms of social responsibility, for instance, a stakeholder-oriented firm's action considers all these interests at once, whereas the 
shareholder view would suggest satisfying the profit objectives first (responsibility towards the owners) and until it is realized, alternative goals should not figure in the equation. Annex II.2 shows how this aspect is slowly gaining emphasis in American business in the twenty-first century, especially since the global financial crisis.

But still, in academia, Japan is typically categorized as a stakeholder-oriented nation with the employees' interests taking precedence, whereas the Americans are described to be shareholder-oriented (Olcott 2009, Jacoby 2007, Dore 2000). As Abegglen (2006) noted, commenting on the difference:

[In Japan...] "The share in the company held by whoever now has it represents a capital investment. That investment is entitled to a return, and that return is provided when at all possible. But there is no further obligation to, nor right held by, the shareholder." (93)

By contrast, in the American system, shareholders have "total entitlement" to the company, even though many claim that employees ought to be considered more because they bear a higher risk today than individual shareholders (Yaziji, 2008). According to the definition of the OECD, "generating long-term economic gain to enhance shareholder value is the corporation's central function." (Abegglen, 2006: 132)

The difference matters, because stakeholder-oriented systems can apparently be more stable but less reactive to change than shareholder models. As pointed out by Liker et al. (1999), the influence of multiple stakeholders can easily curtail flexibility and make individual firms rigid. Yet in a survey carried out in large Japanese corporations in $1990,80 \%$ of the respondents still claimed that the company belonged to its employees, the major stakeholder group in Japan (Yoshimori, 1995). It is also clear that the principles of agency theory are difficult to apply in Japan because unions, takeovers, suppliers, managers, creditors and debtors do not play the same roles as in Western countries. According to Kester (1996), the Japanese shareholders' interest can be ranked relatively low because most of them are also their company's major creditors, customers, and suppliers. For them, these trading and/or lending relationships are at least as important as their equity investments. Therefore, the owners may bear substantial agency cost while the Japanese focus stays on the reduction of transaction cost and stable relationships. In contrast, argues Kester, the American commercial relationships may cause higher transaction costs.

Another implication of the greater emphasis on employees' interest rather than the simple consideration of the shareholders' interest is the lack of short-term incentives 
in Japanese business, and consequently, a longer strategic time-horizon (Pucik \& Hatvany 1982, Dore 2000). In general, the danger that an employee will misuse current circumstances at the expense of future goals is minimal in Japan, since many of these employees tend to remain in the organization for most of their working lives.

Naturally, the historical evolution of Japanese firms leads them to adopt relatively cooperative strategies compared to the US for instance (a phenomenon we will also see with the company unions). We discussed earlier how collectivism can reduce transacttional costs. A study led by Richard Nielsen shows the same: "In most, but not all, cases, cooperative strategy appears to improve value-added efficiency in a wide variety of environments and situations" (Nielsen, 1988: 475). Using strategic management, game theory, evolutionary biology, and ecosystems theory, he examined and explained cooperative strategy and several cases from Japan such as policies of the MITI and Keidanren, the relation of Hitachi and IBM, Matsushita with the VHS technology, or the trade between Japan and China.

\section{2) Cost and quality leadership (vs. product differentiation)}

Cost leadership as described by Porter (1980) is one possible business strategy, alternative to the product differentiation and the focusing on a specific part of the market (niche). Cost leadership typically helps emerging countries with cheap labor to become competitive and accumulate some basis for growth: indeed it helped Japan as well, but once industrialization reaches a certain level and labor becomes relatively expensive, this same strategy can become a burden and an ill-directed focus, as is now the case in Japan (Porter et al., 2000).

The old strategy in Japan represents obvious advantages. Since the clearly established way for Japanese companies to grow is from internal competitive strength, they naturally concentrate on making products which fit customers' needs and are cheaper and/or of better quality than the competitors' products (Pucik \& Hatvany, 1982). Indeed, Japanese products have been excelling for many decades at international levels with their price to quality ratio, with their high-end technical solutions, with their level of precision, while profit was not such an important objective (Jacoby, 2007).

Thus, production became the major driving force and strategic concern of firms, with an emphasis on continuous innovation, on upgrading quality and on lowering 
costs. In addition, historically, sales activity is performed by the trading firms in Japan, not the manufacturer. This may provide another explanation why there has been an apparent lack of concern for sales and marketing in Japanese firms as compared to Western companies (Abegglen, 1960). But, as mentioned above, the strategy of cost leadership is not adequate or sufficient in a highly competitive global context where the competitors have cheaper labor and relatively advanced technology. The time may have come for Japan to jump to the 2.0 paradigm. Fields et al. (2000) took the same stance: "Marketing skill will be one of the key factors that separates winners and losers in this new consumer-driven market. [...] Customers will no longer "drink in" the latest products at high prices." (xii)

\section{Figure 16: Japan's trade balance (Customs Clearance Basis)}

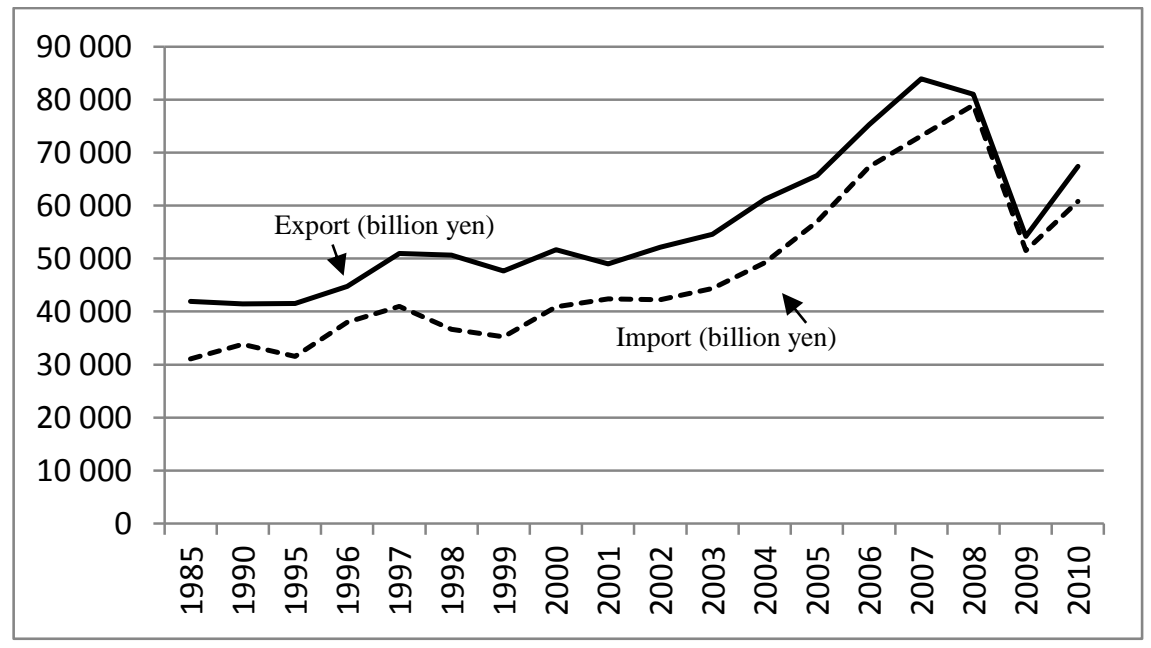

Source: Ministry of Finance

However, one important contextual factor differs greatly from the American competitive challenge of the 1970s: the Japanese trade balance is not damaged to the extent the American was. Figure 16 shows the value of both Japan's imports and its exports. Since the balance is continuously positive, Japanese authorities may not feel the same urgent need for change as Americans did forty years ago.

\section{3) Diversified portfolios, spin-offs and start-ups}

Japan's period of growth, lasting until 1990, encouraged companies to invest and grow. But sometimes firms, even in groups, do not have the autonomy to move in desired directions, due either to a lack of resources or a lack of political leverage. In this case, 
the practical solution is to create a new venture-a typical practice in Japanese business. In any case, large Japanese companies and keiretsu "prefer to grow by accretion, affiliation, alliance-building, that is by adding new business units to existing inter-firm groupings or by restructuring transactions within a group of essentially singleproduct/dominant-product firms" (Fruin, 1992: 203). There are several reasons for this behavior.

It is claimed that Japanese society attaches greater value to a manager who maintains his firm as a "semipermanent group of individuals tied together with lasting bonds" (Pucik \& Hatvany, 1982: 37). The job of top management being to ensure stable employment, any kind of drastic change in regard to the legal corporate framework, such as takeovers, mergers and acquisitions (especially involving unrelated firms), or divestitures are typically rare in Japan (Clark, 1979).

It was mentioned earlier that from feudalism until World War II, most of Japan's industrial activity was covered by family-owned conglomerates (zaibatsu). Under the industrialization of the country during the Meiji era, these families were the only potential actors capable of major investments. As a result, nearly all of them grew into greatly diversified, huge corporate giants with a few well known names on the top: Mitsui, Mitsubishi, Sumitomo, Yasuda, Furukawa, Konoike, and Kawasaki (Hamada 1991, Hirschmeier \& Yui 1981).

After World War II, these conglomerates were banned by the American occupation and were mostly divided and sold out part by part. By the end of 1950s, the newly regrouping individual companies could not officially recreate the holding structure of the past, but gradually they adopted informal inter-firm networks or groupings, more or less similar to the zaibatsu with separate ownership and professional management. These groupings covered highly diversified business portfolios, similar to their family-owned predecessors, especially during and after the high-growth era, ${ }^{68}$ and due to the investments generated by the endaka (the overvalued yen following the Plaza-accord). Forming these kogaisha (subsidiaries) was the way Japanese companies were able to remain centralized and reduce heterogeneity (Jacoby, 2007).

The single firms themselves, forming the keiretsu groups, are not greatly diversified (see the next point). According to Fruin (1992), their strategy is "to offer a complete range of goods and services in one or a few related line of products" which he

${ }^{68}$ For this period from the 60 s to the early 70 s, see Abegglen (2006). 
calls a "full-line strategy" (22). Apparently, distinctive product lines in the same company are at least 50 percent lower than in American or European industrials, and in 1987 three-fifths of the largest Japanese firms were focusing their production on a single or dominant product (this latest accounting for at least 80 percent of total sales).

It is evident that growth and diversification strategies are valid mainly in a growing economy, which was obviously the case in Japan until 1990. After this date, strategies had to alter according to the new environment. As Kuroda and Maruyama (1997) stated: "new corporate strategies of Japanese corporations, such as M\&A, divestment, corporate alliances with Japanese as well as non Japanese companies are all the efforts of those businesses to cope with the new environment" (179). Thus today, sadly, company closures outnumber the creation of new ones.

\section{4) The development of structural elements}

Comparing American and Japanese firms, one of the first noticeable differences is the organizational form or structure. In the US, the experience of Williamson or Chandler suggested that the most innovative and efficient way to organize large corporations is the multidivisional or M-form. In these firms, the top management in the headquarters will supervise the divisions' activity, based mainly on financial monitoring (management control), and the corporate governance practices will ensure that managers do not misuse their power, as described by agency theory. Thus, the firm will operate according to the benefit of its owners.

In Japan, one of the most advanced countries in the world, this multidivisional form is not particularly common and not as highly regarded as the functional structure (Fruin, 1992). Monitoring and corporate governance also greatly differ, and in this point we will examine in what respects.

\section{1) Big and complex, U-form based group hierarchy}

The basic postwar, legal entities in Japan focused their output on a specific product category, for instance automobile, electronics, or drinks and beverages. Within that specific category however, they were able to offer a vast amount of diverse products or 
different flavors (Marosi, 2003). ${ }^{69}$ Nevertheless, these single-product firms are highly bureaucratized: Japanese corporate hierarchies are on average taller than the management pyramids of Western organizations (Dore 1973, Azumi \& McMillan 1975). These numerous layers certainly create opportunities for promotion and other kinds of benefit, which makes large firms in Japan consistently more attractive workplaces than small ones (Cole, 1971). Dore (1973) adds that hierarchies of Japanese organizations also work against class consciousness. Instead of classes, Japanese employees are linked to one another in long chains of superior-subordinate relations. In such a structure, status equals are scarcer, which weakens the power of unions.

Based on these single units, an important Japanese feature has been the elaboration of an inter-firm network for each corporation. In literature on Japanese business, the reader encounters different types of groups or networks, although some authors deny that such things as keiretsu exist (Miwa \& Ramseyer, 2006).

The term "horizontal network" (or kigyoshudan) refers to the grouping of large mother manufacturing firms with trading houses, financial institutions (a main bank, an investment and an insurance company). The member companies own shares in each other, called cross-shareholding, which ensures "friendly" capital and blocks unwanted takeover attempts. The group is also characterized by debt and trade interlocks, as well as director flows between its members plus various ceremonial and symbolic activities such as the meetings of the presidents (Johnston \& McAlevey, 1999).

By "vertical networks" we mean the whole supplier pyramid (numbering sometimes thousands of small firms) ${ }^{70}$ under a large assembling company which then commercializes the final product. The keiretsu, Japan's large corporations, often include all these aspects, although some large firms are known of which are not members of any horizontal groupings but have their own supplier network. Analysts state that these supplier-customer relationships in Japan do not fit either "market" or "hierarchy" categories of the transactional cost theory described in Chapter 1 (Liker, Fruin, \& Adler, 1999). This relation is described in Japanese as shigarami: emotional bonds between suppliers and customers in keiretsu groupings. ${ }^{71}$

\footnotetext{
${ }^{69}$ In terms of its strategy, this type of firm is called a "single-product" firm (Locke, 1996).

${ }^{70}$ In 1989, Daimler Benz employed 370,000 workers, General Motors 750,000, while Toyota Motor Company 65,000. That year GM produced close to 7.9 million vehicles whereas Toyota made over 4.5 million. But at the same time, according to a study by MITI from 1977, Toyota Motor had 168 suppliers at the first level, 5,437 at the second (supplier's supplier), and 41,703 at the third (Fruin, 1992).

${ }^{71}$ For further details on different types of networks, see Fruin (1992) or Lincoln \& Gerlach (2004).
} 
The advantages and raison d'être of the keiretsu groups compared to a single unaffiliated firm are obvious in Japan. They play the role of a centralized resource allocator (due to capital reserves from former, profitable operations such as mines, landholdings etc.), provide management talent and experience, and political connections. Similar to the generally applied idea of egalitarianism, groups apparently ensure the same redistributive support, for the weak firms at the expense of healthy ones. ${ }^{72}$ Redistribution is usually associated with the government, but as practiced in Japanese companies, it allows the state to remain strong but small.

Lincoln and Gerlach (2004) proposed that the keiretsu groups with the main bank could be a potential solution to the principal-agent problem: by concentrating the ownership and investment in the hands of a few close business partners, inter-firm groups seemed to provide superior monitoring and governance at lower transaction cost. The problem comes with the performance measurement because evidence shows that sales growth and profitability are weaker in the six biggest groups' affiliates than in unaligned firms. The logical dilemma of performance (if networks cost less, why do they not increase profits?) will be investigated later in Point 6.

According to Johnston and McAlevey (1999), the first network structures in Japan emerged with the zaibatsu holdings and they provided strategic advantages and supplementary resources to their member units. As for their historical roots, Fruin (1992) claimed that the interwar period was also important because by then, the segmentation and specialization of work (mostly to meet war demands) had been implemented among independent but interrelated business entities, characterized by long-term contracting (to ensure trust). In that way, alliances and coalitions played the same role as divisions and divisional functions did in American corporations. The two developments of constrained divisionalization and inter-firm networks, states Fruin, "represent a corporate response to economic growth and product/market proliferation in post-war Japan" (177).

Under the Occupation, the Americans launched several projects aiming to impose a democratic social and business model on Japan and banned the holding structure by the anti-trust law. The main zaibatsu were destroyed as their stocks were liquidated and the conglomerates split into smaller business units. The exaggerated influence of the financial families of the past was indeed lessened but it was not

\footnotetext{
${ }^{72}$ Criticized also for keeping alive badly managed firms.
} 
possible to introduce massive individual stock ownership: the originally banned corporate acquisition of shares and was authorized by the Dodge plan ${ }^{73}$ and the liquidated stocks were typically bought by other corporations. In addition, most of these acquiring companies purchased stocks in companies with which they had already been doing business before (keeping former partnerships). Bank ownership, originally banned as well, was authorized up to $10 \%$ in 1953 (the ceiling was downscaled again from 1987 to 5\%). Once the peace treaties were made in the early 1950s, MITI was launched to rebuild the trading companies' international network and then assigned these branches to enterprises. In a few years time, the result was new companies informally linked into business groups by cross-shareholding ties. The MITI even promoted the stable cross-shareholding, harboring as it did concerns over capital liberalization and foreign takeovers (Locke 1996, Lincoln \& Gerlach 2004).

As during the war economy, the rapid growth era encouraged the development of the subcontractor system in order to meet fast-rising demand. These self-forming networks have been called keiretsu from the early 1950s. Similar to their predecessors, the zaibatsu, keiretsu groupings have finally expanded "to be active in most every field of business endeavor. The drive to compete across-the-board by having at least one member company in each business is termed the 'one-set' principle” (Fruin, 1992: 189).

After the 70s (the end of high growth), network forms may have lost their usefulness, state Lincoln and Gerlach (2004) and Katz (1998). According to what is called the modernization theory, there is less call for the groups' role in allocating capital, or structuring supply chains and distribution channels due to the maturing of capital and product markets. During the endaka (high yen period of 1986-90), group cohesion fell considerably due to the rise of speculation. In addition, after the bubble burst, firms had to sell off (at least partly) their cross-shareholdings, and the banks' bad debt diminished their capital reserves and lending capacity, hindering the main bank function (Ozsvald, 2007). Changing corporate governance made it more difficult to dispatch directors, a traditional practice of human resource management. ${ }^{74}$ Crossshareholdings declined further in the late-1990s, when a financial crisis occurred in South-east Asia and the effects of Japan's bubble burst were already obvious at a global level (Jackson \& Miyajima, 2007). Japanese shares were increasingly held by foreign investors, who then put strong pressure on Japanese companies to reform (Olcott 2009).

\footnotetext{
${ }^{73}$ Newly established recovery plans for Japan supervised by Dodge from the late-40s.

${ }^{74}$ Lincoln and Gerlach (2004) state that cross-shareholding and dispatching of directors are the Japanese answer to agency theory.
} 
On the other hand, Johnston and McAlevey (1999), or Lincoln and Gerlach (2004) still found that inter-firm connections remained in Japanese business.

Due to the often informal nature of the linkages, it is rather difficult to delineate where the boundaries of these inter-firm groups are today. Dore (2000), when evaluating current tendencies, emphasized that cross-shareholding had two elements: mutual and stable shareholding. He stated that $21 \%$ of all shares in 1987-92 were held in mutual shareholdings, before falling to $16 \%$ in March 1999. Stable holdings have also been decreasing for about 6 years and stood at around 41\% in 1999. Remarkably, non-financial companies had a higher proportion of cross-held shares in March 1999 than in 1987. Also, keiretsu presidents still have their monthly lunches, and Mitsubishi, Sumitomo and Mitsui have the same ratio of cross-held shares as in 1992, and higher than in 1987. Jacoby (2007) affirmed that in the Big Six keiretsu, cross-shareholding was higher in 2001 than in the early 80s. According to his analysis, even recently, $90 \%$ of the companies engage in some cross-shareholding scheme.

\section{2) Large boards dominated by insiders}

In the 1980s, American shareholders had very little appropriate information about their managers, and the Japanese companies, due to their high level of trust in the top management, were set as example (Lincoln \& Gerlach, 2004). Then, since the 90s, the downside of this "trust" began to come into the limelight. One such aspect is the practice in which Japanese boards of directors were filled merely with insider members (such as former executive managers of the same company), and these members were far too many to operate efficiently (Abegglen 2006, Schaede 2008, Katz 2003).

Beyond a higher level of trust, the advantage is that when senior managers fill board positions, it ensures smooth cooperation with the operational level and enables company assets to be used as efficiently as possible due to the professional expertise of the board. At the same time however, these managers only know their own company and the business they are used to; their knowledge of best practices is therefore limited. Moreover, this structure filled only with internal players cannot provide sufficient control on management as required by international investors and standards. ${ }^{75}$

\footnotetext{
${ }^{75}$ One of the recent corporate scandals in Japan was the Olympus affair, in which huge losses were concealed: see http://www.japantimes.co.jp/text/fl20111213zg.html
} 
It could be said that one consequence of the transactional cost oriented (as opposed to agency theory) way of organizing Japanese business is that the boards' main role has not been to ensure the control of shareholders over the management. That has been done by the main bank, the self-monitoring of employees (including managers), the community nature of the firm, and the institutionalized governance structure ${ }^{76}$ (Dore, 2000). The boards in Japan became instead a sort of compensation or career endstage for senior executives, including the CEO, where they could decently spend their last years in the company.

Again, there is a historical logic behind the phenomenon. In the family-owned early enterprises, such as the zaibatsu, the owners did not need an institutionalized representation of their interests, not even in case of engaging professional managers. By the time when the joint stock companies appeared (especially in the interwar period), the stock exchange could not develop into a reliable and frequented investment market, but remained a place for speculation and risk. At the same time, the banking system was modern and well developed since the 1880s. As a consequence, the source of investment became the main bank, able to control the use of its resources through the zaibatsu holding (Nakagawa, 1983).

Although some abuses such as excessive CEO pay are better controlled, the Japanese boards are criticized for being too tight with management: the consequence can be accounting frauds (also frequent in the US however) and damage to the individual shareholders. Providing boards with an external (including ideally foreign) perspective is increasingly a requirement of foreign investors, and one which is considered with more attention now that Japan is short of money to save firms with heavy debts and maintain high employment.

The problem of transparency and control in general was set to be solved during Hashimoto's Big Bang reforms ${ }^{77}$ at the end of the 1990s. Since then, consolidated returns have been reported, assets have been held in market value, and pension liabilities have been recognized, to mention a few of the reforms (Abegglen 2006, Hayes 2000). Quite a few analysts agree that these reforms did change the old elements of the Japanese model of corporate governance dramatically (i.e. Aoki et al., 2007).

\footnotetext{
${ }^{76}$ The Japanese CEO does not have as much power as the American for instance, and the fact that he has been in the company for long time decreases the chance of an abuse of power at the end.

${ }^{77}$ Reforms in corporate law (finance and governance issues) and new accounting rules in force from 1999, made under Prime Minister Hashimoto.
} 
Others say that cross-shareholding, although slowly dissolving, still represents a major obstacle to transparency and higher profit levels (Dore, 2000).

By the end of 2001, foreigners controlled $19 \%$ of domestic listed companies in Japan, up from 5\% a decade earlier (Lincoln \& Gerlach, 2004). By the mid-2000s however, the ratio of foreign ownership stood still at about $18 \%$ in Japanese industry (Jacoby, 2007). In addition, as noted by Olcott (2011), the number of external directors is still extremely small in the Japanese boards.

Miyajima (2007) found that greater disclosure of information correlated significantly with performance, whereas minority shareholder protection and board reforms resulting in an influx of more outsiders did not. There is obviously no guarantee that the addition of foreign board members will enhance performance. There is no one best way in corporate governance either and no correlation has been found between the governance model used in different countries and their per capita GDP (Jacoby, 2007). Thus, there must be several "optimum points" or solutions to the same problem. However, analysts usually agree that in Japan, a country where globalization of management is of a great concern now, the old model of corporate control needs to change (Morikawa 2001, Lincoln \& Gerlach 2004, Dore 2000). ${ }^{78}$

\section{3) Central HRM prevails over Finance}

Traditionally, one of the strongest and most powerful functional units in large Japanese corporations has been the human resources department. According to Jacoby (2007), in Japanese firms in 1980, head office HR departments were on average twice as big as those in the US, relative to the number of employees. What might be the reason for the HR unit being relatively powerful, influential and large? In order to ensure and coordinate all their traditional tasks (such as mass-recruitment and induction, regular rotation, seniority-based promotion and wages, job evaluations, the spring wage offensives with the unions, and so forth), HR departments indeed need to be strong and centralized. Therefore, when moderns firms emerged in Japan and the custom of long-

\footnotetext{
${ }^{78}$ At the same time, we must note that American practices do not escape without criticism either. Ideally, the CEO and the chairman of the board are two different people but this seems not to be the case even in the US. In addition, the "external members" are often cronies of the chair: actual or former CEOs from different firms where they operate the same way. The result resembles the effects of cross-shareholding in Japan. Thus, it is not obvious that Japan's corporate governance is worse than that of the US, and there are severe convictions for fraud in both countries. Beyond the arguments on corporate governance, analysts also explain the "poorer performance" of Japanese firms and economy by insufficient domestic competition, the lack of mobility of labor and of executives, the lack of hostile takeovers, the poorly functioning capital markets, and so on (Katz, 2003).
} 
term employment became embedded in corporate life, blocking the external labor market, the need naturally emerged for internal labor markets which implied a big HR department, able to reach every organizational unit even at the subsidiary level. Therefore, in contrast to American custom, the Japanese central HR department is traditionally larger and more powerful than the finance department (Jacoby, 2007).

Once we understand the stakeholder-shareholder differences, and the problem of scarcity of skilled labor versus capital, it comes as no surprise to learn of the limited power of finance departments. Due to late industrialization and the underdeveloped stock market in the Meiji era, the first large zaibatsu were inclined not to raise capital on the stock market but to use their own banks to finance their investments. Even in the post-war business system, it was much easier for the keiretsu to use their main banks ${ }^{79}$ rather than the capital (stock, or even the bond) market; otherwise they simply financed their needs from internal funds. This latter became the major source of capital especially after the mid-1980s, as firms' cash flow has exceeded their investment. Consequently, stock options are not a traditional part of the executives' compensation as they are in the US (Hirschmeier \& Yui 1981, Dore 2000).

By the same token, the financial sector in Japan historically has other functions than creating extra profit. Its raison d'être is to support industry and retail. Jacoby (2007) adds that due to the regular rotation, managers in headquarters have a good grasp of business fundamentals in divisions. Consequently, there is no need for a heavy reliance on financial data and monitoring as in American corporations, which makes the role of the finance department a less important one.

The lack of speculative money might be either good or bad for business. Most Japanese households are risk-averse money savers, providing cheap capital for the state to finance government debt or to subsidize export (Móczár, 1987). In the form of postal savings, even these households choose safety against profit, and this risk-aversion may have increased since the disastrous effects of the bubble burst. As an indicator, more than two decades after 1990, the Nikkei index is barely above the post-bubble low.

The role and weight of finance, however, is apparently increasing in companies and based on his observations of which department the executives in Japan typically

\footnotetext{
${ }^{79}$ In Japan's post-war business system, each keiretsu group has a bank called its "main bank", inspired by the German bank structure, which owns until 5\% of the members' shares, and provides them with preferential loans and other services. According to the Nihon Keizai Shimbun survey from 2003, 96\% of the responding 343 firms still had main bank(s), and only 14 companies, such as Toyota or Sony, stated not to have one (Abegglen, 2006).
} 
come from, here is Jacoby's ranking after the mid-2000s: (1) Planning / strategy; (2) Marketing / sales; (3) Finances and HR; (4) R\&D; and (5) Production / operations. The department which ranks first is still planning in Japan, whereas in the US it is finance.

\section{4) Processes of decision making: a consensual approach}

Instead of going into a "who-is-right" fight (i.e. voting), the Japanese tend to negotiate with each other until the point they can reach a common solution, acceptable for each parties. One clear sign of this consensual decision-making is the number of lawyers in Japan compared to the US: for disagreements that do arise, litigation is indeed quite uncommon (Keys \& Miller, 1984).

Thus, Japanese decision-making is commonly described as participatory and consensual or consensus-oriented, with the initiative coming from lower levels (Yoshino, 1968). Classical examples illustrating this decision-making behavior are the processes of nemawashi ("twisting the tree roots around") and ringi-sho or ringi-seido ("circulate a proposal, discuss, and decide"). ${ }^{80}$ The classical way of initiating a proposal or decisionmaking in large Japanese companies starts from lower ranks (i.e. young employees), who, before making a formal proposal, go to the other employees concerned and collect opinions from all of them. Ideas and concerns can be voiced freely at this stage of the process, because they do not involve any official commitment (Pudelko, 2006). When the draft of the basic idea reaches consensus, the nemawashi phase is concluded.

Then, a formal proposal (ringi-sho) is drafted and wends its way up the hierarchy, acquiring in the process the signatures of other relevant officials on the cover sheet. All proposals go to the top, so the chief executive bears symbolic responsibility for every decision. Some scholars (Dore 1973, Yoshino 1968) claim that these authority structures combine a high concentration of formal authority with decentralization of de facto participation. Yet we may conclude that the circulation of a ringisho is just the formal manifestation of a process of consensus-building through informal networking (nemawashi). By the time the proposal is drafted, the idea has been communicated to all parties concerned, and their general consent or support is assured (Hatvany \& Pucik, 1981a). Olcott (2009) noted that most firms have already an electronic (computer-based) form of ringi system, which certainly speeds up the process.

\footnotetext{
${ }^{80}$ The translations are taken from Pudelko (2006).
} 
Pudelko (2006) notes that one reason for harmonious cooperation and smooth consensus is the homogeneity of Japanese organizations: participants are basically all male Japanese, from the same universities, who have socialized over many years in the same company. The same reason explains though the difficulty of any "outside-the-box" thinking and the lack of more substantial changes of direction.

This latter became a problem only after the 1990s when the stable growth period of Japan ended and there was a keen need for new, sometimes radically new ideas and solutions. In particular, radical actions such as divestment (seen in Point 3), closures, and massive dismissals are hardly possible to undertake on the basis of participative and consensual decision-making (Pudelko, 2006). Therefore, top managers have recently tended to play a much greater role in strategy formulation, but the implementation and related decisions are still made in a bottom-up process, creating a synthesis of the traditional Japanese and the Western-style approach (Kono \& Clegg, 2001).

\section{5) Working teams}

According to the widely-held "American brick, Japanese stone wall" theory, separate jobs are established for each individual in American companies but not in Japanese ones (Hanaoka, 1997b). In Japan, jobs are not designed for individuals but for teams, so an individual's tasks and responsibilities are rather blurred.

Teamwork (shīdan shugi) was listed among the keywords of Japanese Management, as described in the United States, when the Global Competition paradigm emerged (Pascale \& Athos 1981, Ouchi 1981, Gordon 1998). The Japanese were efficient because they had been working in teams which enhanced communication and cooperation, and made the work process more fluid and more efficient. They used an open-office system where there were no individual offices, communication was open, colleagues were aware of the other's ongoing projects (a circumstance which helped them to replace each other in case of illness for instance), and groups were seated together with the line manager. This led to a better supervision in the office and to the practice of "management by walking around" in the shop floor. So when copying the Japanese model, American firms also introduced the open-office system and strongly encouraged teamwork and group-based solutions.

Of all the different types of Japanese working groups, the most famed worldwide may be the "quality circles". Although there may be variations in their form or 
objectives, basically every quality circle is a relatively small group of employees who meet together on a regular basis to discuss and develop solutions for work problems relating to production (quality, cost, etc.).

Presumably similar to every other country, we can find group-based work dating from the beginning of Japan's history. In modern management studies however, in spite of the widely held association of teamwork with Japan, there are also scholars who claim that these group principles were developed first in the US by Argyris, McGregos, Likert and others. Presumably the Japanese, schooled in behavioral techniques, would have borrowed from them (Keys \& Miller, 1984). Others found evidence that teamwork in Japan, such as quality circle participation, is perceived merely as an extra duty demanded by management, and thus the extent to which it is voluntary might be highly questionable (Cole 1980, Tokunaga 1983). On the other hand, Lincoln \& Kalleberg (1985), surveying Japanese and US manufacturing employees, found strong, positive relationships between quality circle membership and employee commitment to the organization (in both samples). The implications of group-based thinking are highlighted in several other points of this chapter.

\section{5) Organizational Behavior and employment philosophy}

In the previous points on the organizational context, strategy or structure, we have found several interconnections with the behavioral elements of Japanese firms. This is no surprise, since we based the whole model of contingency theory on this feature of interconnectivity of the elements, in which change, when it occurs, ought to affect the whole chain. In this point we shall examine the major elements and consequences of human resource management in Japan. Its weight cannot be overestimated: for a long time, Japanese management has been identified with the so-called three pillars: lifetimeemployment, seniority and company unions. In addition, it is tempting to think that corporate law and governance issues for instance are more flexible and easier to reform than the mindset of people and the basics of interpersonal relations. For many observers, this point touches the core of Japanese management. 


\section{1) Recruitment from schools}

Japanese students start job-hunting from the beginning of their last year in school or often before, this being a long process which can determine their whole professional career. The fresh recruits would then begin April 1, immediately after their graduation. The importance of job-hunting is explained by the fact that companies in Japan all tend to recruit directly from school; the chances of being hired later in mid-career are traditionally scarce (Abegglen 1960, Dore 1973).

Accordingly, companies intending to hire approach schools and universities about one year in advance, holding presentations or organizing a job fair. The students interested in working in the company show that interest by filling out an application form, or sending a postcard or mail. Then selection process starts, which involves up to seven or eight steps in total. Some students will be recommended by their professors or supported by existing alumni and can get in direct contact by phone or visit the company right away. The most important selection criteria include adaptability, proper social behavior, school references or even family background, rather than former work experience or language proficiency as in Western firms (Schulz 2006).

These hiring practices have several implications. Obviously, the system is characterized by the human needs of large companies. Small- and medium-sized firms, which cannot recruit masses each year, have always had to make more effort to attract suitable candidates.

Another consequence is the enhanced interdependence of a firm's employees. A new recruit is usually selected on the basis of which school or university he belongs to. His recruiter will probably be a former member of the same institution, thus creating another interpersonal link, and this employee would be available to the younger for useful information or behavior, conduct, or manners normal in the company. Subsequently, each recruit is also assigned to an official instructor who has been working with the firm for about five years, and who would be responsible for his onthe-job training and supervise his evolution. Other useful exchanges of information happen during school alumni meetings or company outings when junior and senior members of the same company gather in an informal context (Methé \& Miyabe, 2006).

The early merchant houses of the Edo era such as the Mitsui family considered it important to raise employees from infancy, but taking staff from schools really 
developed from the Meiji period, or the industrialization of Japan (Sakudo, 1990). The system of taking, each spring, some fresh graduates had a simple reason: the massive introduction of new machinery from Europe. At the end of the 1800s, the oyakata ${ }^{81}$ were still ruling industrial production. The acute shortage of skilled labor for fastgrowing industry arose during and from the Sino-Japanese war (1894-95): the total engineering workforce in 1890 amounted to 13,000, growing to 150,000 by 1905 (Dore, 1973). The mechanized production system demanded new competencies and companytrained competent personnel. The easiest way to get it had been to recruit young boys from schools who could be trained efficiently (even molded) to fit the company's needs. ${ }^{82}$ The training included both technical and moral programs. This practice was in harmony with former feudal customs but was in this case generated by the necessities of industrialization as well. Some firms even created their own schools.

After the early initiatives, the school-based recruitment system gained legal support in 1949 with the revised Employment Stabilization Law, and became widespread practice in the 1960s and 70s (Sugimoto, 2003). From the 1990s however, Japanese companies have faced multiple difficulties related to these traditional hiring processes. One is growing uncertainty: it is clear that in an economic downturn, estimating the workforce needed one year in advance becomes even harder than before. Observers also note that high potentials tend to apply for foreign firms rather than Japanese ones, because the former provide higher pay, shorter working hours, gender equality, direct reward of performance, objective and faster promotion prospects and so on (Schultz, 2006). With more frequent lay-offs and changes in employment, recruitment of those in mid-career is also becoming a hotter topic.

\section{2) Core (permanent) vs. "irregular" staff}

There are two basic employment categories in Japan: regulars and irregulars. Regulars are the base or the core of the employment system: the salarymen with permanent contracts recruited from school, typically males, who spend their life in the company, who live for the company, and whose life is secured by the company. Even today the

\footnotetext{
${ }^{81}$ Skilled foremen mentioned earlier.

${ }^{82}$ Why could Japan build a recruitment system based on school leavers? Dore (1973) explains it by the high literacy from early time, and the fact that schools had disciplined the new generation to timekeeping and provided reports to recruiting companies. Also, we must note that there was shortage only in skilled workers and young girls willing to enter textile factories, but never of boy school leavers.
} 
news reflects this security: in 2009 for instance, the Health, Labor and Welfare Ministry announced that in six months from October 2008, 184,347 jobs were cut in Japan. Of the people concerned, about 12,000 were regular workers, the rest being mostly temporary workers (Fukue, 2009).

Women, foreigners, minority groups, and those who have failed in education or in their first job are usually excluded from these privileges and can be employed as "irregulars": temporary and seasonal workers, part-timers, or contract workers who are only indirect employees of the firm (Hanami, 2006).

The category seems rude and discriminatory, yet some advantages and disadvantages can be found at each side. Higher involvement brings certainly a higher level of job security and income (see Table 5), but, in common wisdom, these regular workers (salarymen) are often considered to be workaholics, they have less freedom and weaker exit opportunities from working conditions which they may dislike.

Table 5: The wage gap between full-time and part-time workers (without bonuses)

\begin{tabular}{|l|l|l|}
\hline & 2001 & 2010 \\
\hline $\begin{array}{l}\text { Hourly income, male part-timers } \\
\text { (full-time male }=100 \% \text { ) }\end{array}$ & $51.5 \%$ & $55.2 \%$ \\
\hline $\begin{array}{l}\text { Hourly income, female part-timers } \\
\text { (full-time female }=100 \% \text { ) }\end{array}$ & $44.6 \%$ & $50,0 \%$ \\
\hline
\end{tabular}

Source: Ministry of Health, Labor and Welfare

The real issue at stake between regulars versus irregulars is not, however, related to wages: status in Japan has been traditionally more important than money. According to Confucian values, status can be provided by education and, particularly until 1868, status has been hereditary (Cole 1971, Bellah 1957, Rozman 2002). According to the caste system of the Tokugawa, warriors are of higher status than peasants, followed by artisans and merchants. ${ }^{83}$ But even within the caste of farmers, in villages, two important groups emerged during the Edo period: wealthier farmers owning land (honbyakushoo), who were the "official members" of the village, and poor ones without land (mizunomi). This difference was emphasized during famines or scarcity of resources (Nakane, 1990).

\footnotetext{
${ }^{83}$ The second half of the Edo period became increasingly tense, because merchants gained more than the castes above them, they were obliged to lend to the landlord or the samurai who sometimes did not return the money.
} 
After the land reform of the Meiji government and with the transformed status quo in farming, the new owners needed some permanent workers and many irregulars for seasonal jobs. After industrialization and the beginning of lifetime employment, regular contracts were institutionalized in factories, but employers have needed irregulars as well, for jobs which could not have been foreseen one year earlier (Dore, 1973). Naturally, with the growing uncertainty of business prospects, the proportion of irregulars increased. The Ministry of Health, Labor and Welfare disclosed in 2009 that about $34 \%$ of non-regular workers existed in the entire labor market, compared to less than $17 \%$ in 1984 .

Yet the main development is not only or not simply the increasing proportion of non-regular workers in society. Beyond the growing numbers, there is also a wider variety of jobs available for temporary workers, even white-collar jobs (ippanshoku), specific technical positions or engineering jobs in electronics (Keizer, 2010).

\section{3) Long-term employment}

The fact that Japanese organizations tend to selectively recruit new school graduates and retain them until their retirement age is mostly termed "lifetime employment" or "permanent employment" (shushin koyo). Abegglen (2006), who first described it in the West and originally called it "lifelong commitment", deplored these former terms, which too often lead to misunderstanding. To avoid this debate and focus on what it means in practice, we will call this "pillar" of the Japanese system "long-term employment". Abegglen confirmed its validity even for today's society: "Then [in 1958] and no less now, this is the measure of the degree to which the kaisha as social organization is meeting its obligations to its members" (2006: 10). ${ }^{84}$

This system has positive consequences, such as the greater motivation and loyalty of workers, or the social benefits of higher employment, but at the same time disadvantages are apparent as well. For instance, Abegglen (1973) lists weaker labor mobility, the difficulty of firing incompetent workers, the dependence on growth, the high fixed labor cost, the challenge of eventually merging two different firms, and the management of international units and operations.

\footnotetext{
${ }^{84}$ The debate whether the LTE still exists or not is complex and biased: see Saito \& Vaszkun (2010).
} 
Beyond the obvious advantages, there are historical reasons as well, explaining why companies tend to avoid dismissals today-although this has not always been the case.

We know that in pre-industrial Japan, craftspeople and artisans moved freely from one job to another without necessarily staying in the same company for long periods. During those years (from the end of 1880s to the 1890s), recruiting even general factory staff became increasingly difficult: employers were trying to substitute better wages and decent work conditions with a paternalistic ideology (Hirschmeier \& Yui, 1981).

Later, during the Meiji industrialization, a considerably high proportion of factory workers moved from factory to factory. Nakane (1972) provided a simple reason for that: in these early times some specific occupations were in high demand. Evidently, this frequent changing of workplace caused great uncertainty and inconvenience for employers. They tried to retain a constant labor force and keep workers for their entire working lives in the same company instead of relying on short-term contracts. The forming of recruitment methods (hiring young workers) therefore paved the way for the lifetime employment system.

From the 1930s up to the end of World War II, the "immobilization" of the labor force was further emphasized. "The prohibition on movement of labor between factories was bolstered by the moral argument that it was through concentrated service to his own factory that a worker could best serve the nation. The factory was to be considered as a household or family, in which the employer would and should care for both the material and mental life of his worker and the latter's family." (Nakane, 1972: 17)

The post-war era changed many old ways in Japan, but during its early years, dismissal may well have been equivalent to being condemned to starvation (Gordon, 1998). Supported strongly by the union movement, lifetime employment remained as a major employment form in firms. Familialism and emphasis on welfare services were also fully developed under circumstances of the war. They were later retained as institutional patterns in the post-war era; encouraged by union activity. Then, the bursting of the economic bubble skewed this picture once more. Due to the restructurings in suffering companies, dismissals became more common in society, and changes in employment lost the stigma which they represented several years ago (Schulz 2006, Ahmadjian \& Robinson 2001).

Despite the certitude of Abegglen, cited above, on the continuity of the long-term employment today, recent evaluations of the LTE practices are highly ambiguous in 
Japan. Hanaoka (1997a) examined a Ministry of Labor White Paper from 1993 on high school leavers, junior college and university graduates, and claimed that by the third year of their employment, between 25 and $50 \%$ of the fresh recruits leave the company. He admitted however, that the long service of employees is still a basic policy in Japan and although it exists in Europe and America as well, overall staff turnover is lower in Japan. Inagami and Whittaker (2005) found that the average tenure (number of years spent in the same firm) in Japan showed a steady increase from the 1980s to the 2000s. For men, the average tenure increased from 10.8 in 1980 to 13.3 in $2000 .{ }^{85}$

Long-term employment is also supported by the law: in June 2003 an amendment was made to the Labor Standards Law guaranteeing greater protection to workers, which may have the adverse effect of hindering recruitment (Hanami, 2006). Another amendment introduced in 2003 was intended to make the employment system more flexible, and extended the maximum period of short-term employment contracts, or the use of dispatched workers. According to the Employment Contracts Law, still in force today, firms should not discard employees without "objectively reasonable grounds." ${ }^{86}$ It would thus appear that the lifetime or secure employment policies are being continued, not in the rigid traditional framework, but within a flexible, new form appropriate to the circumstances of individual companies.

\section{4) Formal induction with the chairman: creating a family}

There is a flourishing literature describing Japanese firms mainly as communities. Some of its main proponents are Tsuda, Hazama, Abegglen, or Cole. As explained by Abegglen (1960): "the factory, or company, is relatively undifferentiated from other types of groups in the society" (139). The idea is also called the "community firm" concept and the stakeholder orientation is definitely related to it. One symbolic act in which this concept is manifest is that after the recruitment of a new cohort of young graduates, on April 1 (their first work day), the president of the company holds a greeting ceremony, and speaks as a father would to his sons. ${ }^{87}$ This important moment may recall the past when the heads of $i e$ often adopted sons, so that the family business

\footnotetext{
${ }^{85}$ According to OECD data.

${ }^{86}$ Employment Contracts Law: no abuse of right (2007). Article 16 stipulates that "[a] dismissal shall, where the dismissal lacks objectively reasonable grounds and is not considered to be appropriate in general societal terms, be treated as a misuse of that right and invalid."

${ }^{87}$ This practice, still in use, is often reported among the news in Japan on April 1, when the speeches are held all over Japan in front of the large audiences of the young freshmen.
} 
could continue (Hirschmeier \& Yui, 1981). The same kind of communication was used in the early textile factories where workers were typically young girls under the rule of the owner, playing the role of a second father. Inagami \& Whittaker (2005) emphasized however that in terms of the community concept, and in spite of the old origins, interwar and postwar companies were not the same. There was an important shift from "managerial familialism" to "managerial welfarism" or "welfare corporatism". ${ }^{88}$ With the growing size of the firms, the hitherto emphasized family concept could no longer be sustained (workers did not know each other) and transformed into paternalistic care from management, still present in today's society. As Inagami and Whittaker (2005) put it: "Many of the features of community companies depend on long-term employment. This has come under strain, but has not collapsed. It is not surprising, then, that community firms persist." (109)

In that sense, the company in Japan "form[s] the basis for people's family and social life, provides an environment in which they can develop, make friends, get married, raise children, and then pass away, an environment in which they experience the joys and the sadness of this life." (Maruyama, 1997: 111) ${ }^{89}$

\section{5) Cohort training "on-the-job"}

Japanese companies are traditionally responsible for developing their employees' skills and cultivating their careers. Once social and group behavior is acquired at home and at school with some academic knowledge, the young Japanese will be recruited while still at school, and start on the same day without specific jobs targeted for the new recruits (Dore, 1973). Thus, a collective need for induction creates the first opportunities for training, in which fresh members typically learn how to behave in their new environment according to the accepted professional manner. What they need for their daily work will be learned by doing and by dealing with daily events or problems. If necessary, this on-the-job training (OJT) will be combined with off-the-job education, such us postgraduate programs, training and so forth, which will be initiated by the company (Fujimura, 2006).

Based on the logic of routine processes of transaction cost theory, Fruin (1992) claims that large Japanese corporations benefit from "economies of learning": due to the

\footnotetext{
${ }^{88}$ As labeled by Hazama and Dore, respectively.

${ }^{89}$ One of the reasons is probably that alternative opportunities for forming relationships and doing social activities are rare in Japan. So, as in many other cases, the companies assume this role as well.
} 
low turnover in personnel, what employees learn on the job is likely to stay in the company. This makes production cheaper. Economies of scale can be also achieved in companies which can recruit greater numbers at the same time: the practice of cohort training makes the job of the HR department easier.

However, one may think that grouped general skills training is not particularly appealing for the individual employees. In order to examine and develop vocational education in Japan, a survey was carried out by the Fuji Research Institute in 2000 on behalf of the Ministry of Health, Labor and Welfare. After the analysis of responses from 1099 principally large companies (managers) and 3103 employees, they concluded that companies still see vocational training as their own responsibility although they estimate that this will change in the future (see Figure 17). As for the employees, they tend to claim that training is their own responsibility, but despite that they wish to continue to receive general skills training from the company instead of more personalized individual solutions (Figure 18).

Figure 17: Survey results of who has been/should be responsible for vocational training

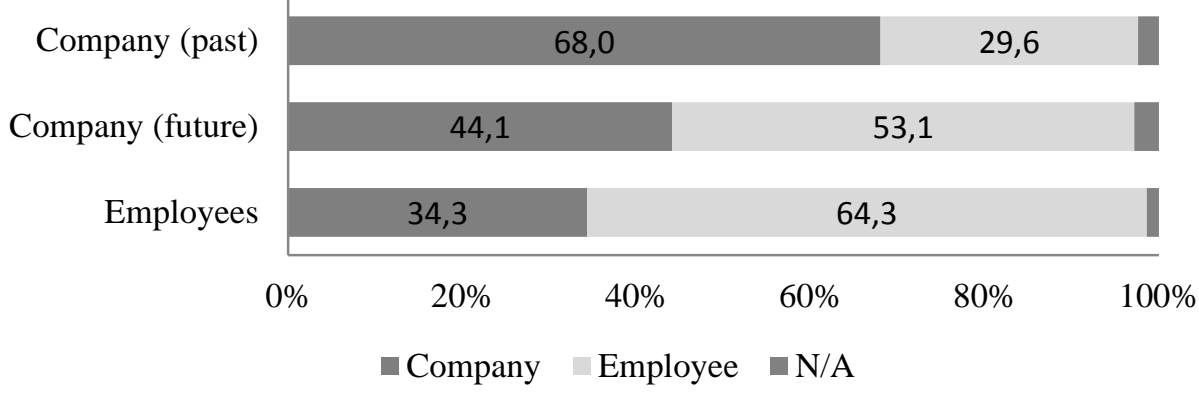

Source: Fujimura (2006: 110).

Figure 18: Opinions on employee training policies: what sort of training should be provided

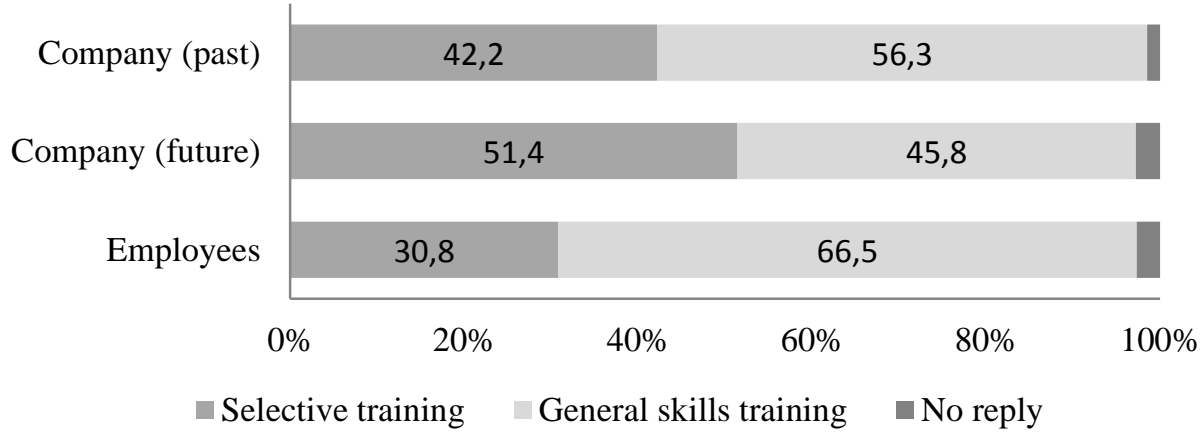


Source: Fujimura (2006: 111).

\section{6) Slow promotion}

Another feature of Japanese Management is a relatively slow and dual promotion system: Japanese employees can classically be promoted in "status", linked rather to seniority, and in "position", based on the results of past evaluations and on the vacancies in the level above (Pucik \& Hatvany, 1982). The basic principle is to provide a promotion scale long and high enough to reward the employees all through their corporate life. As they (regulars) tend to stay at the same company or group from the beginning of their career up to retirement age, the period to cover can vary from 20 to 40 years. Needless to say, the classical pyramidal structure has to be complemented by other means and the pace of moves must also slow down, compared to the Western model where workers spend significantly less time at the same firm. Due to the slow promotion schemes, in 2004, a newly appointed CEO's average age was 58.4 years in Japan versus 49.1 years in the US (Olcott, 2009).

In case of blocked or missing opportunities for upper-level positions, a promotion in status would still provide an employee with more respect and money, and a talented young person can have more responsibility even if he does not yet fulfill the seniority requirements for promotion (Pucik \& Hatvany, 1982). Abegglen (2006) emphasized that the Japanese practice of slow, seniority-based promotion was never pure either: being lifted to the top was not automatic, and younger persons were also able to exercise some authority without holding high ranks. Another advantage is that promotion by seniority provides every worker with the same objective criteria, is perceived as more equitable, and the usual tension between "winners" and "losers" in Western-type firms can be greatly reduced. This often leads to misunderstanding, as observers may think that the actual performance does not count in promotion decisions. But the slower pace simply lengthens competition for positions, maintaining the motivation of the ones who finally will miss most of the promotion chances. On the other hand however, talented workers may express dissatisfaction by leaving the firm, since globalization and liberalization have brought more foreign employers in Japan and they offer an increasing number of jobs with Western-type career paths. 
We can find the historical roots of slow promotion as far back as feudalism: during the Tokugawa era, the merchant houses also recruited employees at a very young age and their contracts were long-term. Consequently, they had already come to use a long-term, gradual grading system for promotions (dry goods stores had at least 16 different ranks). The hierarchy was based strictly on seniority rather than performance, and status was marked by a ritual of passage for each promotion, different hair style or clothing, or permission to smoke (Sakudo 1990, Dore 1973, Nakane 1972). However, Sakudo (1990) makes it clear that seniority prevailed as basis for promotions in the Mitsui house until the 1720s. From the mid-1730s, seniority helped to reach the rank "group foreman" only, and from then on (up to managerial level), selection was based mainly on performance. Step by step, these early personnel practices (such as those of Mitsui) were widely adopted by the mid-Tokugawa period in both the primary cities and in provincial castle towns. In addition, Mitsui was the first merchant house to build a holding company (zaibatsu) after the Meiji Restoration, a circumstance which promoted the continuation of their management style. Then, the possibilities of long-term promotion were further enhanced in the 1920s and 1930s by the bureaucratization of manufacturing firms, and the proliferation of sections and upcoming layers of middlemanagers offered finer gradations in rank (Nakane, 1972).

\section{7) Rotation}

The aspect of rotation has multiple facets in Japan. One facet which most sources describe is that the Japanese employees often have to change service or department, and each year or each two or three years, from April 1 they are assigned to a different workgroup. Hanaoka (1997a) even claims that rotation can be carried out about once or twice each year, or even more often if necessary. This practice has both advantages and disadvantages. Regular rotation is performed in Western countries as well, especially in the talent programs of global companies. Young high potentials are rotated on a regular basis over several years so as to occupy a managerial position at the end of the program. Rotation has proved to be a good tool for developing managers in Japanese firms as well, providing the employees a high level of company network. We have also seen that the Japanese tend to work in functional structures which typically lack horizontal communication channels. Rotation can make the horizontal flow of information easier within and between departments. Rotation can serve as an adjustment method for emp- 
loyee levels, because it also means the transferring of an appropriate member of staff to a vacant position that has arisen in another department or service (Hanaoka, 1997a).

Another facet of rotation, even within a given workgroup in the factory or the office, is that weekly and monthly work schedules are modified according to daily needs and tasks are mostly assigned on a daily basis. It is expected that almost every employee can perform almost every kind of operation within the group, which also reinforces the importance of in-company education and on-the-job training (Fruin, 1992). Fruin describes this phenomenon as "specialization in work content but generalization in work skills" (173). In 2001 Tsutsui observed employees in the National Diet Library in Tokyo who changed post with each other every 30 minutes in a way to ease the monotony of their standardized jobs. So, during a working day, each librarian was rotated through all of the jobs in the circulation department. In 2010, the author of this thesis made a similar observation in the main library of Waseda University. Thus, it may be that the first rotation systems were created during the industrialization of Japan to counterbalance the negative effects of standardization. We have seen similar answers, such as job enrichment, in the US as well. Recently, according to Olcott (2009), an increasing number of firms are adopting a double- or multi-track career system where employees may opt to become a specialist (enforced by mid-career hires) or to stay in the traditional system.

\section{8) Tenure-based compensation or "Seniority pay"}

It is often not obvious why the Japanese today stay so long with the same company. One reason may be the lack of wide-ranging external opportunities. Abegglen emphasized a sort of moral sense of loyalty but others such as Cole or Drucker have rejected this view (Drucker, 1971).

Seniority pay (nenko joretsu) refers to the practice of basing internal promotion and pay decisions on a set of variables including the employees' tenure (seniority), age, and familial circumstances such as marriage or childrearing. As is the case with longterm employment, this practice and the differences between Japanese and American data are most apparent in the largest firms. Some authors found that this Japanese distinctiveness exists only for blue-collar workers (Koike, 1983). Curiously, Debroux (2006) notes that companies were from the outset unhappy with this practice, "which they felt provided too few incentives for efficiency" (122). 
In Japan, regular salaries are typically composed of three parts: the basic wage, the allowances (dependent on age, tenure, family situation or other variables set by each firm), and the bonuses. The basic wage usually rises every spring after the negotiations between the management and the union. These negotiations are the main task for which the unions exist, and they result in the pay increasing somewhat every year (we will return to unions later).

The allowances basically follow the material needs of an average Japanese male: he will get less while still young, then more once married and starting his household, and even more when the children arrive because their education represents a high cost in Japan. The allowances are at their highest at about age 50, and then start decreasing until retirement (Olcott, 2009).

Japanese workers get two bonuses per year, one for the summer and one for the winter. In Western practice, bonuses are usually related to performance, but not so in Japan: they are taken as quasi-granted regardless of the economic situation of the firm, ${ }^{90}$ and can be equivalent to a few months' worth of salary. This practice also has important historical roots (see below) but appears alive even today, in harsher economic circumstances. According to recent government data, the summer bonus in 2011 averaged $¥ 364,252$. This is $0.8 \%$ less than in 2010 , showing the first decline in two years, but among companies (of all types) employing 30 or more, summer bonuses rose by $0.5 \%$ to $¥ 418,875$. For reference, the overall cash wage in September amounted on average to $¥ 267,948$ at firms with five or more employees (Kyodo, 2011).

Back in the Edo period, social reputation was not defined by material wealth. The upper class (the samurai) earned rigid stipends: they had strict categories according to their ranks and their pay basically did not change over 250 years. Since the samurai stipends were not seen as wages, about 5 percent of the population might have been employed in a wage system in Tokugawa society (Dore, 1973). For these employed workers (domestic servants, employees in merchant houses, etc.), the work environment was paternalistic, the contractual nature was blurred by gift-giving, feasting, "voluntary service" etc. and pay increased with seniority.

Due to the post-war industrial relations (from the late-40s), the wage system moved even further away from market principles (Dore, 1973). Production levels and

\footnotetext{
${ }^{90}$ On granted bonuses, Olcott (2009) cites a Japanese expert, Koshiro, stating that "Toyota maintained a payment of 6.1 times the basic monthly salary every year between 1967 and 1986 despite widely fluctuating business conditions and results, including two oil shocks." (145)
} 
earnings plummeted, and the Japanese corporations had to take responsibility for the survival of employees and their families. In order to help these families to live, wages had to be granted according to the number of mouths to feed, instead of according to performance (Gordon 1998, Dore 1973). The revolts of the 1950s also put pressure on firms to recognize their social responsibility, and post-war recovery from time to time allowed them to pay bonuses.

At the same time, wages themselves never galloped away in Japan. When introducing Taylorism, the concept of the "ever-increasing pie" ${ }^{91}$ received much less rhetorical attention than the appeal for cooperation between labor and management (Tsutsui, 2001). Needless to say, low wages in every category were of central interest, because cheap labor was widely assumed to be the root of competitiveness. Given the egalitarianism of Japanese society (and the lack of an external market), it is not surprising that relatively low compensation went to the executives as well, and made the management/worker wage gap considerably smaller than in the US, even in the 2000s (Pucik 1984, Abegglen 2006).

From the 1970s, the weight of the seniority elements in Japanese wages was reduced by the introduction of work-related factors such as the skill-grading system. But welfare corporatism by then had become so strongly embedded socially and economically that it could not be easily reduced or challenged. "Consideration of age, family composition and tenure were not completely removed from the basic wage, and allowances linked to family, housing, transportation and so on continued to be paid" (Debroux, 2006: 123).

After the shock of the early 1990s, the performance-based content of wages was raised further: a growing number of companies are shifting (partly or completely) away from traditional wage systems and place emphasis only on performance elements. There is an obvious logic: today young people are not only less patient but there are also fewer of them and they are therefore more valuable. Keizer (2010) stated that performancerelated pay (seikashugi) was introduced by 2005 in the majority of Japanese companies. But contrary to his expectation, he also concluded that firms only added performance to their existing evaluation criteria and it has therefore not replaced the old elements, only been grafted onto them. Also, Abegglen stated in 2006 that the age element was still an important part and a determinant at least for the range of salary. He also claimed that seniority as a basis for calculation was stronger in the case of general employees than

\footnotetext{
${ }^{91}$ The growing pie refers to the higher profit for managers allowing higher wages for the workers.
} 
for managers. In addition, Inagami and Whittaker (2005) claimed that even if both firms and employees are in favor of a greater emphasis on ability and performance, this may not drastically alter the age-wage structure anyway, at least until the age of 50-54. Pay rises are however becoming more conditional.

Thus, trends to shift towards purely performance-related schemes are strong, but there are still social factors hindering their full implementation, such as security and inequality issues for instance (Debroux, 2006). The social safety net in Japan remains significantly weaker than in Europe and therefore, losing one's job can lead to a drastic decline in living standards which spreads fear and resistance in many employees. The external labor market is also less developed than in Western countries, and moving to another company remains risky, which encourages employees to stay put even without promotion or wage increase. In addition, wage inequalities resulting from performance pay are unusual for the Japanese, because even the skill-grading system provided a common base for all employees. Increasing distinction by job categories makes internal comparisons more difficult whereas external benchmarks from the labor market are still absent. Also seen as a way of salary reduction, it has failed many times to motivate employees, and companies have started to reject it. For Olcott (2009), after several years of experience, the academic community and the media still reflect the view that pay based only on results has an adverse effect on traditional Japanese values such as fairness and equality, and undermines teamwork and knowledge transfer. Therefore, more time is still needed to accept compromises for each party at the table and fine-tune the new pay systems.

\section{9) Company unions}

Japanese unions are organized on a per-enterprise basis (kigyo kumiai), concentrated in the largest firms, and formed into loose federations at higher levels (Kawanishi 1992, Gordon 1998, Abegglen 2006). They include both blue- and white-collar regular employees, as well as first and second-line supervisors. In fact, workers are identified by their workplace (company) rather than by skill category as in the US for instance (Abegglen, 2006). The essence of the differences between the Japanese and the "Western" model ${ }^{92}$ can be formulated as follows.

\footnotetext{
${ }^{92}$ We speak here about an assumed Western model although Western national practices differ greatly in some details.
} 
The main function of unions in the West is typically to protect the safety and well-being of workers, which costs extra money to the owners. At the same time, management seeks to reduce costs and maximize profits, which leads to an incentive of "saving" on human cost. The conflict between these goals seems to be resolved in the Japanese model, where employee interests are stronger than shareholder interests in large firms, and therefore a so-called harmony can be created. Basically, conflict between labor and management becomes something to be avoided, nothing can be accomplished without accord, and the potential negative consequences of a dispute would harm the firm and every party. When managers push for a rise of $2 \%$ rather than $4 \%$ in wage bargaining with unions, it goes for their own salary as well (Dore, 2000).

According to Lincoln and McBride (1987), these arrangements have provoked much speculation that "Japanese unions are highly dependent upon and easily co-opted by the company" (294). Unions are criticized for tending to avoid strong confrontations in the name of their members' interests, and therefore cannot leverage the power of national membership. But on the other hand, they do not really need this leverage in Japan. Work conditions are not bad anyway and, despite the constraints mentioned above, Japanese unions bargain hard on wage and benefit issues at the beginning of every business year, which has become known as the annual "Spring offensives" (Lincoln \& McBride 1987, Gordon 1998, Olcott 2009). We saw earlier with the rising wages even in a time of economic downturn that union militancy in these wage issues has been an important force in the Japanese economy.

In terms of business history, enterprise unionism is one of the relatively recent features of Japanese management. The simple reason is that in the name of corporate paternalism and national patriotism, unions were illegal for most of the pre-war period. During the Occupation, American reforms made unions legal once more, right up until Dodge and the Korean War supplies needed a more stable industrial environment. Indeed, the strong and nation-wide strikes in the late 1940s, "a period of great social unrest," seriously hindered the speedy reindustrialization of the country (Kawanishi, 1992: 73). The solution was partly co-optation, partly oppression, supported by the Occupation and, by the mid-1950s, "unions challenged the legitimacy of a managerial hierarchy less and less" (Fruin, 1992: 170).

The tradition of these unions being organized on a company basis also has a historical reason. We have seen earlier that larger firms in Japan had better means for compensation which made them more attractive on the labor market. The difference was 
naturally reflected in the wage system and, as soon as trade union organization started, enterprise unions became a logical choice: such unions could push each employer to the limit of his capacity to pay. Also, since long-term employment was already established by the late-40s, workers had no interest in the wages paid in other firms (Dore, 1973). Anglo-Saxon trade unionism, present in Britain for instance, evolved in different circumstances. As Dore explains, "British unions were created and achieved definite organizational shape at a time when they were anathema to employers; they therefore had to meet off the factory premises - often with secret society rituals. In the post-war period, when the Japanese union took shape, no employer dared question the unions' right to exist. They could organize openly on the premises. This also helped to make them workshop-based." (1973: 415)

Consequently, we can say that the Japanese management system was partly designed by unions or the needs to be in phase with the unions and the workers. Dore (2000) writes: "before the war Japanese firms were more like Anglo-Saxon firms" (33). During the early years of post-war recovery, the government could only avoid social unrest by transferring the extra labor forces (e.g. the returning soldiers) to the focused strategic industries such as iron and coal production, chemicals, etc. The most important union success was to avoid or reduce the effects of dismissal, as this would have meant starvation. In this way unions acquired some say in decision-making and long-term employment, "a policy initiated by management, has reached its perfected form through the effect of post-war unionism" (Nakane, 1972: 18).

From the 1960s, economic growth and the spring offensives (shuntō) introduced in 1955 brought workers steady wage increases and better promotion prospects. Given stable growth, "labor unions tried to focus their efforts on the negotiation of economic redistribution rather than participation in management." (Imai, 2011: 21) As a consequence, they gradually withdrew from workplace decision-making.

According to Imai (2011) the recent evolution of employment practices in Japan has been characterized by the declining importance of labor unions (see Figure 19 and Table 6) for two main reasons. One is that labor was simply marginalized in the planning and implementation of deregulatory reforms, and the other is that, in parallel with these employer-led reforms, the unions failed to establish a valid alternative. But despite the fading significance, this management characteristic still prevails in Japan. In a certain way, a continuous struggle with unions in revolt negatively affects harmony and can contribute to the losing of face for top management. Therefore, ever since 
stable ownership has been established, industrial relations have naturally been friendlier in Japan than in any other country and continue to focus on wage issues. 
Figure 19: Unionization ratio in Japan with comparative data for the 2000s (\%)

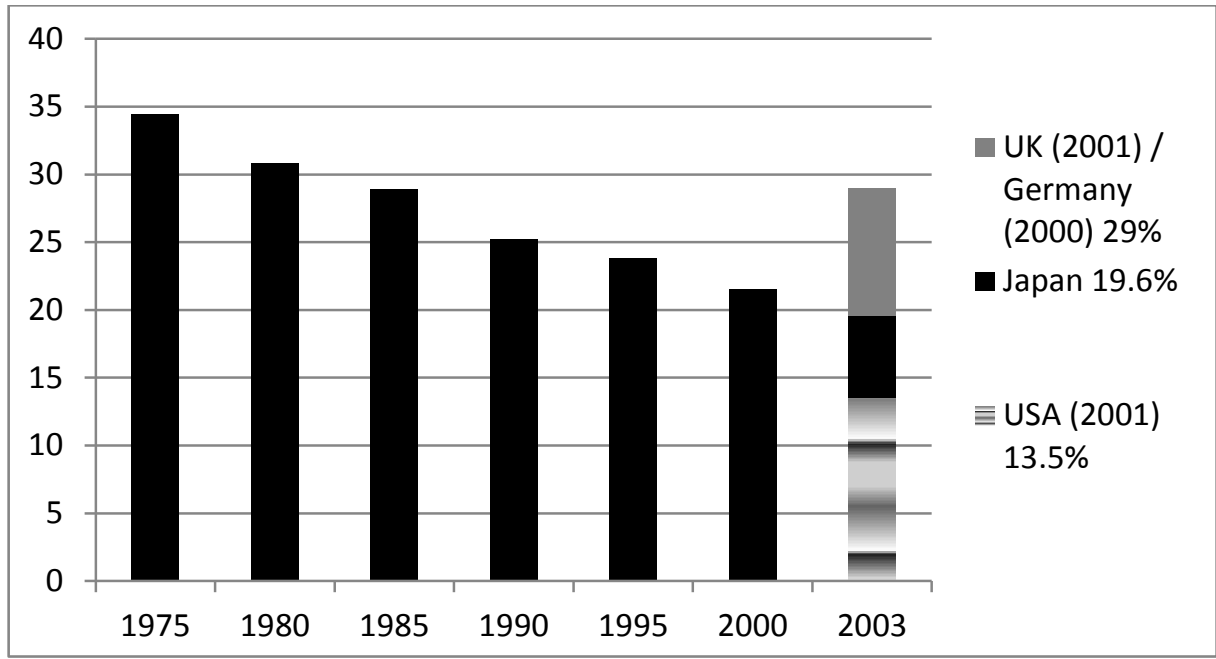

Source: Ministry of Health, Labor and Welfare; Japan Institute of Labor (International Labor Comparison Databook, 2004)

According to the Ministry of Health, Labor and Welfare, in about $7 \%$ of all labor disputes in 2009 workers demanded better work conditions, about $42 \%$ revolved around wage issues and 58\% around union or employment security.

Table 6: $\quad$ Labor Disputes in Japan (1975-2002)

\begin{tabular}{rrrr} 
& Disputes & Workers involved $(1,000)$ & Worker-days lost $(1,000)$ \\
\hline $\mathbf{1 9 7 5}$ & 7,574 & 4,614 & 8,016 \\
$\mathbf{1 9 8 5}$ & 4,230 & 1,355 & 264 \\
$\mathbf{1 9 9 5}$ & 685 & 222 & 77 \\
$\mathbf{2 0 0 0}$ & 305 & 85 & 35 \\
$\mathbf{2 0 0 5}$ & 708 & $28^{*}$ & 5.6 \\
$\mathbf{2 0 0 9}$ & 780 & $21^{*}$ & 7.5 \\
\hline
\end{tabular}

Source: Ministry of Health, Labor and Welfare (* figures indicate strikes)

\section{6) Control and performance measurement}

According to the contingency theory presented in Chapter 1, an evaluation of the contingencies of a company must include its performance. Yet performance itself needs to be defined: as we have argued earlier, the criteria for success are not necessarily the same in different countries or even firms, at different times, and for different persons. To evaluate change and the necessity of change, the study of the performance in Japanese firms seems indeed to be a key element, and once defined it will be possible to give the relative weight of reforms, success and failure. 
In the previous points, we gained an overview on basic Japanese values and country specificities. Criteria for success in Japan must reflect these values and be natural consequences of them. We will also see that good performance in the stable growth era, i.e. until the early 1990s, is necessarily different from that of today, when growth is uncertain and competition has been placed on a more open and global basis. And, finally, the person drawing a conclusion on performance makes his or her evaluation on a subjective basis: the employee of the firm may first and foremost appreciate a stable and rewarding workplace, rather than a highly profitable one which is more important for individual owners in general. A client would give a good evaluation to a company producing the best quality at a reasonable price, while suppliers usually look for long-term and trustful relations. Society in general seems to value the high sense of corporate responsibility towards the given population and the environment. With all this to take into account, is it possible to evaluate performance?

We shall argue that all aspects need a relative basis. Japan's past decades have been described as recession but in fact they rather show stagnation and slow growth: the worst annual growths vary around -1 percent (except for 2009, see Figure 20), whereas the American GDP shrank by more than 6\% per year between 1930 and 32 (Hoshi \& Kashyap, 2004).

\section{Figure 20: The Japanese real GDP growth, 1990-2010}

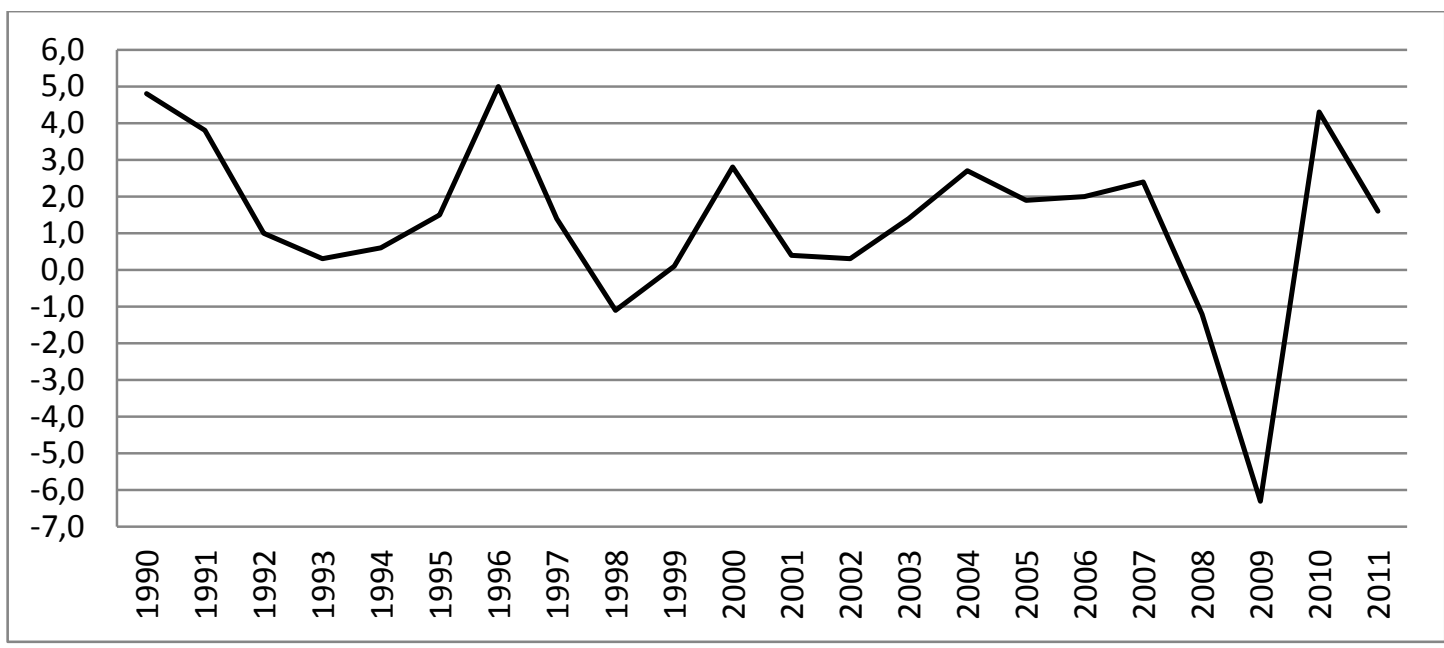

Source: Economic Report of the President 2011, OECD Economic Outlook 88 database

To sum up, performance is subjective and relative. The last triggering question concerns bad performance: even if we evaluate a result as a bad performance, would this involve a change in the system? Would other elements be affected? The contingency theory says they would. But is it really the case? 


\section{1) Behavior-based control}

In every company, ambitious workers who seek reward and recognition have to engage in activities that will make them visible by their superiors. In most Western companies, this leads them to strive for higher performance which will be evaluated during the regular work assessments. In Japanese companies however, the criteria of performance and the evaluations have a multiple focus. For blue-collars, Cole (1971) observed that the emphasis was put on (1) seriousness, (2) performance, and (3) cooperation. In the case of white-collars, cooperation became the most significant factor. As Pucik and Hatvany (1982) put it, this situation "encourages easily observable behavior, such as volunteer overtime, that appears to demonstrate willingness to exert substantial effort on behalf of the organization." (23) Olcott (2009) also confirmed that the lack of precise criteria led employees to devote their whole life to the company. Moreover, the focus of management in Japan tends to be on encouraging the average employee, rather than developing high-performer "stars".

As a consequence, Japanese employees would work on an assigned mission regardless of the spent time and effort, in order to achieve a perfect result by the due deadline, whereas in American firms the "how" is rarely controlled and incomplete details can be tolerated in regards to the constraints in time and other resources (Umezu, 2009). On the other hand, genuine mistakes are tolerated in the Japanese evaluation process as well which, at least theoretically, minimizes the aversion to risk and facilitates creativity (Pucik \& Hatvany, 1982). Since each member of a group shares the consequences of their peers' efforts, the emphasis on group performance tends to increase both productivity and the level of "mutual aid and tutoring" (23).

\section{2) Multi-monitoring group effect}

We have already mentioned how the group has been an important element in the evaluation process since the rise of modern factories, in contrast to American Taylorism for instance. As Dore (1973) also noted, performance evaluation is often a rather complex process: he observed annual assessments in April for promotion, monthly ones for merit premium, and twice yearly for bonus payments in June and December. But for all and even for the piecework incentives, these assessments have usually not been individual but group-based. Consequently, the Japanese team mates are tied to each 
other by many invisible links: they work in teams, they are, for example, supposed to be able to perform each other's job in case of illness, and group performance is also one of the evaluation criteria. Naturally, workers are used to watching each other (referred to as "multi-monitoring”). As Pucik and Hatvany (1982) explained: "peer pressure on an individual to contribute sufficiently to group performance becomes an important mechanism of performance control" (23). Jacoby (2007) sees multi-monitoring as a complementary means of corporate governance to control directors by the watchful bank, employees, and management.

This pressure is sometimes seen as negative but the advantages of the system are clear: supervisors need less direct control on people as this is effected by the efforts of co-workers; the system is cheaper and more efficient in combating free-riding; interdependences bind people together which (along with the whole seniority system) makes undesired resignation more difficult and rare. At the same time, mutual trust becomes fragile and the Japanese tend to hide themselves behind a social mask called tatemae.

Group control has deep roots in Japan so it is no surprise it has become the accepted practice in modern corporations as well. As early as the Edo period, villages used to have common responsibility on tax issues. The village's portion to be paid was split by the village elder to individuals (Sato, 1990). The same author adds that in fact, the basic units of villages were not individuals or even households, but small groups of five households. These gonin-gumi (five-men groups), introduced under the Shogunate, formed a means of keeping control of the peasantry: group members had an obligation to make up each other's tax shortfalls, which encouraged them to cooperate with one another in farm work. In addition, they prevented criminal activity by policing each other, and they served each other as guarantors in civil suits and in contractual agreements. "In other words, the smallest organization in the village served as the upholder of the village's system of joint responsibility." (50) So the self-policing or multi-monitoring system has been a major development from the mid-Tokugawa: in the early decades of their rule, control was ensured by force.

\section{3) Decisions are joint responsibility}

According to Iwata or Maruyama (1997), most Japanese do not have a clearly founded awareness of personal responsibility, which means that the extent of an individual's responsibility is not obvious. We stated earlier that Japanese workers tend to be rotated 
not only within the organization but within their own group as well and sometimes on a daily basis, which makes the responsibility over a period of one week, month or year relatively obscure. It means that in Japan individual mistakes (which are common with regular rotation practices) are often corrected by the group. Abegglen (1960) adds that since decisions are worked out by groups, it becomes a hard task to fix individual responsibility for decisions or errors anyway.

Authors such as Lincoln or Pudelko state that Japanese managers also tend to accept formal responsibility for bad decisions taken by subordinates whereas Pudelko (2006) claims that in the US subordinates are often blamed for wrong decisions taken at the top. For Dore (1973), the whole decision-making system of ringi is merely about dealing with responsibility: the decision is known in advance but the organization needs people to take responsibility in a formal way. Yet this responsibility has a different meaning from that in the West: the formal guarantor will "take responsibility", but normally he will not be "held responsible" (228).

This common sense of responsibility, as other features of Japanese Management, can have both positive and negative facets, according to each situation. Keys and Miller highlight the positive impact on performance:

"The presence of a hard-working, orderly workforce can be related to the orientation to collective responsibility of the Japanese. When coupled with a high degree of goal congruence between employer and employee, the emergence of cohesive, productive, disciplined work groups is not surprising. The impressive performance of the Japanese work force, particularly their high productivity and exceptional quality levels, reasonably derives from those underlying conditions that support vigorous implementation of high output standards and superior quality control systems." (1984: 351)

At the same time, expert tend to claim that unclear responsibilities are rather harmful for performance for obvious reasons of free-riding, which tends to be neglected in Japan due to its rarity.

The historical origins of group responsibility such as the common taxes (see above) are to be found in the Edo period. Decentralized decision-making ${ }^{93}$ gains additional importance in Japan probably due to the nature of top management as well. In

\footnotetext{
${ }^{93}$ For instance, workers on the shop floor are authorized to stop the assembly line when they judge it is necessary for corrective actions (Pudelko, 2006).
} 
traditional Japanese companies, top management serve mainly representative functions, and the real decision-making power lies with middle managers and below. For Pudelko (2006), this situation is changing and executives have recently shown a tendency to become more proactive.

\section{4) Good performance means increasing market share and harmony}

Observers such as Pucik and Hatvany (1982) noted as early as during the high-growth era of Japan that Nippon firms achieved lower profitability compared to American ones, and they focused mainly on maintaining a general level of workplace harmony (i.e. consensus), and increasing the market share, in order to fully use their production capacity and keep their staff in employment. One may think that this is simply a natural consequence of their stakeholder-orientation and the lack of shareholder pressure on short-term goals (Dore, 2000). Or, as explained by Pucik and Hatvany (1982): “the Japanese firms' desire to maintain stable employment, combined with a heavy dependence on debt financing, increases the "real" fixed costs of production. It follows that in times of business retrenchments, it is more advantageous to slash prices and keep output high than to follow the strategy typical of Western firms which attempt to protect margins by trimming output and consequently employment." (36)

Abegglen (2006) explains the same phenomenon with the post-war history of Japanese industry: under rapid growth, the eventual failure to match competitors' growth rates often led to a brutal loss of market share in a short time (markets doubling each year). Therefore, growing companies simply had to double their manufacturing capacity each year to keep the rhythm, which turned the managers' attention exclusively to growth. The same argument rules out raising profit by setting higher prices as this would have jeopardized growth. Reasons why the shareholders' interest could be traditionally considered with lower priority in Japan have already been dealt with.

Another aspect of the weaker profitability is usually explained by the group performance perspective of the keiretsu groupings, lowering the performance of the group's best performers. Since the 1960s, Japanese companies affiliated with the largest keiretsu groupings realized a $1.1-2.7 \%$ lower rate of average profit than comparable independent firms (Fruin, 1992). But on the other hand, it is also proven that the grouped large companies pay higher and more stable average wages than independent ones do, and they also enjoy lower interest rates on their loans. Jacoby (2007) asserted 
that in Japan, a director's pay rises also in response to job preservation efforts, not only with good performance when employee's bonuses increase. Group membership is also said to be beneficial for lowering transaction costs associated with inter-firm relations due to reduced monitoring, especially in uncertain market conditions (Fruin, 1992). Some explain the lower profit stating that the value of other group members' financial, commercial or other services will be internalized within a given firm's performance (Sheard, 1986). This explanation is built on the idea of firms cross-subsidizing each other and suggests that high profit is sacrificed for group-level stability.

Using market share as a performance indicator has the advantage of being clear and understandable to all (Pucik \& Hatvany, 1982). In a stable growth period, it leads to general satisfaction because market shares do indeed increase. However, aiming for the same growth during stagnation or recession easily becomes unrealistic and frustrating. Therefore, since the 1990s, there has been a natural tendency in Japanese companies to change their perspective and strive for profitability, such as return on equity or return on investment, rather than simply seeking harmony and growth. Abegglen (2006) argued that between 1995 and 2004, the focus of management shifted from market share to cash-flow, especially in order to pay back debts.

\section{7) Quo vadis Japanese management?}

Since the 1990s, academic and business literature has been claiming with increasing intensity that the requirements of business had altered and change was needed in Japan (Dore 2000, Inagami \& Whittaker 2005, Olcott 2009). Newspapers such as the Financial Times or the Wall Street Journal found several causes for praise, stating that the Japanese were "finally" abandoning their irrational habits: some firms refused to give financial help to banks from the same group, abandoned long-serving suppliers in favor of cheaper ones, or declared an end to long-term employment practices (Dore, 2000). However, due to the absence of an internal sense of crisis mentioned previously, the real state of the economy is rather difficult to evaluate, and therefore, the reforms and their effects could also be interpreted in different ways. To the present day, there is no common agreement on how far Japan went with changes compared to the 90s but the Japanese move for deregulation (as in the US with the GC paradigm) has obviously started. 
Observers of the new trends in Japan also note the challenge of an ageing society (bringing changes in demand, and a decreasing labor force), the need for more creative work, the move towards a more balanced economy (less dependence on exports), public support for the traditional HR practices, and a still strong role of the government, for instance in promoting egalitarianism (Blomström et al. 2001, Inagami \& Whittaker 2005, Abegglen 2006, Aoki et al. 2007). This latter is indeed highlighted in several sources as the main reason for Japan's rigidity (Carpenter 2008, Miyamoto 1995). The high growth era is definitely over. Should Japan adapt and change faster? This is a difficult question to answer, especially since the performance of the system is not obviously bad, as we saw earlier. We have overviewed a historical time horizon in order to better understand management system in Japan. Framing this experience with our theoretical model on change, designed in Chapter I, will help us to create a link between the management system and its social context. Looking at the relationship between management and society will later guide us towards a survey study: the final step to understand change in management.

\section{1) The absence of radical change}

We concluded in Chapter 3 that managerial revolutions have been rare phenomena in Japan. In the case of the few radical transformation, the Japanese have been able to rely on successful external examples which they adopted and polished to perfection. The challenge since the 1990s in Japan has been that there are no clear driving forces as in the previous cases. In 1991, with stock and real estate prices sharply diminished, Japan's economy was still going well-according to official declarations. The minister of state for the Economic Planning Agency wrote in August 1991 on the first page of the 1990-1991 Economic Survey of Japan: “The world economy in FY 1990 was hit by major upheavals, [...] some industrial countries such as the United States entered the economic recession. The Japanese economy, regardless of the above tough conditions, has still been expanding for long period although economic expansion is slowing down."

The mid-90s brought some common sense of crisis but the major part of Japanese population still considered that traditional structures of business continue to fulfill their roles. Indeed, the question of whether or not this structure needs radical change seems not to have been settled. Also, there is no clear (geopolitical) dependence. 
Until the end of the 1990s, the American model seemed to be clearly dominant with healthy indicators while Japan was still suffering the deep recession of the bubble-burst. However, the corporate scandals of Enron, WorldCom and similar cases gave sharp arguments to those defending the Japanese system and the recent global crisis has caused even more confusion in benchmarks and best practices. Therefore, there is no clear model today which could be easily copied in the case of economic transformation, nor are there any powerful agents to form a cross-national network and drive change in a specific direction. It is therefore understandable that old business practices continue to evolve in a rather incremental way. Haghirian (2010) makes it clear in her foreword:

"The concept of change differs greatly between Japan and the West. Change from a Western perspective is mostly radical; things really have to be very different from previous conditions. In Japan, however, the principle of kaizen (continuous change) dominates." (page $\mathrm{x}$ )

\section{2) A questionable change led by new generations}

In Chapter 1, we argued that important changes in a business system can be given internally as well, for instance by new demographic circumstances. Accordingly, in regard to the transformation of the old Japanese system, final change may come with the changing generations. This aspect could have a great potential in leading change: "[a]lthough young people have a tendency to distinguish themselves from their parents in any society, the growth and change in Japan's place in the global community within living memory has been so extraordinary that it seems legitimate to seek genuine differences between generations in contemporary Japan" -writes Hendry (2003: 20-21).

After 1945, when the Occupation Forces dismissed one or two thousand men from the business elite, there was indeed a "new generation" coming into power, though not in demographic terms. This young generation certainly aided the implementation of important subsequent reforms.

A "real" generational change, similar to the one in 1867, could have happened in the late 1960s when the "baby boomers" finished university. Exaggerated maternal expectations, pushing children as high as possible in the education system created much resistance in young people (Sakurai, 2004). However, apart from some student revolts and small-scale conflicts with authorities (culminating in the forceful removal of those 
students), this resistance was transformed into a lethargic generation rather than a revolutionary one.

This lethargy probably continued in the 1980s with youth rejecting old, hierarchical relations and escaping into long telephone conversations or into the virtual world of the internet from the 1990s (Sakurai, 2004). In 1995, Ohmae pointed out that the generation after the "baby boomers" (which he called the "lost generation"), who had different lives and never challenged authority as their parents had done, was more willing to accept what they had: "[to] keep their heads down and make the best of it" (160).

The next generation (the "Nintendo kids", in their twenties in 1995), for Ohmae, seemed to see the world differently again but members of the "lost generation" blocked their chances to get positions of responsibility at work.

For the 2000s, Sakurai (2004) asserts that this mental isolation of the past is clearly about to change, in part due to foreigners' influence. Thus, if youth today resist old business practices, the effect may be more significant than it was for previous generations. Indeed, according to several anthropologists, they apparently do not want to be involved in corporate life as their fathers did or to sacrifice themselves for their family as their mothers (Mathews \& White 2004, Matsumoto 2002). If this gap is still of relevance today, a survey questioning youth about their career prospects and work attitudes will confirm this argument on the changing values.

There is another demographic tension in the Japanese business system today: the "silver generation" (or ageing society) and the declining birth rate (Kohlbacher \& Weihrauch, 2009). The number of young workers, traditionally cheaper labor in Japan, is decreasing, whereas both the proportion of the more expensive senior employees and the number of retirees are increasing (Methé \& Miyabe, 2006). The same phenomenon represents a challenge in every developed economy where industrialization has made a major part of human work redundant, creating unemployment and discouraging parents from having more children. This being the case, the ageing population becomes a factor which in fact hinders active generational change rather than encouraging it because it may be many years before the upcoming young managers outnumber the current ones. And, if a revolutionary generation is to come, many old practices must go and the new ways are unclear: the consensual approach of decision making may not be appropriate for radical change. However, the demographic trend will in any case force companies to revise their employment practices. 
Thus, globalization might create a revolutionary move in the near future, but until now the generation effect in Japan's business history has remained marginal: economists usually rank the Occupation, the oil crises and the bubble burst as being of much higher importance.

\section{3) The step-by-step process of institutional change}

The origin of Japanese management practices is not quite certain in many cases: some academics argue for origins back to the Edo Period and feudalism, stating that today's customs evolved step by step, in an incremental or evolutionary way (Nakane \& Oishi, 1990). Advocates of the so-called 1940-system emphasize the continuity between the wartime and post-war economy (Ferber, 2007). Others say that modern management was created after World War II and has hardly anything to do with the historical past of Japan. Olcott (2009) defines these aspects as the culturalist versus the rationalist explanation. There is probably some truth in all opinions and we have attempted to reflect that in this chapter. The feudal origins in any case reinforce institutional theories and the idea of continuity in corporate practices.

Presumably in any society, incremental change prevails over a radical one when dominant groups support the existing institutions and resist change. In that case, only step-by-step weakening of old systems can be witnessed following environmental changes in a slow, adaptive process without any specific change leader. Japan's institutions are "more tightly linked and embedded in shared social values than are those in the US", states Jacoby (2007: 173), which makes the system more difficult and slow to change. Change is slow also because there is a general, strong opposition to reforms in Japan (Katz, 2003).

Based on Oliver, Olcott (2009) differentiated three types of pressure, all significant in the case of Japan, which may force practices be deinstitutionalized. These are political, functional, and social pressures. For the first one, as long as employment was kept high and stable, political pressure was meager in Japan. At present, in spite of an increasing unemployment rate, the performance of the Japanese economy does not obviously lead to unemployed masses on the brink of starvation. The functional pressure would mean increasing technical specificity and changing organizational objectives and means under the pressure of foreign stakeholders. This will be seen in the next point. The social pressure means a loss of cultural consensus among members-this 
is in our model what fosters the internal source of change: American management history has proven that paradigm change can only be accomplished with the active support of opinion leaders in society, namely academic experts and practitioner managers. The Japanese model so far seems to have resisted this type of paradigm change-while a weakening of traditions can be observed. The several examples from business history, seen in this chapter, linking the management practices with old Japanese tradition may greatly contribute to the stabilization of the system:

"Innovations in industrial relations and employment practice [...] are selected and legitimated within a framework of cultural values and institutional pressures. Though not a simple survival from the past, their apparent congruence with tradition may be a crucial factor in winning them acceptance and ensuring their institutionalization over time" (Lincoln \& McBride, 1987: 292).

\section{4) The incremental effects of foreign ownership and international trade}

Using institutional theory as a framework, Olcott (2009) made a thorough analysis on whether an institutionally distant merger causes organizational change and deinstitutionalization of communitarian practices in Japan. His answer was uncertain: "The conclusion in the case of Japan is that, once institutionalized, employment systems are hard to dislodge, at least from the inside, by insiders." $(224)^{94}$

Through this chapter, we have seen several examples, especially in corporate governance, of reforms which were greatly encouraged by the foreign investors present in Japan-and the Japanese government was willing to attract these foreign funds. But we have also concluded that foreign pressure was able to make only a limited impact on Japanese institutions, although this impact might be two-way. Another example of this type of change is the evaluation of Hanaoka (1997b) stating that American and Japanese practices will converge somewhat over time on long-term employment and seniority: the US will tend to use longer term employment whereas seniority in Japan will fade and be replaced by result-oriented management (see Figure 21).

\footnotetext{
${ }^{94} \mathrm{He}$ also mentioned that after the mergers, integration takes very long time (20-30 months in Japan versus 2-4 in the US) to avoid conflict, while old customs slowly disappear and merge into new ones.
} 


\section{Figure 21: A convergence model for management systems}

\begin{tabular}{|c|c|c|}
\hline Japan & & The USA \\
\hline Lifetime Employment & (1) A high degrees of & $\leftarrow$ Short-term labor agreements \\
\hline $\begin{array}{l}\text { - Basic custom to continue } \\
\text { - Part of labor force becomes } \\
\text { more mobile }\end{array}$ & $\begin{array}{l}\text { loyalty to the company, } \\
\text { because employees stay } \\
\text { longer. }\end{array}$ & $\begin{array}{l}\text { - Trends toward longer term } \\
\text { employment }\end{array}$ \\
\hline Seniority Systems & (2) Ability-oriented & $\leftarrow$ Result-oriented management \\
\hline $\begin{array}{l}\text { - Will be replaced by result } \\
\text { (ability/effort) oriented } \\
\text { management }\end{array}$ & $\begin{array}{l}\text { management to achieve } \\
\text { long-term results }\end{array}$ & $\begin{array}{l}\text { - Result-oriented management } \\
\text { with expected long-term } \\
\text { potential }\end{array}$ \\
\hline
\end{tabular}

Source: Hanaoka, 1997b: 159.

Step-by-step, evolutionary changes can be observed in any society. Specific companies represent numerous variations of national patterns, and common moves in their behavior may be reflected at a macro level if their number is high enough. ${ }^{95}$ But clearly, the most visible transformations occur when several change factors (internals and externals) act at the same time. So far, this chapter has dealt in particular with the main external driving forces. In the following one, we will turn to society to study the internal ones. In the last point of this chapter, we will attempt to overview how the potential opinion leaders in academia see Japanese Management today.

\section{5) Different views on Japan changing}

The last part before a summary of this chapter continues to focus on identifying change and the way it is seen by society and analysts in Japan. In order to have a detailed and precise picture at least of what has already been written, the author carried out a specific literature review with a new aspect: change. Did Japan change her major institutions and business practices since the bubble burst? Is the system more or less the same as it was one or two decades ago? Does Japan really have to change so drastically, anyway? Sources are contradictory and analysts see the achievements of Japan in the last two decades differently, summarized in the table below.

The names of authors with the dates refer to their books (see in Annex II.), published in English after January 1, 2000, and catalogued at the library of Waseda University, Tokyo. For this specific literature review, we studied books referenced with

\footnotetext{
${ }^{95}$ Hanaoka (1997b) categorized individual firms in a research as (1) "Exciting": proactive and employeeoriented; (2) "Progressive": proactive and organization-oriented; (3) "Stable": reactive and organizationoriented; and (4) "Traditional": reactive and employee-oriented.
} 
the keywords "Japanese Management" as of November 1, 2011. There were 116 works in total, of which 81 were selected as potentially relevant in title, and for content dealing with change. Through the analysis, a total of 33 titles could be classified as having an identifiable message on the current status of the Japanese management system.

In Table 7 below, the output of this literature study, JM stands for Japanese Management. The first column categorizes authors stating that there was no "real" major change in the Japanese system since the 90 s or the changes which took place were not important enough, and drastic, further transformation is needed. According to authors in the third column, the changes needed have already been made and there is no further need to change in a "radical" way.

Table 7: An attempt to classify major works on Japanese Management published after 2000

\begin{tabular}{|c|c|c|c|}
\hline & No drastic change (yet) & $\begin{array}{l}\text { Ongoing change, } \\
\text { uncertain results }\end{array}$ & Drastically changed \\
\hline $\begin{array}{l}\text { JM } \\
(+)\end{array}$ & $\begin{array}{ll}\text { - } & \text { Keizer, 2010 } \\
\text { - } & \text { Oyabu, 2010 } \\
\text { - } & \text { Abegglen, 2006 } \\
\text { - } & \text { Hamada, 2010 } \\
\text { - } & \text { Kawamura, 2011 } \\
\text { - } & \text { Jackson \& Tomioka, } \\
& 2004 \\
\text { - } & \text { Kono \& Clegg, 2001 } \\
\text { - } & \text { Basu \& Miroshnik, 2000 } \\
\text { - } & \text { Jacoby, 2007 } \\
\text { - } & \text { Monden, 2000 } \\
\text { - } & \text { Whittaker \& Deakin, } \\
& \text { 2009 } \\
\text { - } & \text { Ohtsu, 2002 } \\
\text { - } & \text { Richter, 2000 }\end{array}$ & $\begin{array}{ll}\text { - } & \text { Ogura, 2004 } \\
\text { - } & \text { Tsuneyoshi, } 2001 \\
\text { - } & \text { Aoki et al., } 2007\end{array}$ & $\begin{array}{ll}- & \text { Vogel, 2006 } \\
\text { - } & \text { Haghirian, 2010 } \\
\text { - } & \text { Ohara \& Asada, } 2009 \\
\text { - } & \text { Schaede, 2008 } \\
\text { - } & \text { Fields et al., 2000 }\end{array}$ \\
\hline $\begin{array}{l}\text { JM } \\
(0)\end{array}$ & & $\begin{array}{ll}\text { - } & \text { Haak (ed.), } 2006 \\
\text { - } & \text { Imai, 2011 } \\
\text { - } & \text { Okabe, } 2002\end{array}$ & $\begin{array}{ll}\text { - } & \text { Roehl \& Bird (eds.), } \\
2005\end{array}$ \\
\hline $\begin{array}{l}\text { JM } \\
(-)\end{array}$ & $\begin{array}{ll}- & \text { Fuller, 2009 } \\
\text { - } & \text { Black \& Morrison, } 2010 \\
\text { - } & \text { Kimoto, 2005 } \\
\text { - } & \text { Olcott, 2009 } \\
\text { - } & \text { Mouer \& Hirosuke, } \\
& 2005 \\
\text { - } & \text { Graham, 2003 } \\
\text { - } & \text { Maswood et al., } 2002\end{array}$ & - Oh, 2004 & \\
\hline
\end{tabular}


In the rows, the sign (+) refers to a generally positive evaluation or attitude of the author(s) to Japanese Management, putting an emphasis on its achievements rather than criticism. The overall message of these books is that the Japanese system is good as it is, or has a reason to be like it is, therefore it should not be forced to change, or the changes that have taken place have already brought satisfactory results. The sign (0) stands for descriptions / analyses which could not be categorized as either positive or negative. Finally, (-) shows a negative evaluation or attitude, stating that the traditional system is wrong, basically ineffective or inadequate, and its transformation would lead Japanese economy to a better performance.

The density of references in each block makes the interpretation rather obvious, but, for a better illustration of this literature review, we shall present below some of the main ideas of the reviewed works.

Jacoby (2007), who compared the American and the Japanese management systems, examined the hypothesis that Japanese Management would converge towards the American style. His final conclusion was that the gap between the two is widening rather than narrowing with time. In addition, after a study of foreign owners in Japan, even Olcott (2009) concluded that no radical change has occurred yet in Japan, not even in several foreign-owned firms:

"While my hunch that Japan, at the end of the twentieth century, was about

to enter a new age of a more open form of capitalism has so far proved incorrect, it is only a matter of time." (264)

Others seem to support his conclusion:

“...Change is still at an experimental stage and has not penetrated HRM policy or its architecture." (Benson, 2006: 45)

"Even though lifetime employment is on the decline and more flexibility is being sought in respect of mid-career recruitment and the release of personnel, it still dominates corporate thinking at least as an ideal and it remains more prevalent than in the West." (Pudelko, 2006: 59)

Mouer \& Hirosuke (2005) cite four major sources of the transformation problem in Japan: (1) the failure to implement the badly needed structural reforms, (2) a highly conservative attachment of Japan's leaders to the formerly successful, traditional ways, (3) an apparent ignorance of the crisis caused by globalization and multiculturalism, and (4) a loss of confidence in risk-taking following the bubble burst. 
"Why doesn't Japan change? Because an inefficient system for companies or countries is a very efficient system in the eyes of the people who are holding the power", states Graham (2003: 92), claiming that powerful groups in the current nomenclature have an interest in the status quo and therefore seek to sustain the traditional system.

Some (fewer) authors have stated that the major transformation of the Japanese business system is an ongoing process.

"Japan is now in a major period of transition. Some are calling it the greatest period of change since the Meiji Restoration and Japan's defeat in World War II, and I am inclined to agree. But the Meiji Restoration and World War II transformed politics, law, government, and society, so it was natural that the economy likewise did a 180degree turn; in the present period of transition, neither the political or governmental systems have altered significantly, and as a result economic change has also been spotty, stopping well short of a radical transformation in most cases." (Ogura, 2004: 215)

Finally, certain works also gave the message that Japan is a post-transformation country.

"The changes that Japan has undergone since 1998 are so elemental that they have triggered a deep-seated restructuring of Japanese business organization. In the $21^{\text {st }}$ century, what we used to know about keiretsu (business groups), main banks, Japan's system of ownership and corporate governance, the subcontractor system, and lifetime employment is no longer true." (Schaede, 2008: 2) But she complements this summary with: “...changes in HRM practices got under way only in the early 2000 s. It will be a decade before these changes are truly incorporated-or even longer, until the first generation of employees hired under performance pay will reach managerial levels" (Schaede, 2008: 17). Schaede focuses mainly on corporate governance issues such as amendments in corporate law, cross-shareholding, or the subcontracting system. We have also noted, however, that the year of 2008 with the Lehman shock raised serious questions regarding the shareholder system and steps back have been recorded since.

Fields et al. (2000) argues that Japan is transformed sufficiently for foreign investors to enter its market without serious obstacles. At the same time, they claim that the real impact of contextual changes is only arriving now, with a further need for the sophistication of marketing practices: "Beneath all the visible changes that have 
dominated the media, there have been fundamental transformations in the Japanese consumer and market. A rise in single working women, a shift from a producer-driven to a consumer-driven market, innovations in distribution, and a relaxation of regulations are just a few of the pounding waves of change that are reshaping the coastline of the Japanese market.” (Fields et al., 2000: xi)

\section{8) Summary of the Japanese management literature}

In this chapter we have been looking at the main management characteristics of large Japanese firms. We omitted to deal specifically with some 4-5 million small and medium-sized companies which number-wise represent $99 \%$ of the total corporate world in Japan, not because they are not important, but because the pioneering in management techniques and the contribution to scholarship is undoubtedly made by big business, due to its economic power and its systematic, conscious and planned management.

We are aware that the elements reviewed cannot fully reflect any of the large firms in Japan. Each organization will present a selection of these, with, possibly, specific extras. But we believe that there is a sense in bringing all these aspects together, because it greatly helps to understand traditional management in Japan, and because this is the only way to evaluate change precisely on a national scale. A simplified form of this analysis is summarized in Table 8.

It is also clear that the Japanese management system, with all 30 features described previously, was designed and developed in an era where "catching up", "protecting the markets", "reaching efficiency" were the key words of economic policies. Yet circumstances have changed, and Japan has grown to the position of leader in a global economy based on free trade and competition. Many of its old practices must have become obsolete. We have seen an increasing number of flexible contracts, performance-based evaluation schemes, corporate law reforms and fading keiretsu networks, weakening unions and HR departments, strengthening shareholder power and individualism, with the average Japanese who may enjoy more freedom. But still, the traditional values and management seems to persist and prevail in most of the cases. Since the early 90s, growth has certainly been slow if it exists at all, but the core of the Japanese system, obsolete or not, seems to function even today. For some, two decades 
are not long, or maybe not long enough, to transform institutions. This may be true, but for comparison (even though it is hardly a good comparative example), the first internet browser ("WorldWideWeb" [sic!]) was also created in the early 1990s.

Table 8: $\quad$ The 30 elements of Japanese management as observed in literature

\begin{tabular}{|c|c|}
\hline Management elements & Trends based on the studied literature \\
\hline \multicolumn{2}{|l|}{ Environment } \\
\hline 1. A small living area with frequent catastrophes & Still valid \\
\hline 2. Collectivist culture, Confucianism & Still valid \\
\hline 3. Historical isolation, late industrialization & Still valid \\
\hline 4. Developmental state and protected markets & Still valid \\
\hline 5. An economy with continuous growth & Disappeared \\
\hline 6. An ambiguous and rigid labor market & Still valid (but major changes to come) \\
\hline \multicolumn{2}{|l|}{ Intra-organizational context } \\
\hline 7. Easy-to-train and devoted employees & Still valid (although not real devotion) \\
\hline 8. Superiors are more managers than leaders & Still valid \\
\hline 9. Male dominance, homogeneity & Still valid (but changing career for women) \\
\hline \multicolumn{2}{|l|}{ Strategy } \\
\hline 10. Stakeholder orientation & Still valid \\
\hline 11. Cost leadership (vs. product differentiation) & Still valid \\
\hline 12. Spin-offs, start-ups, diversified portfolios & Almost disappeared \\
\hline \multicolumn{2}{|l|}{$\begin{array}{l}\text { Structure } \\
\end{array}$} \\
\hline 13. Big and complex, U-form based group hierarchy & Still valid \\
\hline 14. Large boards dominated by insiders & Valid but markedly decreasing strength \\
\hline 15. Central HRM, prevails over finance & Valid but markedly decreasing strength \\
\hline $\begin{array}{l}\text { 16. Processes of decision making: a consensual } \\
\text { approach }\end{array}$ & Still valid \\
\hline 17. Working teams (open office, group seating...) & Still valid \\
\hline \multicolumn{2}{|l|}{ HR / OB / Employment philosophy } \\
\hline 18. Recruitment from schools & Still valid \\
\hline 19. Core (permanent) vs. "irregular" staff & Valid but markedly decreasing strength \\
\hline 20. Long-term employment & Still valid \\
\hline 21. Formal induction, creating a family & Still valid \\
\hline 22. Cohort training "on-the-job" & Still valid \\
\hline 23. Slow promotion & Valid but markedly decreasing strength \\
\hline 24. Rotation & Unclear \\
\hline 25. Seniority pay (tenure-based compensation) & Valid but markedly decreasing strength \\
\hline 26. Enterprise-based or company unions & Valid but markedly decreasing strength \\
\hline \multicolumn{2}{|l|}{ Control \& Performance } \\
\hline 27. Behavior-based control & Valid but markedly decreasing strength \\
\hline 28. No direct control, multi-monitoring & Still valid \\
\hline 29. Decisions are joint responsibility & Valid but markedly decreasing strength \\
\hline 30. Good performance: market share, harmony... & Almost disappeared \\
\hline
\end{tabular}

The apparent lack of strong reactions might be surprising for a country which was the first Asian country to transform its obsolete customs into a modern economic development and industrialization. Using the framework of our change theory, we have understood why radical, power-driven transformation could not happen after the 90 s, we 
have overviewed the impact of foreign partnerships and seen how the academics are confused or uncertain about the current state of management in Japan, but we still lack feedback from the potential actors for change in society in regards to these management practices. As can be read in the introduction of the HBR list in the January-February issue of the Harvard Business Review: "when a business community supports an idea, change can happen fast” (42). Inagami and Whittaker (2005) stated something similar: "lifetime employment cannot be maintained without the support of employees" (37).

In my view, the issue with Japan today is not simply the debate about the Japanese versus the US models. The techniques themselves in detail have no true importance in a global perspective and we believe that there is no such thing as "better management" at a national scale. The real question is whether the people in this country would rather live in a more protected economy, where employment is more stable, group members can cover each other and the lack of talent or ambition of certain members is compensated by other, high potential employees, OR whether they would prefer a more liberal and more competitive economy, which, due to the harsh global competition, may be more demanding and probably more exploitive. Obviously, the question is very complex without any clear-cut answers, but planning this new context in a central way is certainly not the solution. The only good answer can be given by society itself. 


\section{V) UNDERSTANDING THE INTERNAL PRESSURES IN SOCIETY}

In this part, we will describe the last step of our analysis: a questionnaire survey reflecting people's attitude to traditional management practices in Japan. The findings, as a support for our theoretical conclusions, will draw a new model of management based on recent attitudes in society and help us to identify internal pressures leading for change.

We concluded in the previous chapter that since the 1990s, despite many amendments, there has been no drastic change in the major characteristics of Japanese business. As an explanation so far, we have found historical and cultural reasons which seem to guarantee continuity against change. But we have found little evidence on the current attitude of society to these "old" management practices, evidence which might have enriched the explanatory force of our hypotheses. As Hanaoka (1997b) stated, management systems are operated by the members of the organization, and there is a correlation between their behavior, or attitudes, and the nature of the given management system at the corporate level. Thus, our analysis must include a reliable picture of these members of the system.

Would the Japanese not want to change? Or do they wish to, but are prevented by the system which is too deeply rooted? What do they think of the traditional management elements of Japan? Answering these questions will help us to evaluate the internal drivers of change in Japan and estimate in which direction this system is supposed to make further changes. In our theoretical model on change, we saw that the quickest results were achieved in cases where internal and external pressures were present at the same time. The Meiji era is a famous example of a Japan driven by a combination of a sense of crisis, an external pressure and powerful change agents (i.e. the Sat-Cho reformers).

Beyond the direction of internally-driven change, another key element in this research will be the identification of change agents in Japan. It is genuinely uncertain and ambiguous whether a more Americanized system would better fit the Japanese than their traditions do. Dore (2000) asked very wisely: in whose interest should Japan change? The way in which the Japanese themselves approach the question is the main concern of this chapter. 


\section{1) Preparing the field: Research Design}

It is clear from the literature that major old practices still prevail in Japan, though certainly lesser in number and dimension. The extent is not clear and it is difficult to gather enough up-to-date, existing research data to clearly assess how management philosophy has changed since the bubble burst in 1990. A new research project on Japanese management ought to provide statistical evidence on the current situation while uncovering details on how society in Japan feels about those practices, which ones they support and which ones they would like to see disappear. Most sources on Japan are based on qualitative research for which adequate skills in Japanese are needed. The resources and skills of a single foreign researcher made this method inappropriate but previously done qualitative research studies, detailed in the previous chapter, served as a basis for preparing this one. Thus, to answer our research question and measure the current attitudes in society, a scaled feedback on each element with a relatively large panel involved seemed an ideal solution.

\section{1) Research question for the survey}

Institutionalism gave us some understanding of inertia and of why big structures change only incrementally. One advantage of questioning people may be that it better clarifies the human side of change: whether people support change or not and why, or what kind of attitude they have towards each phenomenon examined. Our change theory and the dominant institutionalist approach in Japan would suggest that recent developments since the early 1990s, summarized above, will reflect the attitudes of people in Japan towards traditional management.

As we have seen, foreign commentators often display amazement at statistical evidence showing that the main Japanese companies still maintain their old ways in management. Considering this research data, we will assume that a significant part of Japanese society supports these traditional practices, presumably because that is where their social power originates from. This group might be important in numbers (proportion) or in power, compared to the rest of society. Another possibility is that elements of the Nippon management system are so interconnected that it becomes hard, if not impossible, to change one without affecting the others-which creates further obstacles to significant transformation. 
Our research must bring a clear picture on these issues. On one hand, we must clarify what the general attitude of society is in Japan, including representatives of all groups (employed and unemployed, male and female, young and senior, etc.), to the 30 management characteristics described previously. On the other hand, we must find out whether there are supporters of these elements, and, if any, who. Ideally, complementary to these questions, we will be able to identify a high level of interconnection between the 30 elements, as we have found to be the case theoretically.

\section{2) Hypothesis (1) on the link between observed trends and attitudes}

As we stated earlier, institutional theory would suggest that management and organizational structures are shaped by the need for fit with preconceived notions of society about ways and means which are effective and legitimate. If Jacoby is right, Japan's institutions are even "more tightly linked and embedded in shared social values than are those in the US" (2007: 173).

Consequently, the developments of two decades concerning management in Japan must somehow reflect the attitudes and values of society. If we find for instance the weight of seniority wages decreasing over a period of 20 years, the institutional approach will propose that it is because more people favor performance-related pay today, and their desire prevails over those who want to keep seniority. If the time horizon is long enough, society will internalize economic reality, which lends a good explanatory power to this approach.

Hypothesis (1): The majority of the trends summarized in Table 8 (p.154) reflects the general attitude of society.

\section{3) Hypothesis (2) on internal support}

It seems hardly possible that literally everybody wants the management patterns to change and, moreover, to change in the same way. As a hypothesis we will assume that some want changes but others resist them.

In Table 8 we found that most of the traditional elements still prevail today despite their decreasing strength in many cases. Starting again from the institutionalist 
approach, we must admit that this is so because the current management and regular workers in Japanese firms support these elements. The supporters may be connected with the political elite of Japan and/or come from the business elite of companies (interconnected with the former group in any case due to the amakudari), but they are probably senior male members of large companies.

Hypothesis (2): The majority of the Japanese managers and salarymen support most of the 30 elements, but there are other (probably less powerful) groups in society which do not.

\section{4) Hypothesis (3) on interconnectivity}

In many cases, analysts agree on the main advantages and disadvantages of the Japanese system. They praise the highly motivated employees, the sense for perfection and innovation (when not radical), the efficient teamwork and highly productive industries. At the same time they deplore outdated lifelong patterns in employment or career management, seniority in promotions, inefficient, long office hours and decisionmaking, closed, protected markets and the uncompetitive agricultural and service sectors. However, it is hard to imagine how the advantages could be easily kept while discarding only the disadvantages. Probably they would affect each other due to interconnections between the elements of the management system.

Figure 22 shows a preliminary model of interconnectivity, based on Chapter 4 and Annex VI (the numbering is given in Table 3). The model represents every theoretical connection signaled when describing the 30 elements. The lines are the links, the arrows symbolize dependence. It would be too complex to formulate a detailed hypothesis on it, but the figure helps us in some way to estimate the possible extent of the level of interconnectivity.

Hypothesis (3): Every element is significantly connected with at least another one within the group of 30 . 
Figure 22: Hypothetical scheme of the Japanese management system

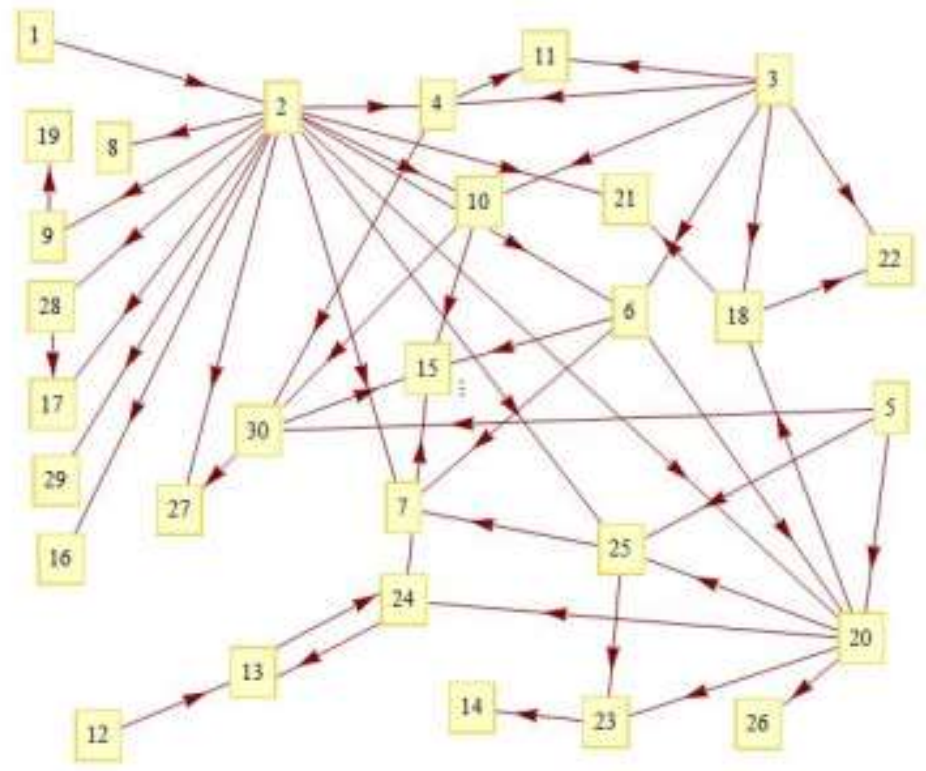

Source: Figure generated by Wolfram Mathematica 7.0

In what follows, we may be able to simplify this chart using data reduction techniques and formulate some general learning based on the result. Obviously, at least on a theoretical basis, some elements such as 2,3 , or 20, are of key importance in the system.

\section{5) The questionnaire}

All "classical" elements of the Japanese management system described by literature have been listed (see Table 3) and then transformed into variables for a questionnaire. The aim of this questionnaire was to reveal the attitudes of Japanese society (including foreign residents) to management and to test the three hypotheses formulated in the previous point. To achieve this, it was necessary to gather at least one response per item, or more, if the topic was sensitive or deeper understanding was needed.

Out of the 30 elements, 26 could be operationalized and thus have at least one variable which could be measured in the survey. To the items generated by the operationalization, a total of 73 questions, we added two extra statements as general or control variables, forming a total of 75 questions. With the aim of drawing a contrast between responses and the literature, all the questions had a similar logic: one part formulated a level of support for a managerial practice, and the other part offered an argument found in literature, in order to help respondents to understand the issue. Some 
items were formulated reflecting a positive view on traditional management, some others were the opposite, in order to monitor the respondents' attention. Following a test phase with ten respondents, the final questionnaire was uploaded to the Surveymonkey website and all respondents answered online.

The questionnaire (see Annex IV) can be divided into three parts. The first six variables are "yes-or-no" type questions (closed questions) which do not allow space for detailed opinions. The main role of this part was more to induce respondents into the "mood" of decision-making, so as to push them to make choices between extremes concerning management issues. As a consequence, values for these variables were not considered in the main analysis, but only as control data in some cases.

The second part consists of 69 statements where respondents were asked to rate on a seven-point scale the extent to which they agreed with them. The original idea was to use a five-point scale but in the testing phase it became clear that the Japanese tend to avoid extremes more than expected. Thus, in order to keep the information content of the data as high as possible, the scale was upgraded. Also, the numbered scale for the statements proved to be confusing during the testing phase because the sense of the variables (positive or negative, confirmation or rejection) often changed chaotically and an intention to support or reject the item was difficult to match with numbers. The aim of those changes was to gain a better picture of the respondents' attention. In the final (internet-based) survey, the numbering of the scale was changed to ' +++ ' (coded as 7 , completely agree); ‘++' (6, mostly agree); ‘+' (5, rather agree); '0’ (4, neutral); ' -' (3, rather disagree); '--' (2, mostly disagree), and '-- -' (1, completely disagree).

Thus, the first two parts contain a total of 75 attitude questions for the 26 operationalized elements. The higher number of variables can be explained by the author's choice to use summated scales (multivariate measurements) for the most important elements or concepts in the model. This choice was made in order to obtain a more rounded perspective of these concepts and enhance the reliability of the related data (Hair et al., 2006).

The third part of the survey consisted of 17 profile questions which also had to be answered (except for that on salary) in order to complete the questionnaire. This profile part made it possible to know what type of person answered the questionnaire and link the responses with social status, income, or age for instance. 


\section{6) Panel, methodology and relevance}

The questionnaire survey was conducted in Japan between March, 2010 (start of the test phase) and August, 2010 (last data collected).

Although the aim of the research was to reflect the opinion of Japan's society as a whole, some key target groups were designated for the questionnaire in order to ensure meaningful data. These target groups were managers (practitioners, a potentially dominant group at present), professors in BA, MA, or MBA-level business programs (academic experts, a potentially dominant group at present), and business students (a potentially dominant group for the future). In parallel, control opinions were to be collected from other, diverse categories, with the aim of having respondents from different hierarchical levels, different locations, different nationalities, with balanced gender and age cohorts.

Respondents were recruited using three methods. One was snowball sampling based on the researcher's personal network. The second was targeted mailing and contact to business professors at different universities, who answered the survey together with their students. The third group was provided by an online marketing agency operating in Japan (Macromill). By September 2010, a total of 880 questionnaires had been collected.

On one hand, the online collecting method proved to be a good way for limiting missing data. All variables were mandatory to answer before going on to the next page (except for the income level at the end), and, as a consequence, there are no random missing values. In addition, all incomplete questioners were ignored.

On the other hand, it should be recognized that collecting responses online has its disadvantages as well because no personal contact is made with the respondents to help them if needed, and the process of giving responses is also less controlled. However, the monitoring of the respondents' honesty can also be ensured with an online process and the lack of physical contact can also be an advantage because respondents have fewer factors influencing them. In our case for instance, the built-in checking system of the questionnaire could be used for verifying the level of coherence and the level of attention of respondents, and incoherent answers were filtered out in order to enhance the reliability of the data. Ready for further analysis, the final panel contained 796 answered questionnaires. 
The survey was designed for quantitative data analysis of the collected and coded responses. The assumption was that we expected to discover what kind of person a supporter of traditional practices is by using cluster analysis. A picture of the connections between the measured elements would ideally be acquired with correlation matrixes and multidimensional scaling techniques.

In the sample obtained, we can find a rather good balance of gender: $51.6 \%$ of respondents are male compared to $48.4 \%$ female. They range from 19 to 74 years old and the highest tenure is 42 years in the same company. For their country of origin, $86.8 \%$ are Japanese, $4.4 \%$ came from other Asian countries, 3.5\% from Europe, $4.2 \%$ from Anglo-American countries, ${ }^{96}$ and $1.1 \%$ from elsewhere. Roughly $40 \%$ are single, $49 \%$ married, $11 \%$ in a relationship. About $40 \%$ have children and $60 \%$ do not. Among the respondents, $88 \%$ have already worked in Japan, $96 \%$ plan to do so in the future, and 54\% live in Kanto (the Tokyo area). They are relatively well educated as more than $63 \%$ hold at least a BSc degree.

\section{2) Preparing the database}

\section{1) Risk factors, possible errors: data reliability}

Before the analysis, some remarks should be made on possible measurement errors, which are a feature of all quantitative analyses (Hair et al., 2006). In this paragraph, the main issue will be the reliability of the database, as its validity was ensured mainly by the thoroughgoing analysis of related literature. While reviewing history, sociology and similar field studies, the author was able to grasp an accurate understanding of the phenomena in question and their operationalization.

The internet-based collecting of responses can be mentioned as a primary factor endangering the overall quality of the database. Respondents could answer when and where they wished to do so, but also without any control by the researcher. In order to ensure a better reliability for the data, all incomplete responses (about 10-20\%) were ignored as they were taken as proof of lack of motivation. In addition, the author filtered out responses as detailed in the previous point. The remaining responses have three key

${ }^{96}$ USA, GB, Australia, Canada 
characteristics which provide a generally good reliability to the database: (1) they were registered in an appropriate timeframe, about 18-19 minutes on average; (2) they are all complete; (3) they have some basic internal coherence which shows that the values were given in a deliberate manner. However, as it is often difficult to distinguish accurately between these options, we must assume some degree of measurement error in the database. The answers to the profile questions may be reasonably accurate, although not perfectly precise.

Another risk in reliability is the sampling: respondents were not selected at random, and we cannot know how representative their views are for the whole of society. Although translations were double-checked for accuracy and efforts made for the universality of meaning, possibly different interpretations of the same notions or cultural assumptions may lead to distortions and limit the generalization of our findings. Finally for the interpretation of data, one must not forget these responses may be wishes but are certainly not facts.

Respondents' feedback made it clear that some felt it difficult to judge two things at the same time. Actually, respondents rated not only a management practice but also the reason why they liked or rejected it. This was deliberate: those statements were purely based on existing literature (which might contain errors) and aimed to collect feedback on the literature as well.

To sum up, we can assume that the fact that respondents could express themselves in 75 different ways made the overall database valid enough to work with. Fortunately, our sample is big enough to attenuate the risk factors mentioned above. Finally, due to the questionnaire being in Japanese, respondents did not have to be English-speakers, part of a specific group, or have a specific background in international business. In that respect, the survey creates an opportunity for a deeper understanding of local attitudes and a better comparison between national patterns.

\section{2) Examining the data}

Once all cases with missing data have been deleted, we can turn our attention to outliers and the basic assumptions concerning multivariate analysis.

We explained above how the filtering out of incoherent responses was carried out using the built-in checking system of the questionnaire. This process greatly enhanced the reliability of the data but also eliminated possible outliers: in the final 
database, none could be identified using scatter plots. When performing the cluster analysis, two outliers were detected and withdrawn, which made a final panel of 794 responses for the rest of the data analysis.

Before the data analysis could begin, the examination of the data involved some testing for the assumptions underlying the statistical bases for multivariate analysis, which we could carry out with success. Every variable was found to correspond to normal distribution when represented on histograms (for both kurtosis and skewness). During the check on linearity, we could not identify nonlinear relationships (correlations) between the variables.

\section{3) Preparing the data}

Being aware of the possible measurement errors, the work with the data could begin. However, after the clearing of our database, some further actions were needed in order to prepare efficient data analysis. The first six (yes-or-no type) questions were separated as control variables due to the previously mentioned reasons. It would have been technically possible to upgrade these six variables to an ordinal measurement scale with some distortion in the data (Füstös et al., 2004) but the other 69 items proved to be sufficient for the analysis. This option was thus rejected.

In the next step, to make the attitude analysis more efficient, variables needed to be aligned according to their content. The statements holding a positive meaning towards traditional Japanese management were left as they were. Negative statements, assuming that the traditional elements needed to change, were reformulated and their answers inversed.

\section{3) Discussion of the survey results}

We shall expound here the significance of our survey results (see in Annex V) while putting them in perspective with the previous chapters. First: can we find any general message(s) from the survey, concerning Japanese management? Is there any specific direction most people would like to go or should managers simply consider the trends offered by literature? We found that a message could be indeed formulated and the main directions identified, at least in the case of our 794 respondents. 
We believe that there are some banalities amongst the variable findings but there might be some surprises as well. In any case, their message can be greatly enriched by some figures from parallel studies which we will introduce at several points. Suffice to note here, we will not deal in this point with the essential dilemma of shareholder versus stakeholder orientation. This is partly because it could be weakly operationalized in this survey, and partly because the topic merits greater attention than a discussion "footnote" after the survey. Thus, we will come back to it later.

One of the strongest messages of this panel is on the changing role of female employees at the workplace. Before the 1990s, a woman had to give up everything in her life to be able to get into the "career track" and not the "traditional track for girls", this latter consisting of making coffee and fulfilling representative (and temporary) positions. The general attitude towards this in society has been under transformation for a long time now. In the longitudinal study with data from 1972, 1979, and 1992, described by Dore (2000), the following question was examined: "What do you think of the idea that men should go out to work and women look after the home?" The response was "Fine!" by 83,70 , and then $56 \%$ of the women respectively, while the same proportion among men went down from 83 to $66 \%$. In our sample, a similar question showed only $18.5 \%$ of the women support this traditional idea, and $31 \%$ of the men. A radical fall from 1992!

However, according to a survey of women aged less than 49 years in 1997, 40\% of them resigned from regular work when they married, and, of those who continued working, another $40 \%$ resigned when they became pregnant or when they gave birth (Rebick \& Takenaka, 2006). The same survey in 2002 showed that more women returned to work with shorter non-participation, but trends about leaving appeared similar. That is reality compared with attitudes. In the panel, about $70 \%$ of mothers were full-time housewives after 0-4 years of marriage, and $60 \%$ after 5-9 years of marriage. In both cases, only about $17-19 \%$ of the women respondents were employed full-time. In parallel, Thomann (2008) cited another survey from 1998 on managers which found that only $2.4 \%$ of the section chiefs (kacho) and $1.2 \%$ of the division chiefs (bucho) were female in the overall panel and the same figures went down to 0.9 and $0.2 \%$ respectively in the firms employing at least 5,000. In our panel, $82 \%$ of the female and $76 \%$ of the male respondents were against the idea that male managers would do a better job than females. At the same time, 23 and $27 \%$ respectively admitted that they feel more comfortable with a male superior. 
In parallel with more chances for females, our respondents desired a higher level of mid-career opportunities as well. About $69 \%$ of the panel would like to see an increased role of recruitment agencies with more mid-career jobs. More than half want the agencies to handle mid-career leaves with their own cases (i.e. CVs) included. According to Olcott (2009), the proportion of mid-career hires in companies with foreign owners is always higher than in comparator companies. We have indeed found a high level of correlation between the willingness to send out CVs when changing job and the willingness to work for foreign firms (versus Japanese ones). Another piece of background for mid-career hires is the decreasing role of the HR department of the head office: concerning their recruitment, the central HR does not grasp the business need so well, which moves recruitment to the level of the division.

Apparently, society is ready for and willing to have "modern" work conditions for women and mid-careers and we believe that the trends will remain positive in that sense for the forthcoming years. The clear advantage in inviting more young female workers back to the market is the at least partial remedy for the problem of the ageing population. On the other hand, this trend does not remedy the country's shrinking population or falling birth rate, because with more career chances the girls are more reluctant to leave work even temporarily to give birth. These two issues are global challenges without any stable solution so far.

Our survey shed some light on the inter-firm networks and hierarchies as well. The cross-shareholding question obviously lack interest for the respondents: more than half of the answers for both related items were neutral. The other half varied between support and aversion on a more-or-less equal basis. Clearly, the issue seems to be more a theoretical one than something which would occupy an average employee's or even manager's mind. On the other hand, differences between large and small firms are well received and tolerated in society. An average of $71.5 \%$ found that it was normal that they offered different levels of compensation and benefits. Almost half of the students aimed to work for large organizations after graduation. The differences can be indeed quite significant: Thomann (2008) found for instance that in 1991, firms with staff of over 5,000 could pay an average salary of 419.579 yen, whereas the pay in firms with 30-99 employees was only 263.224 yen, with far fewer benefits. And, as long as interfirm groups exist, these differences will probably remain since they provide the essential level of flexibility so that employment can be maintained in difficult times as well. 
As for the protracted debate about long-term employment, we have identified a tendency to support it in our panel, perhaps due to the recent crises. According to Olcott (2009), employment security (government policy) must be among the factors reinforcing LTE, together with union pressure and the attitude of managers. For this latter, he cited a 2003 JIL managerial survey, in which only $20 \%$ of companies stated that they either did not have long-time employment (5.2\%) or saw fundamental change as necessary $(15.3 \%)$. The majority saw no need for change $(36.1 \%)$ or the need for only partial adjustment (40.0\%). That means $76 \%$ of companies still wanted to keep the traditional system of LTE. In a more recent survey, four years later (JIL 2007), 30\% of Japanese companies still expressed commitment to long-term employment and seniority-based pay, but $40 \%$ introduced a new model including long-term employment but with pay based on performance. Over the age of 40, we find hardly anyone (a maximum of 5-10\%) opposing long-term employment in Japan and even below, the majority of respondents are in favor of maintaining it.

Linked with long-term employment, another interesting point that we have found was the risk avoidance of the youngest age cohort. That may be one of the effects of the recent global crisis: since their childhood, Japanese in their early twenties cannot help noticing worsening economic conditions, an increasing number of unemployed, and shrinking payrolls. They see the stress around and they may seek security more than people in their early thirties. A higher proportion of respondents below 25 seem to support protected markets than the ones between 25 and 35. The same goes for claiming that life was better 20 years ago. They rank second in believing (or being willing to believe) that mass dismissals are unacceptable in society. They rank equally with people over 40 in claiming that risk in business should be avoided if it endangers employment. At the same time, once employed, they seem willing to take on internal competition and look for quick promotions. A study by the Ministry of Labor (Rodosho) makes a good parallel with our findings: in 1985 and in 1998, they found that the chance was bigger for people to potentially change job (i.e. take risk) from their late 20 s to their late 40 s, but low in their early 20s or above 50 (Inagami \& Whittaker, 2005). ${ }^{97}$ The same authors noted that risk aversion was among the obstacles of creative work, badly needed today in every developed economy.

\footnotetext{
${ }^{97}$ Other studies described in Chapter 4 claimed that the chance of leaving a job within three years after employment was actually quite high.
} 
However, the youngest cluster in our analysis turned out to be reformist and very much against traditional Japanese management in general. To our surprise, the other young cluster (community) based itself on common activities with colleagues such as afterwork socializing and drinking. As described by Nakane (1972): "Each evening in Tokyo after the offices close many office workers stop at bars on their way home, and some of them remain drinking there until well after the last train. It is not the drink itself that attracts them so much as the chance of relaxation after the tension and competition in the office; bars are thought to be soothing the nerves" (124). Despite this parallelism, the age seems to be (at least in 2009-10, for these generations) a determinant factor in the respondents' attitude to management. This conclusion leads us back to our change model and the generational approach, suggesting that such a shift may happen in the near future.

Beyond age, our clusters were differentiated by the two dimensions of hierarchy/equality and passivity/activity. The level of activity was rather obvious with the immovable mass of Cluster 2 on one side, and the young, active, initiative-taking two clusters on the other. The term equality here may be unclear but the Japanese egalitarianism described earlier can serve as a reference: clusters here seek homogeneity or equality in terms of material wealth (e.g. salary), gender, and education. Since Confucianism suggests that a strong level of hierarchy is necessary in society, the origin and the talk about egalitarianism may seem a mystery. It may be the political left wing, which was one of the leading political forces in post-war Japan. According to a civil service head from MITI: "with a Socialist Party able to get something like a third of the votes, a system of 'proportionate consensus' had developed. The Socialists were able to get 80 per cent of what they wanted by negotiated compromise. Now, with the Socialist Party practically disintegrated, it was difficult to predict what would happen to egalitarian policies" (Dore, 2000: 63). For the moment, perhaps the most powerful and influential cluster, number 3 , tends to favor egalitarianism rather than hierarchy.

\section{4) Conclusion of the field research}

Our short analysis was based on three assumptions: (1) there is a link between recent trends of management elements (institutions) and the societal attitude towards them. (2) One or several group(s) of people is (are) still strongly in support of traditional Japanese management practices and they must be important in terms of number and/or social 
influence. (3) The elements of the Japanese management system are highly interconnected-which probably makes change even more difficult.

We have found evidence for all the three hypotheses: a good match between theory and observation, two significantly supportive clusters which largely outnumbered the rest of the panel and represented a higher level of social influence as well, and more than one pair of correlations for each of the 26 elements operationalized. We stated that the old system is probably supported by senior Japanese males who work as regular (core) employees or managers in rather large companies and enjoy long-term employment. Another group was also identified as a contrast to the former one, with younger members, more diversity and a higher level of education. As they grow older, the second group may become socialized into the Japanese system as happened in the past, or continue to reject traditional methods. In this latter case, Japanese management ought to change more dramatically in the near future.

We also succeeded in compressing the 26 operationalized management characteristics into eight main indicators and, based on the results of a discriminant analysis, we found that respondents' attitudes range along three lines of logics or aspects: growth, group emphasis and insiderism. 


\section{VI)THESIS SUMMARY: PARADIGM CHANGES IN MANAGEMENT}

The aim of this thesis was to make clear how national management patterns can change. We attempted to answer the question with a focus on historical facts and quantitative evidence; noting that management, including most of our bibliography, is a topic generally discussed on a qualitative, case study basis. ${ }^{98} \mathrm{We}$ have covered three main topics: we started with a short historical presentation of how management thought evolved in the US and in Japan, described what management meant in a large, so-called "traditional" Japanese company, and examined to what extent this traditional management fits the general public's taste today. We will briefly summarize what we have learned concerning these main topics and what sort of impact this knowledge may involve.

In Chapters 2 and 3 we presented the management history of the last one hundred years in the US and in Japan respectively. We had specific goals with this parallel, such as to identify so-called "paradigms" and to provide a picture on the pace of how these changed in both countries. We distinguished four distinct paradigms in the US: Scientific Management, Human Relations, Structural Revision and Global Competition. They have presumably spread through the world catalyzed by globalization and the growing American influence, especially after World War II. The evolution of management through these paradigms has been combined with the evolution of contingency theory and the resulting figures and parallels helped us to frame all the major areas of management within this evolution framework: production technology, organizational behavior, organizational structure, strategy, leadership, etc. Concerning change in management, we differentiated incremental versus drastic, and internally versus externally driven changes. Through these distinctions, we acquired both a clearer picture on the national motors of corporate change, and a tool to evaluate national characteristics in regards of management change. The essence of this learning in the case of the US is summarized in Table 9.

\footnotetext{
${ }^{98}$ It is recommended in research that the two be combined (see for example Balaton \& Dobák, 1982).
} 
Table 9: $\quad$ Paradigms and the evolution of the management system

\begin{tabular}{|c|c|c|c|c|}
\hline & $\begin{array}{l}\text { Production } \\
\text { efficiency }\end{array}$ & Human efficiency & $\begin{array}{l}\text { Structural } \\
\text { efficiency }\end{array}$ & $\begin{array}{l}\text { Strategic means of } \\
\text { survival }\end{array}$ \\
\hline $\begin{array}{l}\text { 1910s- } \\
30 \mathrm{~s}\end{array}$ & $\begin{array}{c}\text { Scientific } \\
\text { Management }\end{array}$ & Welfare services & $\begin{array}{c}\text { Division of work, } \\
\text { Weber's } \\
\text { bureaucracy }\end{array}$ & Production plans \\
\hline $\begin{array}{l}1930 \mathrm{~s}- \\
50 \mathrm{~s}\end{array}$ & $\begin{array}{c}\text { Oper. research, } \\
\text { Management } \\
\text { Science, Qual. } \\
\text { Control }\end{array}$ & Human Relations & U-form structures & $\begin{array}{l}\text { Strategic analysis, } \\
\text { Forecasting }\end{array}$ \\
\hline $\begin{array}{l}\text { 1950s- } \\
70 \mathrm{~s}\end{array}$ & Automation & $\begin{array}{l}\text { OB, theories of } \\
\text { decision-making } \\
\text { and motivation }\end{array}$ & $\begin{array}{l}\text { Structural } \\
\text { Revision }\end{array}$ & $\begin{array}{l}\text { Knowledge } \\
\text { Management } \\
\text { Excellence } \\
\text { monitored by } \\
\text { Controlling }\end{array}$ \\
\hline $\begin{array}{l}\text { 1970s- } \\
90 \mathrm{~s}\end{array}$ & McDonaldization & $\begin{array}{l}\text { Corporate culture, } \\
\text { empowerment, } \\
\text { entrepreneur-ship }\end{array}$ & $\begin{array}{c}\text { Matrix structures, } \\
\text { BPR }\end{array}$ & $\begin{array}{c}\text { Global } \\
\text { Competition }\end{array}$ \\
\hline $\begin{array}{l}\text { Current } \\
\text { trends }\end{array}$ & $\begin{array}{l}\text { Robotics, Web- } \\
\text { based } \\
\text { technologies }\end{array}$ & Leadership & $\begin{array}{c}\text { Virtual structures, } \\
\text { start-ups, web- } \\
\text { based processes }\end{array}$ & $\begin{array}{c}\text { Strategic alliances, } \\
\text { Sustainability, } \\
\text { new channels of } \\
\text { communication } \\
\text { with customers }\end{array}$ \\
\hline
\end{tabular}

Source: author

As stated in our "Palm Tree Model", the paradigms and the different cells of the table are not distinct and there is no clear-cut beginning or end for these concepts. There are roots in every cases (cells before the paradigm for each column), and there is a continuity, a "life" after the dominant period for each paradigm. Linking the main paradigms with the main corporate functions is designed to highlight and support this idea.

In American history, change between paradigms has implied somewhat large-scale and deep effects, whereas the Japanese seem to keep the focus on Scientific Management (or production-oriented) paradigm which was only partly altered by the others (HR, etc.). It may be that enhancing the ways of production until perfection has been so emphasized in Japan that this perfection finally turns the system into a more rigid one and the means (efficiency) becomes an aim in itself. We had the same feeling analyzing correlations in the survey: every element seemed to be highly embedded into the system. To complete another loop of understanding, based on the theories raised in Chapter 1, we can structure these paradigms in the matrix of management change as in Table 10. The table is a graphical way of emphasizing the different level of reactivity in the two countries' management systems. The analysis of the two different systems greatly helped us to understand the dimension of pace in the matrix. 
Table 10: Paradigm changes in the US and in Japan

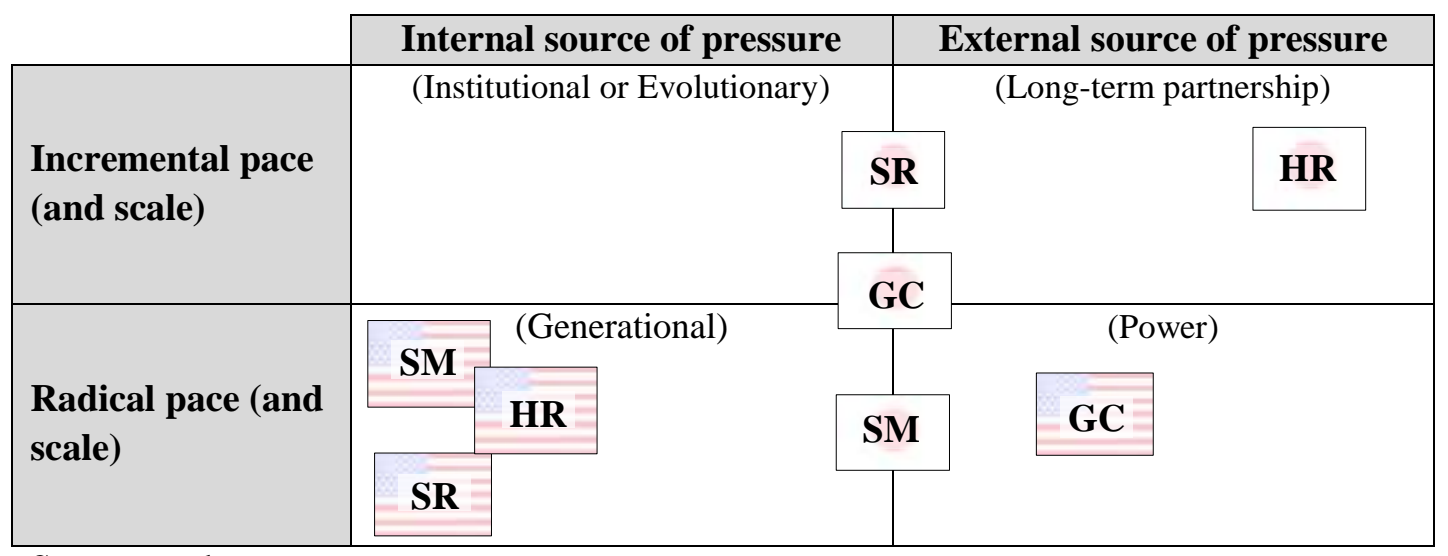

Source: author

The difference could be partly explained by the agency and transaction cost theories: we have found that the American governance was based on the principles and rules of the agency theory, whereas Japan sought (especially from the late-40s) to reduce transaction costs as much as possible, a goal which can be achieved by more stable contracts and relations, among other factors.

The other related difference was the stakeholder versus shareholder orientation of firms in a country. In the US, where the central power used to have less redistributive power and influence on banks, capital became scarce, but highly demanded in order to generate economic growth. Accordingly, the holders of this capital gained a more prominent role in the economy than other firm-related parties (stakeholders). In Japan, we found a historical concentration of capital in a few hands, the state could influence banks through the ministries, but the scarcity of skilled labor seriously hindered economic growth once industrialization started. Thus, more economic importance and weight was given to the employees than to the owners of capital (since these latter were not driven by short-term profit interest). During stable growth, maintaining employment proved to be a good means to attenuate social dispute and calm industrial relations, but the socio-economic context of Japan has greatly changed during recent decades: on one hand, it rose to the ranks of the industrialized, highly developed countries; on the other hand, stable growth ended with the bubble burst.

Once again, we have examined and tested the recent transformation of the Japanese system based on our matrix of management change. We could identify all the four types of changes as described below. 
For internally-driven change with a radical impact, we witnessed some central reforms which, at least for some authors, transformed the corporate life in Japan. The aim was typically to reduce corporate insiderism and make large groups more transparent. These changes may be categorized as externally-driven in some cases, as the Japanese government often acted under foreign pressure, in order to attract more foreign funds into the struggling economy after the bubble burst.

Still internally driven, but more incremental, institutionalist change could be analyzed thoroughly with a field survey study.

We found incremental externally driven changes (in some cases with quite significant pace and impact), in the form of foreigner pressure for more liberal markets, less trade protection, greater transparency in corporate governance, or the four global trends described in Annex II: the increasing power of capital and shareholders, the innovative competition for customers, the intensifying groupism and alliances, and the greater need for leaders.

Needless to say, change depends greatly on the sector, too. Dramatic change tends to happen more in the most competitive sectors, such as the automobile. To deal with change by industries was not within the scope of this study, and we had to maintain our focus on national patterns. Our aim was not to draw the picture of a representative Japanese company either, if such a thing exists. Rather, we attempted to approach the kind of large firms which are likely to be found in Japan today. Therefore, the management characteristics, described in Chapter 4, are not necessarily present in every Japanese company, and certainly not to the same extent. They are to be seen rather as the primary colors in the toolkit of a painter: they will be a constituent part of all firms but this itself does not guarantee a good picture, neither a homogeneous set of pictures in the end.

Among the new managerial trends in Japan, we found several points of note. The challenge of the ageing society involves changes in demand, and a decreasing labor force, which raise further need for adjustment in the business system. Mass-immigration as a solution to the ageing of population is rejected by Abegglen (2006) who noted that it mostly causes new problems to be solved, such as delinquency, growing unrest and social conflicts. A more likely remedy lies in the use of automation and robotics, along with the increasing role of female labor and the extension of the retirement age. The trend of the hollowing out of the Japanese industry forced by expensive labor and the high yen have as a consequence that rather than importing laborers, labor-intensive jobs 
would be given to China and other East Asian countries. It should also be noted that medical science is constantly aiming to lengthen both life and youth, and achievements in this area might modify existing demographic projections.

Another current hot topic is animated by Japan's monetary and fiscal problems, such as the high yen or the increasing national debt. Here again, no consensus could be reached among economists on whether deflation represents a problem and how much inflation or deflation should be in a national economy. We also saw the problem of inefficient service and food sectors: the industry where Japan has reached world-leading efficiency is moving out, while the inefficient service and food sectors stay and remain protected. Consequently, we are witnessing a move towards a more balanced economy (less dependence on exports), public support for the traditional HR practices, and a continuing strong role of the government for instance in promoting egalitarianism (Blomström et al. 2001, Abegglen 2006, Aoki et al. 2007). It is also clear that the role and importance of capital versus labor remains a key factor in maintaining or altering the Japanese management system.

Of all issues, the most significant might be this latter (the shareholder versus stakeholder debate), since its future development will certainly define a large stake of Japanese management. Entire books have been written focusing only on this dilemma. As we saw earlier, the traditionally shareholder-oriented US is today the arena of fierce controversy over whether focusing merely on profit is a poor motor for the economy, and better care should be take of the other stakeholders (i.e. Washburn, 2009). In Japan, at the other extreme of the scale, arguments go in the opposite direction. As Tadokoro (1999) claimed: "In a society where individuals are not allowed to get rich and stockholders' interests are largely ignored, who is going to invest in risky or unorthodox ventures? In other words, problems with Japanese egalitarianism are now becoming obvious" (64)..$^{99}$ The majority of analysts may have tended to evaluate the American model as superior until the 2000 s, but the corporate scandals of 2001 redressed a certain balance between the two systems again.

In this thesis, we argued that there is no winner between the two. Society must decide which way to go, but visibility is often clouded by coexisting, contradictory logics: path dependency and convergence is and will be present at the same time in every economy. In our analysis, it became clear that Japanese society prefers incremental reform: the majority agree that Japan must improve transparency and shift

${ }^{99}$ Cited by Dore (2000). 
to performance-based schemes, but no radical move is needed toward shareholder sovereignty. Worsening performance indicators such as foreign trade balance may trigger a deeper change of attitudes in society but one must be cautious in linking management directly with performance. ${ }^{100} \mathrm{We}$ examined this relationship within the framework of contingency theory but saw the difficulties in evaluating performance on one hand, and, on the other, stated that macroeconomic factors, rather than the corporation may be the main source of performance at a national level.

Nevertheless, it would be rash to conclude that national management patterns cannot have a direct impact on performance. In that matter, the strategic question referred to as Paradigm 2.0 may be of key importance. The Japanese focus to date has remained on scale and scope economies and production efficiency, although the most competitive production plants are being hollowed out in countries with cheaper labor. The business sectors remaining in Japan, such as the agriculture or the domestic services, are behind in the competitiveness game. Common wisdom would suggest that a developed country must make a shift when its labor becomes significantly more expensive than its competitors and find other value-adding possibilities such as innovative products, creative services, brands with enhanced market value, etc. However, the moment when this shift is required is not clear-cut and some performance indicators in Japan such as the positive trade balance, the low unemployment rate, peaceful industrial relations, or the low level of delinquency do not push for radical change. Still, Japan must decide for the form of capitalism that it will take in the twenty-first century, and we attempted here to provide an overview of the possible direction. The traditional stakeholder-oriented view looks interesting and might have more social value, but offers a weaker capability for change and for "creative destruction". The question is: to what extent Japan will approach the shareholder scheme.

\footnotetext{
${ }^{100}$ We saw for instance that the form of corporate governance had no proven direct impact on performance.
} 


\section{ANNEX I: A parallel between contingency theory and management history}

The aim of this annex is to highlight to what extent contingency theory and management history are based on the same logic.

Taylor's work impacted nearly all American production systems, and radically transformed vast swathes of them. To understand this impact and its consequences for the evolution of management, let us recall Figure 2 of contingency theory and use it to illustrate Taylorism in a contingency framework. Scientific Management is usually called "a closed system" by historians and theorists and now we can understand why. The adapted figure (Figure 23) illustrating contingency below shows that the focus of both Taylor and his followers remained inside the core of the corporation box: the growing market simply affected the production technology of companies. Consequently, technological innovation had a great effect on production methods. ${ }^{101}$

\section{Figure 23: The contingency model of Scientific Management}

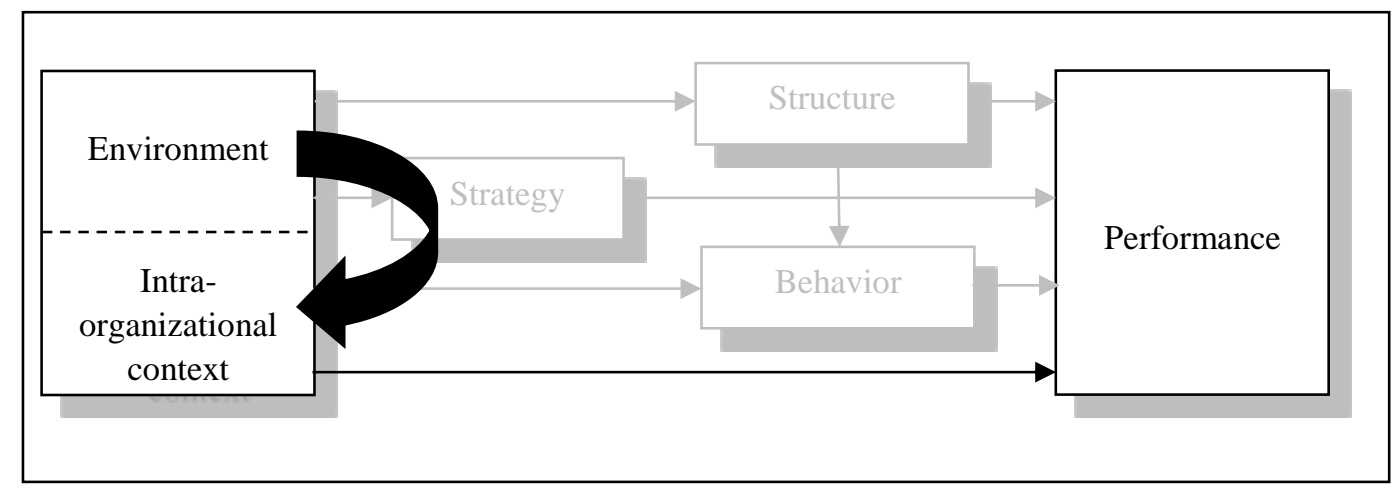

Source: author, based on Dobák (1988)

The Human Relations paradigm went further in the sense that the borderlines of the corporation box are reached in managerial thinking. For a summary of this evolution, in Figure 24, the two bold arrows symbolize the two waves of the paradigm: the black arrow represents the early advocates, while the grey stands for the latecomers (from the late-1940s), opening for the behavioral approaches in management.

\footnotetext{
${ }^{101}$ Some examples highlighted by Boyer and Equilbey (1990) are: steam power, the steel, the conveyor belt, nylon, the computer, digital command of machines, or later computer-based technologies.
} 
Figure 24: The contingency model of Human Relations

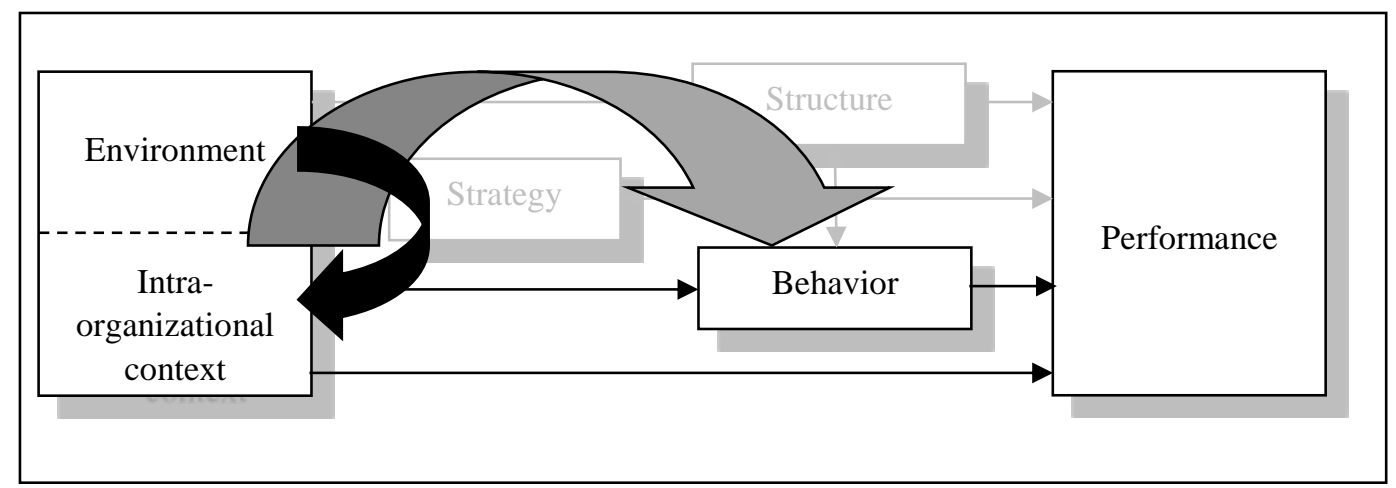

Source: author, based on Dobák (1988)

Figure 25 illustrates what the Structural Revision paradigm brought for managers in the contingency framework. It may seem curious that structure, the first factor studied by researchers during the development of contingency theory, comes only as a third stage in management history. However, on one hand, we should not mix the evolution of contingency theory with the evolution of management. The parallel used here is purely representative and does not affect the theory described in Chapter 1.

On the other hand, we must remember what the bold arrows mean: the focus of attention of corporate managers. It does not mean that with Scientific Management the structure was not affected. Structure was simply not the focus, it (structural change) happened as a consequence of technological change, for example. We still remember what Woodward successfully proved: technology affects structure.

\section{Figure 25: The contingency model of Structural Revision}

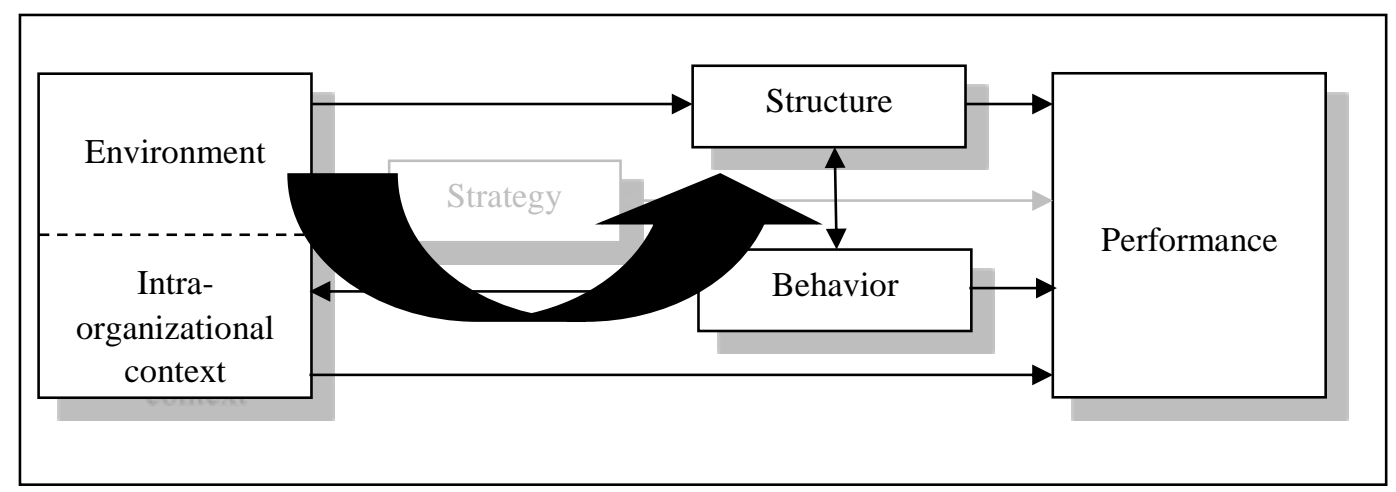

Source: author, based on Dobák (1988)

The aspect of rising strategic thinking, in close connection with the environment of firms and their competitive performance is shown in Figure 26. Again, the context of contingency theory offers a good representation of the whole managerial system. By the 
1980s managers had acquired enough skill to pay careful attention to every contingency element studied in Chapter 1, and to manipulate them according to the need for match. Henceforth, the game still remained open for "playing" with the arrows. The opening of the strategy box made the environment extremely important, with a special focus on competitors, because the chance to be displaced from the game grew significantly. Also, competitors with radically different sets of intra-organizational resources entered into the game, which redesigned the rules and stakes of the competition.

Figure 26: The contingency model of Global Competition

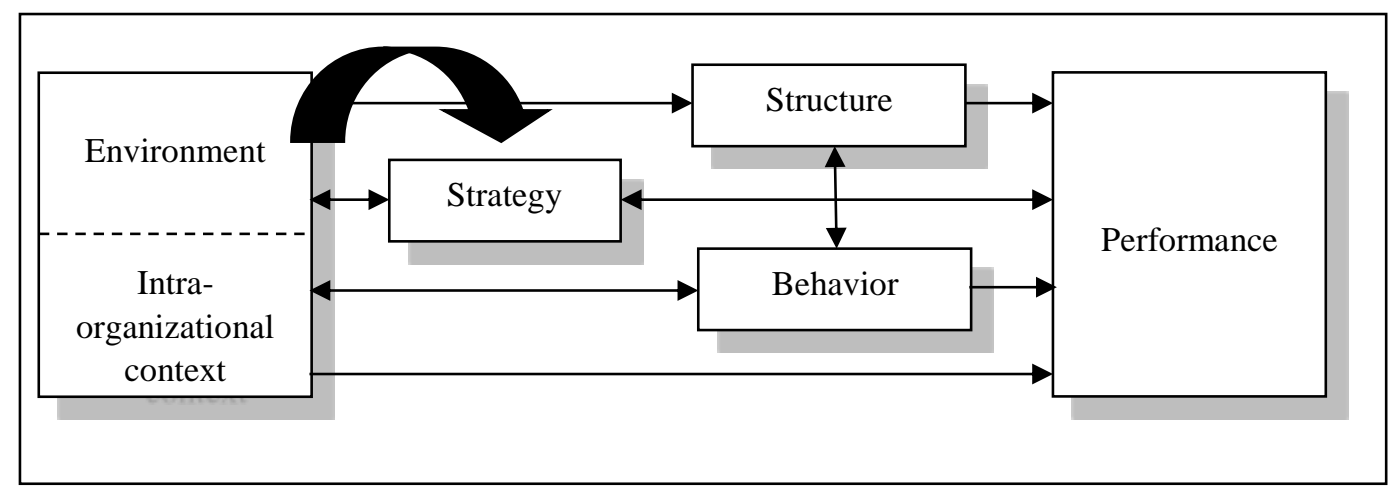

Source: author, based on Dobák (1988) 


\section{ANNEX II: Further potential paradigms - recent trends and models}

In Chapter 2, based mainly on the work of Wren, Guillén, and the author's content analysis of issues of the Harvard Business Review, we overviewed paradigms which are already validated by many social scientists and management experts. But how can management history tell anything about the "present" (post-1990s)? It is certainly a challenging task, strewn with pitfalls.

However, it would also be counter-productive to review and analyze 1,944 articles (HBR articles from 1991 to 2010, and a total of 3,839 from 1971 to 2010), without any conclusion at the end concerning the latest trends. We shall attempt to visualize these trends but beforehand, we need some information on how the analysis was carried out.

First, we must note that it is a somehow personal and therefore subjective evaluation of literature. Given the four previously described paradigms and some new ones (perceived and identified in the article contents), the author categorized HBR articles according to their eventual fit in one of these "boxes". Articles of one page or less were ignored, as were cartoons, letters to the editor and award winning announces. Categories were decided on the basis of the managerial dilemma which the article dealt with, and the proposed solutions or tools. Non-categorized (NC) articles cover analyses of a business sector or industry (e.g. health care, the energy sector, or even government policies); analyses of geographical areas (markets in the Middle East, China, etc.); management tools without real impact on philosophical or policy issues (EDP, MRP, Supply Chain, etc.); and pitfalls of business such as personal life of managers, discrimination, employee rights or legal issues. Some non-categorized articles describe new professions or related specific issues or techniques (accounting methods, purchasing, logistics, etc.).

The following issues have been specifically followed in order to identify current trends (with the abbreviations explained as used for the analysis):

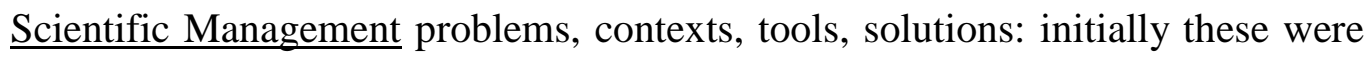
simply Taylorite methods but with time and technological development, the category also covered operations research, management science, cybernetics, time management, automation, and some labor productivity issues. 
Human Relations as detailed with the related paradigm: articles on industrial fatigue, turnover, labor unrest first, then a broad variety of topics related to the human side of work and interpersonal relations at the workplace.

Structural Revision: covering everything related to organizational structure, diversifying and then internationalizing companies, contingency fit and pressures for adaptation.

Articles related to Japan, whether it is the rising Japan, the Japanese business model, or just the competitive crisis which her products and manufacturing techniques caused.

Global Competition: including articles on competition and on strategy (strategic planning, strategic management, etc.).

Finance with two aspects: (1) these are articles related to corporate finance issues, corporate performance (company returns, profitability, dividends...), and (2) articles about the capital market: financial institutions, securities, pension funds (where the money comes from for investments).

Articles focusing on the Customer: marketing, Corporate Social Responsibility (CSR), or environmental issues. These are topics related to the question of how companies try to communicate with (potential) customers, this communication is being used as a means to create a good image, to attract people's attention to the company, to make them choose its products above others, and to encourage them to buy more.

Partnering: The last trend includes consolidation, partnerships, networks, alliances, mergers \& acquisitions and issues related to corporate governance. These topics are also connected, because corporate governance is designed to deal with the basic dilemma of agency theory, and if it fails to protect the shareholders' interests, the value of shares would decrease to a point where the company would be taken over by somebody else.

In the following paragraphs, we will survey how these trends evolve after the 1990s and before, as a brief introduction, we will make a review of the main socioeconomic background information and major managerial focus points of recent decades. 


\section{1) Socio-economic background after the $1990 \mathrm{~s}$}

The competitive crisis and the related subsequent restructuring also transformed the fundamental business model in countless corporations: dispensing with manufacturing, the majority transformed into service companies. This transformation brought an eventual decline in members for trade unions and the question of labor unrest totally disappeared for most companies. From the 1980s, as a consequence of free trade and deregulation, the "small is beautiful" philosophy and the rising entrepreneurship concept, a huge wave of smaller companies (considered hitherto as "anachronistic vestiges" of feudalism) was born parallel to the furor of mergers \& acquisitions. As Levitt (1987) points out:

"Entrepreneurship is the LSD of the 1980s [...] [But] if entrepreneurship is the LSD of the 1980s, than making money is its long hair. That too has become automatically fashionable, like being slim, patriotic, "sensitive", elegantly rugged like Ralph Lauren or tough like Rambo, being "into" jogging and weekending, switching to white wine, solemnly affirming that the Japanese make things better than anybody, and going crazy over the Superbowl” (4).

One consequence of the entrepreneurship and spin-off movement is the increasing difficulty in retaining talents for companies. The dominance of HR articles from the 90s is partly related to this: human resource managers were constantly looking for new ways to construct golden cages. Many of their best workers left due to the increasing opportunities available to them as entrepreneurs for instance, or simply because of the heavy workload and broken work-life balance, which became a social problem in the 80s. In other HR-related articles, due to the turbulent markets and fiercer competition, the emphasis was put on learning organizations or learning skills (involving also business process reengineering and leadership). Job enrichment, delegation and empowerment reached such a point that it became hard to find people without manager titles in companies. Employee stock options and open-book management were developed to reflect a message similar to the executive compensations and in order to foster an owner-like consciousness of employees at work. It was not always easy; the delegation of important decisions rarely is, and the process does not necessarily lead to the same decision which the CEO would have made. As Kotter (1999) confirmed, the two biggest challenges of managers in the 90 s became getting the job done through a 
diverse set of people with little direct control over them, on one hand, and selecting the relevant information from the huge variety of sources, on the other. This latter problem of information came from the development of informatics.

An easy guess for the most important change in the environment contingency for companies would be indeed the development of information technology and data processing. Electronic data processing and management information systems emerged as early as from the 1970s, yet without real breakthrough technological change. However, the new, modern electronic systems made it possible for large companies to build a more automatized and cheaper production process, whereas in smaller companies they prepared the terrain and created an expectancy in people for the forthcoming technological revolution: the internet. It is far beyond the scope of this thesis to attempt a comprehensive analysis on the effects of the World Wide Web, launched in the early 90s. It certainly transformed competition and made it easier even for small companies to become global, at least globally present on the web. It certainly transformed the way firms could communicate with their customers, or production teams could communicate with retail. It also certainly contributed to the rise of American start-up companies, causing a hysteric dot-com boom first, and then an economic crisis due to the over-evaluation of such companies on the stock market. Another aspect of the crisis was the wave of corporate scandals and false financial statements.

Through a review of all HBR articles from 1991 to 2010, four tendencies were detected, along which current business logic tends to move. Those four trends are (1) the constantly overriding role of profit and capital; (2) the stronger role of leaders; (3) the growing importance of partnerships and alliances; and (4) the fiercer fight to get closer to customers via marketing and advertising. It would be easy to say that these four aspects are actually one: we want to be stronger in competing for customers, so we create strong leaders and make partnerships to displace others, but in the end the whole game is merely about income and profit. The point of content analysis ought to have a slightly more detailed picture of what is going on in business currently, but nevertheless, there is a deep logic linking the simple ideas above into one system, already identified by the author (Saito \& Vaszkun, 2010).

What all firms basically need for their operations are capital, human resources and customers (daily income). We can assume that all national management systems have been historically shaped by the easy or difficult access to these basic elements and 
it is perfectly normal if cohesion is found in between. In this case, instead of human resources, we have alliances. With all the waves of lay-offs and decentralizations in American business history, we should not be surprised that companies apparently recognized their hiring capacities and limitations, and supplemented their human structure with external partners. The transaction costs may differ in some cases but the output is the same and to emphasize that, the best label for this category may be partners: standing both for employees and external allies. This aspect merely complements the power approach mentioned before; where two players cooperate in order to displace their competitors.

\section{2) More emphasis on finance, more power to shareholders}

Since the separation of ownership and control, the question of where to find capital is essential for American firms. And it was indeed a scarce resource: the US was a debtor nation before the world wars. Thus, except for specific and limited periods of time, financial issues were always of import, even in the Harvard Business Review-but the growth in their weight since the 90s is spectacular (Figure 27).

\section{Figure 27: Theoretical importance of finance from 1991 as in HBR}

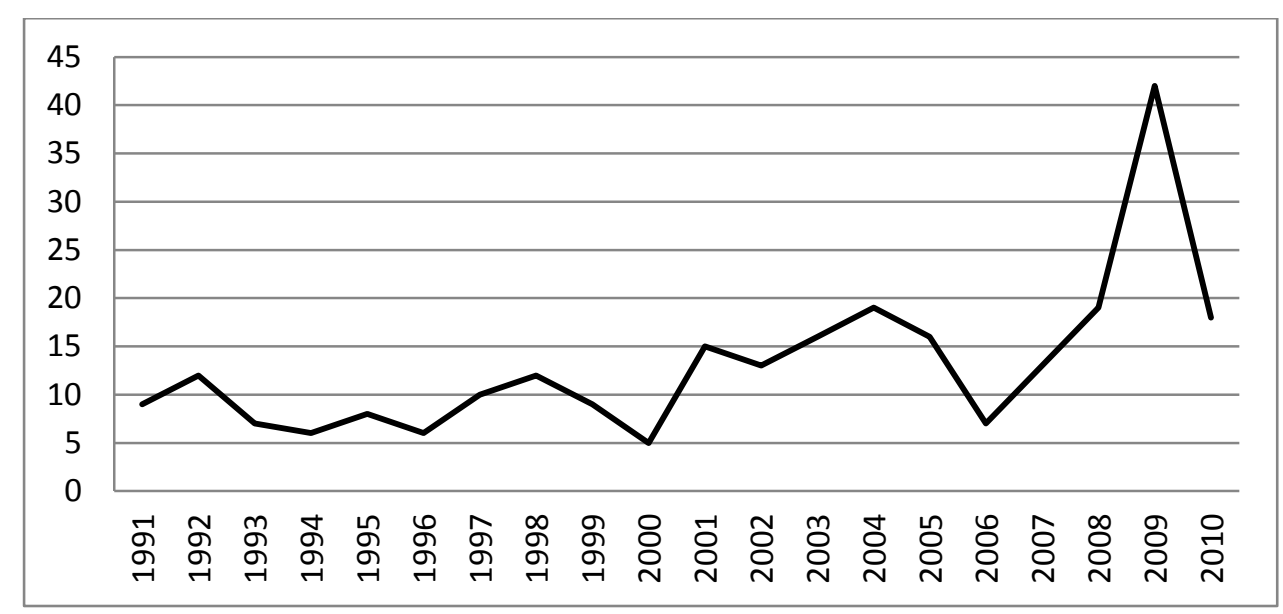

Source: author

Regarding its relevance in the business press, we can now shed light on the hitherto ignored financial aspect and raise it almost to the level of a paradigm. The only reason for not granting whole, paradigm-like chapters to any of the four trends mentioned in the previous point is that they are not answers to a specific dilemma in a specific period: 
they represent the ultimate needs of companies (capital, managers, partners and customers). Yet they have their own toolboxes and promoters.

In the early 1990s, Mark Roe wrote on the powerful, centralized managers and the distant shareholders as the distinctive characteristic of American companies-and that is still true today (Roe, 1994). But the Savings and Loan Crisis of the early 1990s, new techniques like financial engineering or shareholder-value analysis, or the growing role of institutional investors (pension funds, brokerage, etc.) contributed to the increasing importance of finance and raised new corporate governance issues. When owners did not receive high enough returns, a sell-out or a takeover of the company became more likely which was generally followed by restructuring and downsizing. New practices (such as BPR-Business Process Reengineering) emerged seeking efficiency and profitability, and concentrating on the "core businesses" of the companies.

Along with the massive downsizing wave, job stability sank sharply. Even managers' positions, hitherto safe and comfortable, became fragile from the 80 s on. Hostile takeovers attacked the traditional stakeholder view, and junk bonds, outsider CEOs, and institutional shareholders with more say reshaped corporate governance. Risky ventures had to be avoided, because poor returns brought the threat of a takeover. For the 1990s, layoffs and the broken work-life balance became a real issue for American society:

"The mass layoffs and growing marketization of employment brought a raft of negative publicity. In 1996 the New York Times ran a series on 'the downsizing of America'. It was the longest continuous piece the Times had published since the Pentagon Papers in 1971" (Jacoby, 2007: 97).

At the same time, the increased profit expectations may have partly caused the accounting scandals of the early 2000s and, as a consequence, American firms had to reconsider the importance and the role of profit in the corporate life. To cut a long story short, I present here the alleged reasons and context for the increasing importance of financial issues (matched to the previous paradigm logic).

With the development of information technology, production systems witnessed radical transformation. Robots in production, assembly, logistics and delivery systems, all linked together by IT hubs, and embedded informatics made production more efficient but also more expensive as an investment. Accordingly, this transformation increased the need for capital in firms, which thus became more dependent on finance. 
In regards to the human side of firms, the transformation of employment practices (resulting in empowerment, creative jobs, and so forth) redesigned compensation packages, and the new solutions (such as employee stock ownership) had to be worked out together with the finance team.

ROI and similar profitability measurement tools first gained ground with the divisionalisation of corporations as the dominant control method. Entrepreneurship in the 90s brought similar effects with the redefinition of control. At the same time, with mergers \& acquisitions, new corporate governance questions arose as well, for instance, should acquisitions be paid in cash or stock (Rappaport \& Sirower, 1999).

Finally, with emerging global competition, financial flow and products also went global, and administered by hedge funds, capital was also set free from borders to travel unchecked. Developing markets made the call for this hot money, as the investment opportunities and the potential profit was much higher rated in those countries than in the US, for instance. This phenomenon increases the demand for capital in developed countries compared to the supply. The answer was typically short term (quarterly) goals, great attention paid to the stock market's reactions and stock prices, and a marked will to please to the shareholders: it reduced the takeover risk but hindered companies in making long-term investments ( $\& \& D$, innovation, etc.).

The trend of the strengthening financial perspective became controversial after 2008, when the Lehman Brothers Inc. collapsed and suddenly all speculative risks, hitherto hidden and veiled by the beneficiaries, came to light and contributed to the escalation of the problems. The US government allowed Lehman Brothers to collapse in September 2008 with the presumption that the market could absorb the consequences (Mauboussin, 2009). But Lehman's losses were larger than expected and the bankruptcy announcement contributed to a global financial crisis and risk aversion.

The Lehman shock and the crisis do not mean the end of the upward progress of finance, however. In the 2000s, the financial products became so complex and complicated that they shifted the weight of finance from strategic to technical, not always reaching the top management's attention. This definitely changed with the new global crisis and it seems obvious now that financial instruments must be controlled. The pursuit of financial wealth and shareholder value creation has proved to be unsatisfactory and business trends are apparently moving towards stakeholder value, green business and sustainability. 


\section{3) The rise of the Leaders (Leadership)}

\section{Figure 28: Theoretical importance of leadership from 1991 as in HBR}

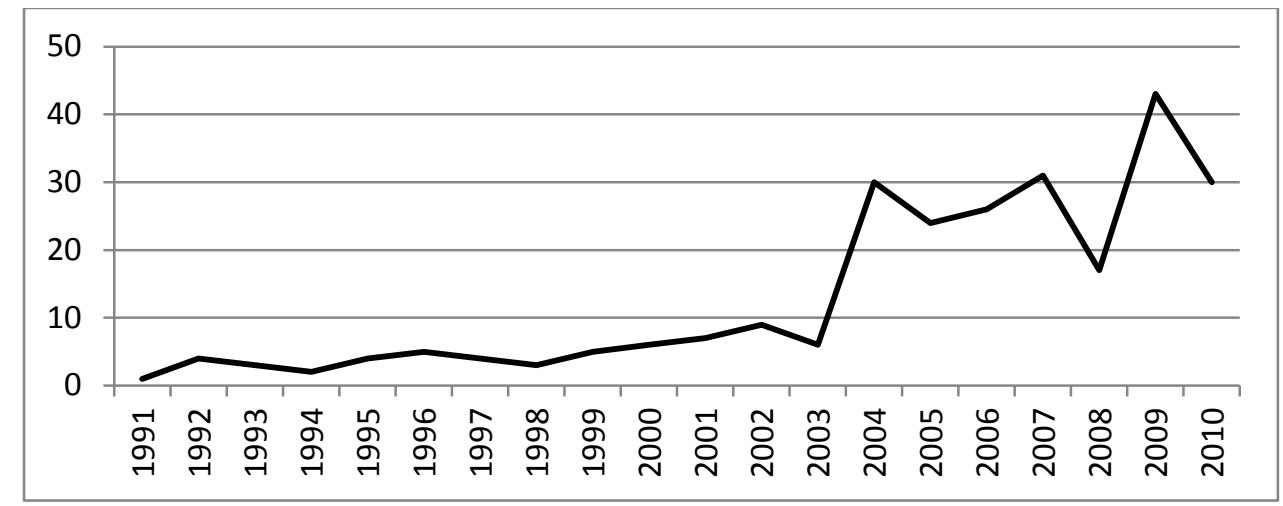

Source: author

In the literature review, it was possible to observe an apparent link between finance receiving more emphasis and the growing importance of leadership. Obviously, an organization which aims to tighten expenditure and make higher profit needs to have stronger guards for watching over the door of the treasury. The logical way for the shareholders of a company to make money on their shares is to grant great packages of stock options to the few at the top in order to ensure convenient stock prices and dividends. From a neo-Marxist perspective, this can lead to the higher exploitation of labor: "managers act as agents of capital to extract profits from the disciplined labor of workers" (Skaggs \& Leicht, 2005: 143). In short, short-term management inflates the importance of the CEO.

From the 50s, researchers have been attempting to identify personal traits and behaviors ensuring success and efficiency for managers, but partly due to the reasons above, this research became a genuinely hot topic in the 2000s. In HBR, the main topics mostly cover CEO succession, gender issues and female executives, executive compensation, and the leaders' ability to unite people in crisis contexts and turn them in a specific direction. Many articles have also been written because of the increasing problems with management education and the different MBA programs (Podolny, 2009). In 2004 Peter Drucker said: "The CEO is the link between the Inside that is 'the organization,' and the Outside of society, economy, technology, markets, and customers. Inside there are only costs. Results are only on the outside" (Lafley, 2009: 56). This result-orientation makes the job of the CEO extremely important. Indeed, the executive level seems to gain so much importance in business literature that Skaggs and 
Leicht (2005) even stated that mid-level managers will almost completely disappear while the role of top-managers is growing.

What is behind this strong shift, other than the stronger financial perspective? One reason is obviously the more automatized bottom line: computers ensure coordination between the different production units, sales points and the management, which indeed makes the work of middle managers redundant.

At the same time, more sophisticated employees need more sophisticated motivation schemes, and since technology is available on the market, differentiation from one's competitors is manifest rather through the employees. The skill of making these employees deliver their best as efficiently as possible becomes a key element at the top level. The control function is also greatly changing since the emergence of empowerment and entrepreneurship: rather than a direct supervision of line management, organizations increasingly need to have an indirect, panopticon-like control system conceived at the top level, where employees control and motivate themselves or each other.

Entrepreneurship and the "small is beautiful" principle is affecting the organizational structures as well: large firms are more and more complex but in parallel, small businesses are proliferating, resulting in an increasing number of CEOs and top managers. That creates a larger pool of executives who need education, trainings, regular information, and also attention.

Finally, global competition encourages business trips and missions abroad, and makes a firm's human resources diverse and global. It brings new perspectives to the job of the executives because diversity requires a more powerful leadership to create unity and efficiency.

To sum up, we can see that from the 2000s the perspective of the top management dominates a major part of business literature, at least according to our HBR analysis. Today, top managers and managerial skills clearly have a particular impact on the contingency elements, seen in Figure 2, but they are also subject to these elements and might with time be replaced by a better fit person. Consequently, it became necessary to explicitly reflect this relationship on the contingency chart. Therefore, Figure 31 below now contains the leadership as the seventh element of contingency. 


\section{4) Stronger connection with customers}

Figure 29: Theoretical importance of marketing (without CSR and environmental) issues from 1991 as in HBR

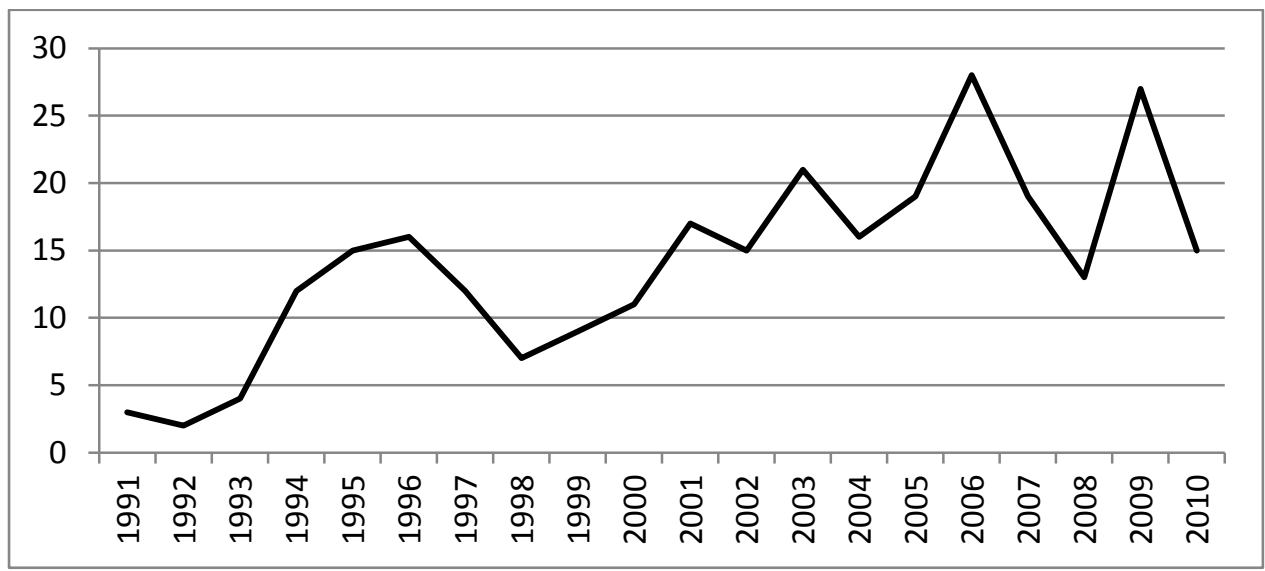

Source: author

We have found an increasing number of articles regarding customers and customer relations. From the 1990s, there are also an increasing number of tools for communication with customers: these include classical marketing tools (advertising, PR-Public Relations, promotions, etc.) and also alternative ways to transfer the image or values of a given company (CSR, environmental issues, prizes, customer communities, social media, etc.). In particular, environmental issues are tending to gain increasing importance and green energy is likely to become one of the hottest topics in the 2010s. Customers today are usually more conscious about their purchases and integrate in their product selection process many factors other than price, design or quality, including the social responsibility of the manufacturer, for instance.

Even the earliest factory owners and managers assumed certain social responsibility while providing welfare services to their employees' families, for instance. In the 1970s this social conscience was already more widespread although it also received criticism for reducing profit and introducing activities which did not fall under the "normal" operation of companies (Davis, 1973).

In the US, issues about CSR (Corporate Social Responsibility) gained importance together with the increasing recognition of the "stakeholders" of a company. As we mentioned before, Chester Barnard already observed that the firm as a legal entity was also part of a larger system (including suppliers, investors, customers, or even the broader society), influencing business decisions. 
Later on, it became quite clear for some commentators, that firms usually use CSR issues or the "responsible actions" as another tool to reinforce corporate image and get closer to their customers, who are also more conscious about limited resources, growing poverty and so on. The internet is also a new and easy way to communicate with customers, and many kind of social networks and interactive forums are available to build new, potentially closer relationships with customers. By the 2000s, CSR issues had clearly become a major factor in corporate communication, but the pressure of society regarding it was at least twofold. On the one hand, a great stir of publicity about different CSR rankings made customers more conscious of sustainability and social responsibility, and created a new, socially beneficial competition between firms. On the other hand, these issues pit business against society, when rather the two are interdependent, and "good" society tends to create successful firms or vice-versa (Porter \& Kramer, 2006).

As in the case of finance, customer issues in recent times are not new or drastically different from what they were before. But the topic of how to approach potential customers has certainly become more popular, and one wonders why. During the content analysis, the connection with customers was studied in the contexts of direct (marketing strategy, marketing research), or indirect tools (corporate image, PR, CSR) affecting customer relations. The main ideas for recent decades are as follows.

Common wisdom says that production-oriented economies pay relatively less attention to marketing. In the US, it was certainly true up to the 1950 s, because markets in any case absorbed almost the total output produced. A new, production-oriented wave emerged in the $70 \mathrm{~s}$ and $80 \mathrm{~s}$, and marketing in Japan is also far less important than production. But during the $80 \mathrm{~s}$, as described by the global competition, the US economy also shifted towards being more driven by the service sector and clearly, marketing issues became much more important than before. The higher margin or added value on services requires more communication to sell, compared to large-scale, low-margin industrial goods.

Concerning human relations, the general attitude is that humans are more mature and conscientious not only as customers but also as workers: they are sufficiently skilled and motivated to make responsible decisions and work alone or in teams. At the same time, their work-life balance has become more fragile: people spend more time at work than at home (or with their families), which in the end increases the importance of 
the firms' role in their lives. Along with that, corporate or brand images also have an increased value never experienced before.

Internet and e-commerce have significantly transformed the firms' environments and technical possibilities, affecting marketing more than other functions. Different divisions of a corporation usually have different marketing strategies and priorities, and internationalization increases the need for local communication and marketing in every country.

This aspect is also greatly significant in the context of global competition. When globalizing, some corporate functions like logistics must play an integrative, global role, creating a benefit of economies of scale. Other functions like human resources management usually keep a local profile, staying close to each market in the portfolio. Finally, functions like marketing must play both of these roles: create and communicate a global image or international brands, while approaching customers on a local or even one-to-one level. Moreover, when competition increases and becomes fiercer, it naturally emphasizes the value of customers and leads to more attention being paid to them.

\section{5) Creating networks: Groupings, partnerships and alliances}

Figure 30: Theoretical importance of consolidation, alliances and partnerships from 1991 as in HBR

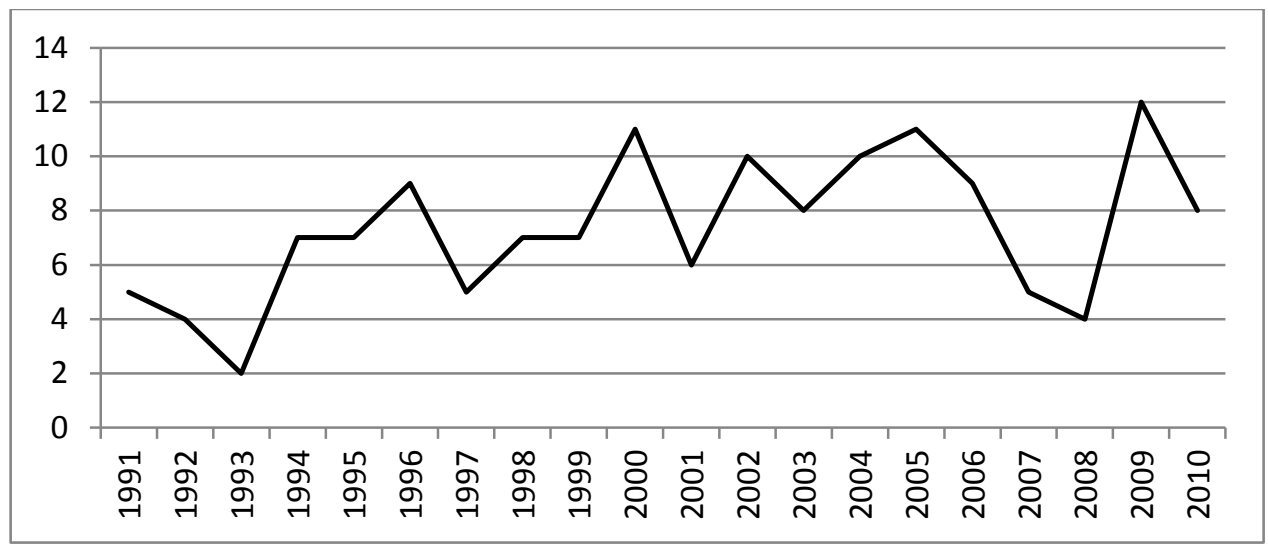

Source: author

The 1990s brought important corporate governance reforms in the US, and a new term appeared in literature: networks in business. There are basically two tendencies to be observed in HBR articles. One is consolidation; the other is the increasing volume of 
strategic alliances. Papers referring to corporate governance are often written in order to emphasize different aspects of a takeover. Mismanagement, the lack of satisfactory dividends or stock prices, or bad governance can all lead to the buy-off of the company, which is rarely beneficial to shareholders. Therefore, it is important that the executives be correctly supervised by the board, and that the boards truly represent the owners' interests. Mergers and acquisitions, along with partnerships and strategic alliances raise the same issue: despite all the "small-is-beautiful" concepts, grouping together clearly has an increasing appeal for companies.

One reason for this might be technical: the development of information technology, the use of computers and internet have made it easier to organize work processes at physically distant places. Production sites and robots, delivery chains, retail channels can all be connected into giant networks, where cooperation is facilitated by or based on technology, but the participating entities can be legally different, can have different ownership, or can be in different countries.

We saw earlier how empowerment and entrepreneurship have emerged in companies, transforming management and raising questions such as control or corporate integrity. However, the intended result is cheaper and more efficient management which could be a competitive advantage and a survival factor for the company. There may be other consequences as well, for instance, it becoming more difficult to retain the best talents. However, employment in its pure and simple form is only one option in order to get a specific job done (and often rather a complicated one, due to the difficulty of retaining talents in general, the massive dismissals during downturns, productivity targets, budget stops and so forth). This dilemma occurred with the transaction cost theory as well. The experience of the evolution of management is that hybrid solution between market and organization in the form of partnerships and alliances are becoming easier and more appealing. In practice it offers unlimited potential resources to get a specific task done, is less regulated and therefore more flexible than employment, and alliances can benefit from diversity (different people working together) without the long-term boundaries of employment and staff policies. Skaggs and Leicht described the same phenomenon in 2005: "[b]y designing employment contracts to be project and time specific, managers preserve their flexibility of action in firm-level decisions. As a result of this paradigm, growing numbers of firms, skilled workers, and investors are in networks of contractual relationships that resemble a diversified investor's stock portfolio" (140). 
One form of organizational structure to become fashionable was the virtual one, turning organizations more into a network of independent entities than a classical, hierarchical firm with central management, rank-and-file, etc. The unquestionable advantage of virtual structure is its dynamism and flexibility, making it more reactive to any kind of change.

In terms of competition and competitive strength, consolidation and alliances are a good means to increase size without the classical problems of increasingly difficult coordination or the negative effects of bureaucratization, a size large enough to become stronger than the competitors and displace them by strength.

To sum up the recent trends in management, we can again make use of the contingency model, now adapted to every paradigm. Figure 31 shows all connections made possible by technology, organizational power and skills, as well as the three ultimate management resources as detailed above.

Figure 31: Redesigned model for the contingency theory of management

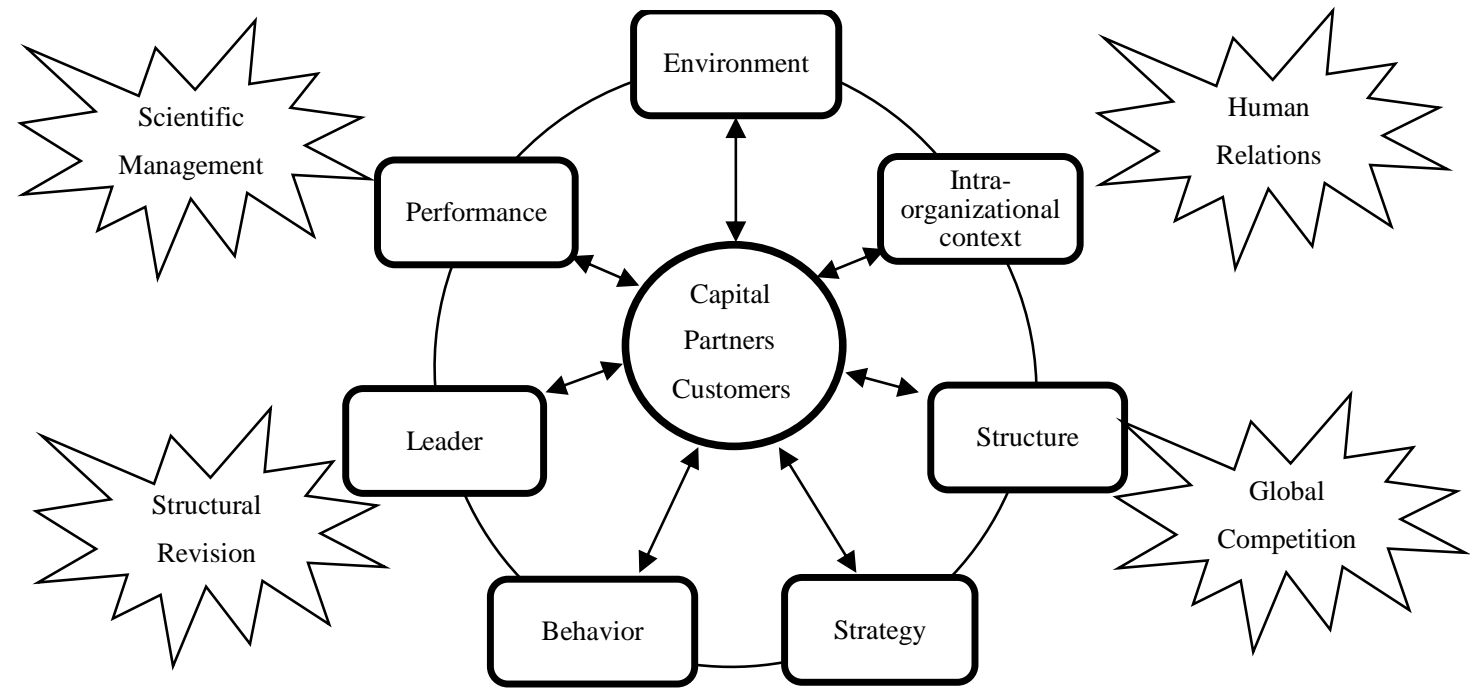

Source: author 


\section{6) The contingency logic behind the content analysis of the HBR}

In the analysis described above, the following logic was used to categorize article contents.

\section{External environment:}

Market characteristics; State / governmental politics; Legal / Technological environment; Culture...

Intra-organizational context:

Size; Production technology; Resources (material \& human); Origin; Industry...

\section{Structure:}

Organizational form; Division of work; Delegation of authorities; Coordination, processes...

Strategy:

Strategic management; Strategic planning; Competitive advantage; Global competition...

\section{Behavior:}

Personal management; Labor productivity; Interpersonal relations; HRM; Training; Retention; Empowerment...

Leadership:

Executive's competences and skills; What a leader should know; Succession; Characteristics of a good leader...

\section{Performance:}

Profitability; Controlling; Accounting... 


\section{ANNEX III:Content analysis at Waseda's main library}

\section{Categorized books (presented in Table 7)}

1. Abegglen, James C. (2006): 21st-century Japanese management : new systems, lasting values

2. Aoki, Masahiko, Jackson, Gregory \& Miyajima, Hideaki (2007): Corporate Governance in Japan: Institutional Change and Organizational Diversity

3. Basu, Dipak R. \& Victoria Miroshnik (2000): Japanese multinational companies: management and investment strategies

4. Black \& Morrison (2010): Sunset in the Land of the Rising Sun

5. Fields, George et al. (eds) (2000) Leveraging Japan: marketing to the new Asia

6. Fuller, Ellen V. (2009): Going global : culture, gender, and authority in the Japanese subsidiary of an American corporation

7. Graham, Fiona, (2003): Inside the Japanese company / OR: / A Japanese company in crisis

8. Haak, René (ed.) (2006): The Changing Structure of Labour in Japan

9. Haghirian, Parissa (2010): Innovation and change in Japanese management

10. Hamada, Kazuki (ed.) (2010): Business group management in Japan

11. Imai, Jun (2011): The transformation of Japanese employment relations: reform without labor

12. Jackson, Keith \& Tomioka, Miyuki (2004): The changing face of Japanese management

13. Jacoby, Sanford M., (2005): The embedded corporation: corporate governance and employment relations in Japan and the United States

14. Kawamura, Tetsuji (ed.) (2011): Hybrid factories in the United States: the Japanese-style management and production system under the global economy

15. Keizer, Arjan B. (2010): Changes in Japanese Employment Practices

16. Kimoto, Kimiko (2005): Gender and Japanese management

17. Kono, Toyohiro \& Clegg, Stewart (2001): Trends in Japanese management : continuing strengths, current problems, and changing priorities

18. Maswood, Javed, Graham, Jeffrey and Miyajima, Hideaki (eds) (2002): Japan-change and continuity

19. Monden, Yasuhiro (ed) (2000): Japanese cost management

20. Mouer, Ross E. \& Hirosuke, Kawanishi (2005): A sociology of work in Japan

21. Ogura, Masao (2004): Delivering the goods : entrepreneurship and innovation in a Japanese corporation

22. Oh, Ingyu (2004): Japanese management: past, present, and future

23. Ohara, Shigenobu \& Takayuki Asada (eds) (2009): Japanese project management : KPM - innovation, development and improvement

24. Ohtsu, Makoto, (2002): Inside Japanese business : a narrative history, 1960-2000

25. Okabe, Mitsuaki (2002): Cross Shareholdings in Japan: A New Unified Perspective of the Economic System

26. Olcott, George (2009): Conflict and change : foreign ownership and the Japanese firm

27. Oyabu, Takeshi (2010): Work Behavior and Human Resource Management in Japanese Firm

28. Richter, Frank-Jürgen (2000): Strategic networks: the art of Japanese interfirm cooperation

29. Roehl, Thomas \& Bird, Allan (2005): Japanese firms in transition: responding to the globalization challenge

30. Schaede, Ulrike (2008): Choose and focus: Japanese business strategies for the 21st century

31. Tsuneyoshi, Ryoko Kato (2001): The Japanese model of schooling : comparisons with the United States

32. Vogel, S. K. (2006): Japan Remodeled

33. Whittaker, D. Hugh \& Deakin, Simon (2009): Corporate Governance and Managerial Reform in Japan

Not (directly) relevant for Japanese corporate management or stance towards change cannot be categorized

1. Abo, Tetsuo (ed) (2007): Japanese hybrid factories: a comparison of global production strategies

2. Adeel, Zafar (ed) (2003): East Asian experience in environmental governance : response in a rapidly developing region

3. Andō, Kenichi, (2005): Japanese multinationals in Europe: a comparison of automobile and pharmaceutical industries

4. Baba, Naohiko (2000): A re-examination of ex ante pricing of currency risk in the Japanese stock market : a pricing kernel approach

5. Ballon, Robert J. \& Honda, Keikichi (2000): Stakeholding: the Japanese bottom line

6. Bankoff, Greg \& Boomgaard, Peter (eds) (2007): A history of natural resources in Asia: the wealth of nature

7. Beamish, Paul, Andrew Delios, Shige Makino (eds.) (2001): Japanese subsidiaries in the new global economy

8. Bird, Allan (ed.) (2002): Encyclopedia of Japanese business and management

9. Burgelman, Robert A. \& Chesbrough, Henry (2001): Comparative studies of technological evolution

10. Coffey, Dan, (2006): The myth of Japanese efficiency: the world car industry in a globalizing age

11. Daníelsson, Jón \& Morimoto, Yuji (2000): Forecasting extreme financial risk: a critical analysis of practical methods for the Japanese market

12. Data book : Japanese administrative. (2000)

13. Dent, Christopher M. (ed) (2008): China, Japan and regional leadership in East Asia 
14. Elger, Tony, (2005): Assembling work : remaking factory regimes in Japanese multinationals in Britain

15. Faison, Elyssa, (2007): Managing women: disciplining labor in modern Japan

16. Gaunder, Alisa (ed) (2011): The Routledge handbook of Japanese politics

17. Haak, René (2004): Theory and management of collective strategies in international business: the impact of globalization on Japanese-German business collaboration in Asia

18. Haak, René \& Hanns Günther Hilpert (eds): Focus China : the new challenge for Japanese management

19. Harvard business review on manufacturing excellence at Toyota. Boston, Mass.: Harvard Business School Pub., c2008.

20. Hozumi, Toshihiko \& Wohlmuth, Karl (eds) (2000): Schumpeter and the dynamics of Asian development

21. Ihara, Ryōji (2007): Toyota's assembly line : a view from the factory floor

22. Itō, Yoshio (2003): Strategy and innovation in Japanese business

23. Jones, Kimberly \& Ono, Tsuyoshi (eds) (2008): Style shifting in Japanese

24. Kaufman, Bruce E. (2009): Advances in industrial and labor relations [electronic resource]

25. Keeley, Timothy Dean (2001): International human resource management in Japanese firms: their greatest challenge

26. Kubota, Takashi (ed) (2008): Cyberlaw for global E-business: finance, payment, and dispute resolution

27. Kudo, Akira; Matthias Kipping and Harm G. Schröter (eds) (2004): German and Japanese business in the boom years : transforming American management and technology models

28. Legewie, Jochen \& Hendrik Meyer-Ohle (eds) (2000): Corporate strategies for Southeast Asia after the crisis: a comparison of multinational firms from Japan and Europe

29. Masumoto, Tomoko (2000): American interns in Japanese organizations : participant perceptions and interpretations of intercultural communication in the U.S.-Japan Industry and Technology Management Program

30. McDonald, Darren (2004): Top views of diversity: Japanese top management perspectives of workforce diversity in Japan

31. Miyamoto, Kanji (ed.) (2008): International management accounting in Japan: current status of electronics companies

32. Mizunuma, Emiko (2002): Cross-cultural impression management: Japanese presentation of self in job interviews

33. Morgan, Glenn, Kristensen, Peer Hull \& Whitley, Richard (eds) (2001): The multinational firm : organizing across institutional and national divides

34. Ohbuchi, Kenichi (ed) (2007): Social justice in Japan: concepts, theories and paradigms

35. Okazaki, Tetsuji (ed) (2007): Production organizations in Japanese economic development

36. Parto, Saeed \& Herbert-Copley, Brent (eds) (2007): Industrial innovation and environmental regulation : developing workable solutions

37. Pearson, Christine M., Christophe Roux-Dufort, Judith A. Clair (eds) (2007): International handbook of organizational crisis management

38. Peters, B. Guy, Rhodes, R.A.W \& Wright, Vincent (2000): Administering the summit : administration of the core executive in developed countries

39. Pinner, Jonathan W. (2003): TQM practices and organizational culture: Japanese versus American perspectives

40. Raoprasert, Tanachart \& Islam, Sardar M. N. (2010): Designing an Efficient Management System: Modeling of Convergence Factors Exemplified by the Case of Japanese Businesses in Thailand

41. Robertson, Jennifer (ed) (2005): A companion to the anthropology of Japan

42. Sanyal, Bishwapriya (ed) (2005): Comparative planning cultures

43. Spencer-Oatey, Helen (2000): Culturally speaking : managing rapport through talk across cultures

44. Taplin, Ruth (2004): Valuing intellectual property in Japan, Britain, and the United States

45. Tietze, Susanne (2008): International management and language

46. Uchiyama, Kenichi (2003): The theory and practice of actuality : reinterpreting soft systems methodology (SSM) from the Japanese point of view and its implications for management and information systems studies

47. Uchiyama, Yū: Koizumi and Japanese politics : reform strategies and leadership style

48. Yoshino, Naoyuki, Hidefumi Yamagami, Wataru Takahashi (eds) (2007): Pilot study 2002 of Asian bond markets 


\section{ANNEX IV: The "MS Word" format of the questionnaire}

Dear Sir/Madam,

Before the questions, let us give you some background information.

\section{The project}

This short survey is the last phase of a doctoral research project which aims to show what people today think about companies and the way they should be managed. You can receive the results of the survey-see the information after the questions please. Thank you for helping us to get a better picture of what people feel about business in Japan!

\section{The method-this website}

'Surveymonkey' is the most popular website to conduct surveys (this is a printed version). We benefit from the same security policy as Fortune 100 global companies collecting opinions. Only aggregate data will be published (individual answers will be preserved for 1 year but not used or given to third parties).

\section{Your contribution}

We are going to ask your opinion (agree or not) about 75 sentences related to the workplace. It takes about 19 minutes to answer all the questions. While you do that, please think of your actual workplace or (if you don't work) the company which you would like to work for. Every question is related to the workplace but may cover different topics.

\section{Do you agree with the following statements? Please indicate yes or no:}

1. The company should welcome a new recruit like a family member. $\quad$ Yes No

2. You can say no at your workplace to your superior. $\quad$ Yes No

3. On-the-job training is the best way to learn one's job. $\quad$ Yes No

4. It is OK to fall in promotion behind colleagues recruited at the same time as you. Yes No

5. Would you in a crisis situation accept reduced wages / work time in order to Yes No keep general job safety?

6. A company should guarantee lifelong employment for its best workers. Yes No

\section{Please give a mark for each of the statements.}

\section{Questions related to the workplace}

$7=$ Agree completely $6=$ Mostly agree $5=$ Rather agree $4=$ Neutral $3=$ Rather disagree $2=$ Mostly disagree $1=$ Disagree completely

7. Work is always a team achievement, never just individual performance.

8. Salaries should be entirely based on performance, no matter the age or seniority of employees.

9. Going out with colleagues after work is important.

$7-6-5-4-3-2-1$

10. Staying in the same company long term is not good because it blocks internal competition and limits career prospects.

$7-6-5-4-3-2-1$

$7-6-5-4-3-2-1$

$7-6-5-4-3-2-1$

11. If I were graduating now, I would rather go to a company with foreign management: they understand better what a young employee needs.

$7-6-5-4-3-2-1$

12. It is good to have internal competition in a company among employees as it enhances performance.

$7-6-5-4-3-2-1$

13. If a person is highly qualified he/she should be quickly promoted even if his/her subordinates end up being much older than he/she is.

$7-6-5-4-3-2-1$

14. Individual appraisal of performance is a threat to harmony; companies should measure group performance.

$7-6-5-4-3-2-1$

15. Recruitment agencies (head hunters) should gain a more prominent $7-6-5-4-3-2-1$ 
role in job hunting because the companies only hire new graduates: older people also need job opportunities.

16. I am grateful to my company and I express this with my hard work every day.

17. The best way for decision-making is to vote: it is clear and efficient.

18. It is good to have a limited number of "core workers" with some privileges in a company: achieving this status will motivate every employee.

19. I try to pursue hobbies / social activities away from work.
20. Company postings involving separation from family are acceptable / unavoidable.

21. Skill development (training) is the responsibility of the company, not the individual worker.

22. People should try harder to achieve consensus in decision-making: group harmony is worth the time invested in that process.

23. Lifetime (or long-term) employment is outdated: I don't want to stay in the same company for such a long time.

24. Performance should be a significant element of the wage but it is not good if a young person earns more than an older one.

25. Mainly performance-based pay is not good as it leads to merely shortterm goals and hinders cooperation.

26. The best way to increase size for a company is to hire more young graduates from top universities.

27. In a company it is always desirable to have a leader with a strong vision: so people following him/her go in the same direction and raise their performance.

28. It is all right and sometimes even desirable to take risk in business.

29. If one day I want to find a new job, I will send my CV to several recruitment agencies.

30. I recognize equality between men and women but somehow I feel more comfortable having a male superior.

31. The Japanese companies are too homogeneous: they should hire people with different backgrounds - even from foreign countries.

32. Small and large firms have different characteristics and possibilities: it is acceptable and normal that compensation and benefits are also different according to the size of the company.

33. If possible, taking risk is to be avoided when it can endanger job security.

34. It is possible to lay off considerable numbers of employees without strong reactions (quarrel) within either the company or in the broader society.

35. In a company the group consensus is more important than any leader or manager: group cohesiveness is the best tool to ensure common vision and good performance.

36. Recruitment and career management is better held at central (Human Resources department) level because it costs less and gives a better overview on employee transfers.

37. I always express my personal opinion during important meetings and others should do the same: people without opinion cannot give any contribution to the group.

38. Recruitment and career management is better held at division / unit level because it would be more appropriate to the real needs of the company.

$7-6-5-4-3-2-1$

$7-6-5-4-3-2-1$

$7-6-5-4-3-2-1$

$7-6-5-4-3-2-1$

$7-6-5-4-3-2-1$

$7-6-5-4-3-2-1$

$7-6-5-4-3-2-1$

$7-6-5-4-3-2-1$

$7-6-5-4-3-2-1$

$7-6-5-4-3-2-1$

$7-6-5-4-3-2-1$

$7-6-5-4-3-2-1$

$7-6-5-4-3-2-1$

$7-6-5-4-3-2-1$

$7-6-5-4-3-2-1$

$7-6-5-4-3-2-1$

$7-6-5-4-3-2-1$

$7-6-5-4-3-2-1$

$7-6-5-4-3-2-1$

$7-6-5-4-3-2-1$

$7-6-5-4-3-2-1$

$7-6-5-4-3-2-1$

$7-6-5-4-3-2-1$ 
39. Before decision-making, it is always better to know the others' opinion about the issue.

40. It is normal that women quit their job at marriage or childbirth.

$7-6-5-4-3-2-1$

41. Achieving the goals as a team is our common responsibility, not only our manager's.

42. Differences between "core workers" and temporary staff or part-timers are nonsense: they are doing the same job anyway.

43. The re-employment of retirees should be banned because it takes jobs from young people.

44. The job of the union is to confront the management in order to represent purely the workers' interests.

45. It is better to evaluate workers by the way they do their job than by the result, as the result may depend on many things.

46. People should never work alone, co-workers can bring help and play an important role in correcting each others' mistakes.

47. Working in an open office is tiring; every company should try to give individual offices for their white-collar staff.

48. Making friends is one of the most important things in a company.

$7-6-5-4-3-2-1$

$7-6-5-4-3-2-1$

$7-6-5-4-3-2-1$

$7-6-5-4-3-2-1$

$7-6-5-4-3-2-1$

$7-6-5-4-3-2-1$

$7-6-5-4-3-2-1$

$7-6-5-4-3-2-1$

$7-6-5-4-3-2-1$

49. Regular rotation of employees should be avoided: it is confusing and they cannot specialize in their jobs.

$7-6-5-4-3-2-1$

50. Employees recruited at the same time should basically be promoted together: it fosters cooperation between members, limiting harmful competition.

51. It is better not to promote people very fast, older managers are wiser and usually do a better job.

52. There is nothing wrong with having a female boss: as a manager they can perform as well as men.

53. It is better if the union cooperates and keeps friendly relations with the management as the economic health of the company is also in the interest of the workers.

54. Labor unions and their activity are nowadays irrelevant to employees' lives.

55. I would rather work for a large organization than a small one.

56. The performance of older people is usually better due to their greater experience.

57. Rotating employees regularly is good because they can get better knowledge and vision about the company as a whole, so probably they can become better managers.

58. There is too much stress and depression related to corporate life today: life was better 20 years ago.

$7-6-5-4-3-2-1$

$7-6-5-4-3-2-1$

$7-6-5-4-3-2-1$

$7-6-5-4-3-2-1$

$7-6-5-4-3-2-1$

$7-6-5-4-3-2-1$

$7-6-5-4-3-2-1$

$7-6-5-4-3-2-1$

$7-6-5-4-3-2-1$

\section{Questions related to the economy / companies in general}

7=Agree completely 6=Mostly agree 5 =Rather agree 4=Neutral 3=Rather disagree 2= Mostly disagree $1=$ Disagree completely

59. It is important to protect our markets and jobs from foreign competition.

$7-6-5-4-3-2-1$

60. Japan should move more towards the American economy and its institutions, changing its old, outdated practices.

61. Japan should find its own way to recover from crises, based on its traditions and culture.

62. It is very important for directors of a company to not only represent the owners' (shareholders') interests but also the ones of employees, business

$7-6-5-4-3-2-1$

$7-6-5-4-3-2-1$

$7-6-5-4-3-2-1$ 
partners, or other members of our society.

63. Big companies need more transparency and control by the market: there should be at least one external director on the board.

$7-6-5-4-3-2-1$

64. It is good if the company can offer a seat on the board of directors to its senior managers at the end of their career.

$7-6-5-4-3-2-1$

65. A top manager (CEO) recruited from another organization usually succeeds better in making the company more efficient and productive than a CEO who is promoted from within the lower ranks of the same company.

66. If the owners of a company do not put pressure on managers to achieve good results even in the short term, the company will perform less well.

$7-6-5-4-3-2-1$

67. The key success factor for a company is to produce good quality products at an affordable price - succeeding in this ensures almost automatic success.

68. Japanese companies should pay more attention to efficient marketing: today it may be more important than the quality of the products.

$7-6-5-4-3-2-1$

69. Financial and profitability indicators are more important for judging a company's performance than sales or market share.

70. Japanese top managers should earn much more than 10 times the young graduate new recruits' salary (in the USA it can be 50 times more).

71. Companies should always form interest groups so they can be much stronger.

$7-6-5-4-3-2-1$

$7-6-5-4-3-2-1$

$7-6-5-4-3-2-1$

$7-6-5-4-3-2-1$

72. Stakeholders of a company are not limited to shareholders, and management must appropriately reflect multiple interests.

$7-6-5-4-3-2-1$

$7-6-5-4-3-2-1$

73. The company can prosper more in the long term if shareholders are "silent" and do not demand short-term profit above all.

$7-6-5-4-3-2-1$

74. Owning shares on a reciprocal basis between companies (crossshareholding) is good, mostly enhancing cooperation.

$7-6-5-4-3-2-1$

75. Owning shares on a reciprocal basis between companies (crossshareholding) is bad, tying them together, hindering financial results.

$7-6-5-4-3-2-1$

III. Please answer these questions about you

\begin{tabular}{|c|c|c|}
\hline Male / Female & 77. Year of birth: & $\begin{array}{l}\text { 78. Marital status: } \\
\qquad \text { Single / In relationship / } \\
\text { Married }\end{array}$ \\
\hline $\begin{array}{l}\text { 79. Do you have children? } \\
\qquad \text { Yes / No }\end{array}$ & $\begin{array}{l}\text { 80. Did you already work in } \\
\text { Japan? } \quad \text { Yes / No }\end{array}$ & $\begin{array}{l}\text { 81. Do you plan to work in Japan in } \\
\text { the } \\
\text { Yes / No }\end{array}$ \\
\hline $\begin{array}{l}\text { 82. Which is the country where } \\
\text { you have mostly spent the first } \\
20 \text { years of your life? }\end{array}$ & $\begin{array}{l}\text { 83. What is your current } \\
\text { country (residence): }\end{array}$ & $\begin{array}{l}\text { 84. If Japan, please specify prefecture } \\
\text { (ken): }\end{array}$ \\
\hline \multicolumn{3}{|c|}{ 85. Please specify your education level (or the expected degree if you are student): } \\
\hline \multicolumn{2}{|c|}{ a, Elementary school/Junior high school b, } & High \\
\hline \multicolumn{2}{|c|}{ c, Technical school/Vocational school/Two-year college d, } & Four-year \\
\hline \multicolumn{2}{|c|}{$\begin{array}{l}\text { e, MBA, Law school, Accounting School } \\
\mathrm{g}, \mathrm{PhD}\end{array}$} & or $\mathrm{MSc} \quad($ except \\
\hline 86. Do you have work experience & lready (any kind of paid job & y country)? \\
\hline
\end{tabular}

If you already have work experience... (if not, please jump to $\boldsymbol{n}^{\circ 92}$ )

87. In which sector is it the most significant?

88. Please specify your most relevant 


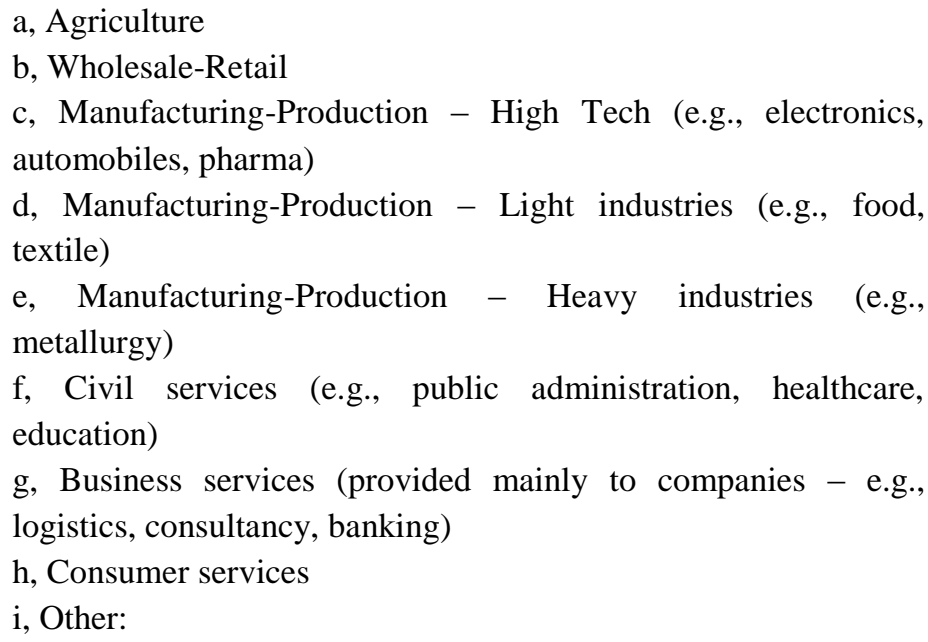

90. What has been the longest time until now that you have stayed in the same company?

years

professional activity:

a, Manual work- Production (factory)

b, Sales-marketing

c, R\&D / Engineering

d, HR / Logistics / Legal / Finance-

Economics

e, Training-education

f, Other: worker

d, part-time worker

$$
\mathrm{g} \text {, senior or top manager }
$$

If you would like to be informed of the aggregate result, please leave your e-mail address here:

Please share with us if you have any comment or experience to tell: (optional) 


\section{ANNEX V: Details and findings of the survey}

Table 11 summarizes the nature of measurement scales and variables of the survey. All non-metric information was coded numerically.

Table 11: The variables of the survey

\begin{tabular}{|l|l|l|}
\hline Variable & Type & Measure \\
\hline Yes-or-no questions (6) & non-metric & nominal (dummy) \\
\hline 7-point scale statements (69) & metric & ordinal \\
\hline Gender & non-metric & nominal (dummy) \\
\hline Age & metric & interval (scale) \\
\hline Marital status & non-metric & nominal \\
\hline Has children? & non-metric & nominal (dummy) \\
\hline Already worked in Japan? & non-metric & nominal (dummy) \\
\hline Plan to work in Japan & non-metric & nominal (dummy) \\
\hline Country of origin & non-metric & nominal \\
\hline Living area in Japan & non-metric & nominal \\
\hline Level of education & metric & ordinal \\
\hline Experience: Sector / Industry & non-metric & nominal \\
\hline Experience: professional activity & non-metric & nominal \\
\hline Company size & metric & ordinal \\
\hline Tenure & metric & interval (scale) \\
\hline Income level & metric & ordinal \\
\hline Professional status & metric & ordinal \\
\hline
\end{tabular}

\section{1) Findings (1): comparing theory with practice}

With the new, transformed database it became possible to analyze to what extent respondents are in favor of Japanese-style management. In the first round, the general level of support of the whole system (all the 26 operationalized elements together) was examined.

\section{1) A global picture of support}

As answer 7 represented total agreement with traditional methods in Japan, and answer 1 a total rejection or disagreement, it made sense to summarize those values for each respondents. It is certainly not a sophisticated way to get convincing, significant results 
but this simple step offers some preliminary findings and helps us to decide which way to move forward. Figure 32 represents the curve of those sums for the whole panel. The two tails of the curve suggest a need for centering data.

\section{Figure 32: General support of traditional management ${ }^{102}$}

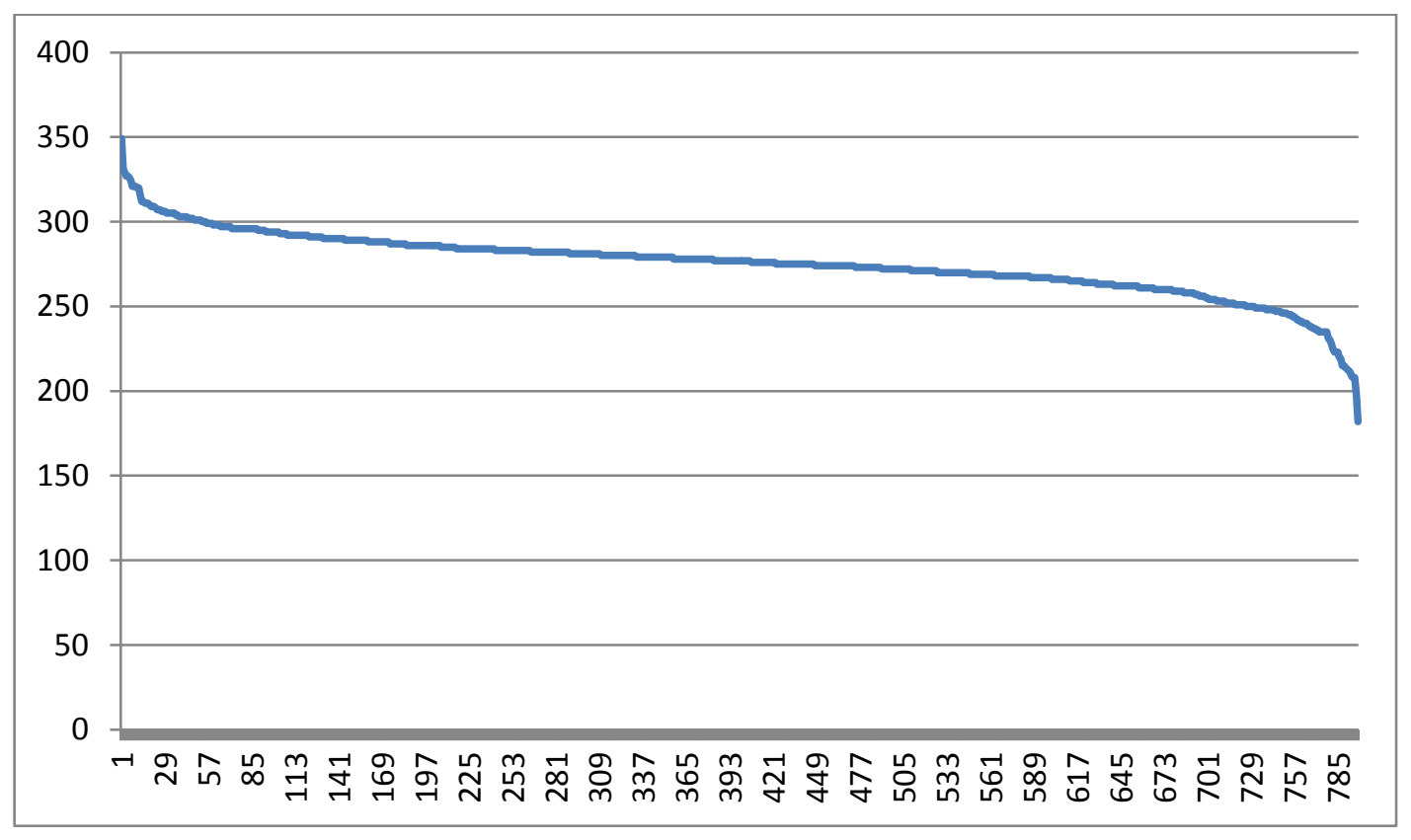

It seems to be logical to differentiate some groups according to their level of support. There are two extremes both in the positive (above 300) and in the negative (below 250) edges. We will first examine these two groups in order to see what kind of characteristics they have. It is difficult to know whether they are really strong supporters and rejecters, or whether they are just finding it easier to rate on the extremes in their evaluation. The minimum value was 182 and the maximum 349. Parallel to the two extremes, the range between 300 and 250 can be also examined. In order to do so, we can identify four groups in the panel: respondents with SUM over 300, between 300 and 275 (called together "supporters"), and with SUM between 274 and 250, or under 250 (called "rejecters"). The whole panel is divided by the mode at 274 points. These groups are represented in Table 15.

The number at the top of each cell represents the mean of the selected category, with the standard deviations below. Genders in the database were coded 1 as male and 2

\footnotetext{
${ }^{102}$ This figure is based on a computed variable called "SUM", which summarize the ratings of the 69 variables for each respondent.
} 
as female. For the country of origin, 1 stands for Japan, 2 for Asia, 3 for Europe, 4 for the Anglo-American countries, ${ }^{103}$ and 5 for others (only a few cases).

Table 12: Crosstab on the general support of Japanese management (SUM)

\begin{tabular}{|l|l|l|l|l|}
\hline $\begin{array}{l}\text { MEANS } \\
\text { St.dev. }\end{array}$ & SUM $>\mathbf{3 0 0}$ & $\begin{array}{l}\text { SUM }>\mathbf{2 7 4} \\
\text { but }</=\mathbf{3 0 0}\end{array}$ & $\begin{array}{l}\text { SUM }>/=250 \\
\text { but }</=\mathbf{2 7 4}\end{array}$ & SUM<250 \\
\hline \multirow{2}{*}{ Gender } & 1.33 & 1.48 & 1.51 & 1.49 \\
& 0.47 & 0.5 & 0.5 & 0.50 \\
\hline \multirow{2}{*}{ Age } & 39.3 & 40.76 & 37.26 & 34.37 \\
& 14.35 & 12.33 & 10.84 & 10.14 \\
\hline \multirow{2}{*}{ Origin } & 1.15 & 1.12 & 1.35 & 2.04 \\
& 0.67 & 0.5 & 0.916 & 1.31 \\
\hline \multirow{2}{*}{ Education } & 4.0 & 3.44 & 3.82 & 4.67 \\
& 1.24 & 1.15 & 1.18 & 1.37 \\
\hline \multirow{2}{*}{ Company size } & 3.9 & 3.67 & 4.05 & 4.44 \\
& 1.6 & 1.634 & 1.63 & 1.5 \\
\hline \multirow{2}{*}{ Tenure } & 12.27 & 12.175 & 9.13 & 5.98 \\
& 11.7 & 10.2 & 7.48 & 6.0 \\
\hline Total cases & 52 & 395 & 284 & 67 \\
\hline
\end{tabular}

Source: author

What we can see from Table 12 is that a strong "supporter" of the traditional Japanese system is probably a man (though gender does not seem to be a significant differentiating factor). In this group, 35 respondents out of 52 were men (67.3\%) and in the opposite (strong rejecters) group, 34 out of 67 (50.7\%). Also, a supporter is probably an older person, five years more senior compared to the other group. Age is apparently a more important factor in making difference as a continuous trend marks the four groups. Perhaps the most striking difference is the origin of respondents: a strong supporter is most probably Japanese (94.2\%, or $93.1 \%$ for the second column) with no case from Anglo-Saxon countries (1.3\% for the second group). Thus, a rejecter may easily be a foreigner living or working in Japan $(5.7 \%$ for the third, $17.9 \%$ for the fourth group). Standard deviation in this case is naturally higher because respondents came not only from Japan (only $55.2 \%$ in the fourth group) as did most of the supporters.

Curiously, strong "rejecters" are on average more educated, and this is because their group includes 27 respondents out of 67 with a master level or above, although this number is 8 for the strong "supporters". These rejecters seem to work for even larger companies, which sounds surprising as flagships of Japanese-style management are

${ }^{103}$ The U.S.A., Canada, the UK and Australia. 
rather big corporations in Japan. Our amazement is somewhat dispelled by the tenures: the first two groups clearly have more job security at their workplaces. It is difficult to say whether rejecters do not want or cannot enjoy longer tenures but lifelong employment seems to affect the attitude towards traditional management style, as pointed out by Saito and Vaszkun (2010) as well.

At this point in our analysis we can confirm, as yet without statistical evidence, that there appears a group tending to support traditional practices, and another one rejecting them. Those who want change are younger and more heterogeneous in terms of gender and origin, and they cannot or do not want to stay in the same company for a long time. They are rather highly educated and may be working for the biggest companies in Japan without a tenure contract, or they may still be university students. The others, who are strongly supporting or defending the traditional system, are apparently rather older, Japanese males with an education level stopping at BA degree and enjoying long-term employment in rather big organizations. We can also note that in our panel we identified $56 \%$ as supporters of the traditional system and $44 \%$ who were not, but we cannot claim our panel to be representative in any sense.

\section{2) Looking at the variables: a general picture}

To evaluate which are the variables with the highest or lowest level of support, the easiest way is to look at their average ratings. Based on these numbers, it is possible for example to distinguish variables with a high level (above 5), or a moderate level of support, variables with a neutral impact and variables with weaker or stronger (below 3) aversion (see Tables 13-17). We can see for instance, that famous decision making practices such as nemawashi are not likely to disappear in the near future. It is not surprising: "preparing the ground" before decision-making has become widely used in every country. Similarly, stakeholder orientation, long-term employment, working in teams, and the hierarchy between small and large firms clearly meet with a relatively high level of support in Japanese society. In contrast, profitability, appraisal of performance, and especially gender equality are to be enhanced in Japanese companies. 


\section{Table 13: $\quad$ Strongly supported variables}

\begin{tabular}{|l|c|c|}
\hline Label & Average & St Dev \\
\hline Before decision-making, it is always better to know the others' opinion about the issue & 5.350 & 1.04 \\
\hline $\begin{array}{l}\text { It is very important for directors of a company to not only represent the owners' } \\
\text { (shareholders') interests but also those of employees, business partners, or other } \\
\text { members of our society }\end{array}$ & 5.313 & 1.09 \\
\hline Achieving the goals as a team is our common responsibility, not only our manager's & 5.277 & 1.17 \\
\hline Japan should find its own way to recover from crises, based on its traditions and culture & 5.093 & 1.16 \\
\hline $\begin{array}{l}\text { Small and large firms have different characteristics and possibilities: it is acceptable and } \\
\text { normal that compensation and benefits are also different according to the size of the } \\
\text { company }\end{array}$ & 5.031 & 1.21 \\
\hline
\end{tabular}

\section{Table 14: Supported variables}

\begin{tabular}{|c|c|c|}
\hline Label & Average & St Dev \\
\hline $\begin{array}{l}\text { Stakeholders of a company are not limited to shareholders, and management must } \\
\text { appropriately reflect multiple interests }\end{array}$ & 4.937 & 1.09 \\
\hline $\begin{array}{l}\text { People should never work alone, co-workers can bring help and play an important role in } \\
\text { correcting each others' mistakes }\end{array}$ & 4.907 & 1.19 \\
\hline $\begin{array}{l}\text { It is better if the union cooperates and keeps friendly relations with the management as } \\
\text { the economic health of the company is also in the interest of the workers }\end{array}$ & 4.852 & 1.18 \\
\hline It is important to protect our markets and jobs from foreign competition & 4.817 & 1.44 \\
\hline $\begin{array}{l}\text { People should try harder to achieve consensus in decision-making: group harmony is } \\
\text { worth the time invested in that process }\end{array}$ & 4.685 & 1.06 \\
\hline $\begin{array}{l}\text { Staying in the same company for long term is good because it does not block internal } \\
\text { competition or limit career prospects }\end{array}$ & 4.664 & 1.28 \\
\hline If possible, taking risks is to be avoided when it can endanger job security & 4.640 & 1.24 \\
\hline I am grateful for my company and I express this with my hard work every day & 4.558 & 1.34 \\
\hline $\begin{array}{l}\text { Rotating employees regularly is good because they can get better knowledge and vision } \\
\text { about the company as a whole, so probably they can become better managers }\end{array}$ & 4.536 & 1.11 \\
\hline $\begin{array}{l}\text { The re-employment of retirees should not be banned as it does not take jobs from young } \\
\text { people }\end{array}$ & 4.535 & 1.43 \\
\hline $\begin{array}{l}\text { It is good if the company can offer a seat on the board of directors to its senior managers } \\
\text { at the end of their career }\end{array}$ & 4.511 & 1.18 \\
\hline $\begin{array}{l}\text { Lifetime (or long-term) employment isn't outdated: I want to stay in the same company } \\
\text { for a long time }\end{array}$ & 4.472 & 1.45 \\
\hline Making friends is one of the most important things in a company & 4.456 & 1.34 \\
\hline $\begin{array}{l}\text { There is too much stress and depression related to corporate life today: life was better } \\
20 \text { years ago }\end{array}$ & 4.432 & 1.27 \\
\hline Work is always a team achievement, never just individual performance & 4.425 & 1.32 \\
\hline $\begin{array}{l}\text { Japan should not move towards the American economy and its institutions to change its } \\
\text { old practices }\end{array}$ & 4.388 & 1.31 \\
\hline $\begin{array}{l}\text { Working in an open office is not tiring; every company should try to have common office } \\
\text { for their white-collar staff }\end{array}$ & 4.377 & 1.39 \\
\hline $\begin{array}{l}\text { If I were graduating now, I would rather go to a company with Japanese management: } \\
\text { they understand better what a young employee needs }\end{array}$ & 4.336 & 1.53 \\
\hline $\begin{array}{l}\text { It is better to evaluate workers by the way they do their job than by the result, as the } \\
\text { result may depend on many things }\end{array}$ & 4.333 & 1.13 \\
\hline Going out with colleagues after work is important & 4.272 & 1.38 \\
\hline
\end{tabular}


Table 15: Neutral variables

\begin{tabular}{|c|c|c|}
\hline Label & Average & St Dev \\
\hline Voting is not the best way of decision-making & 4.212 & 1.29 \\
\hline Companies should always form interest groups so they can be much stronger & 4.180 & 1.02 \\
\hline $\begin{array}{l}\text { Regular rotation of employees should not be avoided: it is not confusing and doesn't } \\
\text { block specializing }\end{array}$ & 4.175 & 1.32 \\
\hline $\begin{array}{l}\text { Skill development (training) is the responsibility of the company, not the individual } \\
\text { worker's }\end{array}$ & 4.105 & 1.33 \\
\hline $\begin{array}{l}\text { In a company the group consensus is more important than any leader or manager: group } \\
\text { cohesiveness is the best tool to ensure common vision and good performance }\end{array}$ & 4.096 & 1.19 \\
\hline $\begin{array}{l}\text { Owning shares on a reciprocal basis between companies (cross-shareholding) is good, } \\
\text { mostly enhancing cooperation }\end{array}$ & 4.085 & 1.00 \\
\hline $\begin{array}{l}\text { The key success factor for a company is to produce good quality products at an } \\
\text { affordable price - succeeding in this ensures almost automatic success }\end{array}$ & 4.080 & 1.28 \\
\hline I would rather work for a large organization than a small one & 4.065 & 1.35 \\
\hline $\begin{array}{l}\text { It is not possible to lay off considerable numbers of employees without ructions within } \\
\text { the company or in the broader society }\end{array}$ & 4.058 & 1.35 \\
\hline $\begin{array}{l}\text { It is good to have a limited number of "core workers" with some privileges in a company: } \\
\text { achieving this status will motivate every employee }\end{array}$ & 4.058 & 1.32 \\
\hline $\begin{array}{l}\text { Recruitment and career management is better held at central (Human Resources } \\
\text { department) level because it costs less and gives a better overview on employee } \\
\text { transfers }\end{array}$ & 4.024 & 1.18 \\
\hline Labor union and its activity are even nowadays relevant to the employees' life & 4.013 & 1.29 \\
\hline $\begin{array}{l}\text { A top manager (CEO) from another organization usually succeeds no better in making } \\
\text { the company more efficient and productive than a CEO who is promoted from within the } \\
\text { lower ranks of the same company }\end{array}$ & 3.985 & 0.92 \\
\hline Company postings involving separation from family are acceptable / unavoidable & 3.960 & 1.51 \\
\hline $\begin{array}{l}\text { Owning shares on a reciprocal basis between companies is not bad, and not endeavoring } \\
\text { financial results }\end{array}$ & 3.937 & 0.97 \\
\hline $\begin{array}{l}\text { The company can prosper more in the long term if shareholders are "silent" and do not } \\
\text { demand short-term profit above all }\end{array}$ & 3.930 & 1.15 \\
\hline $\begin{array}{l}\text { The performance of older people is usually better than younger colleagues' due to their } \\
\text { greater experience }\end{array}$ & 3.926 & 1.27 \\
\hline $\begin{array}{l}\text { If the shareholders do put pressure on managers to achieve good results even in short } \\
\text { term, the company will not perform better }\end{array}$ & 3.919 & 1.08 \\
\hline $\begin{array}{l}\text { Mainly performance-based pay is not good as it leads to merely short-term goals and } \\
\text { hinders cooperation }\end{array}$ & 3.897 & 1.16 \\
\hline $\begin{array}{l}\text { Japanese top managers should not earn much more than } 10 \text { times the young graduate } \\
\text { new recruits' salary (in the USA it can be } 50 \text { times more) }\end{array}$ & 3.845 & 1.32 \\
\hline $\begin{array}{l}\text { The job of the union is not to confront the management in order to represent purely the } \\
\text { workers' interests }\end{array}$ & 3.798 & 1.38 \\
\hline
\end{tabular}

Table 16: Not supported / rejected variables

\begin{tabular}{|l|c|c|}
\hline Label & Average & St Dev \\
\hline $\begin{array}{l}\text { Profitability indicators such as ROE should not be given greater priority than sales or } \\
\text { market share }\end{array}$ & 3.600 & 1.01 \\
\hline $\begin{array}{l}\text { Individual appraisal of performance is a threat to harmony, companies should measure } \\
\text { group performance }\end{array}$ & 3.568 & 1.22 \\
\hline $\begin{array}{l}\text { I don't always express my personal opinion during important meetings and others should } \\
\text { do the same }\end{array}$ & 3.559 & 1.33 \\
\hline $\begin{array}{l}\text { Salaries should not be entirely based on performance, age or seniority of employees do } \\
\text { also matter }\end{array}$ & 3.541 & 1.40 \\
\hline $\begin{array}{l}\text { I recognize equality between men and women but somehow I feel more comfortable } \\
\text { having a male superior }\end{array}$ & 3.538 & 1.55 \\
\hline
\end{tabular}




\begin{tabular}{|l|c|c|}
\hline $\begin{array}{l}\text { Japanese companies should not pay more attention to efficient marketing: it is not as } \\
\text { important as the quality of the products }\end{array}$ & 3.520 & 1.24 \\
\hline $\begin{array}{l}\text { Recruitment and career management is not better held at division / unit level because it } \\
\text { would not be more appropriate to the real needs of the company }\end{array}$ & 3.496 & 1.11 \\
\hline $\begin{array}{l}\text { It is not good to have internal competition in a company among employees as it does not } \\
\text { enhance performance }\end{array}$ & 3.452 & 1.36 \\
\hline $\begin{array}{l}\text { Differences between "core workers" and temporary staff or part-timers are ok: they are } \\
\text { not doing the same job }\end{array}$ & 3.436 & 1.56 \\
\hline It is normal that women quit their job at marriage or childbirth & 3.404 & 1.64 \\
\hline If one day I want to find a new job, I will not send my CV to recruitment agencies & 3.318 & 1.45 \\
\hline The Japanese companies are doing well enough with their recruitment & 3.144 & 1.30 \\
\hline $\begin{array}{l}\text { It is better not to promote people very fast, older managers are wiser and usually do a } \\
\text { better job }\end{array}$ & 3.139 & 1.25 \\
\hline $\begin{array}{l}\text { Performance should be a significant element of the wage but it is not good if a young } \\
\text { person earns more than an older one }\end{array}$ & 3.099 & 1.23 \\
\hline It is usually not desirable to take risk in business & 3.051 & 1.16 \\
\hline $\begin{array}{l}\text { Recruitment agencies (head hunters) should not gain a more prominent role in job } \\
\text { hunting }\end{array}$ & 3.021 & 1.17 \\
\hline
\end{tabular}

\section{Table 17: Strongly rejected variables}

\begin{tabular}{|l|c|c|}
\hline Label & Average & St Dev \\
\hline $\begin{array}{l}\text { Employees recruited in the same time should basically be promoted together: it fosters } \\
\text { cooperation between members, limiting harmful competition }\end{array}$ & 2.994 & 1.23 \\
\hline $\begin{array}{l}\text { Big companies don't need more transparency and the control of the market: there does } \\
\text { not have to be an external director in the board }\end{array}$ & 2.922 & 1.16 \\
\hline I don't try to pursue hobbies / social activities away from work & 2.896 & 1.30 \\
\hline In a company it is not always better to have a leader with a strong vision & 2.818 & 1.15 \\
\hline $\begin{array}{l}\text { The best way to increase size for a company is to hire more young graduates from top } \\
\text { universities }\end{array}$ & 2.784 & 1.31 \\
\hline $\begin{array}{l}\text { Even if a person is highly qualified he should not be quickly promoted as his subordinates } \\
\text { may be much older than he is }\end{array}$ & 2.723 & 1.15 \\
\hline $\begin{array}{l}\text { There is something wrong about having a female boss: as manager they cannot perform } \\
\text { as well as men }\end{array}$ & 2.579 & 1.32 \\
\hline
\end{tabular}

Once this easiest step to approaching societal feedback on variables has been taken, we can move to the details. We can get a better illustration of these findings if we match the variable mean values with the management elements including these variables.

Thus, in the next step, we will attempt to verify our first hypothesis and contrast the findings of the survey with our theoretical summary. For this, we need to measure the level of support for the 69 variables, reformulate the 30 management elements on the basis of the variables, and compare our results with Table 8 .

Presumably, we can grasp a good picture on the respondents' attitude if we compare the number of supporters (ratings above four) with the number of rejecters (ratings below four). Point 1.3 presents the items of the questionnaire as reformulated when preparing the data, with the original items in parentheses. 


\section{3) Looking at the variables: detailed feedback}

This point provides a short feedback based on the responses: we will see whether each item is supported or not and to what extent. Bolded figures outnumber the others; Table 18 at the end summarizes these bolded groups of respondents. ${ }^{104}$

\section{The elements of the environment}

\section{Collectivist culture, Confucianism}

"Work is always a team achievement, never just individual performance."

Supporters (5 or more) / neutrals (4) / rejecters (less than 4): 388 / 195 / 211

\section{Developmental State and protected markets}

"It is important to protect our markets and jobs from foreign competition."

Supporters / neutrals / rejecters: 519 / 149 / 126

"There is too much stress and depression related to the corporate life today: life was better 20 years ago."

Supporters / neutrals / rejecters: 335 /335 / 124

\section{An ambiguous and rigid labor market}

"Recruitment agencies (head hunters) should not gain a more prominent role in job hunting." (Recruitment agencies (head hunters) should gain a more prominent role in job hunting because the companies only hire new graduates: older people also need job opportunities.)

Supporters / neutrals / rejecters: 67 / 178 / 549

"If one day I want to find a new job, I will not send my CV to recruitment agencies." (If one day I want to find a new job, I will send my CV to several recruitment agencies) Supporters / neutrals / rejecters: 140 / 224 / 430

\footnotetext{
${ }^{104}$ In case of multiple items composing a management characteristic, the numbers were added and the total scores were compared to determine support, rejection or neutrality.
} 


\section{The elements of the intra-organizational context}

"Easy-to-train" and devoted employees

"I am grateful to my company and I express this with my hard work every day."

Supporters / neutrals / rejecters: 427 / 235 / 132

"If I were graduating now, I would rather go to a company with Japanese management: they understand better what a young employee needs." (If I were graduating now, I would rather go to a company with foreign management: they understand better what a young employee needs)

Supporters / neutrals / rejecters: 326 / 270 / 198

\section{Superiors are rather managers than leaders}

"In a company it is not always better to have a leader with a strong vision." (In a company it is always desirable to have a leader with a strong vision: so people following him/her go in the same direction and improve their performance)

Supporters / neutrals / rejecters: 58 / 129 / 607

"It is usually not desirable to take risk in business." (It is all right and sometimes even desirable to take risk in business)

Supporters / neutrals / rejecters: 69 / 184 / 541

\section{Male dominance, homogeneity}

"I recognize equality between men and women but somehow I feel more comfortable having a male superior."

Supporters / neutrals / rejecters: 201 / 255 /338

"There is something wrong about having a female boss: as manager they cannot perform as good as men." (There is nothing wrong with having a female boss: as a manager they can perform as well as men) Supporters / neutrals / rejecters: 52 / 116 / 626

"It is normal that women quit their job at marriage or childbirth."

Supporters / neutrals / rejecters: 199 / 203 /392 
"Japanese companies are doing well enough with their recruitment." (The Japanese companies are too homogeneous: they should hire people with different backgrounds even from foreign countries)

Supporters / neutrals / rejecters: 93 / 218 / 483

\section{The elements of the strategy}

\section{Stakeholder orientation}

"The company can prosper more in the long term if shareholders are "silent" and do not demand short-term profit above all."

Supporters / neutrals / rejecters: 204 /358 / 232

"It is very important for directors of a company to not only represent the shareholders' (owners') interests but also the ones of employees, business partners, or other members of our society."

Supporters / neutrals / rejecters: 618 / 150 / 26

"If the shareholders do put pressure on managers to achieve good results even in short term, the company will not perform better." (If the owners of a company do not put pressure on managers to achieve good results even in the short term, the company will perform less well)

Supporters / neutrals / rejecters: 176 /396 / 222

"Stakeholders of a company are not limited to shareholders, and management must appropriately reflect multiple interests."

Supporters / neutrals / rejecters: 507 / 236 / 51

\section{Cost leadership (vs. product differentiation)}

"The key success factor for a company is to produce good quality products at an affordable price - succeeding in this ensures almost automatic success."

Supporters / neutrals / rejecters: 296 / 286 / 212

"Japanese companies should not pay more attention to efficient marketing: it is not as important as the quality of the products." (Japanese companies should pay more 
attention to efficient marketing: today it may be more important than the quality of the products)

Supporters / neutrals / rejecters: 148 / 233 / 413

\section{The elements of structure}

\section{Large and complex, U-form based group hierarchy}

"Small and large firms have different characteristics and possibilities: it is acceptable and normal that compensation and benefits are also different according to the size of the company."

Supporters / neutrals / rejecters: $\mathbf{5 6 8} / 156 / 70$

"I would rather work for a large organization than a small one."

Supporters / neutrals / rejecters: 243 / 339 / 212

"Owning shares on a reciprocal basis between companies (cross-shareholding) is good, mostly enhancing cooperation."

Supporters / neutrals / rejecters: 239 / 409 / 146

"Owning shares on a reciprocal basis between companies is not bad, and does not endanger financial results." (Owning shares on a reciprocal basis between companies (cross-shareholding) is bad, tying them together, hindering financial results)

Supporters / neutrals / rejecters: 165 / 442 / 187

"Companies should always form interest groups so they can be much stronger."

Supporters / neutrals / rejecters: 241 / 413 / 140

\section{Large boards dominated by insiders}

"Big companies don't need more transparency and the control of the market: there does not have to be an external director on the board." (Big companies need more transparency and control by the market: there should be at least one external director on the board) Supporters / neutrals / rejecters: 33 / 232 / 529

"A top manager (CEO) from another organization usually succeed no better in making the company more efficient and productive than a CEO who is promoted from within 
the lower ranks of the same company." (A top manager (CEO) recruited from another organization usually succeeds better in making the company more efficient and productive than a CEO who is promoted from within the lower ranks of the same company)

Supporters / neutrals / rejecters: 139 / 515 / 140

"It is good if the company can offer a seat on the corporate board for its senior managers at the end of their career."

Supporters / neutrals / rejecters: 375 / 309 / 110

\section{Central HRM, prevails over finance}

"Recruitment and career management is better held at central HR level because of economies of scale and a better overview on employee transfers."

Supporters / neutrals / rejecters: 264 / 296 / 234

"Recruitment and career management is not better held at division / unit level because it would not be more appropriate to the real needs of the company." (Recruitment and career management is better held at division / unit level because it would be more appropriate to the real needs of the company)

Supporters / neutrals / rejecters: 124 / 273 /397

\section{Processes of decision-making: aiming consensus}

"In a company the group consensus is more important than any leader or manager: group cohesiveness ensures common vision and good performance the best."

Supporters / neutrals / rejecters: 306 / 266 / 222

“I don't always express my personnel opinion during important meetings and others should do the same." (I always express my personal opinion during important meetings and others should do the same: people without opinion cannot give any contribution to the group)

Supporters / neutrals / rejecters: 184 / 234 / 376

"Before decision-making, it is always better to know the others' opinion about the issue." 
Supporters / neutrals / rejecters: 665 / 94 / 35

"Voting is not the best way of decision-making." (The best way for decision making is to vote: it is clear and efficient)

Supporters / neutrals / rejecters: 293 / 292 / 209

"People should try harder to achieve consensus in decision making: group harmony is worth the time invested in that process."

Supporters / neutrals / rejecters: 492 / 215 / 87

\section{Working teams (open office, group seating...)}

"Working in an open office is not tiring; every company should try to have common office for their white-collar staff." (Working in an open office is tiring; every company should try to give individual offices for their white-collar staff)

Supporters / neutrals / rejecters: 361 / 256 / 177

\section{The elements of behavior}

\section{Recruitment from schools}

"The best way to increase size for a company is to hire more young graduates from top universities."

Supporters / neutrals / rejecters: 78 / 155 / 561

\section{Core (permanent) vs. "irregular" staff}

"It is good to have a limited number of "core workers" in a company: achieving this status will motivate every employee."

Supporters / neutrals / rejecters: 294 / 266 / 234

"Differences between "core workers" and temporary staff or part-timers are ok: they are not doing the same job." (Differences between "core workers" and temporary staff or part-timers are nonsense: they are doing the same job anyway)

Supporters / neutrals / rejecters: 196 / 174 / 424 


\section{Long-term employment}

"Staying in the same company for long term is good because it does not block internal competition or limit career prospects." (Staying in the same company long term is not good because it blocks internal competition and limits career prospects)

Supporters / neutrals / rejecters: 442 / 223 / 129

"Lifetime (or long-term) employment isn't outdated: I want to stay in the same company for a long time." (Lifetime (or long-term) employment is outdated: I don't want to stay in the same company for such a long time)

Supporters / neutrals / rejecters: $\mathbf{4 0 8}$ / 218 / 168

"If possible, taking risk is to be avoided when it can endanger job security."

Supporters / neutrals / rejecters: 471 / 190 / 133

"It is not possible to lay off considerable numbers of employees without ructions within the company or in the broader society." (It is possible to lay off considerable numbers of employees without strong reactions (quarrels) within either the company or in the broader society)

Supporters / neutrals / rejecters: 284 / 197 /313

\section{Formal induction, creating a family}

"Going out with colleagues after work is important."

Supporters / neutrals / rejecters: 384 / 220 / 190

"I don't try to pursue hobbies / social activities away from work." (I try to pursue hobbies / social activities away from work)

Supporters / neutrals / rejecters: 81 / 157 / 556

"Company postings involving separation from family are acceptable / unavoidable."

Supporters / neutrals / rejecters: 302 / 220 / 272

"Making friends is one of the most important things in a company."

Supporters / neutrals / rejecters: 410 / 220 / 164 


\section{Cohort training "on-the-job"}

"Skill development is the responsibility of the company, not the individual worker's." Supporters / neutrals / rejecters: 322 /218 / 254

\section{Slow promotion}

"Employees recruited at the same time should basically be promoted together: it fosters cooperation between members, limiting harmful competition.”

Supporters / neutrals / rejecters: 84 / 197 / 513

"It is not good to have internal competition in a company among employees as it does not enhance performance." (It is good to have internal competition in a company among employees as it enhances performance)

Supporters / neutrals / rejecters: 171 / 172 / 451

"Even if a person is highly qualified he should not be quickly promoted as his subordinates may be much older than he is." (If a person is highly qualified he/she should be quickly promoted even if his/her subordinates end up being much older than he/she is)

Supporters / neutrals / rejecters: 55 / 101 / 638

"It is better not to promote people very fast; older managers are wiser and usually do a better job."

Supporters / neutrals / rejecters: 105 / 205 / 484

\section{Rotation}

"Rotating employees regularly is good because they can get better knowledge and vision about the company as a whole; they can become better managers."

Supporters / neutrals / rejecters: 406 / 271 / 117

"Regular rotation of employees should not be avoided: it is not confusing and is no block to specialization." (Regular rotation of employees should be avoided: it is confusing and they cannot specialize in their jobs)

Supporters / neutrals / rejecters: 310 / 248 / 236 


\section{Seniority pay (tenure-based compensation)}

"Individual appraisal of performance is a threat to harmony, companies should measure group performance."

Supporters / neutrals / rejecters: 185 / 220 /389

"Salaries should not be entirely based on performance; age or seniority of employees also matter." (Salaries should be entirely based on performance, no matter the age or seniority of employees)

Supporters / neutrals / rejecters: 212 / 169 / 413

"Performance should be significant element of the wage but it is not good if a young person earns more than an older one."

Supporters / neutrals / rejecters: 96 / 193 / 505

"The performance of older people is usually better due to their greater experience." Supporters / neutrals / rejecters: 265 / 288 / 241

"Mainly performance-based pay is not good as it leads to merely short-term goals and hinders cooperation."

Supporters / neutrals / rejecters: $216 / 310$ / 268

"The re-employment of retirees should not be banned as it does not take jobs from young people." (The reemployment of retirees should be banned because it takes jobs from young people)

Supporters / neutrals / rejecters: 418 / 215 / 161

"Japanese top managers should not earn much more than 10 times of the young graduate new recruits." (Japanese top managers should earn much more than 10 times the young graduate new recruits' salary (in the USA it can be 50 times more))

Supporters / neutrals / rejecters: 214 / 290 / 290 


\section{Enterprise-based or company unions}

"The job of the union is not to confront with the management in order to represent purely the workers' interests." (The job of the union is to confront the management in order to represent purely the workers' interests)

Supporters / neutrals / rejecters: 204 / 287 /303

"It is better if the union cooperates and keeps friendly relations with the management as the economic health of the company is also in the interest of the workers."

Supporters / neutrals / rejecters: 501 / 227 / 66

"Labor unions and their activity are even nowadays relevant to the employees' life." (Labor unions and their activity are nowadays irrelevant to the employees' life)

Supporters / neutrals / rejecters: 246 /314 / 234

\section{The elements of control and performance}

\section{Behavior-based control}

"It is better to evaluate workers by the way they do their job than by the result, as the result may depend on many things."

Supporters / neutrals / rejecters: 344 / 302 / 148

\section{No direct control, multi-monitoring}

"People should never work alone; co-workers can bring help and play an important role in correcting each others' mistakes."

Supporters / neutrals / rejecters: 557 / 145 / 92

\section{Decisions are of common responsibility}

"Achieving the goals as a team is our common responsibility, not only our manager's." Supporters / neutrals / rejecters: 628 / 112 / 54

\section{Good performance: market share, harmony...}

"Profitability indicators as ROE should not be given greater priority than sales or market share." (Financial and profitability indicators are more important for judging a company's performance than sales or market share) 
Supporters / neutrals / rejecters: 117 /349/328

All these findings are summarized in Table 18 below.

Table 18: The 30 elements of Japanese management in literature and practice

\begin{tabular}{|c|c|c|c|}
\hline & Trends in literature & Survey results & Нyp \\
\hline \multicolumn{4}{|l|}{ Environment } \\
\hline 1. A small living area with frequent catastrophes & Still valid & N.O. & \\
\hline 2. Collectivist culture, Confucianism & Still valid & Support & ok \\
\hline 3. Historical isolation, late industrialization & Still valid & N.O. & \\
\hline 4. Developmental State and protected markets & Still valid & Support & ok \\
\hline 5. An economy with continuous growth & Disappeared & N.O. & \\
\hline 6. An ambiguous and rigid labor market & Valid but... & (Q) Aversion & ok \\
\hline \multicolumn{4}{|l|}{ Intra-organizational context } \\
\hline 7. Easy-to-train and devoted employees & Valid but... & Support & $?$ \\
\hline 8. Superiors are rather managers than leaders & Still valid & Aversion & $?$ \\
\hline 9. Male dominance, homogeneity & Valid but... & (Q) Aversion & ok \\
\hline \multicolumn{4}{|l|}{ Strategy } \\
\hline 10. Stakeholder orientation & Still valid & Support & ok \\
\hline 11. Cost leadership (vs. product differentiation) & Still valid & Rather reject & \\
\hline 12. Spin-offs, start-ups, diversified portfolios & Almost disappeared & N.O. & \\
\hline \multicolumn{4}{|l|}{ Structure } \\
\hline 13. Big and complex, U-form based group hierarchy & Still valid & Neutral & \\
\hline 14. Large boards dominated by insiders & Valid but... & Unclear & \\
\hline 15. Central HRM prevails over finance & Valid but... & Rather reject & \\
\hline 16. Decision making: a consensual approach & Still valid & Support & ok \\
\hline 17. Working teams (open office, group seating...) & Still valid & Support & ok \\
\hline \multicolumn{4}{|l|}{ HR / OB / Employment philosophy } \\
\hline 18. Recruitment from schools & Valid but... & (Q) Aversion & ok \\
\hline 19. Core (permanent) vs. "irregular" staff & Valid but... & Rather reject & \\
\hline 20. Long-term employment & Still valid & 7 Support & ok \\
\hline 21. Formal induction, creating a family & Still valid & Unclear & \\
\hline 22. Cohort training "on-the-job" & Still valid & Support & ok \\
\hline 23. Slow promotion & Valid but... & Aversion & ok \\
\hline 24. Rotation & Unclear & 7 Support & ok \\
\hline 25. Seniority pay (tenure-based compensation) & Valid but... & (Q) Aversion & ok \\
\hline 26. Enterprise-based or company unions & Valid but... & Unclear & \\
\hline \multicolumn{4}{|l|}{ Control \& Performance } \\
\hline 27. Behavior-based control & Valid but... & Rather support & \\
\hline 28. No direct control, multi-monitoring & Still valid & Support & ok \\
\hline 29. Decisions are joint responsibility & Valid but... & Support & $?$ \\
\hline 30. Good performance: market share, harmony... & Almost disappeared & Neutral & \\
\hline
\end{tabular}

In this point we summarized, based on the survey responses, how society feels about traditional management practices in Japan. We have mostly found that, as predicted in our first hypothesis, definite aversion (marked by the crossed circles) matches practices which are in the process of disappearing. The only exceptions are the managerial risk avoidance and lack of leadership, and the school-based recruitment. Analyzing why 
Japan still lacks leaders is beyond the scope of this thesis, but risk avoidance is probably so deeply rooted in personality that eradicating it takes at least a generation, if it can be done at all. The measurement of corporate performance is apparently a neutral topic for Japanese employees, but not for managers and students who demanded more weight for profitability than for market share.

For the institutions (practices) remaining valid, we have indeed found definite support (marked by heart signs). For joint responsibility and employees' devotion, we found in literature (by theoretical logic) a declining strength, which does not perfectly match the feedback of the survey. For these items, and of course, for all the rest as well, we must note again that the operationalization of these practices in a questionnaire is not obvious clear-cut task and there is no guarantee that the result is perfectly appropriate in that sense. In the overall picture however, the field results match the theory well, which ensures a satisfactory level of validity for the survey.

\section{2) Findings (2): internal pressures in society}

In this point, as planned in the survey design, we will split the panel of respondents into different clusters in order to gain a clearer picture on who are the supporters of Japan's traditional practices and who are not.

\section{1) Attempting cluster analysis with 4 clusters}

After the preliminary analyses, we can now turn back to the respondents with more sophisticated methods. We will proceed with a K-means (non-hierarchical) cluster analysis: after iterations from 9 to 4 clusters, the best choice seemed to have $4 .{ }^{105}$ Multidimensional scaling showed that with 5 clusters, cluster centers had already great distance from each other, and only two of them seemed a little too close. With a merge of these two into one cluster, center distances appear as near-perfect (see Figure 33). We can assume that each group must have significantly different characteristics. The SStress value (0.00024) also confirmed that the 4 clusters were appropriate way to reduce data dimensions.

\footnotetext{
${ }^{105}$ In order to have 4 valid clusters, we had to delete 2 outliers as one cluster contained only those two items.
} 


\section{Figure 33: MDS Proxscal map of 4 clusters in two dimensions}

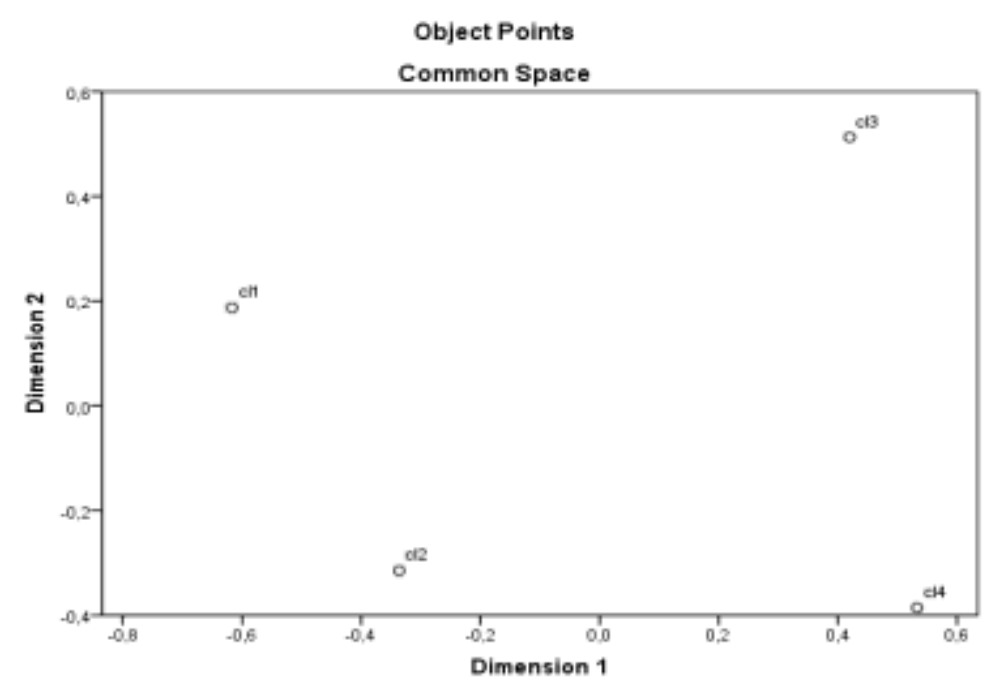

Source: SPSS (PASW Statistics 18)

Preparing crosstabs from the profile data of respondents, we can see that most of them show significant impact on the cluster variable. The gender's chi-square is also valid with a 0.053 level of significance, although its added value is only clear in one special case (see later). As for the strength of the link between variables, we also know that an adjusted residual greater than 2 usually means "good significance" (Sajtos \& Mitev, 2007). The following paragraphs consist of a short analysis on clusters.

\section{Cluster 1: "Breaking the china" (the anti-Japanese)}

Below are the cluster mean values given for the variables and their differences compared to the total means. Only lines where this difference appears important are shown.

Table 19: Cluster 1 mean values compared to total means

\begin{tabular}{|l|c|c|}
\hline CLUSTER No.1 (N=112) & Clust. & Diff. \\
\hline $\begin{array}{l}\text { Small and large firms have different characteristics and possibilities: it is acceptable } \\
\text { and normal that compensation and benefits are also different according to the size of } \\
\text { the company }\end{array}$ & 5.56 & 0.53 \\
\hline Achieving the goals as a team is our common responsibility, not only our manager's & 5.59 & 0.31 \\
\hline $\begin{array}{l}\text { Japan should not move towards the American economy and its institutions to change } \\
\text { its old practices }\end{array}$ & 3.74 & -0.64 \\
\hline
\end{tabular}




\begin{tabular}{|l|c|c|}
\hline $\begin{array}{l}\text { Mainly performance-based pay is not good as it leads to merely short-term goals and } \\
\text { hinders cooperation }\end{array}$ & 3.22 & -0.67 \\
\hline $\begin{array}{l}\text { It is good if the company can offer a seat on the board of directors to its senior } \\
\text { managers at the end of their career }\end{array}$ & 3.81 & -0.70 \\
\hline It is usually not desirable to take risk in business & 2.29 & -0.76 \\
\hline $\begin{array}{l}\text { Even if a person is highly qualified he should not be quickly promoted as his } \\
\text { subordinates may be much older than he is }\end{array}$ & 1.95 & -0.77 \\
\hline If one day I want to find a new job, I will not send my CV to recruitment agencies & 2.54 & -0.79 \\
\hline $\begin{array}{l}\text { It is not good to have internal competition in a company among employees as it does } \\
\text { not enhance performance }\end{array}$ & 2.66 & -0.80 \\
\hline $\begin{array}{l}\text { Staying in the same company long term is good because it does not block internal } \\
\text { competition or limit career prospects }\end{array}$ & 3.86 & -0.81 \\
\hline $\begin{array}{l}\text { Individual appraisal of performance is a threat to harmony, companies should } \\
\text { measure group performance }\end{array}$ & 2.69 & -0.89 \\
\hline It is normal that women quit their job at marriage or childbirth & 2.51 & -0.89 \\
\hline $\begin{array}{l}\text { It is better not to promote people very fast; older managers are wiser and usually do a } \\
\text { better job }\end{array}$ & 2.23 & -0.91 \\
\hline $\begin{array}{l}\text { Employees recruited at the same time should basically be promoted together: it } \\
\text { fosters cooperation between members, limiting harmful competition }\end{array}$ & 2.07 & -0.93 \\
\hline $\begin{array}{l}\text { The performance of older people is usually better than younger colleagues' due to } \\
\text { their greater experience }\end{array}$ & 2.96 & -0.97 \\
\hline It is important to protect our markets and jobs from foreign competition & 3.79 & -1.03 \\
\hline Japanese companies are doing well enough with their recruitment & 2.11 & -1.03 \\
\hline $\begin{array}{l}\text { Salaries should not be entirely based on performance, age or seniority of employees } \\
\text { also matter }\end{array}$ & 2.47 & -1.07 \\
\hline $\begin{array}{l}\text { Performance should be a significant element of the wage but it is not good if a young } \\
\text { person earns more than an older one }\end{array}$ & 2.03 & -1.08 \\
\hline $\begin{array}{l}\text { If I were graduating now, I would rather go to a company with Japanese } \\
\text { management: they understand better what a young employee needs }\end{array}$ & 2.94 & -1.40 \\
\hline $\begin{array}{l}\text { Lifetime (or long-term) employment is not outdated: I want to stay in the same } \\
\text { company for a long time }\end{array}$ & 3.01 & -1.46 \\
\hline
\end{tabular}

We can see there is not much in traditional Japanese management this cluster would support. The first two lines attempt in vain to give a positive start, but it is very clear that this group fervently rejects everything related to old, "Japanese-style" practices (the summarized mean difference for all variables from total is -27.8). As our previous assumption was that reforms are slow, perhaps too slow in Japan, this result may be surprising. It is clear that were this group important in terms of size and status, the Japanese system would have been totally changed by now.

To soften our astonishment, we can see that this group is far from being dominant: they are young, for a large part foreigners, rather rich but typically lower status people.

The average cluster 1 respondent is in his or her twenties or thirties: the mean value is 35 (years old), but the mode is 22; and $75 \%$ of the group is not older than 41 . 
There are Japanese among the members of the cluster, but this nation is underrepresented here, as opposed to some greatly overrepresented foreign nations (compared to the total panel). Some $63.6 \%$ of the Anglo-Americans and 53.6\% of the Europeans became part of cluster 1, and so one-third of the cluster is not even Asian. As the panel has dominantly Japanese origins, this is the highest incidence of foreigners, all clusters included. As a consequence, all immigrants from outside of Asia would most probably contribute to the strengthening of cluster 1 in the future.

The average cluster 1 respondent has also a very high record of education: the median is at 4 (bachelor level) and 50\% of the group has an MBA or BSc degree. Only $17.9 \%$ of the group is under BSc level, the MA/MSc degrees are overrepresented by about $200 \%$ and almost the same is true for the $\mathrm{PhD}$ degrees (by 300\%). The $\mathrm{PhD}$-level respondents typically $(40.6 \%)$ become members of cluster 1 . We may conclude that the longer a person keeps on with studies, the more likely he or she will be cluster 1 . Also to be noted is that doctoral programs are mainly based on American models and accordingly, Japanese often obtain their doctorates in the US.

We can also see that the higher income levels are over-, the lower levels are underrepresented in cluster 1: not even $50 \%$ of the group has 2 or 1 as the level of income; the same figure is much higher elsewhere. It may be that money is more important for cluster 1 than for the others, but it is just a possibility.

The average cluster 1 member works for about 7 years in the same company (the lowest figure in the panel), and $75 \%$ of the cluster spends no more than 10 years in the same place. This is not so surprising, given their relative young age. The mean value for the company size is the highest (4.48) of all, and it seems that the bigger a respondent's workplace is, the more likely this person is to be in cluster 1. As this is true for clusters 2 and 3 as well, we can assume that this effect is due to the relative important size of bigger companies in the panel. According to the high adjusted residual for cluster 1, it may also be that the biggest companies ${ }^{106}$ impose such a great pressure on the employees due to their old-style practices that it turns them into rejecters of the system.

The average status (2.4) is relatively low in cluster 1 , the likely reason being the young age of the cluster. For the Japanese, seniority and the respect of the elderly is still important, more so than in Western countries. Status 1 (students) is overrepresented in cluster 1, opposed to the rest of the statuses, and statuses 1 and 2 make together $50 \%$ of

\footnotetext{
${ }^{106}$ The big companies are said to be the flagships of the traditional system as their sizes allow them to turn the ideas into practice.
} 
the group which is relatively high in this panel. Also to be noted is, however, that $25 \%$ of the cluster is over 41 years old and $21.4 \%$ works as manager.

To sum up, we can describe cluster 1 as anti-Japanese or US-friendly in terms of management philosophy, and its members as young Westerners or Japanese with a high level of education, high income but low status (i.e. students).

\section{Cluster 2: Harmony and performance}

Cluster 2 can be considered as slight rejecters as their summarized mean difference is -3 compared to the total. We can see although that there are many elements that they support, some other variables are quite strongly rejected. Our point here is to find out which variables they are for and which they are against.

Table 20: Cluster 2 mean values compared to total means

\begin{tabular}{|c|c|c|}
\hline CLUSTER No.2 (N=89) & Clust. & Diff. \\
\hline $\begin{array}{l}\text { Japan should not move towards the American economy and its institutions for } \\
\text { changing its old practices }\end{array}$ & 5.44 & 1.06 \\
\hline Voting is not the best way of decision-making & 5.13 & 0.92 \\
\hline $\begin{array}{l}\text { Regular rotation of employees should not be avoided: it is not confusing and does not } \\
\text { block specializing }\end{array}$ & 5.08 & 0.90 \\
\hline $\begin{array}{l}\text { If I were graduating now, I would rather go to a company with Japanese } \\
\text { management: they understand better what a young employee needs }\end{array}$ & 5.12 & 0.79 \\
\hline $\begin{array}{l}\text { Stakeholders of a company are not limited to shareholders, and management must } \\
\text { appropriately reflect multiple interests }\end{array}$ & 5.71 & 0.77 \\
\hline $\begin{array}{l}\text { If the shareholders do put pressure on managers to achieve good results even in the } \\
\text { short term, the company will not perform better }\end{array}$ & 4.67 & 0.75 \\
\hline Achieving the goals as a team is our common responsibility, not only our manager's & 6.02 & 0.75 \\
\hline $\begin{array}{l}\text { It is very important for directors of a company to not only represent the owners' } \\
\text { (shareholders') interests but also the ones of employees, business partners, or other } \\
\text { members of our society }\end{array}$ & 6.03 & 0.73 \\
\hline $\begin{array}{l}\text { The re-employment of retirees should not be banned as it does not take jobs from } \\
\text { young people }\end{array}$ & 5.25 & 0.71 \\
\hline $\begin{array}{l}\text { Before decision making, it is always better to know the others' opinion about the } \\
\text { issue }\end{array}$ & 5.69 & 0.34 \\
\hline $\begin{array}{l}\text { It is better if the union cooperates and keeps friendly relations with the management } \\
\text { as the economic health of the company is also in the interest of the workers }\end{array}$ & 5.06 & 0.19 \\
\hline $\begin{array}{l}\text { People should try harder to achieve consensus in decision making: group harmony is } \\
\text { worth the time invested in that process }\end{array}$ & 4.80 & 0.11 \\
\hline $\begin{array}{l}\text { Recruitment agencies (head hunters) should not gain a more prominent role in job } \\
\text { hunting }\end{array}$ & 2.90 & -0.12 \\
\hline
\end{tabular}




\begin{tabular}{|l|c|c|}
$\begin{array}{l}\text { Even if a person is highly qualified he should not be quickly promoted as his } \\
\text { subordinates may be much older than he is }\end{array}$ & 2.39 & -0.33 \\
\hline In a company it is not always better to have a leader with a strong vision & 2.29 & -0.53 \\
\hline Japanese companies are doing well enough with their recruitment & 2.61 & -0.53 \\
\hline $\begin{array}{l}\text { The best way to increase size for a company is to hire more young graduates from } \\
\text { top universities }\end{array}$ & 2.18 & -0.60 \\
\hline $\begin{array}{l}\text { Employees recruited at the same time should basically be promoted together: it } \\
\text { fosters cooperation between members, limiting harmful competition }\end{array}$ & 2.30 & -0.70 \\
\hline $\begin{array}{l}\text { It is better not to promote people very fast, older managers are wiser and usually do a } \\
\text { better job }\end{array}$ & 2.34 & -0.81 \\
\hline $\begin{array}{l}\text { It is good to have a limited number of "core workers" with some privileges in a } \\
\text { company: achieving this status will motivate every employee }\end{array}$ & 3.21 & -0.85 \\
\hline $\begin{array}{l}\text { The key success factor for a company is to produce good quality products at an } \\
\text { affordable price-succeeding in this ensures almost automatic success }\end{array}$ & 3.11 & -0.97 \\
\hline $\begin{array}{l}\text { There is something wrong about having a female boss: as manager they cannot } \\
\text { perform as well as men }\end{array}$ & 1.57 & -1.01 \\
\hline $\begin{array}{l}\text { I recognize equality between men and women but somehow I feel more comfortable } \\
\text { having a male superior }\end{array}$ & 2.19 & -1.34 \\
\hline It is normal that women quit their job at marriage or childbirth & 1.96 & -1.45 \\
\hline
\end{tabular}

As we did with cluster 1, we will take a look on both the cluster's responses and profile characteristics.

First, in spite of the general scores, cluster 2 apparently does not reject the Japanese system: they agree to join companies with Japanese-style practices, they support Japanese-type solutions to problems and what they do reject is rather the American way!

Cluster 2 mostly shares a stakeholder-oriented management philosophy, denying the ultimate power of owners in the company. They also support regular rotation of employees; a practice strongly linked to lifetime-employment (also rated positively here) and also a means of training future managers. Opponents of rotation highlight its efficiency-reducing effects, as regular changes hinder specialization. However, rotation is a good way to build connections and get to know the company.

The support for re-employment favors aged, retired ex-employees who need the extra money or the feeling of usefulness at work. This support with the preference for not voting (aiming for consensus), and the emphasis on cooperation and common responsibility, are all "typical" in Japan and express a positive attitude towards "harmony": an attitude avoiding conflicts, welcoming long-term stability and satisfaction of all parties. 
On the other hand, members of cluster 2 express aversion towards the Japanese recruitment practices, ${ }^{107}$ and the related, seniority-based promotions. They highlight the importance of (individual) performance, competition and marketing skills. Briefly, this group prefers to work in a peaceful atmosphere, but they are also ready for "war".

Perhaps the most marked characteristic of the cluster is an extreme aversion towards discrimination; they have especially convictions about protecting women's rights, although $53.9 \%$ of the group is male. Their average age is 39.3 years (with a mode of 33,50\% being between 31 and 47.5) and statistically they have been working for about 11.2 years in the same company (mode: 10). More precisely, half of the cluster spent between 3 and 18 years in the same place.

The origin of cluster members follows the means of the panel, the Japanese are slightly under- and foreigners overrepresented. Levels of education are quite similar to cluster 1 (rather high): $70 \%$ of all $\mathrm{PhDs}$ are either in cluster 1 or 2 . The average income level (2.07) remains slightly under cluster 1 , and $67.4 \%$ earns level 2 or less.

Managers can be found most likely in this cluster as $28.1 \%$ is status 4 (the highest figure among all clusters). Accordingly, managers are over-, students and regular workers are underrepresented here. In this group, $43.8 \%$ is status 2 or 1 only this figure was $60 \%$ for cluster 1 . Thus, as opposed to cluster 1 or 3 , the higher the status of a respondent is, the more likely he or she will be classed cluster 2 .

To sum up, cluster 2 statistically represents people with good education and relatively high status in their thirties or forties, for whom equality, harmony and all stakeholders are important, who tend to support Japanese-style management but prefer performance-based promotions to seniority. They would probably move towards a more individualized recruitment system as well.

\section{Cluster 3: Community firm}

Cluster 3 is about twice as big as the previous one and can be considered by far the strongest supporter of the J-type management, since the summarized cluster mean is +6.2 compared to the panel mean value, the highest figure among all clusters. Their (probably most significant) characteristics are highlighted by Table 21.

\footnotetext{
${ }^{107}$ Hiring goes in "batches", directly from school.
} 
Table 21: Cluster 3 mean values compared to total means

\begin{tabular}{|c|c|c|}
\hline CLUSTER No.3 (N=177) & Clust. & Diff. \\
\hline Making friends is one of the most important things in a company & 5.33 & 0.86 \\
\hline Going out with colleagues after work is important & 5.13 & 0.85 \\
\hline Company postings involving separation from family are acceptable / unavoidable & 4.76 & 0.80 \\
\hline I am grateful to my company and I express this with my hard work every day & 5.32 & 0.77 \\
\hline $\begin{array}{l}\text { It is good to have a limited number of "core workers" with some privileges in a } \\
\text { company: achieving this status will motivate every employee }\end{array}$ & 4.81 & 0.74 \\
\hline $\begin{array}{l}\text { It is good if the company can offer a seat on the board of directors to its senior } \\
\text { managers at the end of their career }\end{array}$ & 5.23 & 0.72 \\
\hline $\begin{array}{l}\text { Before decision-making, it is always better to know the others' opinion about the } \\
\text { issue }\end{array}$ & 6.01 & 0.66 \\
\hline It is normal that women quit their job at marriage or childbirth & 4.06 & 0.65 \\
\hline $\begin{array}{l}\text { Rotating employees regularly is good because they can get better knowledge and } \\
\text { vision about the company as a whole, so probably they can become better managers }\end{array}$ & 5.18 & 0.64 \\
\hline $\begin{array}{l}\text { It is very important for directors of a company to not only represent the owners' } \\
\text { (shareholders') interests but also the ones of employees, business partners, or other } \\
\text { members of our society }\end{array}$ & 5.93 & 0.62 \\
\hline $\begin{array}{l}\text { Small and large firms have different characteristics and possibilities: it is acceptable } \\
\text { and normal that compensation and benefits are also different according to the size of } \\
\text { the company }\end{array}$ & 5.65 & 0.62 \\
\hline $\begin{array}{l}\text { Performance should be a significant element of the wage but it is not good if a young } \\
\text { person earns more than an older one }\end{array}$ & 2.99 & -0.11 \\
\hline $\begin{array}{l}\text { Employees recruited at the same time should basically be promoted together: it } \\
\text { fosters cooperation between members, limiting harmful competition }\end{array}$ & 2.85 & -0.15 \\
\hline I don't try to pursue hobbies / social activities away from work & 2.51 & -0.39 \\
\hline $\begin{array}{l}\text { There is something wrong about having a female boss: as managers they cannot } \\
\text { perform as well as men }\end{array}$ & 2.17 & -0.41 \\
\hline $\begin{array}{l}\text { Big companies don't need more transparency and the control of the market: there } \\
\text { does not need to be an external director in the board }\end{array}$ & 2.41 & -0.51 \\
\hline $\begin{array}{l}\text { Recruitment agencies (head hunters) do not need to gain a more prominent role in job } \\
\text { hunting }\end{array}$ & 2.51 & -0.51 \\
\hline Japanese companies are doing well enough with their recruitment & 2.61 & -0.53 \\
\hline $\begin{array}{l}\text { Even if a person is highly qualified he should not be quickly promoted as his } \\
\text { subordinates may be much older than he is }\end{array}$ & 2.18 & -0.54 \\
\hline In a company it is not always better to have a leader with a strong vision & 2.15 & -0.67 \\
\hline $\begin{array}{l}\text { It is not good to have internal competition in a company among employees as it does } \\
\text { not enhance performance }\end{array}$ & 2.77 & -0.68 \\
\hline If one day I want to find a new job, I will not send my CV to recruitment agencies & 2.56 & -0.76 \\
\hline $\begin{array}{l}\text { Japanese top managers should not earn much more than } 10 \text { times the young graduate } \\
\text { new recruits' salary (in the USA it can be } 50 \text { times more) }\end{array}$ & 3.06 & -0.78 \\
\hline
\end{tabular}

What we conclude here is that cluster 3 is neither pro- nor anti-Japanese per se: they just strongly support the concept of community firm ${ }^{108}$ and its related features.

Cluster 3 members gave the highest scores (5.13) to "company drinking parties" after work where they can spend the night mainly with their peers. By way of

${ }^{108}$ Concept focusing on the interpersonal relations of firms, rather than their profit or performance. 
reinforcement of this image, this group is also first (5.33) in seeing friendship or making friends as "one of the most important things in a company." Moreover, cluster 3 is apparently the only cluster supporting (4.76) company postings away from home as well. This is still current practice in Japanese business but certainly not a familyfriendly one. The community firm approach includes lifetime-employment as this longterm perspective is the basis of company friendships. Accordingly, cluster 3 members accept or even support related hierarchical distances and status gaps between employees.

On the other hand however, cluster 3 members also support internal competition and seek for more mid-career job options through external recruitment agencies. Indeed, Japanese companies often lack a developed external job market and still tend to recruit directly from schools, which make job hunting difficult once somebody is slow in getting a job contract or wants to change employer afterwards.

Common wisdom suggests that a cluster supporting drinking parties, status gaps and hierarchy, must be male-dominated and inspired by Confucius.

Indeed, all clusters have a good balance between their male and female members-except for cluster 3 . Of the cluster 3 respondents, $59.9 \%$ are male and the adjusted residual confirms this difference is important. This is the only group where discriminatory practices are openly supported or at least more easily accepted (although cluster 4 also exhibits this tendency in some cases). If we look at foreign respondents, Anglo-Americans are typically member of cluster 1, and Asians mainly (48.6\%) join cluster 3. People who see Asian societies as rather hierarchical ones may think those hierarchical distances are connected to discrimination. For instance, cluster 3 still welcomes a definite separation between core and irregular workers (4.81) although all the others are apparently against it. Also, they tend to accept (4.06) the idea that women should be homemakers, or strongly support bigger gaps between salaries for men and for women.

Members of cluster 3 are relatively young (35 years old on average, with a mode at 21 ; and $75 \%$ are 43 or under) which has several consequences. First, as for cluster 1, there is a high proportion (37.3\%) of students in the group which is well above the panel mean. Moreover, somebody from school (status 1) in Japan would most probably $(51.2 \%)$ be in cluster 3. Also, their education lasts relatively long: a typical degree is a bachelor (61.6\%), meaning four years of college. Somebody with an MBA level would 
also probably (42.5\%) prefer to join cluster 3 . The average cluster 3 tenure is 8.8 years but $75 \%$ stayed no more than 11 years in the same company. As students are greatly overrepresented, all the other statuses get relatively low weight in this cluster: the mean status is 2.26 , the mode is 1 and $56 \%$ of the group is status 1 or 2 , the second lowest figure in the panel.

Young employees usually have a greater need to acquire new skills and gather new knowledge at work. This may be the explanation for why this cluster is first in supporting regular rotation of workers. They also express a preference (4.47) for working in bigger organizations where their learning process and rotation for instance is facilitated by organization size. Their gratefulness for work (5.32) is also the highest of all the clusters which may be partly due to their age, but also to the harsh economic situation with the new global crisis. This is also the only group which expressed a positive attitude (4.77) to company groupings in order to strengthen their positions through alliances: the others are not really concerned by the question.

To sum up, members of cluster 3 are looking at companies as communities where males have to take the biggest workloads, strive to do their best until retirement when they would merit a seat in the board as a director. This picture is colored by their average age: relatively young, many of them do not have family yet and apparently think that his or her office may substitute for it.

\section{Cluster 4: Pro-J-style regulars}

Last but not least stands the biggest cluster with 416 members. The size suggests that we should give great attention to the analysis of this group. To judge from their summarized mean $(+5.5)$, this cluster is also a supporter of the Japanese system. As with cluster 1 it was hard to find anything the cluster would support, we have the same difficulty with negative attitudes: the few there are are paired with a still supportive mean (see Table 22). How is it that cluster 4 does not have the highest summarized score for mean differences? The reason for this is that its members rate the positive side also relatively low. 
Table 22: Cluster 4 mean values compared to total means

\begin{tabular}{|c|c|c|}
\hline CLUSTER No.4 (N=416) & Clust. & Diff. \\
\hline If one day I want to find a new job, I will not send my CV to recruitment agencies & 3.96 & 0.64 \\
\hline Japanese companies are doing well enough with their recruitment & 3.76 & 0.62 \\
\hline $\begin{array}{l}\text { There is something wrong about having a female boss: as manager they cannot } \\
\text { perform as well as men }\end{array}$ & 3.13 & 0.56 \\
\hline It is usually not desirable to take risk in business & 3.57 & 0.52 \\
\hline $\begin{array}{l}\text { It is not good to have internal competition in a company among employees as it does } \\
\text { not enhance performance }\end{array}$ & 3.98 & 0.52 \\
\hline $\begin{array}{l}\text { Even if a person is highly qualified he should not be quickly promoted as his } \\
\text { subordinates may be much older than he is }\end{array}$ & 3.23 & 0.51 \\
\hline $\begin{array}{l}\text { Employees recruited at the same time should basically be promoted together: it } \\
\text { fosters cooperation between members, limiting harmful competition }\end{array}$ & 3.46 & 0.46 \\
\hline $\begin{array}{l}\text { Performance should be a significant element of the wage but it is not good if a young } \\
\text { person earns more than an older one }\end{array}$ & 3.56 & 0.46 \\
\hline In a company it is not always better to have a leader with a strong vision & 3.27 & 0.45 \\
\hline $\begin{array}{l}\text { I don't always express my personnel opinion during important meetings and others } \\
\text { should do the same }\end{array}$ & 3.98 & 0.42 \\
\hline $\begin{array}{l}\text { It is better not to promote people very fast, older managers are wiser and usually do a } \\
\text { better job }\end{array}$ & 3.56 & 0.41 \\
\hline $\begin{array}{l}\text { If I were graduating now, I would rather go to a company with Japanese } \\
\text { management: they understand better what a young employee needs }\end{array}$ & 4.70 & 0.36 \\
\hline $\begin{array}{l}\text { I recognize equality between men and women but somehow I feel more comfortable } \\
\text { having a male superior }\end{array}$ & 3.86 & 0.33 \\
\hline $\begin{array}{l}\text { Lifetime (or long-term) employment isn't outdated: I want to stay in the same } \\
\text { company for a long time }\end{array}$ & 4.72 & 0.26 \\
\hline $\begin{array}{l}\text { The best way to increase size for a company is to hire more young graduates from } \\
\text { top universities }\end{array}$ & 2.87 & 0.09 \\
\hline $\begin{array}{l}\text { People should try harder to achieve consensus in decision making: group harmony is } \\
\text { worth the time invested in that process }\end{array}$ & 4.50 & -0.18 \\
\hline $\begin{array}{l}\text { Japan should find its own way to recover from crises, based on its traditions and } \\
\text { culture }\end{array}$ & 4.88 & -0.21 \\
\hline Company postings involving separation from family are acceptable / unavoidable & 3.69 & -0.26 \\
\hline $\begin{array}{l}\text { It is better if the union cooperates and keeps friendly relations with the management } \\
\text { as the economic health of the company is also in the interest of the workers }\end{array}$ & 4.59 & -0.28 \\
\hline $\begin{array}{l}\text { Before decision making, it is always better to know the others' opinion about the } \\
\text { issue }\end{array}$ & 4.93 & -0.41 \\
\hline $\begin{array}{l}\text { It is very important for directors of a company to not only represent the owners' } \\
\text { (shareholders') interests but also those of employees, business partners, or other } \\
\text { members of our society }\end{array}$ & 4.88 & -0.43 \\
\hline $\begin{array}{l}\text { Small and large firms have different characteristics and possibilities: it is acceptable } \\
\text { and normal that compensation and benefits are also different according to the size of } \\
\text { the company }\end{array}$ & 4.60 & -0.43 \\
\hline $\begin{array}{l}\text { Stakeholders of a company are not limited to shareholders, and management must } \\
\text { appropriately reflect multiple interests }\end{array}$ & 4.46 & -0.47 \\
\hline Achieving the goals as a team is our common responsibility, not only our manager's & 4.79 & -0.48 \\
\hline
\end{tabular}


What we know of cluster 4 is that this is the oldest one: its average member is 41.5 years old (the mode is 45) and 50\% of the group is between 34 and 48.75. Accordingly, they have also the longest tenures (12.18 on average): $50 \%$ of the cluster stays between 5 and 16 years in the same company. Of the members, $98.3 \%$ are Japanese (99\% from Asia), so there are hardly any foreigners: 0\% from Anglo-American countries at least. The level of education (3.3) here is the lowest of all clusters: $52.6 \%$ of the members do not have a bachelor degree yet and $95 \%$ are not higher than B.Sc. level. Moreover, more than $75 \%$ of all respondents below bachelor level became members of this cluster, which is highly overrepresented, as typical for the Japanese-type companies.

As incomes in J-type companies are also rather homogeneous, it is not surprising that the lower income levels (1 and 2) are significantly over-, the higher levels (3-5) are underrepresented in the cluster. The average income level is 1.88 (the lowest of the panel) and $78.8 \%$ of the cluster does not earn more than 400,000 yen (level 2).

The exact opposite can be stated for the status characteristics: status 3 (regular workers) is the mode (almost 40\%) but statuses 2 and 4 are also overrepresented. Only $3.1 \%$ of the cluster are students, and students and irregulars (status 2) together make only $36.1 \%$, which is the lowest proportion of students in the panel. Accordingly, the status mean value of cluster 4 (2.85) is the highest.

We can conclude that cluster 4 is mostly made of people from their mid-thirties to mid-fifties, with a not especially high level of education or income but very long tenure and, most importantly, people of high social status by Japanese standards. And it is obvious that this high-status, dominant group of Japanese society benefits from the traditional system (e.g. long-term employment, social respect) and continues to support its management practices.

Strange though it may be, but even with close scrutiny and a long list of characterizing cluster means, it is difficult to find out how this cluster really feels. Stronger opinions of other clusters seem to be dulled here into a slight but significant, general support. As cluster 4 is the largest one in the panel, this lack of certitude appears as an element pushing us to go further and deeper in order to identify this type of respondent as much as possible. In pursuing this aim, we will try to split the cluster into two and see whether the result brings us closer to the understanding of the different types of attitude people in Japan have towards management. 


\section{2) Completing the picture: the $5^{\text {th }}$ cluster}

We might expect that most of the clusters would be nearly similar to the previous point, but adding one more cluster will sharpen our picture of the supporters of the Japanese system. In this new setting, we have five clusters, still well spread as shown by Figure 38. The two closest centers must be the two clusters created from cluster 4 . The new $S$ Stress value (0.0007) still confirms that our model is a good representation of the reality.

\section{Figure 34: MDS Proxscal map of the five clusters in two dimensions}

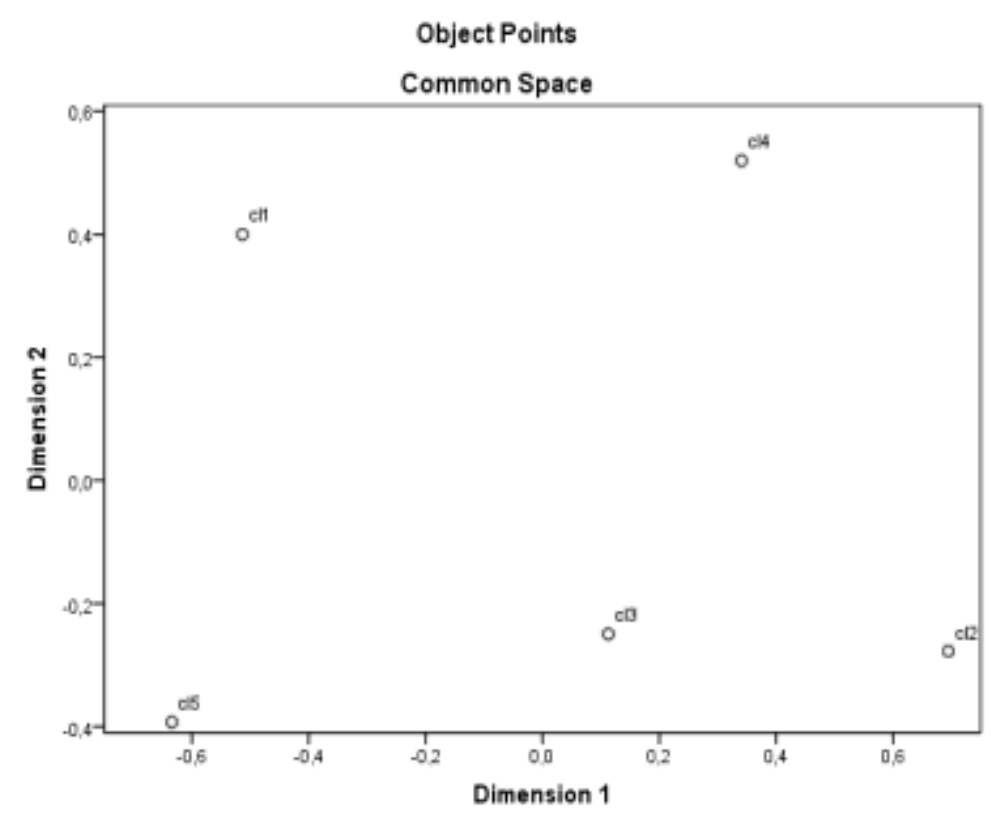

Source: SPSS (PASW Statistics 18)

Taking a closer look on the clusters, we can indeed identify our previous pro-US ("breaking the china") cluster as number 1, the "community firm" cluster as number 4 , and the "harmony and performance" as number 5 . In order to save space, not all tables for cluster means and cluster characteristics (profile data) are presented here. In what follows, we will refer to clusters already described only by a short résumé. 


\section{Cluster 1: (still) "Breaking the china"}

A total of $6.7 \%$ of all Japanese are in Cluster $1^{109}$ which is relatively small, but also in the cluster are $57.6 \%$ of those from Anglo-American countries, which is extremely big. The total of -31.8 points (total distance, all variables included) compared to global means makes this group extremely anti-Japanese in terms of management philosophy.

Looking at how the 92 members of Cluster 1 think compared to the average respondent, we may call them "rejecters" (of the traditional Japanese management). Not only this cluster is roughly identical to the previous cluster 1 but it also looks more or less similar to the one that we have identified as "strong rejecters" in our preliminary analysis (i.e. the one of the crosstab) with 67 members. Indeed, their profile characteristics are not really surprising: 33.3 years old with a mode at 21 years, and 5.84 years tenure (the longest time spent in one company). Moreover, the curve of tenure is strongly left-skewed, with most of the members spending only between 0 and 5 years in the same company, and the cluster comes down squarely against the practice of lifetime employment. Not only they are relatively young but also their education is protracted: in this respect they are the "champions", together with members of Cluster 5. A proportion of $37 \%$ of them are still at school and typically reach master or doctoral degree. These two factors together can also explain the relatively short tenure, in parallel to the fact that they do not want to spend a long time in the same place either. Income levels correlate to the level of education: rich people (40\% of income level 5) typically become members of Cluster 1.

It is also interesting to note that they work in rather large companies: $72.3 \%$ come from firms sized from 4 to 6 , and Cluster 1 seems to be the most likely choice for somebody working in a company staffed over 5,000 (size 6). As education correlates with company size, one explanation could be that large companies are not causing employees to become Cluster 1, but people with a longer education (and thus members of Cluster 1) tend to work in rather large companies where their skills and knowledge are better appreciated. Another possible explanation is that lifetime employment is more appealing for somebody who works for a small company and is therefore less likely to achieve it. Thus, the higher pressure of big structures emphasizes problems with the Japanese practices.

\footnotetext{
${ }^{109}$ In order to make a clearer distinction between the new and the former clusters, the ones in the fivecluster system begins with a capital letter.
} 
To sum up, as in the previous case, members of Cluster 1 are rather young, well educated, and likely of Anglo-American origins. They tend to be rich and work for large companies. They are against lifetime employment, protected markets, seniority, sex discrimination, and they praise performance as an ultimate gauge to decide pay or promotion. By Japanese "standards", they are strong risk-takers and individualists.

\section{Cluster 2: Flag for status quo}

At this point the new setting of clusters becomes more interesting: Cluster 2 was (partly) cluster 4 in the previous point and we proceeded with the analysis of 5 clusters with a special focus on this group.

\section{Table 23: $\quad$ Cluster 2 mean values compared to total means}

\begin{tabular}{|l|c|}
\hline CLUSTER No.2 & N=311 \\
\hline There is something wrong about having a female boss: as manager they cannot perform as well as men & 0.82 \\
\hline Japanese companies are doing well enough with their recruitment & 0.66 \\
\hline $\begin{array}{l}\text { Employees recruited at the same time should basically be promoted together: it fosters cooperation } \\
\text { between members, limiting harmful competition }\end{array}$ & 0.64 \\
\hline If one day I want to find a new job, I will not send my CV to recruitment agencies & 0.63 \\
\hline It is better not to promote people very fast, older managers are wiser and usually do a better job & 0.61 \\
\hline $\begin{array}{l}\text { Even if a person is highly qualified he should not be quickly promoted as his subordinates may be much } \\
\text { older than he is }\end{array}$ & 0.60 \\
\hline It is normal that women quit their job at marriage or childbirth & 0.56 \\
\hline It is usually not desirable to take risk in business & 0.55 \\
\hline In a company it is not always better to have a leader with a strong vision & 0.54 \\
\hline $\begin{array}{l}\text { I recognize equality between men and women but somehow I feel more comfortable having a male } \\
\text { superior }\end{array}$ & 0.53 \\
\hline $\begin{array}{l}\text { Performance should be a significant element of the wage but it is not good if a young person earns more } \\
\text { than an older one }\end{array}$ & 0.52 \\
\hline $\begin{array}{l}\text { Stakeholders of a company are not limited to shareholders, and management must appropriately reflect } \\
\text { multiple interests }\end{array}$ & -0.55 \\
\hline Achieving the goals as a team is our common responsibility, not only our manager's & -0.57 \\
\hline $\begin{array}{l}\text { It is very important for directors of a company to not only represent the owners' (shareholders') } \\
\text { interests but also the ones of employees, business partners, or other members of our society }\end{array}$ & -0.57 \\
\hline
\end{tabular}

Of all Japanese, $43.9 \%$ became members of Cluster 2. With this high figure, an average Japanese respondent would most likely be in this group. Also, this cluster has the highest membership of all, with 311 members. Therefore, Cluster 2 seems to be the most important group of the panel.

The average age is 41.2 years with a rather good balance in age-groups (normalcurved frequencies). The average tenure is 11.9 years in the same company, and $50 \%$ of 
the group stay between 5 and 16 years, which is much longer (5-10 years more) than in Cluster 1.

In terms of education, a high proportion $(24.1 \%)$ has only a high school degree which is, together with cluster 3, the lowest among all clusters. However, most of the Cluster 2 members $(44.1 \%)$ have a bachelor degree.

Looking at company sizes, Cluster 2 respondents come mainly from size 1 to 4 (less than 1,000 employees), and employees of small companies (size 1 or 2) are statistically predisposed to join this cluster (50\% and 47.9\%).

The most likely status for this group is regular worker (status 3, with 41.8\%), who do often enjoy lifetime employment in Japan. Managers (status 4) have a 39.6\% chance of becoming a Cluster 2 member. However, Cluster 2 is not typically rich: $76.2 \%$ of the members claim to have income level 1 or 2 . It is well to remember here that Japanese managers are usually not extremely well-paid compared to low-rank workers, even at the CEO level (at least by US standards).

In total, the summarized mean value is 4.9 points more for the cluster compared to the whole panel. We can say that respondents here tend to be supporters of the traditional system but clearly not as much as Cluster 1 was rejecting it. We must note however that older Japanese people have a propensity to respond relatively less on the extremes and rather close to the center. Cluster 2 may strongly support the traditional system but its members express their feelings only moderately, compared to foreigners or even other clusters.

We must also note that a positive figure is relative to the total mean and does not mean absolute support. The first item, about having a female boss for instance, is ranked 0.8 points higher than the panel's mean, but the cluster mean value of 3.4 still represents a slight rejection of the idea that female managers would perform less well than men. And this point goes for most cases in this table, even for the negative distances (e.g. on the stakeholder view), whose variables are rated above 4 and therefore supported.

At the same time, we must understand that due to the high weight of Cluster 2 and 3 in the panel (as perhaps in Japanese society), it is logical that cluster means do not differ as much from the global average as in Cluster 1. By consequence, in order to have a firmer grasp of this cluster's opinion, we would do better to look at the mean values themselves as well. 
Table 24: Cluster 2- the two extremes of cluster mean values

\begin{tabular}{|c|c|}
\hline Before decision making, it is always better to know the others' opinion about the issue & 4.87 \\
\hline It is important to protect our markets and jobs from foreign competition & 4.86 \\
\hline Japan should find its own way to recover from crises, based on its traditions and culture & 4.74 \\
\hline $\begin{array}{l}\text { It is very important for directors of a company to not only represent the owners' } \\
\text { (shareholders') interests but also those of employees, business partners, or other members of } \\
\text { our society }\end{array}$ & 4.74 \\
\hline Achieving the goals as a team is our common responsibility, not only our manager's & 4.71 \\
\hline $\begin{array}{l}\text { Staying in the same company for long term is good because it does not block internal } \\
\text { competition or limit career prospects }\end{array}$ & 4.67 \\
\hline If possible, taking risk is to be avoided when it can endanger job security & 4.64 \\
\hline $\begin{array}{l}\text { People should never work alone, co-workers can bring help and play an important role in } \\
\text { correcting each others' mistakes }\end{array}$ & 4.63 \\
\hline $\begin{array}{l}\text { Lifetime (or long-term) employment isn't outdated: I want to stay in the same company for a } \\
\text { long time }\end{array}$ & 4.58 \\
\hline $\begin{array}{l}\text { Small and large firms have different characteristics and possibilities: it is acceptable and } \\
\text { normal that compensation and benefits are also different according to the size of the company }\end{array}$ & 4.58 \\
\hline $\begin{array}{l}\text { If I were graduating now, I would rather go to a company with Japanese management: they } \\
\text { understand better what a young employee needs }\end{array}$ & 4.53 \\
\hline $\begin{array}{l}\text { It is better if the union cooperates and keeps friendly relations with the management as the } \\
\text { economic health of the company is also in the interest of the workers }\end{array}$ & 4.50 \\
\hline Recruitment agencies (head hunters) should not gain a more prominent role in job hunting & 3.43 \\
\hline $\begin{array}{l}\text { Big companies don't need more transparency and the control of the market: there does not } \\
\text { need to be an external director in the board }\end{array}$ & 3.42 \\
\hline $\begin{array}{l}\text { There is something wrong about having a female boss: as manager they cannot perform as } \\
\text { well as men }\end{array}$ & 3.40 \\
\hline In a company it is not always better to have a leader with a strong vision & 3.36 \\
\hline $\begin{array}{l}\text { Even if a person is highly qualified he should not be quickly promoted as his subordinates } \\
\text { may be much older than he is }\end{array}$ & 3.32 \\
\hline I don't try to pursue hobbies / social activities away from work & 3.30 \\
\hline $\begin{array}{l}\text { The best way to increase size for a company is to hire more young graduates from top } \\
\text { universities }\end{array}$ & 3.10 \\
\hline
\end{tabular}

What we can see from the table above is that even the extreme values are not so far from 4 in this group. This small distance is surprising especially when compared to Cluster 3, which is the other cluster expressing relatively strong support towards traditional management.

We can see that members of Cluster 2 share stakeholder views, tend to make decisions by consensus but also accept gender discrimination (mean values around 4) or recruitment practices. If we compare Cluster 2 with 3 more closely, we notice that starting from value 4 (neutral), Cluster 2 means go systematically in the same direction as Cluster 3 answers, but always stop closer to the zero point (rare exceptions are the stronger support for cross-shareholding, emphasis on quality vs. marketing, or the rejection of small-large firm differences and friendly unions). In fact, members of this cluster express relative support for literally all traditional elements compared to the rest of the panel, but they are apparently rather passive: they do not raise their voices for or against hardly anything, as if the best thing to happen would be no change at all. 
We may see them as similar to the former cluster 4, although this is rather a subgroup (or even the core) of it. We have restricted the membership a little in order to have a clearer view of the respondents resistant to change. A typical profile of Cluster 2 is the middle-aged Japanese employee with about 12 years of tenure, a 4-year-college degree, and regular or managerial status in his or her company (almost $40 \%$ of managers are in Cluster 2). Although not typically rich, he or she is a good but passive servant of the Japanese system. If change is difficult to achieve in Japan in terms of management philosophy, this group may be one of the main reasons for it.

\section{Cluster 3: A performance system "à la Japanese"}

\section{Table 25: Cluster 3 means compared to total mean values}

\begin{tabular}{|l|c|}
\hline CLUSTER No.3 & N=191 \\
\hline $\begin{array}{l}\text { If I were graduating now, I would rather go to a company with Japanese management: they understand } \\
\text { better what a young employee needs }\end{array}$ & 0.72 \\
\hline $\begin{array}{l}\text { Staying in the same company for long term is good because it does not block internal competition or } \\
\text { limit career prospects }\end{array}$ & 0.65 \\
\hline Lifetime (or long-term) employment isn't outdated: I want to stay in the same company for a long time & 0.64 \\
\hline It is important to protect our markets and jobs from foreign competition & 0.59 \\
\hline $\begin{array}{l}\text { Japan should not move towards the American economy and its institutions for changing its old practices } \\
0.52\end{array}$ & -0.53 \\
\hline The best way to increase size for a company is to hire more young graduates from top universities & -0.60 \\
\hline It is normal that women quit their job at marriage or childbirth & 0.5 \\
\hline
\end{tabular}

Number 3 is the second largest cluster in terms of population. Some $27.5 \%$ of Japanese belong to this group. Looking at its members' statuses, status 2 (non-regular workers) is the most typical class with a proportion of $34 \%$, though this picture is biased: regular employees $(30.9 \%)$ and managers $(31.4 \%)$ are also highly represented. To gain deeper understanding of status characteristics, we must remember: the largest proportion of Cluster 2 (ca. the same profile) was the regular workers with $41.8 \%$ but it contained also a high number $(23.8 \%)$ of managers. In Cluster 3, the proportion of managers is the highest among all clusters (almost 10\% more than in Cluster 2); which means that proportionally this group probably has the greatest economical-political power in spite of its apparently dominant irregulars.

As for Cluster 2, average education stops at two- (23\%) or four-year college (44\% of the cluster) but many respondents started work immediately after high school $(22 \%)$. The average age (42.4 years) is a little bit higher than Cluster 2 with balanced 
frequencies, and their tenure is the longest of all clusters: 13.1 years on average spent in the same company. We also know that half of the members have a figure of between 6 and 19 years for this indicator: a very long time by Western standards.

Indeed, this cluster can also be identified as a group supporting traditional management style: actually, they have the highest score in our rating of variables. The summarized distance of cluster mean values from global averages is 5.8 points higher than for the total panel (4.9 for Cluster 2). Members of this group have probably been identified as "strong supporters" at the beginning of this chapter (see Point 1.1). They are certainly pro-Japanese and support long-term employment or market protectionism, but at the same time they are apparently more inclined towards gender equality than the global average.

\section{Table 26: Cluster 3 - the two extremes of cluster mean values}

\begin{tabular}{|c|c|}
\hline $\begin{array}{l}\text { It is very important for directors of a company to not only represent the owners' } \\
\text { (shareholders') interests but also the ones of employees, business partners, or other members } \\
\text { of our society }\end{array}$ & 5.46 \\
\hline Before decision making, it is always better to know the others' opinion about the issue & 5.40 \\
\hline It is important to protect our markets and jobs from foreign competition & 5.40 \\
\hline Japan should find its own way to recover from crises, based on its traditions and culture & 5.35 \\
\hline $\begin{array}{l}\text { Staying in the same company for long term is good because it does not block internal } \\
\text { competition or limit career prospects }\end{array}$ & 5.31 \\
\hline Achieving the goals as a team is our common responsibility, not only our manager's & 5.29 \\
\hline $\begin{array}{l}\text { People should never work alone, co-workers can bring help and play an important role in } \\
\text { correcting each others' mistakes }\end{array}$ & 5.14 \\
\hline $\begin{array}{l}\text { Lifetime (or long-term) employment isn't outdated: I want to stay in the same company for a } \\
\text { long time }\end{array}$ & 5.11 \\
\hline $\begin{array}{l}\text { If I were graduating now, I would rather go to a company with Japanese management: they } \\
\text { understand better what a young employee needs }\end{array}$ & 5.06 \\
\hline $\begin{array}{l}\text { It is better if the union cooperates and keeps friendly relations with the management as the } \\
\text { economic health of the company is also in the interest of the workers }\end{array}$ & 4.98 \\
\hline $\begin{array}{l}\text { Stakeholders of a company are not limited to shareholders, and management must } \\
\text { appropriately reflect multiple interests }\end{array}$ & 4.94 \\
\hline If possible, taking risk is to be avoided when it can endanger job security & 4.94 \\
\hline $\begin{array}{l}\text { Japan should not move towards the American economy and its institutions for changing its } \\
\text { old practices }\end{array}$ & 4.91 \\
\hline $\begin{array}{l}\text { Small and large firms have different characteristics and possibilities: it is acceptable and } \\
\text { normal that compensation and benefits are also different according to the size of the company }\end{array}$ & 4.86 \\
\hline $\begin{array}{l}\text { Working in an open office is not tiring; every company should try to have common office for } \\
\text { their white-collar staff }\end{array}$ & 4.85 \\
\hline $\begin{array}{l}\text { People should try harder to achieve consensus in decision making: group harmony is worth } \\
\text { the time invested in that process }\end{array}$ & 4.81 \\
\hline $\begin{array}{l}\text { Rotating employees regularly is good because they can get better knowledge and vision } \\
\text { about the company as a whole, so probably they can become better managers }\end{array}$ & 4.76 \\
\hline $\begin{array}{l}\text { I recognize equality between men and women but somehow I feel more comfortable having a } \\
\text { male superior }\end{array}$ & 3.23 \\
\hline $\begin{array}{l}\text { Differences between "core workers" and temporary staff or part-timers are ok: they are not } \\
\text { doing the same job }\end{array}$ & 3.14 \\
\hline $\begin{array}{l}\text { Performance should be a significant element of the wage but it is not good if a young person } \\
\text { earns more than an older one }\end{array}$ & 3.12 \\
\hline
\end{tabular}




\begin{tabular}{|l|c|} 
I don't try to pursue hobbies / social activities away from work & 3.06 \\
\hline Recruitment agencies (head hunters) should not gain a more prominent role in job hunting & 3.00 \\
\hline $\begin{array}{l}\text { Big companies don't need more transparency and the control of the market: there does not } \\
\text { need to be external director in the board }\end{array}$ & 2.99 \\
\hline In a company it is not always better to have a leader with a strong vision & 2.90 \\
\hline It is normal that women quit their job at marriage or childbirth & 2.81 \\
\hline $\begin{array}{l}\text { It is better not to promote people very fast, older managers are wiser and usually do a better } \\
\text { job }\end{array}$ & 2.79 \\
\hline $\begin{array}{l}\text { Even if a person is highly qualified he should not be quickly promoted as his subordinates } \\
\text { may be much older than he is }\end{array}$ & 2.72 \\
\hline $\begin{array}{l}\text { Employees recruited in the same time should basically be promoted together: it fosters } \\
\text { cooperation between members, limiting harmful competition }\end{array}$ & 2.71 \\
\hline $\begin{array}{l}\text { There is something wrong about having a female boss: as manager they cannot perform as } \\
\text { good as men }\end{array}$ & 2.32 \\
\hline $\begin{array}{l}\text { The best way to increase size for a company is to hire more young graduates from top } \\
\text { universities }\end{array}$ & 2.25 \\
\hline
\end{tabular}

When looking at the cluster mean values here, it is surprising the extent to which this group is more at ease expressing strong opinions than Cluster 2. They seem to have approximately the same profile, but we must not overlook the higher proportion of managers in this group.

According to their responses, Cluster 3 is looking for a Japanese-type management style, with special focus on stakeholder orientation, long-term employment, regular rotation, protected markets, teamwork, and cooperative unions. What they dislike, however, is the strong division between regulars and non-regulars, or between genders, and the slow promotions. For a new management system in Japanese companies, Cluster 3 would clearly prefer one with somewhat protected markets, longterm orientation, strong leaders, quick promotions for good performance, and an equal chance for every employee to attain managerial positions. In other words, they strongly support the existing system, but performance must be the most important evaluation factor for all.

\section{Cluster 4: (new members of the) "Community firm"}

We have again the community firm cluster with its male dominance $(61.2 \%)$, the discriminatory attitude and the relatively high proportion of other Asians. Members of Cluster 4 are also relatively young (33.7 years old), have a high proportion (42.5\%) of students and a good number of higher degrees (60.5\% of them have a BSc). Even somebody with an MBA level is more likely to be a member of Cluster 4 (42.5\%). The 
average Cluster 4 tenure is 8 years but $75 \%$ have stayed less than 10 years in the same company.

Respondents here still support rotation, prefer to work for big organizations (4.53) and are grateful for having a job (5.33). Number 4 is also the only cluster to express a positive attitude (4.89) on company groupings and its members approve that alliances make firms stronger. The other clusters do not seem to be concerned by the question.

As previously in the four-cluster model, the community group gave the highest scores (5.2) to "company drinking parties" after work, and on average 5.31 for friendship at work. They also support (4.77) company postings away from home. Globally, Cluster 4 is apparently a supporter of Japanese-style management $(+4.2$ point compared to total mean values).

On the other hand however, its members support internal competition among employees and seek for more mid-career job options through external recruitment agencies. Indeed, Japanese companies often lack a developed external job market and still tend to recruit directly from schools. This custom makes job hunting rather difficult if somebody is slow in getting a job contract or wants to change employer afterwards.

\section{Cluster 5: Harmony and competition}

Cluster 5 is the smallest group but an interesting one because their "general support" level is negative (-6.1) compared to the total mean values. They have more or less the same characteristics as our former "harmony and performance" cluster.

Members of Cluster 5 show the strongest support for regular rotation of employees: this practice is strongly linked to lifetime employment and it is also a means to train future managers. The support for re-employment favors aged, retired exemployees who need the extra money or the feeling of usefulness at work. Silent shareholders were common during the golden age of cross-shareholding: the importance of ownership is somewhat weakened in the stakeholder approach which the Japanese traditionally have.

Their preference for not voting (aiming at consensus) and joint responsibility, are all "typical" in Japan and express a positive attitude towards "harmony": an attitude avoiding conflicts, welcoming long-term stability and satisfaction of all parties. Cluster 
5 is also the only group "prohibiting" confrontation for unions (with management), though others welcome a predominantly cooperative behavior as well.

On the other hand, members of Cluster 5 seem to be risk-takers, highlighting the importance of (individual) performance, free markets, competition and marketing skills. Both harmony clusters are marked by an extreme aversion to discrimination, especially by gender. Their average age is 37.5 years (with a normal curve) and statistically they work for about 9.3 years in the same company. More precisely, half of the cluster have spent between 2.5 and 13.5 years in the same place. In those respects, Cluster 5 is situated between clusters 1 and 4 and clusters 2 and 3 .

The most significant status in the group is 3, regular employees, but statuses 1 and 2 combined represent the same weight (about 50\%) as 3 and 4. A continuous tendency is to be observed with the company size: the bigger the company a respondent works for, the higher the chance that he or she belongs to Cluster 5. We may conclude that this balance between harmony and competition is indeed a good means of describing large Japanese companies.

\section{3) Turning back to the map of clusters}

Following cluster descriptions, the final point is a restructuring of the MDS map along specific dimensions. The passivity of Cluster 2 seemed to be a key element for this research focusing on change. Another dimension returning regularly has been the hierarchy-equality issue. If our clusters are different in these aspects, we should be able to locate the centers in their two-dimensional space. Figure 35 below appears to satisfy our needs.

With this conclusion, we will close the analysis of our first hypothesis: we have indeed identified several elements of both external support and rejection, and found the groups which mostly resist change in Japan. The crosstab of Point 1.1 provided good preliminary explanations which we could hone through the cluster analysis. We could also see the variables which are more likely to change or disappear in the near future. In the following point, we will look at the potential effects those changes might cause on the other elements or on the management system as a whole. We will discover the 
internal structure of our elements, compare findings with the hypothesis and understand their consequences.

Figure 35: MDS Alscal map with dimension labels

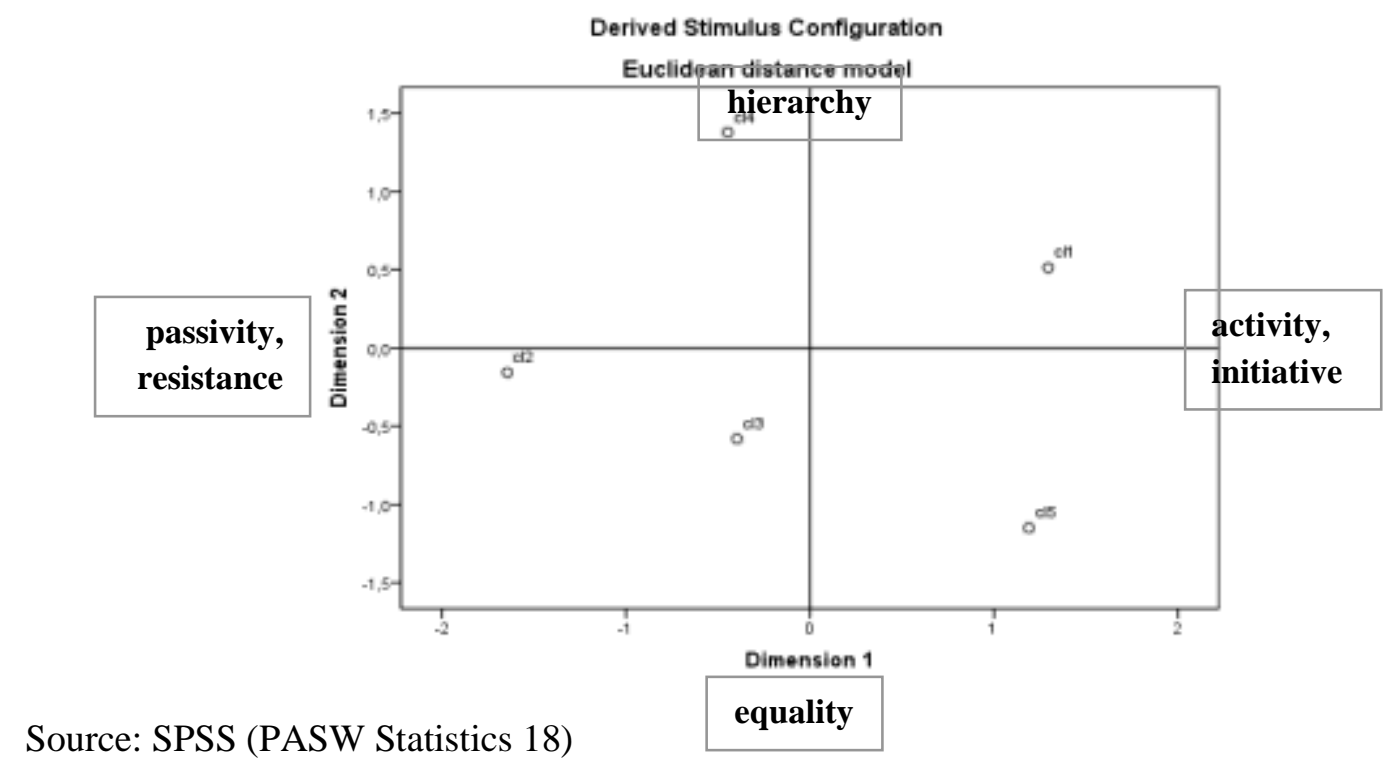

\section{3) Findings (3): measuring interconnectivity}

The next step in our analysis was to uncover a sort of hierarchy or dependence behind the enlisted elements of Japanese management-if there is any. Common wisdom would suggest there is, as their historical evolution is rather logical: elements frequently developed together and became part of the Japanese system at the same time. After verifying that responses for each variable represent approximately a normal curve, we went further with the rearranged items of Point 1.3 when we recreated 26 management elements out of the 67 items (we ignored here the two control questions).

\section{1) Recreating the management elements}

To see whether the items referring to the same management element kept their coherence in the empirical database as well, a preliminary correlation matrix was exported and significant Pearson-coefficients were examined. The first results confirmed that the element-based logic of the items was kept and that the ones referring 
to the same element mostly correlated among each other at a 0.01 (or some at 0.05 ) level of significance (2-tailed). Two exceptions out of 69 could be identified and withdrawn from the given element. Once this test was finished, we were able to compute the 26 elements on the basis of their composing variables (items) using the MEAN tag. The result was 26 new variables, representing the 26 operationalized management elements in the empirical data base. Thus, the links between these elements could be finally examined, first with a new correlation matrix.

At first sight, the result seemed to satisfy our expectations: the number of significant correlations (links) proved to be extremely high. Figure 36 below shows them in three background colors. Light colors signal a significance of level 0.05. Intermediate colors mean a significance of 0.01 . The strong colors locate significances of 0.00 with outstanding Pearson coefficients of 0.2 and above.

\section{Figure 36: The correlation matrix of the recreated elements}

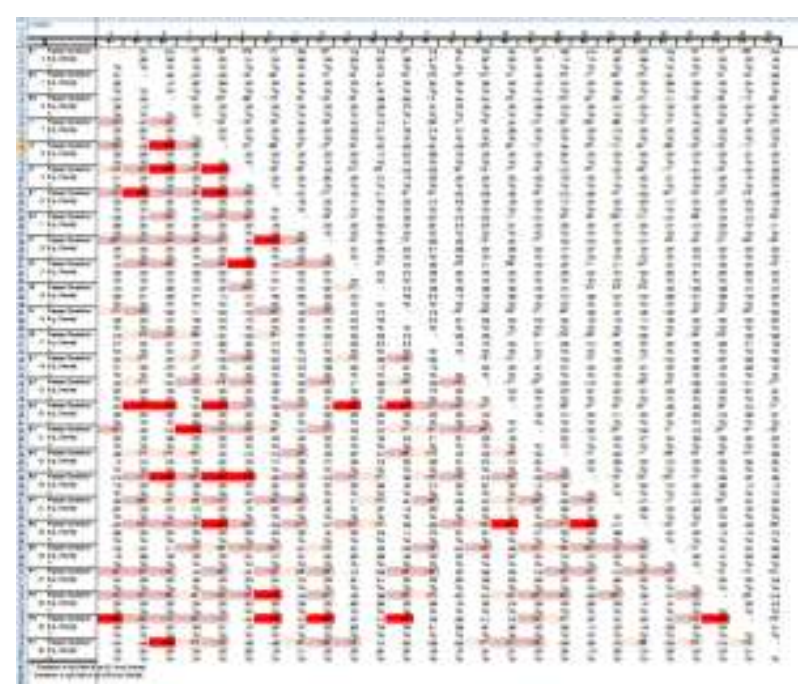

The fact that there is not a single column without at least one significant correlation instantly proves that our third hypothesis was correct and all elements are indeed strongly linked to each other. To understand these links more clearly, we will proceed with further examination.

Needless to say, we cannot expect the same type of correlations or links between the calculated variables as the ones in our theoretical model based on a historical logic. There may be several reasons for this difference. Firstly, the logic of the historical evolution of the management system is no longer relevant today. Indeed, the responses only reflect people's attitude to the different elements. We can see in the correlation 
matrix that if somebody supports Element A, there is a high chance that he would support Element B as well-but this is not based on the theoretical connections.

The second reason, which is also probably true, concerns the operationalization of the elements. Of 30 elements, four were not operationalized at all. Some others were very difficult to transform into questions, especially highly abstract ideas such as collectivism and Confucianism. Thus, in some cases, we can say that the operationalization failed or mirrored a management practice different from the original, theoretical idea. It may also be that some were just not of interest for the respondents.

For the rest of the analysis, we propose to omit the theoretical connections and focus only on the observed ones between the calculated variables.

\section{2) Reinterpreting the management elements}

We have assumed above that the theoretical management elements cannot be defined in the same way as empirical ones. To avoid confusion, Table 27 illustrates the elements both with the numbering of the theoretical model, and a new categorization created for the empirical study. For the analysis of the empirical connections, we will use these new labels.

\section{Table 27: The new labels for the management elements}

\begin{tabular}{|l|c|}
\hline Management elements with numbering used previously & New labels \\
\hline 1. A small living area with frequent catastrophes & not included \\
\hline 2. Confucianism and collectivism & E1 \\
\hline 3. Late industrialization & not included \\
\hline 4. Developmental state and protected markets & E2 \\
\hline 5. An economy with continuous growth & not included \\
\hline 6. An ambiguous and rigid labor market & E3 \\
\hline 7. Easy-to-train and devoted employees & I1 \\
\hline 8. Superiors are rather managers than leaders & I2 \\
\hline 9. Homogeneity and male dominance & I3 \\
\hline 10. Stakeholder orientation & S1 \\
\hline 11. Cost leadership (vs. product differentiation) & S2 \\
\hline 12. Diversified portfolios, spin-offs and start-ups & not included \\
\hline 13. Large and complex, U-form based group hierarchy & F1 \\
\hline 14. Large boards dominated by insiders & F2 \\
\hline 15. Central HRM prevails over Finance & F3 \\
\hline 16. Processes of decision-making: a consensual approach & F4 \\
\hline 17. Working teams & F5 \\
\hline
\end{tabular}




\begin{tabular}{|l|l|}
\hline 18. Recruitment from schools & B1 \\
\hline 19. Core (permanent) vs. "irregular" staff & B2 \\
\hline 20. Long-term employment & B3 \\
\hline 21. Formal induction with the chairman: creating a family & B4 \\
\hline 22. Cohort training "on-the-job" & B5 \\
\hline 23. Slow promotion & B6 \\
\hline 24. Rotation & B7 \\
\hline 25. Tenure-based compensation or "seniority pay" & B8 \\
\hline 26. Company unions & B9 \\
\hline 27. Behavior-based control & P1 \\
\hline 28. Multi-monitoring group effect & P2 \\
\hline 29. Decisions are joint responsibility & P3 \\
\hline 30. Good performance means increasing market share and harmony & P4 \\
\hline
\end{tabular}

Using these new labels, we can now illustrate on a chart what the "interconnectivity" of Japanese Management, represented by the correlation matrix, means graphically. If we omit correlations with a relatively low significance level and consider only levels of 0.01 or below, the whole system of our empirical management elements looks something like this:

\section{Figure 37: Empirical connections between management elements}

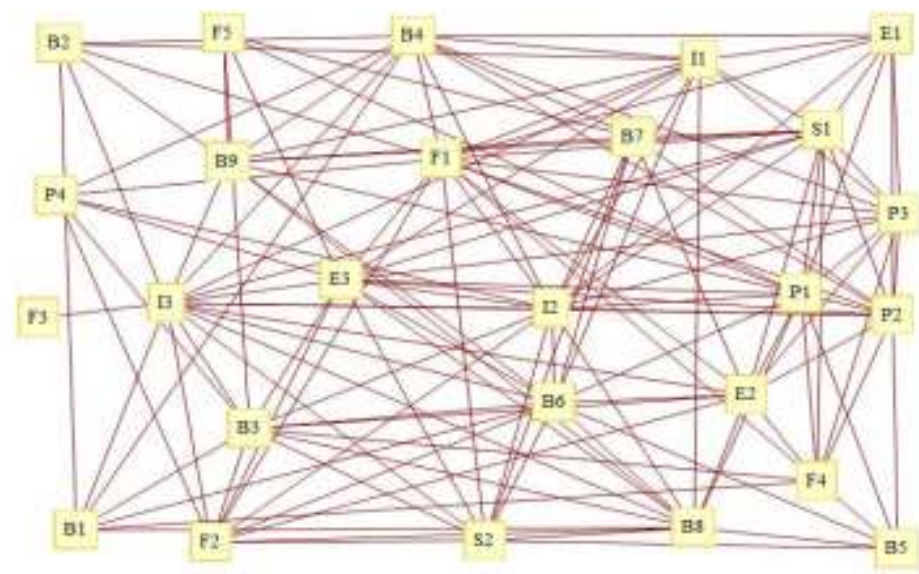

Source: Wolfram Mathematica 7.0

It is quite apparent that each item is totally embedded in the system and the links interfere with each other, the only exception being F3 (the importance of the central HR department which received neutral feedback according to Table 18). To some idea of what these connections mean, it is clear that we need to simplify our model and try to reduce the number of items examined. 
We can go further by re-examining the strongest links in the matrix. Figure 38 shows only the correlations with a Pearson coefficient of 0.20 or above $(0.00$ level of significance). We added the signs of support and rejection used in the previous point. According to this figure, the central element of the Japanese system is B3: long-term employment because it has the highest number of connections with other elements.

\section{Figure 38: The strongest correlations between the empirical elements}

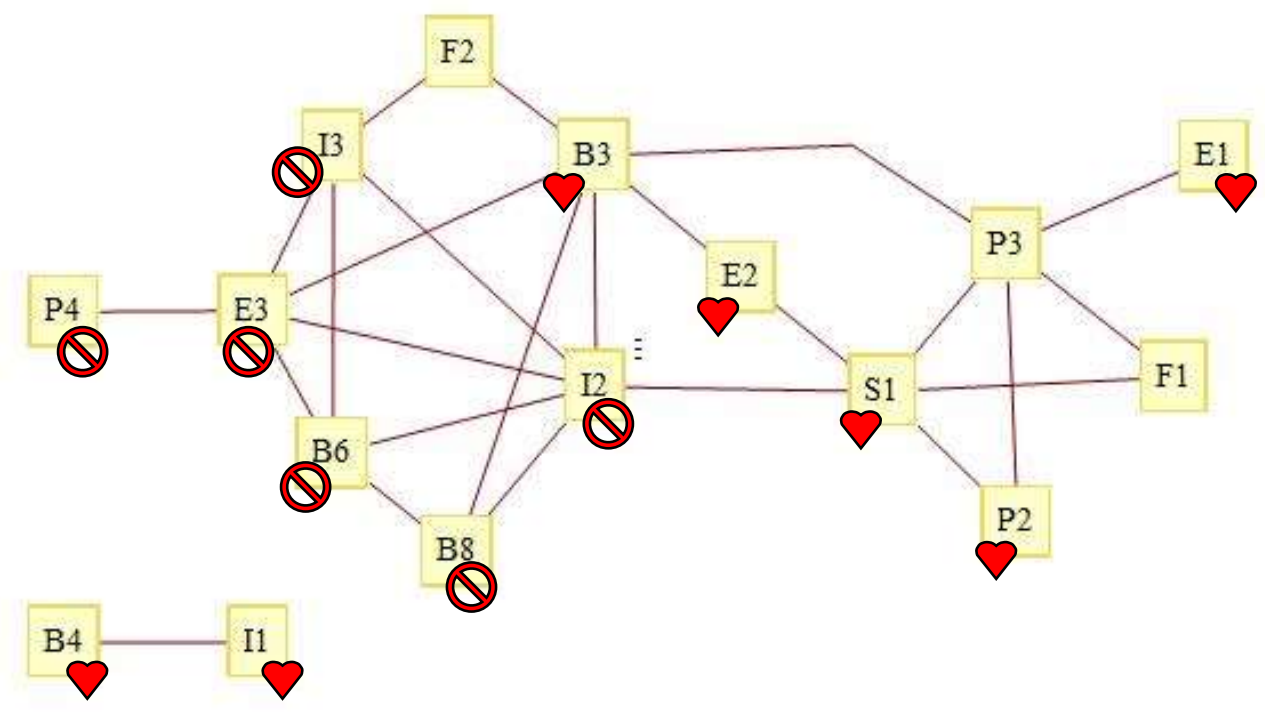

Source: Wolfram Mathematica 7.0

Before further interpretations, we must see the limits of our "empirical elements". We noted earlier that some of these elements might be poorly operationalized: in other words, the interpretation of respondents may possibly differ from the original, historical definitions described in Chapter 3. The sole question related to E1 (collectivism/Confucianism) can obviously not represent the whole concept of collectivism. The question examines whether the respondent interprets professional achievement as more an individual or a group result, and nothing more. The F3 which was not included in the two previous figures deals with the centrality of the HR department in firms, but could not delve deeper and therefore cannot reveal any further connections with the other elements. The E2's focus is more on protection alone, as it is hard to cover the whole concept of the developmental state. So for further analysis, we will have to reinterpret the meaning of the empirical elements in each case.

The highest coefficients on Figure 38 ( 0.35 or above) are between E3 and I2, and between B6, B8, B3, and E2. The next step in simplifying our data will be to 
attempt to merge some highly correlating elements while reconsidering their meaning, as they might have been understood when the related questions were answered. In fact, we proceed as if we had done a main component analysis and interpret now our new factors. The process of examining correlations and identifying strongly correlating elements which cover a similar meaning in practice is explained in Annex VIII.

\section{3) The main indicators of Japanese Management}

Following the process described in Annex VIII, we were able to further reduce the number of variables. We reinterpreted the meaning of the empirical management elements and formed eight new composite variables, called the "main indicators" of Japanese Management. These indicators still correlate with each other to a high degree as shown in Figure 39. We added the signs for support or rejection when that could be clearly determined based on the constituent variables. In the final step of our data analysis, we will use these main indicators to find out with multidimensional scaling techniques, how people possibly perceive relationships between these indicators.

\section{Figure 39: The main indicators and their connections (correlations)}

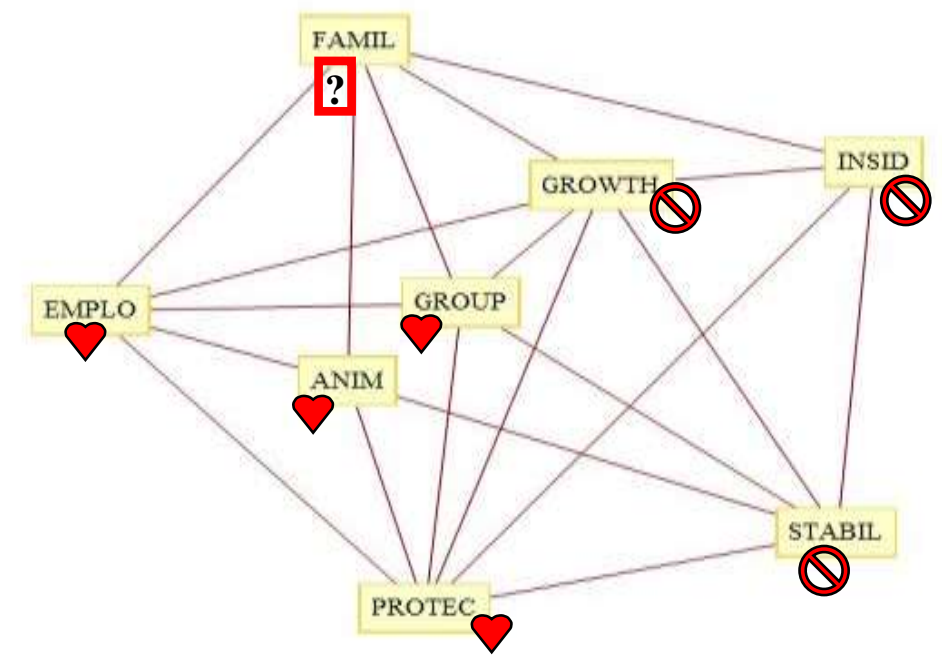

Source: Wolfram Mathematica 7.0

These short labels stand for the eight main indicators. Their description is as follows.

"FAMIL" means Familial Devotion. Its focus is the employees' mindset at the workplace and includes gratefulness to the company, the hiring of youngsters and 
creation of a corporate family, and a decent status for members protected by the union (regulars). Some of its elements are greatly supported by the majority of respondents but some others are less so.

"EMPLO" stands for Employee Friendliness. This is the belief that every employee is important in the firm (and may be more important than anything else), and the recognition that larger companies give better chances for employees. Organizations are above all social institutions.

"PROTEC" refers to Protection and Security. In Japan, it is seen as good that the national economy is somehow protected, the state plays an active role in sustaining it and the firms offer for their part protection to their regular members in form of longterm employment.

"ANIM" means Animated Workplaces where colleagues meet and interact with each other (open-office concept) and continuous change is guaranteed by regular rotation, which keep employees moving.

"GROUP" stands for Group Orientation where the group always prevails over the individuals: one must seek for consensus in decision-making, the work and the training are organized in groups and responsibility is also held in common.

"GROWTH" means Permanent Growth, which, although it can no longer be guaranteed, has still left its mark on Japan: continuous hiring from schools, riskavoiding management, or the focus on market share as a means to measure performance.

"STABIL" stands for Seniority and Stability, when pay and promotion are linked to tenure rather than performance and firms keep playing on product cost and quality instead of differentiating their products in more innovative and creative ways.

Finally, "INSID" refers to Insider Dealers, employees and managers who enjoy being with people like themselves (homogeneity) and prefer to keep a closed, centralized control of the company from inside, not allowing too many opportunities for outsiders in the board of directors, for instance.

After the interpretation of our main elements, we attempted to identify the key dimensions underlying the respondents' evaluations and position them with the help of multidimensional scaling (MDS). Our analysis is based on calculations, since these eight elements were not exactly the variables in the survey but mathematically our 
model does fit and the interpretation of the indicators was possible with relative ease, which is promising in terms of validity as well.

Based on our calculations, the respondents could have evaluated these eight main indicators along three dimensions. Figure 40 represents a map of the indicators in these three dimensions. Estimates for the model were calculated using NewMDSX for Windows $\bigodot$. The Stress value of this model remains satisfactory low: 0.010272 (Dimensions 1, 2 and 3).

\section{Figure 40: The MINISSA model of the eight main indicators in 3D}

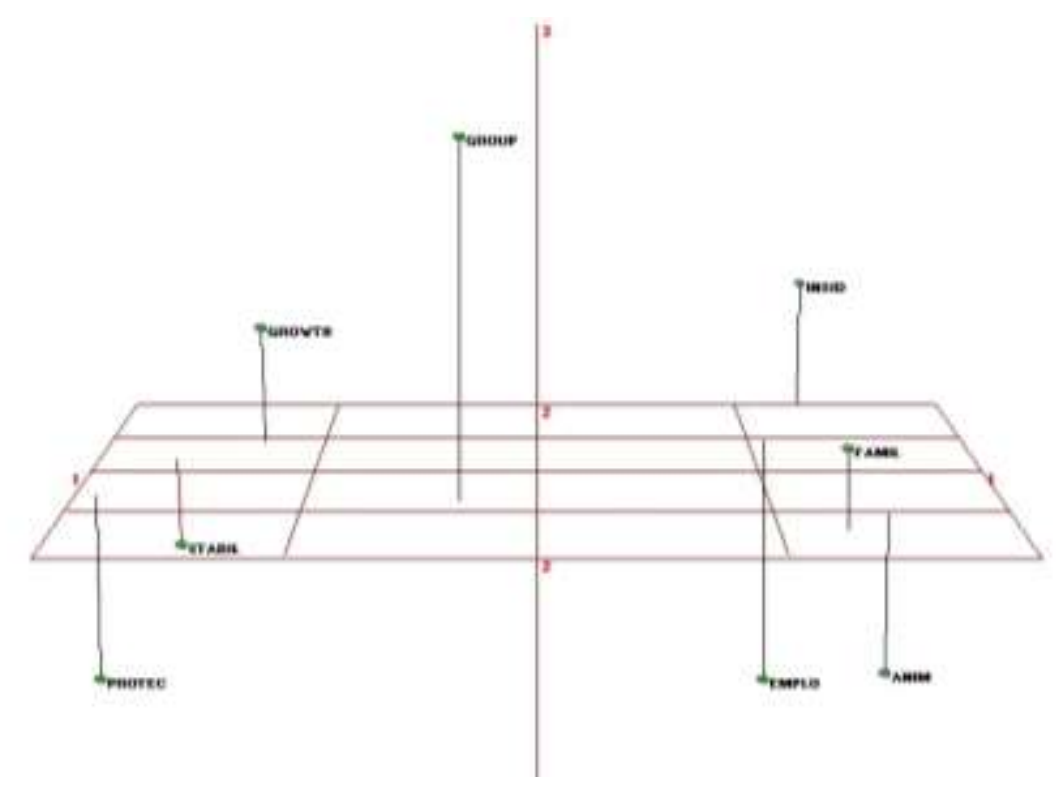

Source: MINISSA (Michigan-Israel-Nijmegen-Integrated-Small-Space-Analysis - MINISmallest-Space-Analysis (Nijmegen version)).

Our next task is to interpret the dimensions again, identifying the three most important factors, based on which society appears to evaluate managerial practices in Japan. Needless to say, compressing a nation's management culture into three main axes or factors involves brushing over many nuances important in real management. The contribution of this model is the depth of insight, and the interpretation of the eight main indicators is already a significant achievement in this aspect. Accordingly, reformulating this in three dimensions can only be a tentative approach and great care is needed in considering these dimensions. In this thesis, we propose to label Dimension 1 as the Subject of Concern (which may vary from people to output or organization), Dimension 2 as the Sense of Collectivity (individualism versus collectivism), and 
Dimension 3 as the Temperature of Personal Attitude ("dry" versus "wet" relationships).

\section{4) The clusters and the main indicators: a discriminant analysis}

Up to this point of our analysis, we examined in detail the responses of nearly eight hundred respondents and the related sixty-nine variables. We achieved satisfactory results proving that all our three hypotheses were correct: the observed societal support of the Japanese characteristics offers a good match with the theoretical (and mostly statistically proven) management trends, the Japanese Salarymen and the majority of managers appear to support most of the traditional characteristics, and these characteristics show strong correlation with each other. In addition, based on these correlations, we succeeded in reducing the 26 elements into eight main indicators which offer a clearer and easy-to-understand picture of how society in Japan evaluates corporate management. We could end the analysis here.

However, there is a triggering question which might be lurking in the minds of many. Are we able to ascertain, based only on the eight indicators, whether someone is in a particular cluster identified earlier? To what extent does the attitude of a respondent to the main indicators determine his or her cluster membership? We may answer that question with a discriminant analysis.

In the model based on the eight indicators, the discriminant analysis carried out estimated four discriminant functions, each representing a different dimension of discrimination. Yet we could see that according to the eigenvalues of these functions $(1.2,0.6,0.3$ and 0.05 respectively), we are able to represent 97.9 percent of the total data information using only the first three functions. The Wilks' Lambda values $(0.72$ testing three through four functions and 0.96 for the four, by a significance level of 0.00) suggest a very good result for the identification of group memberships. Indeed, according to the discriminant analysis, the probability of finding out the cluster membership of respondents, based on the eight main indicators, is fairly good (overall $71 \%$, see details in Table 28), and the 794 respondents remained well grouped around the five group centroids within the space of the main indicators. 
Table 28: Classification results: match of the predicted cluster memberships

\begin{tabular}{|c|c|c|c|c|c|c|c|c|}
\hline & & Cluster & & Predict & oup Mer & hip & & \\
\hline & & Case & 1 & 2 & 3 & 4 & 5 & Total \\
\hline Original & $\%$ & 1 & 75.0 & 4.3 & 4.3 & 6.5 & 9.8 & 100.0 \\
\hline & & 2 & 1.0 & 79.4 & 12.9 & 6.1 & .6 & 100.0 \\
\hline & & 3 & 2.1 & 17.3 & 65.4 & 7.9 & 7.3 & 100.0 \\
\hline & & 4 & 6.8 & 6.1 & 8.8 & 61.9 & 16.3 & 100.0 \\
\hline & & 5 & 5.7 & 3.8 & 11.3 & 18.9 & 60.4 & 100.0 \\
\hline
\end{tabular}

Source: PASW Statistics 18.

Taking a look on the structure matrix of the discriminant functions, we may attempt to find a description or a label for each of them. As we stated earlier, using three functions out of the four indicated already gives a highly significant result, so we merged this function into the first one, as shown in Table 29. The table represents pooled intragroup correlations between discriminating variables and standardized canonical discriminant functions. Variables are ordered by absolute size of correlation within each function, and the indexed star signs indicate the largest absolute correlation between each variable and any discriminant function.

Table 29: $\quad$ Structure matrix of the discriminant functions

\begin{tabular}{|l|r|r|r|r|}
\hline & \multicolumn{4}{|c|}{ Function } \\
\cline { 2 - 5 } & 1 & 2 & 3 & \multicolumn{1}{c|}{4} \\
\hline GROWTH & $.634^{*}$ & -.169 & -.334 & .144 \\
PROTEC & .329 & $.743^{*}$ & -.217 & -.228 \\
GROUP & -.092 & $.467^{*}$ & .084 & -.024 \\
EMPLO & -.305 & $.449^{*}$ & .332 & .411 \\
ANIM & -.097 & $.420^{*}$ & -.217 & .148 \\
INSID & .550 & .135 & $.614^{*}$ & -.232 \\
FAMIL & -.121 & .148 & $.574^{*}$ & -.058 \\
STABIL & .377 & .190 & .155 & $.699^{*}$ \\
\hline
\end{tabular}

Source: PASW Statistics 18.

The structure matrix gives us further indications on the main axes dividing Japanese society in regards of management. We can still find the logic based on growth and stability, the protective effects of group thinking, and the familial insiderism which makes Japan what is known as a "high context" society (Nakane, 1972). 


\section{ANNEX VI:Suspected origins of the management elements}

\begin{tabular}{|c|c|}
\hline Management elements & It can be derived from... \\
\hline 1. A small living area with frequent catastrophes & - \\
\hline 2. Confucianism and collectivism & 1 \\
\hline 3. Late industrialization & - \\
\hline 4. Developmental state and protected markets & 2,3 \\
\hline 5. An economy with continuous growth & - (no relevance) \\
\hline 6. An ambiguous and rigid labor market & 2,3 \\
\hline 7. Easy-to-train and devoted employees & $2,6,25$ \\
\hline 8. Superiors are more managers than leaders & 2 \\
\hline 9. Homogeneity and male dominance & 2 \\
\hline 10. Stakeholder orientation & 2,3 \\
\hline 11. Cost leadership (vs. product differentiation) & 3,4 , \\
\hline 12. Diversified portfolios, spin-offs and start-ups & - (no relevance) \\
\hline 13. Large and complex, U-form based group hierarchy & 12,24 \\
\hline 14. Large boards dominated by insiders & 23 \\
\hline 15. Central HRM prevails over Finance & $6,10,24,30$ \\
\hline 16. Processes of decision-making: a consensual approach & 2 \\
\hline 17. Working teams & 2,28 \\
\hline 18. Recruitment from schools & 3,20 \\
\hline 19. Core (permanent) vs. "irregular" staff & 9 \\
\hline 20. Long-term employment & $2,5,6$ \\
\hline $\begin{array}{l}\text { 21. Formal induction with the chairman: creating a } \\
\text { family }\end{array}$ & $2,18,20$ \\
\hline 22. Cohort training "on-the-job" & 3,18 \\
\hline 23. Slow promotion & 20,25 \\
\hline 24. Rotation & 20,13 \\
\hline 25. Tenure-based compensation or "seniority pay" & $2,5,20$ \\
\hline 26. Company unions & 20 \\
\hline 27. Behavior-based control & 2,30 \\
\hline 28. Multi-monitoring group effect & 2 \\
\hline 29. Decisions are joint responsibility & 2 \\
\hline $\begin{array}{l}\text { 30. Good performance means increasing market share } \\
\text { and harmony }\end{array}$ & $4,5,10$ \\
\hline
\end{tabular}




\section{ANNEX VII: Cluster mean values of all variables (4 clusters)}

\begin{tabular}{|c|c|c|c|c|c|}
\hline \multicolumn{5}{|l|}{ Final Cluster Centers } & \multirow[b]{3}{*}{$\begin{array}{l}\text { Global } \\
\text { Mean }\end{array}$} \\
\hline & \multicolumn{4}{|c|}{ Cluster } & \\
\hline & $\begin{array}{c}1 . \\
(\mathrm{N}=112)\end{array}$ & $\begin{array}{c}2 . \\
(\mathrm{N}=89)\end{array}$ & $\begin{array}{c}3 . \\
(\mathrm{N}=177)\end{array}$ & $\begin{array}{c}4 . \\
(\mathrm{N}=416)\end{array}$ & \\
\hline $\begin{array}{l}\text { I recognize equality between men and women but somehow I } \\
\text { feel more comfortable having a male superior }\end{array}$ & 2.97 & 2.19 & 3.79 & 3.86 & 3.53 \\
\hline $\begin{array}{l}\text { There is something wrong about having a female boss: as } \\
\text { manager they cannot perform as well as men }\end{array}$ & 1.96 & 1.57 & 2.17 & 3.13 & 2.58 \\
\hline It is normal that women quit their job at marriage or childbirth & 2.51 & 1.96 & 4.06 & 3.68 & 3.40 \\
\hline $\begin{array}{l}\text { Japanese companies are doing well enough with their } \\
\text { recruitment }\end{array}$ & 2.11 & 2.61 & 2.61 & 3.76 & 3.14 \\
\hline $\begin{array}{l}\text { In a company it is not always better to have a leader with a } \\
\text { strong vision }\end{array}$ & 2.63 & 2.29 & 2.15 & 3.27 & 2.82 \\
\hline It is usually not desirable to take risk in business & 2.29 & 2.49 & 2.60 & 3.57 & 3.06 \\
\hline $\begin{array}{l}\text { The company can prosper more in the long term if } \\
\text { shareholders are "silent" and do not demand short-term profit } \\
\text { above all }\end{array}$ & 3.43 & 3.64 & 4.37 & 3.94 & 3.93 \\
\hline $\begin{array}{l}\text { It is very important for directors of a company to represent not } \\
\text { only the owners' (shareholders') interests but also the ones of } \\
\text { employees, business partners, or other members of our society }\end{array}$ & 5.34 & 6.03 & 5.93 & 4.88 & 5.31 \\
\hline $\begin{array}{l}\text { If the shareholders do put pressure on managers to achieve } \\
\text { good results even in short term, the company will not perform } \\
\text { better }\end{array}$ & 3.72 & 4.67 & 3.50 & 3.99 & 3.92 \\
\hline $\begin{array}{l}\text { Stakeholders of a company are not limited to shareholders, } \\
\text { and management must appropriately reflect multiple interests }\end{array}$ & 5.16 & 5.71 & 5.51 & 4.46 & 4.94 \\
\hline $\begin{array}{l}\text { Owning shares on a reciprocal basis between companies } \\
\text { (cross-shareholding) is good, mostly enhancing cooperation }\end{array}$ & 3.64 & 3.91 & 4.39 & 4.12 & 4.09 \\
\hline $\begin{array}{l}\text { Owning shares on a reciprocal basis between companies is not } \\
\text { bad, and not endeavoring financial results }\end{array}$ & 3.59 & 3.87 & 4.02 & 4.01 & 3.94 \\
\hline $\begin{array}{l}\text { In a company the group consensus is more important than any } \\
\text { leader or manager: group cohesiveness is the best tool to } \\
\text { ensure common vision and good performance }\end{array}$ & 3.51 & 3.45 & 4.69 & 4.15 & 4.10 \\
\hline $\begin{array}{l}\text { I don't always express my personnel opinion during important } \\
\text { meetings and others should do the same }\end{array}$ & 3.12 & 3.35 & 2.97 & 3.98 & 3.56 \\
\hline $\begin{array}{l}\text { Before decision-making, it is always better to know the others' } \\
\text { opinion about the issue }\end{array}$ & 5.56 & 5.69 & 6.01 & 4.93 & 5.35 \\
\hline $\begin{array}{l}\text { Small and large firms have different characteristics and } \\
\text { possibilities: it is acceptable and normal that compensation } \\
\text { and benefits are also different according to the size of the } \\
\text { company }\end{array}$ & 5.56 & 5.16 & 5.65 & 4.60 & 5.03 \\
\hline $\begin{array}{l}\text { If one day I want to find a new job, I will not send my CV to } \\
\text { recruitment agencies }\end{array}$ & 2.54 & 2.82 & 2.56 & 3.96 & 3.32 \\
\hline $\begin{array}{l}\text { Japan should find its own way to recover from crises, based on } \\
\text { its traditions and culture }\end{array}$ & 4.80 & 5.45 & 5.56 & 4.88 & 5.09 \\
\hline $\begin{array}{l}\text { If I were graduating now, I would rather go to a company with } \\
\text { Japanese management: they understand better what a young } \\
\text { employee needs }\end{array}$ & 2.94 & 5.12 & 3.97 & 4.70 & 4.33 \\
\hline $\begin{array}{l}\text { Japan should not move towards the American economy and its } \\
\text { institutions for changing its old practices }\end{array}$ & 3.74 & 5.44 & 4.10 & 4.45 & 4.38 \\
\hline $\begin{array}{l}\text { Work is always a team achievement, never just individual } \\
\text { performance }\end{array}$ & 4.22 & 4.61 & 4.79 & 4.29 & 4.43 \\
\hline $\begin{array}{l}\text { It is important to protect our markets and jobs from foreign } \\
\text { competition }\end{array}$ & 3.79 & 4.19 & 5.26 & 5.03 & 4.81 \\
\hline
\end{tabular}




\begin{tabular}{|c|c|c|c|c|c|}
\hline $\begin{array}{l}\text { There is too much stress and depression related to corporate } \\
\text { life today: life was better } 20 \text { years ago }\end{array}$ & 4.12 & 3.98 & 4.76 & 4.48 & 4.43 \\
\hline $\begin{array}{l}\text { Profitability indicators as ROE should not be given greater } \\
\text { priority than sales or market share }\end{array}$ & 3.47 & 3.89 & 3.14 & 3.77 & 3.60 \\
\hline $\begin{array}{l}\text { Companies should always form interest groups so they can be } \\
\text { much stronger }\end{array}$ & 3.99 & 4.00 & 4.77 & 4.03 & 4.19 \\
\hline Voting is not necessarily the best way of decision-making & 4.45 & 5.13 & 3.75 & 4.16 & 4.22 \\
\hline $\begin{array}{l}\text { People should try harder to achieve consensus in decision } \\
\text { making: group harmony is worth the time invested in that } \\
\text { process }\end{array}$ & 4.46 & 4.80 & 5.19 & 4.50 & 4.68 \\
\hline $\begin{array}{l}\text { It is better to evaluate workers by the way they do their job } \\
\text { than by the result, as the result may depend on many things }\end{array}$ & 3.96 & 4.54 & 4.55 & 4.30 & 4.33 \\
\hline $\begin{array}{l}\text { People should never work alone, co-workers can bring help } \\
\text { and play an important role in correcting each others' mistakes }\end{array}$ & 4.47 & 5.15 & 5.42 & 4.76 & 4.91 \\
\hline $\begin{array}{l}\text { The key success factor for a company is to produce good } \\
\text { quality products at an affordable price - succeeding in this } \\
\text { ensures almost automatic success }\end{array}$ & 3.54 & 3.11 & 4.72 & 4.16 & 4.08 \\
\hline $\begin{array}{l}\text { Japanese companies do not need to pay more attention to } \\
\text { efficient marketing: it is not as important as the quality of the } \\
\text { products }\end{array}$ & 3.22 & 3.83 & 2.88 & 3.80 & 3.52 \\
\hline $\begin{array}{l}\text { Working in an open office is not tiring; every company should } \\
\text { try to have a common office for their white-collar staff }\end{array}$ & 4.22 & 5.02 & 4.33 & 4.30 & 4.38 \\
\hline $\begin{array}{l}\text { Achieving the goals as a team is our common responsibility, } \\
\text { not only our manager's }\end{array}$ & 5.59 & 6.02 & 5.84 & 4.79 & 5.28 \\
\hline $\begin{array}{l}\text { Staying in the same company long term is good because it } \\
\text { does not block internal competition or limit career prospects }\end{array}$ & 3.86 & 4.99 & 4.64 & 4.82 & 4.66 \\
\hline $\begin{array}{l}\text { Lifetime (or long-term) employment isn't outdated: I want to } \\
\text { stay in the same company for a long time }\end{array}$ & 3.01 & 4.94 & 4.54 & 4.72 & 4.47 \\
\hline $\begin{array}{l}\text { If possible, taking risk is to be avoided when it can endanger } \\
\text { job security }\end{array}$ & 4.06 & 4.40 & 4.94 & 4.71 & 4.63 \\
\hline $\begin{array}{l}\text { It is not possible to lay off considerable numbers of employees } \\
\text { without ructions within the company or in the broader society }\end{array}$ & 3.97 & 4.44 & 3.77 & 4.11 & 4.05 \\
\hline $\begin{array}{l}\text { The job of the union is not to confront with the management in } \\
\text { order to represent purely the workers' interests }\end{array}$ & 3.80 & 4.18 & 3.54 & 3.83 & 3.80 \\
\hline $\begin{array}{l}\text { It is better if the union cooperates and keeps friendly relations } \\
\text { with the management as the economic health of the company } \\
\text { is also in the interest of the workers }\end{array}$ & 4.83 & 5.06 & 5.44 & 4.59 & 4.86 \\
\hline $\begin{array}{l}\text { Labor union and its activity are even nowadays relevant to the } \\
\text { employees' life }\end{array}$ & 4.13 & 4.18 & 3.92 & 3.97 & 4.01 \\
\hline $\begin{array}{l}\text { It is good to have a limited number of "core workers" with } \\
\text { some privileges in a company: achieving this status will } \\
\text { motivate every employee }\end{array}$ & 4.07 & 3.21 & 4.81 & 3.93 & 4.06 \\
\hline $\begin{array}{l}\text { Differences between "core workers" and temporary staff or } \\
\text { part-timers are ok: they are not doing the same job }\end{array}$ & 3.67 & 3.11 & 3.33 & 3.47 & 3.43 \\
\hline $\begin{array}{l}\text { Individual appraisal of performance is a threat to harmony. } \\
\text { companies should measure group performance }\end{array}$ & 2.69 & 2.93 & 3.85 & 3.83 & 3.58 \\
\hline $\begin{array}{l}\text { Salaries should not be entirely based on performance, age or } \\
\text { seniority of employees do also matter }\end{array}$ & 2.47 & 3.94 & 3.07 & 3.94 & 3.54 \\
\hline $\begin{array}{l}\text { Performance should be a significant element of the wage but it } \\
\text { is not good if a young person earns more than an older one }\end{array}$ & 2.03 & 2.55 & 2.99 & 3.56 & 3.10 \\
\hline $\begin{array}{l}\text { The performance of older people is usually better than } \\
\text { younger colleagues' due to their greater experience }\end{array}$ & 2.96 & 3.37 & 4.43 & 4.11 & 3.93 \\
\hline $\begin{array}{l}\text { Mainly performance-based pay is not good as it leads to } \\
\text { merely short-term goals and hinders cooperation }\end{array}$ & 3.22 & 4.09 & 3.72 & 4.12 & 3.90 \\
\hline $\begin{array}{l}\text { The re-employment of retirees should not be banned as it does } \\
\text { not take jobs from the youth }\end{array}$ & 4.48 & 5.25 & 4.57 & 4.39 & 4.54 \\
\hline
\end{tabular}




\begin{tabular}{|c|c|c|c|c|c|}
\hline $\begin{array}{l}\text { Employees recruited in the same time should basically be } \\
\text { promoted together: it fosters cooperation between members, } \\
\text { limiting harmful competition }\end{array}$ & 2.07 & 2.30 & 2.85 & 3.46 & 3.00 \\
\hline $\begin{array}{l}\text { It is not good to have internal competition in a company } \\
\text { among employees as it does not enhance performance }\end{array}$ & 2.66 & 3.40 & 2.77 & 3.98 & 3.46 \\
\hline $\begin{array}{l}\text { Even if a person is highly qualified he should not be quickly } \\
\text { promoted as his subordinates may be much older than he is }\end{array}$ & 1.95 & 2.39 & 2.18 & 3.23 & 2.72 \\
\hline $\begin{array}{l}\text { It is better not to promote people very fast, older managers are } \\
\text { wiser and usually do a better job }\end{array}$ & 2.23 & 2.34 & 3.15 & 3.56 & 3.14 \\
\hline $\begin{array}{l}\text { Big companies don't need more transparency and the control } \\
\text { of the market: there does not need to be an external director in } \\
\text { the board }\end{array}$ & 2.47 & 2.57 & 2.41 & 3.33 & 2.92 \\
\hline $\begin{array}{l}\text { A top manager (CEO) from another organization usually } \\
\text { succeeds no better in making the company more efficient and } \\
\text { productive than a CEO who is promoted from within the lower } \\
\text { ranks of the same company }\end{array}$ & 3.92 & 4.55 & 3.75 & 3.98 & 3.98 \\
\hline $\begin{array}{l}\text { It is good if the company can offer a seat on the board of } \\
\text { directors to its senior managers at the end of their career }\end{array}$ & 3.81 & 4.44 & 5.23 & 4.41 & 4.51 \\
\hline $\begin{array}{l}\text { Rotating employees regularly is good because they can get } \\
\text { better knowledge and vision about the company as a whole. so } \\
\text { probably they can become better managers }\end{array}$ & 4.14 & 4.92 & 5.18 & 4.29 & 4.54 \\
\hline $\begin{array}{l}\text { Regular rotation of employees should not be avoided: it is not } \\
\text { confusing and doesn't block specializing }\end{array}$ & 3.82 & 5.08 & 4.32 & 4.01 & 4.17 \\
\hline I would rather work for a large organization than a small one & 3.85 & 3.97 & 4.47 & 3.97 & 4.06 \\
\hline $\begin{array}{l}\text { I am grateful to my company and I express this with my hard } \\
\text { work every day }\end{array}$ & 4.39 & 4.75 & 5.32 & 4.23 & 4.56 \\
\hline $\begin{array}{l}\text { The best way to increase size for a company is to hire more } \\
\text { young graduates from top universities }\end{array}$ & 2.69 & 2.18 & 2.92 & 2.87 & 2.78 \\
\hline Going out with colleagues after work is important & 4.03 & 4.27 & 5.13 & 3.99 & 4.28 \\
\hline I don't try to pursue hobbies / social activities away from work & 2.44 & 2.44 & 2.51 & 3.29 & 2.90 \\
\hline $\begin{array}{l}\text { Company postings involving separation from family are } \\
\text { acceptable / unavoidable }\end{array}$ & 3.82 & 3.78 & 4.76 & 3.69 & 3.96 \\
\hline $\begin{array}{l}\text { Making friends is one of the most important things in a } \\
\text { company }\end{array}$ & 4.06 & 4.45 & 5.33 & 4.21 & 4.47 \\
\hline $\begin{array}{l}\text { Recruitment and career management is better held at central } \\
\text { (Human Resources department) level because it costs less and } \\
\text { gives better overview on employee transfers }\end{array}$ & 3.74 & 3.60 & 4.57 & 3.96 & 4.03 \\
\hline $\begin{array}{l}\text { Recruitment and career management is not better held at } \\
\text { division / unit level because it would not be more appropriate } \\
\text { to the real needs of the company }\end{array}$ & 3.14 & 3.73 & 3.10 & 3.72 & 3.50 \\
\hline $\begin{array}{l}\text { Skill development (training) is the responsibility of the } \\
\text { company, not the individual worker's }\end{array}$ & 3.67 & 3.87 & 4.31 & 4.18 & 4.10 \\
\hline $\begin{array}{l}\text { Recruitment agencies (head hunters) should not gain a more } \\
\text { prominent role in job hunting }\end{array}$ & 2.72 & 2.90 & 2.51 & 3.34 & 3.02 \\
\hline $\begin{array}{l}\text { Japanese top managers should not earn much more than } 10 \\
\text { times the young graduate new recruits' salary (in the USA it } \\
\text { can be } 50 \text { times more) }\end{array}$ & 3.86 & 3.93 & 3.06 & 4.15 & 3.84 \\
\hline
\end{tabular}




\section{ANNEX VIII: $\quad$ Grouping of the empirical elements}

A new label has been created for each case to aid interpretation. Pearson coefficients are indicated in brackets. S and R stand for measured Support and Rejection, respectively.

Seniority, stability $(0.52,0.21,0.19), R$

\begin{tabular}{|l|l|}
\hline Slow promotion & B6 \\
\hline Tenure-based compensation or "seniority pay" & B8 \\
\hline Cost leadership (vs. product differentiation) & S2 \\
\hline Behavior-based control & P1 \\
\hline
\end{tabular}

Security, protection (0.42), $S$

\begin{tabular}{|l|l|}
\hline Developmental state and protected markets & E2 \\
\hline Long-term employment & B3 \\
\hline
\end{tabular}

Permanent growth $(0.37,0.21), R$

\begin{tabular}{|l|c|}
\hline An ambiguous and rigid labor market & E3 \\
\hline Superiors are more managers than leaders & I2 \\
\hline Good performance means increasing market share and harmony & P4 \\
\hline
\end{tabular}

Group orientation $(0.29,0.2,0.21,0.19), S$

\begin{tabular}{|l|l|}
\hline Confucianism and collectivism & E1 \\
\hline Processes of decision making: a consensual approach & F4 \\
\hline Multi-monitoring group effect & P2 \\
\hline Decisions are joint responsibility & P3 \\
\hline Cohort training "on-the-job" & B5 \\
\hline
\end{tabular}

Animated workplace (0.185), $S$

\begin{tabular}{|l|l|}
\hline Working teams (open office) & F5 \\
\hline Rotation & B7 \\
\hline
\end{tabular}

Familial devotion $(0.21,0.11,0.18,0.15), S R(3: 2)$

\begin{tabular}{|l|l|}
\hline Easy-to-train, and devoted employees & I1 \\
\hline Formal induction with the chairman: creating a family & B4 \\
\hline Recruitment from schools & B1 \\
\hline Core (permanent) vs. "irregular" staff & B2 \\
\hline Company unions & B9 \\
\hline
\end{tabular}

Employee friendliness (0.22), $S$

\begin{tabular}{|l|l|}
\hline Stakeholder orientation & S1 \\
\hline Large and complex, U-form based group hierarchy & F1 \\
\hline
\end{tabular}

Insider dealers $(0.22,0.09), R$

\begin{tabular}{|l|l|}
\hline Homogeneity and male dominance & I3 \\
\hline Large boards dominated by insiders & F2 \\
\hline Central HRM prevails over Finance & F3 \\
\hline
\end{tabular}




\section{Bibliography:}

Abe, M. (2010). Introduction: Japanese Management in the 21st Century. In P. Haghirian, Innovation and Change in Japanese Management (pp. 1-11.). Basingstoke: Palgrave Macmillan.

Abegglen, J. C. (1960). The Japanese Factory: Aspects of its Social Organization. Glencoe, Illinois: The Free Press.

Abegglen, J. C. (1973). Management and Worker: The Japanese Solution. Tokyo: Sophia University Tokyo (in cooperation with: Kodansha International Ltd.).

Abegglen, J. C. (2006). 21st-Century Japanese Management: New Systems, Lasting Values. Hampshire: Palgrave Macmillan.

Abo, T. (2007). Concluding Remarks: Japanese Hybrid Factories in Global Perspective

- Diverging or Converging? In T. Abo, Japanese Hybrid Factories: A Comparison of Global Production Strategies (pp. 235-245). Basingstoke: Palgrave Macmillan.

Adams, T. F., \& Kobayashi, N. (1969). The world of Japanese business. Tokyo: Kodansha International.

Ahmadjian, C. L., \& Robbins, G. E. (2005). A Clash of Capitalisms: Foreign Shareholders and Corporate Restructuring in 1990s Japan. American Sociological Review, 70 (3), pp.451-471.

Ahmadjian, C. L., \& Robinson, P. (2001). Downsizing and the Deinstitutionalization of Permanent Employment in Japan. Working paper.

Aldrich, M. (2010). On the Track of Efficiency: Scientific Management Comes to Railroad Shops, 1900-1930. Business History Review, 84(3), pp.501-526.

Alexander, A. J. (2000). Corporate Restructuring in Japan: A Review. Japan Economic Institute (JEI) Report, No.36: Weekly Review: Available at: <http://www.jei.org/Restricted/JEIR00/0036w2.html> [Accessed November 21, 2011].

Angyal, Á. (2001). Vállalati kormányzás: Corporate Governance. Budapest: Aula.

Ansoff, H. I. (1965). Corporate Strategy. New York: McGraw-Hill.

Ansoff, H. I. (1976). From strategic planning to strategic management. London, New York: Wiley.

Ansoff, H. I., \& McDonnell, E. J. (1988). The new corporate strategy. New York: Wiley. 
Aoki, M., Jackson, G., \& Miyajima, H. (2007). Corporate Governance in Japan. Oxford and New York: Oxford University Press.

Azumi, K., \& McMillan, C. J. (1975). Culture and Organization Structure: A Comparison of Japanese and British Organizations. International Studies of Management \& Organization, 5 (1): 35-47.

Bakacsi, Gy. (1996). Szervezeti magatartás és vezetés. Budapest: Közgazdasági és Jogi Könyvkiadó.

Bakacsi, Gy. (2011). Paradigms of Organization Behavior (MA class lecture). Corvinus University of Budapest, Hungary. June 7.

Bakke, E. W. (1958). The Human Resources Function. New Have, Conn.: Yale LaborManagement Center.

Bakos, G. (1993). Technológia- és innovációpolitika Japánban. Kereskedelmi Szemle, 34(11): pp.19-26.

Balaton, K. (2007). Organizational strategies and structures following the system turnaround. Budapest: Akadémiai Kiadó.

Balaton, K., \& Dobák, M. (1982). Mennyiségi és minőségi módszerek az empirikus szervezetkutatásban. Egyetemi Szemle, 4 (1-2), pp.87-104.

Balaton, K., \& Dobák, M. (1986). A mérnöki szemlélettől a társadalmi megközelítésig (A vezetés-szervezés és szervezetelmélet kialakulása és újabb irányzatai). Közgazdasági Szemle, (6), pp.521-535.

Barakonyi, K., \& Lorange, P. (1991). Stratégiai management (Strategic Management). Budapest: Közgazdasági és Jogi Könyvkiadó.

Barnard, C. I. (1938). The Functions of the Executive. Cambridge, MA: Harvard University Press.

Barnard, C. I. (1948). Organization and Management. Cambridge, Mass.: Harvard University Press.

Bartlett, C. A., \& Beamish, P. W. (2011). Transnational Management. New York: McGraw-Hill.

Bell, D. (1956). Work and its Discontents: The Cult of Efficiency in America. Boston: Beacon.

Bellah, R. N. (1957). Tokugawa religion; the values of pre-industrial Japan. Glencoe, Illinois: Free Press.

Bendix, R. (1974). Work and Authority in Industry: Ideologies of Management in the Course of Industrialization. Berkeley: University of California Press. 
Bennett, J. B., \& Weiher, R. L. (1972). The well-read manager. Harvard Business Review, 50 (4), pp.134-146.

Benson, J. (2006). Convergence and Diversity: Emerging Patterns of Human Resource Management in Japan. In R. Haak, The Changing Structure of Labour in Japan. Bansingstoke: Palgrave Macmillan, pp.40-57.

Berger, S., \& Dore, R. (1996). National Diversity and Global Capitalism. Ithaca and London: Cornell University Press.

Berinato, S. (2010). "You Have to Lead From Everywhere". Harvard Business Review, 88 (11): pp.76-79.

Bertalanffy, L. v. (1951). General Systems Theory: A New Approach to the Unity of Science. Human Biology, 23 (December), pp.302-361.

Bíró, K. (1970). A japán kihívás. Budapest: Közgazdasági és Jogi Könyvkiadó.

Black, J. S., \& Morrison, A. J. (2010). Sunset in the Land of the Rising Sun. Basingstoke: Palgrave Macmillan.

Blau, P. M. (1972). Interdependence and hierarchy in organizations. Social Science Research, 1 (1), pp.1-24.

Blomström, M., Gangnes, B., \& La Croix, S. (2001). Japan's New Economy: Continuity and Change in the Twenty-First Century. Oxford, New York: Oxford University Press.

Bloomberg. (2011). Divided DPJ is Noda's biggest obstacle to backing TPP talks. The Japan Times Online, [online] November 9, 2011. Available at: <http://www.japantimes.co.jp/text/nb20111109n1.html>.

Boone, L. E., \& Kurtz, D. L. (1987). Management: third edition. New York: Random House Business Division.

Bower, M. (1966). Diriger c'est vouloir (The Will to Manage). Paris: Hachette.

Bowey, A. M. (1976). The sociology of organisations. London: Hodder and Stoughton.

Boyer, L., \& Equilbey, N. (1990). Histoire du management (History of the Management). Paris: Les Éditions d'Organisation.

Boyer, R. (1996). Convergence hypothesis revisited: globalization but still the century of nations? In S. Berger, \& R. Dore, National Diversity and Global Capitalism (pp. 29-59). London and Ithaca: Cornell University Press.

Bremmer, I., \& Pujadas, J. (2009). State Capitalism Makes a Comeback. Harvard Business Review, (87) 2, pp.32-34. 
Buchanan, J., \& Deakin, S. (2009). In the Shadow of Corporate Governance Reform: Change and Continuity in Managerial Practice at Listed Companies in Japan. In D. H. Whittaker, \& S. Deakin, Corporate Governance and Managerial Reform in Japan, pp. 28-69. Oxford and New York: Oxford University Press.

Buchanan, L., \& O'Connell, A. (2006). A Brief History of Decision Making. Harvard Business Review, 84 (1), pp.32-41.

Burns, T., \& Stalker, G. M. (1961). The Management of Innovation. London: Tavistock publications.

Campbell, A., \& Alexander, M. (1997). What's Wrong with Strategy? Harvard Business Review, 75(6), pp.42-51.

Carpenter, S. (2008). Why Japan Can't Reform: Inside the System. Hampshire: Palgrave Macmillan.

Chandler, A. D. (1962). Strategy and structure: chapters in the history of the industrial enterprise. Cambridge: M.I.T. Press.

Channon, D. F. (1973). The strategy and structure of British enterprise. London: Macmillan.

Chikán, A. (2005). Vállalatgazdaságtan. Budapest: Aula.

Child, J. (1972). Organizational Structure, Environment and Performance: The Role of Strategic Choice. Sociology,4(1), pp.1-22.

Child, J. (1977). Organisations: A Guide to Problems and Practice. London: Harper \& Row.

Child, J. (1982). A szervezetről - vezetőknek: Útmutató gyakorlati problémák megoldásához. Budapest: Közgazdasági és Jogi Könyvkiadó.

Clark, R. (1979). The Japanese Company. New Haven: Yale University Press.

Coase, R. H. (1937). The Nature of the Firm. Economica, 4(16), pp.386-405. Doi: 10.1111/j.1468-0335.1937.tb00002.x.

Coe, N. M., Johns, J., \& Ward, K. (2006a). Grounding the Temporary Staffing Industry: outlining the Japanese case study (Working Brief 15). The University of Manchester. Available at: <http://www.sed.manchester.ac.uk/geography/ research/gotsu/outputs/workingbriefs/download/gotsu_wb15.pdf>.

Coe, N. M., Johns, J., \& Ward, K. (2006b). The Japanese Staffing Market: International Firm Presence and Embeddedness (Working Brief 17). The University of Manchester. Available at: <http://www.sed.manchester.ac.uk/geography/ research/gotsu/outputs/workingbriefs/download/gotsu_wb17.pdf>. 
Coe, N. M., Johns, J., \& Ward, K. (2009). The 2008 Top 20 Transnational Temporary Staffing Agencies: Rankings by Total Revenue (Working Brief 42). The University of Manchester. Available at: <http://www.sed.manchester.ac.uk/ geography/research/gotsu/outputs/workingbriefs/download/gotsu_wb42.pdf>.

Cole, R. (1980). Learning from the Japanese: Prospects and Pitfalls. Management Review, 69(9), pp.22-42.

Cole, R. E. (1971). Japanese Blue Collar: the changing tradition. Berkeley: University of California Press.

Cole, R. E. (1979). Work, mobility, and participation: a comparative study of American and Japanese industry. Berkeley: University of California Press.

Commons, J. R. (1934). Institutional Economics: Its Place in Political Economy. New York: Macmillan.

Courtney, H., Kirkland, J., \& Viguerie, P. (1997). Strategy Under Uncertainty. Harvard Business Review, 75(6), pp.67-79.

Crozier, M. (1964). The bureaucratic phenomenon. Chicago: University of Chicago Press.

Cusumano, M. (1993). Japanese Manufacturing. Harvard Business Review, 71 (3), pp.10-11.

Czakó, E. (2000). Competitiveness at industry level: In the light of globalization Ph. D. Corvinus University of Budapest.

Davis, K. (1957). Human Relations in Business. New York: McGraw-Hill Book Co.

Davis, K. (1973). The Case for and against Business Assumptions of Social Responsibilities. Academy of Management Journal, 16(June), pp.312-322.

Debroux, P. (2006). The Shift Towards a Performance-Based Management System. In R. Haak, The Changing Structure of Labour in Japan (pp. 122-139.). Basingstoke: Palgrave Macmillan.

Dedoussis, V. (2001). Keiretsu and management practices in Japan - resilience amid change. Journal of Managerial Psychology, 16(2), pp.1-16.

Diamond, J. M. (1999). Guns, germs, and steel: the fates of human societies. New York: Norton.

DiMaggio, P. J., \& Powell, W. W. (1983). The Iron Cage Revisited: Institutional Isomorphism and Collective Rationality in Organizational Fields. American Sociological Review, 48 (2), pp.147-160. 
Djelic, M.-L. (1998). Exporting the American Model: The Postwar Transformation of European Business. New York: Oxford University Press.

Dobák, M. (1988). Szervezetalakitás és szervezeti formák (Organization design and organizational structure). Budapest: Közgazdasági és Jogi Könyvkiadó.

Dobák, M. (2009. February). An Introduction to Management History. Corvinus University of Budapest.

Dobák, M., \& Antal, Z. (2010). Vezetés és szervezés: Szervezetek kialakitása és müködtetése. Budapest: Aula.

Donaldson, L. (1984). Explaining Structural Change in Organizations: Contingency Determinism or Contingency Fit. Australian Journal of Management, 9(2), pp.15-24.

Donaldson, L. (1987). Strategy and Structural Adjustment to Regain Fit and Performance in Defence of Contingency Theory. Journal of Management Studies, 24(1), pp.1-24.

Donaldson, L. (1995). American Anti-Management Theories of Organization: A Critique of Paradigm Proliferation. Cambridge: Cambridge University Press.

Donaldson, L. (2001). The Contingency Theory of Organizations. Thousand Oaks, Calif.: Sage Publications.

Donham, W. B. (1922). Essential Groundwork for a Broad Executive Theory. Harvard Business Review, 1(1), pp.1-10.

Dore, R. (1973). British Factory - Japanese Factory: The Origins of National Diversity in Industrial Relations. London: George Allen \& Unwin.

Dore, R. (2000). Stock Market Capitalism: Welfare Capitalism. Japan and Germany versus the Anglo-Saxons. Oxford: Oxford University Press.

Drucker, P. F. (1954). The practice of management. New York: Harper.

Drucker, P. F. (1971). What We Can Learn From Japanese Management. Harvard Business Review, (2).

Economic Report of the President. (2011). Washington: United States Government Printing Office.

Egeihoff, W. G. (1982). Strategy and Structure in Multinational Corporations: An Information-Processing Approach. Administrative Science Quarterly, 27(3), pp.435-458.

Eisenhardt, K. M. (1989). Agency Theory: An Assessment and Review. The Academy of Management Review, 14 (1), pp.57-74. 
Faison, E. (2007). Managing Women: Disciplining Labor in Modern Japan. Berkeley and Los Angeles: University of California Press.

Farkas, F., \& Dobrai, K. (2007). Professional Service Organizations Meeting the Challenges of a Changing Business Environment. The International Journal of Knowledge, Culture and Change Management, 7 (3), pp.73-84.

Fayol, H. (1956). Administration industrielle et générale : prévoyance, organisation, commandement, coordination, contrôle. Paris: Dunod.

Fayol, H. (1984). Ipari és általános vezetés : Tervezés - szervezés - közvetlen irányitás koordinálás - ellenőrzés. Budapest: Közgazdasági és Jogi Könyvkiadó.

Fazekas, K., \& Ozsvald, É. (2000). Növekvő munkanélküliség, rugalmasabb munkaerőpiac. Közgazdasági Szemle, 47 (2), pp.157-177.

Ferber, K. (2007). Maladies and Remedies. Electronic Journal of Contemporary Japanese Studies. Available at: <http://www.japanesestudies.org.uk/reviews/ 2007/Ferber.html>.

Fields, G., Katahira, H., \& Wind, J. (2000). Leveraging Japan: Marketing to the New Asia. San Francisco: Jossey-Bass.

Follett, M. P. (1941). Dynamic Administration. London: Management Publicatons Trust.

Ford, H. (1922). My Life and Work. Garden City, New York: Doubleday, Page.

Freeman, R. E. (1984). Strategic management: a stakeholder approach. Boston: Pitman.

French, W. (1964). The Personal Management Process: Human Resources Administration. Boston: Houghton Mifflin.

Friedrich, I., Mészáros, T., \& Stahl, J. (1988). A japán felsőoktatásról : Egy hónap a Hosei Egyetemen. Egyetemi Szemle, 0139-4045. 10(1), pp.83-95.

Fruin, W. M. (1992). The Japanese Enterprise System: Competitive Strategies and Cooperative Structures. Oxford: Clarendon Press.

Fujimura, H. (2006). Managing the Development of One's Own Vocational Skills. In R. Haak, The Changing Structure of Labor in Japan (pp. 107-121.). Basingstoke: Palgrave Macmillan.

Fukao, M. (2003). Financial strains and the zero lower bound: the Japanese experience. Basel (BIS Working papers): Bank for International Settlements, Monetary and Economic Dept. 
Fukue, N. (2009). Idled nonregulars to top 190,000. The Japan Times Online [online] April 1. Available at: <http://www.japantimes.co.jp/text/nb20090401a3.html>.

Fuller, E. V. (2009). Going global: culture, gender, and authority in the Japanese subsidiary of an American corporation. Philadelphia: Temple University Press.

Füstös, L., Kovács, E., Meszéna, G., \& Simonné, M. N. (2004). Alakfelismerés (Sokváltozós statisztikai módszerek). Budapest: Új Mandátum.

Gaál, Z. (2001). Általános menedzsment (General Management). Veszprém: VEK.

Gaál, Z., \& Szabó, L. (2002). Segédlet a projekt menedzsmenthez I-II. Veszprém: Veszprémi Egyetemi Kiadó.

Gabor, A. (2000). The capitalist philosophers: the geniuses of modern business-their lives, times, and ideas. New York: Times Business.

Galbraith, J. R., \& Nathanson, D. A. (1978). Strategy Implementation: The Role of Structure and Process. St. Paul, Minn.: West Publishing.

Garon, S. (1997). Molding Japanese Minds: The State in Everyday Life. Princeton, New Jersey: Princeton University Press.

Gause, G. F., \& Witt, A. A. (1935). Behavior of Mixed Populations and the Problem of Natural Selection. The American Naturalist, 69(725), pp.596-609.

Gerschenkron, A. (1962). Economic backwardness in historical perspective: a book of essays. Cambridge, Mass.: Belknap Press.

Gibson, J. W., Hodgetts, R. M., \& Blackwell, C. W. (1999). The role of management history in the management curriculum: 1997. Journal of Management History, 5(5), pp.277.

Gillespie, R. (1991). Manufacturing Knowledge: A History of the Hawthorne Experiments. New York: Cambridge University Press.

Gomez, E. T. (2007). Family Firms, Transnationalism and Generational Change: Chinese Enterprise in Britain and Malaysia. East Asia, 24 (2), pp.153-172, DOI: 10.1007/s12140-007-9012-1.

Gordon, A. (1998). The Wages of Affluence: Labor and Management in Postwar Japan. Cambridge and London: Harvard University Press.

Graham, F. (2004). A Japanese company in crisis. London and New York: RoutledgeCurzon.

Guillén, M. F. (1994a). Models of Management: Work, Authority, and Organization in a Comparative Perspective. Chicago: The University of Chicago Press. 
Guillén, M. F. (1994b). The Age of Eclecticism: Current Organizational Trends and the Evolution of Managerial Models. MIT Sloan Management Review, 36(1), pp.7586.

Guillén, M. F. (2001). The limits of convergence: globalization and organizational change in Argentina, South Korea, and Spain. Princeton: Princeton University Press.

Guiot, J. M. (1984). Szervezetek és magatartásuk. Budapest: Közgazdasági és Jogi Könyvkiadó.

Haak, R. (2006). The Changing Structure of Labour in Japan. Basingstoke: Palgrave Macmillan.

Hair, J. F., Black, W. C., Babin, B. J., Anderson, R. E., \& Tatham, R. L. (2006). Multivariate Data Analysis. New Jersey: Pearson Education.

Hall, D. J., \& Saias, M. A. (1980). Strategy Follows Structure! Strategic Management Journal, 1(2), pp.149-163.

Hamada, T. (1991). American Enterprise in Japan. Albany, New York: State University of New York Press.

Hamel, G., \& Prahalad, C. K. (1985). Do you really have a global strategy? Harvard Business Review, 63(4), pp.139-148.

Hanami, T. (2006). The Changing Labour Market, Industrial Relations and Labour Policy. In R. Haak, The Changing Structure of Labour in Japan (pp. 10-17). Basingstoke: Palgrave Macmillan.

Hanaoka, M. (1997a). A View of the Custom of Lifetime Employment and "Adjustment to Employee Levels”. In D. B. Institute of Business Research, Global Studies in Management: A Japanese Perspective (pp. 127-144). Tokyo: Institute of Business Research, Daito Bunka University.

Hanaoka, M. (1997b). The Characteristics of Japanese Style Human Resource Management. In D. B. Institute of Business Research, Global Studies in Management: A Japanese Perspective (pp. 145-178). Tokyo: Institute of Business Research, Daito Bunka University.

Hatvany, N., \& Pucik, V. (1981a). Japanese Management Practices and Productivity. Organizational Dynamics, 9 (4), pp.5-21.

Hatvany, N., \& Pucik, V. (1981b). An Integrated Management System: Lessons from the Japanese Experience. Academy of Management Review, 6 (3), pp.469-480. 
Hayes, D. (2000). Japan's Big Bang: The Deregulation and Revitalization of the Japanese Economy. Boston: Tuttle Publishing.

Hendry, J. (2003). Understanding Japanese Society. London and New York: Routledge. Hirschmeier, J., \& Yui, T. (1981). The Development of Japanese Business: 1600-1980. London: George Allen \& Unwin.

Hochschild, A. R. (1997). The Time Bind: When Work Becomes Home and Home Becomes Work. New York: Metropolitan Books.

Hofstede, G. (1983). The Cultural Relativity of Organizational Practices and Theories. Journal of International Business Studies, 14(2), pp.75-89.

Hori, S. (1993). Fixing Japan's White-Collar Economy: A Personal View. Harvard Business Review, 71(6), pp.157-172.

Hoshi, T., \& Kashyap, A. K. (2004). Japan's Financial Crisis and Economic Stagnation. The Journal of Economic Perspectives, 18 (1), pp.3-26.

Hoványi, G. (1982). Vezetési Modellek. Budapest: Közgazdasági és Jogi Könyvkiadó.

Imai, J. (2011). The Transformation of Japanese Employment Relations: Reform without Labor. Basingstoke and New York: Palgrave Macmillan.

Imai, J., \& Shire, K. (2006). Employment Deregulation and the Expanding Market for Temporary Labour in Japan. In R. Haak, The Changing Structure of Labour in Japan (pp. 78-89). Basingstoke: Palgrave Macmillan.

Imashiro, M. (1997). The History of Railway Construction and Management in Japan. In D. B. Institute of Business Research, Global Studies in Management: A Japanese Perspective (pp. 1-76). Tokyo: Institute of Business Research, Daito Bunka University.

Inagami, T., \& Whittaker, D. H. (2005). The New Community Firm: Employment, Governance and Management Reform in Japan. Cambridge: Cambridge University Press.

Itami, H., \& Roehl, T. W. (1987). Mobilizing invisible assets. Cambridge, Mass.: Harvard University Press.

Jackson, G., \& Miyajima, H. (2007). Introduction: The Diversity and Change of Corporate Governance in Japan. In M. Aoki, G. Jackson, H. Miyajima, \& (eds), Corporate Governance in Japan. New York: Oxford University Press.

Jacoby, S. M. (2007). The Embedded Corporation: Corporate Governance and Employment Relations in Japan and the United States. Princeton: Princeton University Press. 
Jarrosson, B. (2004). 100 ans de management: Un siècle de management à travers les écrits (2e édition). Paris: Dunod.

Jensen, M. C., \& Meckling, W. H. (1976). Theory of the firm: Managerial behavior, agency costs and ownership structure. Journal of Financial Economics, 3 (4), pp.305-360.

Johnson, C. (1982). MITI and the Japanese miracle: The growth of industrial policy, 1925-1975. Stanford: Stanford University Press.

Johnston, S., \& McAlevey, L. (1999). The rise and fall and rise of Japan's stable shareholders. Journal of Management History, 5 (6), pp.307-319.

Jones, G. (2000). Merchants to Multinationals. Oxford: Oxford University Press.

Jones, G. (2003). Multinationals. In G. Jones \& F. Amatori, Business History around the World (pp.353-371). Cambridge: Cambridge University Press.

Jones, G. (2005). Multinationals and Global Capitalism: From the Nineteenth to the Twenty-First Century. Oxford: Oxford University Press.

Jones, G. (2007). Globalization. In G. Jones, \& J. Zeitlin, The Oxford Handbook of Business History (pp.141-168). New York: Oxford University Press.

Jones, G., \& Abrahams, M. (2006). The Rise of Corporate Nationality. Harvard Business Review, 84 (10), pp.20-22.

Kacsirek, L., Árva, L., Várhelyi, T., \& Mészáros, Á. (2005). Az eltűnt piac nyomában. Kritika, 34, (9), pp.28-30.

Kanter, R. M. (1991). Transcending Business Boundaries: 12,000 World Managers View Change. Harvard Business Review, 69, (3), pp.151-164.

Katz, R. (1998). The System that Soured. The Rise and Fall of the Economic Miracle. New York, London: M.E. Sharpe, Inc.

Katz, R. (2003). Japanese Phoenix: The Long Road to Economic Revival. New York: M.E. Sharpe.

Katz, R. (2011. November 12). note on the NBR's Japan Forum.

Kawanishi, H. (1992). Enterprise unionism in Japan. London: Kegan Paul International.

Keizer, A. B. (2010). Changes in Japanese Employment Practices. Abingdon: Routledge.

Kenney, M., \& Florida, R. (1993). Beyond mass production: the Japanese system and its transfer to the U.S. New York: Oxford University Press. 
Kester, W. C. (1996). American and Japanese Corporate Governance: convergence to best practice? In S. Berger, \& R. Dore, National Diversity and Global Capitalism (pp. 107-137). London and Ithaca: Cornell University Press.

Keys, J. B., \& Miller, T. R. (1984). The Japanese Management Theory Jungle. Academy of Management Review, 9 (2), pp.342-353.

Kieser, A. (1995). Szervezetelméletek. Budapest: Aula.

Klein, J. A. (1989). The Human Costs of Manufacturing Reform. Harvard Business Review, 67 (2), pp.60-66.

Koehn, N. (. (2009). The Story of American Business from the Pages of New York Times. Boston, Massachusetts: Harvard Business Press.

Kohlbacher, F., \& Weihrauch, A. (2009). Japan's Silver Market Phenomenon: Golden Opportunity or Rusty Rwality? JAPAN CLOSE-UP, pp. 18-23 Available at: <http://i.dijtokyo.org/articles/JCU-0905_SilverMarket.pdf>.

Koike, K. (1983). Internal Labor Markets: Workers in Large Firms. Kyoto: Kyoto Institute of Economic Research, Kyoto University.

Kono, T. (1984). Strategy and structure of Japanese enterprises. London: Macmillan.

Kono, T., \& Clegg, S. (2001). Trends in Japanese Management: Continuing Strengths, Current Problems and Changing Priorities. New York: Palgrave.

Koo, R. C. (2011). The world in balance sheet recession: causes, cure, and politics. Real-World Economics Review, Dec. (58), pp.19-37.

Koontz, H. (1961). The Management Theory Jungle. Journal of the Academy of Management, 4 (3), pp. 182-186.

Koontz, H. (1980). The Management Theory Jungle Revisited. Academy of Management Review, (5), April, pp.175-187.

Koontz, H., \& O'Donnell, C. (1955). Principles of Management: An Analysis of Managerial Functions. New York: McGraw-Hill Book Co.

Kornai, J. (2011). Gondolatok a kapitalizmusról: Négy tanulmány. Budapest: Akadémiai Kiadó.

Kotter, J. P. (1990). A Force for Change: How Leadership Differs from Management. New York: The Free Press.

Kotter, J. P. (1999). What Effective General Managers Really Do. Harvard Business Review, 77 (2), pp.145-159.

Kotter, J. P. (2008). A sense of urgency. Boston, Massachusetts: Harvard Business Review Press. 
Kuhn, T. S. (1962). The Structure of Scientific Revolutions. Chicago: The University of Chicago Press.

Kunda, G. (1992). Engineering Culture: Control and Commitment in a High-Tech Corporation. Philadelphia: Temple University Press.

Kuroda, T., \& Maruyama, K. (1997). Corporate Strategy and the Missing Link-An Empirical Research Study of Divestment Strategy of Japanese Corporations-. In D. B. Institute of Business Research, Global Studies in Management: A Japanese Perspective (pp. 179-204). Tokyo: Institute of Business Research, Daito Bunka University.

Kyodo. (2009). Yearend ban planned for 'amakudari,' 'watari'. The Japan Times Online [online] April 1. Available at: <http://www.japantimes.co.jp/text/ nn20090401f4.html>.

Kyodo. (2011). Summer bonuses decrease 0.8\%. The Japan Times Online [online] November 2. <http://www.japantimes.co.jp/text/nb20111102a5.html>.

Ladó, L. (1986). Szervezéselmélet és -módszertan : A vezetés szervezési funkciója. Budapest: Közgazdasági és Jogi Könyvkiadó.

Lafley, A. G. (2009). What Only the CEO Can Do. Harvard Business Review, 87 (5): pp.54-62.

Lamoreaux, N. R., Raff, D. M., \& Temin, P. (2007). Economic Theory and Business History. In G. Jones, \& J. Zeitlin, The Oxford Handbook of Business History (pp.37-66). New York: Oxford University Press.

Lawler III, E. E., \& Mohrman, S. A. (1985). Quality circles after the fad. Harvard Business Review, 63 (1), pp.64-71.

Lawrence, P. R., \& Lorsch, J. W. (1967). Organization and Environment: Managing Differentiation and lntegration. Boston: Division of Research, Graduate School of Business Administration, Harvard University.

Lee, G.-Y. (2000). Japanese Management Style in Achieving the Cost Reduction Targets. In Y. Monden, Japanese Cost Management (pp. 397-415). London: Imperial College Press.

Levie, J. (1993). Paradigmák a vezetéstudományban. Vezetéstudomány, XXIV(1-2), pp.92-98.

Levitt, T. (1987). The LSD of the 1980s. Harvard Business Review, 65 (3), p.4.

Lewin, K. (1947). Group Decision and Social Change. In T. M. Newcomb, \& E. L. Hartley, Readings in Social Psychology. New York: Henry Holt \& Co. 
Lewin, K. (1948). Resolving social conflicts: selected papers on group dynamics [1935-1946]. New York: Harper.

Liker, J. K., Fruin, W. M., \& Adler, P. S. (1999). Bringing Japanese Management Systems to the United States: Transplantation or Transformation? In J. K. Liker, W. M. Fruin, \& P. S. Adler (eds.), Remade in America: Transplanting \& Transforming Japanese Management Systems (pp.3-38). New York, Oxford: Oxford University Press.

Lincoln, J. R., \& Gerlach, M. L. (2004). Japan's Network Economy: Structure, Persistence, and Change. Cambridge: Cambridge University Press.

Lincoln, J. R., \& Kalleberg, A. L. (1985). Work Organization and Workforce Commitment: A Study of Plants and Employees in the U.S. and Japan. American Sociological Review, 50, (6), pp.738-760.

Lincoln, J. R., \& McBride, K. (1987). Japanese Industrial Organization in Comparative Perspective. Annual Review of Sociology, 13 pp.289-312.

Lincoln, J. R., Gerlach, M. L., \& Ahmadjian, C. L. (1996). Keiretsu Networks and Corporate Performance in Japan. American Sociological Review, 61 (1), pp.6788.

Litterer, J. A. (1961). Systematic Management: The Search for Order and Integration. The Business History Review, 35, (4), pp.461-476.

Litterer, J. A. (1963). Systematic Management: Design for Organizational Recoupling in American Manufacturing Firms. The Business History Review, 37, (4), pp. 369-391.

Locke, R. R. (1996). The Collapse of the American Management Mystique. Oxford, New York: Oxford University Press.

Luthans, F. (1969). Cases, Readings, and Review Guide for Pinciples of Management. New York and London: John Wiley \& Sons, Inc.

Luthans, F. (1973a). The Contingency Theory of Management: A path out of the jungle. Business Horizons, 16, (3), pp.67-72.

Luthans, F. (1973b). Organizational behavior: A modern behavioral approach to management. New York: McGraw Hill.

Luthans, F., McCaul, H. S., \& Dodd, N. G. (1985). Research notes. Organizational Commitment: A Comparison of American, Japanese and Korean Employees. Academy of Management Journal, 28 (1), pp.213-219.

MacArthur, D. (1964). Reminiscences. New York: McGraw-Hill. 
Makó, Cs. (1993). Alvállalkozás "japán" módra: Az alvállalkozói munkaszervezet összehasonlító vizsgálata. Vezetéstudomány, 24, (12), pp.8-15.

Makó, Cs., \& Nemes, F. (2002). Paradigmaváltás a munkafolyamatban: Posztfordizmus helyett neo-fordizmus. Harvard Business Manager (Hungarian Edition), 4, (1), pp.60-69.

Makó, Cs., \& Novoszáth, P. (1994). Convergence versus divergence: the case of the corporate culture. Budapest: Dunatáj.

Marosi, M. (1983). Előszó (Foreword). In F. Winslow Taylor, Üzemvezetés - A tudományos vezetés alapjai. Budapest: Közgazdasági és Jogi Könyvkiadó.

Marosi, M. (1985). Japán vállalatok vezetése és szervezése. Budapest: Közgazdasági és Jogi Könyvkiadó.

Marosi, M. (1986). A japán vállalatok sikeres vezetési és szervezési módszereiről. Vezetéstudomány, 17 (11), pp.22-28.

Marosi, M. (1988). A szervezés és irányitás nemzetközi fejlődése - magyar gyakorlata. Budapest: Közgazdasági és Jogi Könyvkiadó.

Marosi, M. (2003). Japán, koreai és kínai menedzsment. Budapest: Aula.

Martin, A. (2011). Timing may be everything in TPP. The Japan Times Online [online] November 3. Available at: <http://www.japantimes.co.jp/text/nn20111103f1. html>.

Maruyama, K. (1997). A Comparative Study of the Japanese Management Theories of Four scholars Masumi Tsuda, Hiroshi Hazama, Ryushi Iwata and Kuniyoshi Urabe. In D. B. Institute of Business Research, Global Studies in Management: A Japanese Perspective (pp. 111-126). Tokyo: Institute of Business Research, Daito Bunka University.

Matsumoto, D. (2002). The New Japan: debunking seven cultural stereotypes. Yarmouth, Me.: Intercultural Press.

Mauboussin, M. J. (2009). When Individuals Don't Matter. Harvard Business Review, (87) 10, pp.24-25.

Maurice, M. \& Sorge, A. (eds.) (2000). Embedding Organizations: Societal Analysis of Actors, Organizations, and Socio-Economic Context. Amsterdam and Philadelphia: John Benjamins.

Mayo, E. (1923). The Irrational Factor in Human Behavior: The Night Mind in Industry. Annals of the Amirican Academy of Political and Social Science, CX (November), 117-130. 
McCall Rosenbluth, F., \& Thies, M. F. (2010). Japan transformed: political change and economic restructuring. Princeton, N.J.: Princeton University Press.

McGregor, D. (1960). The Human Side of Enterprise. New York: McGraw-Hill Book Co.

Mészáros, T. (1992). Merre tart a menedzsment-tudomány? Ipar-gazdaság, 44 (10) pp.1-2.

Methé, D., \& Miyabe, J. (2006). Employment Practices in Japanese Firms: Can Mikoshi Management Survive? In R. Haak, The Changing Structure of Labour in Japan (pp.90-106). Basingstoke: Palgrave Macmillan.

Mintzberg, H. (1979). The structuring of organizations: a synthesis of the research. Englewood Cliffs, N.J.: Prentice-Hall.

Mintzberg, H. (1980). Structure in 5's: a synthesis of the research on organization design. Management Science, 26 (3) pp.322-341.

Mintzberg, H. (1981). Organization design: fashion or fit? Harvard Business Review, 59 (1), pp.103-116.

Mintzberg, H. (1994). The Fall and Rise of Strategic Planning. Harvard Business Review, 72 (1), pp.107-114.

Mintzberg, H., Ahlstrand, B., \& Lampel, J. (2005). Stratégiai szafari: Útbaigazítás a stratégiai menedzsmentben. Budapest: HVG Rt.

Miwa, Y., \& Ramseyer, J. M. (2006). The Fable of the Keiretsu: Urban Legends of the Japanese Economy. Chicago and London: University of Chicago Press.

Miyajima, H. (2007). The Performance Effects and Determinants of Corporate Governance Reform. In M. Aoki, G. Jackson, \& H. Miyajima, Corporate Governance in Japan (pp.330-369). Oxford and New York: Oxford University Press.

Miyamoto, K. (2008). International Management Accounting in Japan: Current Status of Electronic Companies. Singapore: World Scientific.

Miyamoto, M. (1995). Straitjacket Society. Tokyo: Kodansha International.

Móczár, J. (1987). Gazdaságirányítás és tervezés japán módra. Budapest: Közgazdasági és Jogi Könyvkiadó.

Moreno, J. L. (1953). Who shall survive?: Foundations of sociometry, group psychotherapy and sociodrama. Beacon, N. Y.: Beacon House.

Morgan, G. (1997). Images of organization. Thousand Oaks, Calif.: Sage Publications. 
Morikawa, H. (2001). A History of Top Management in Japan: Managerial Enterprises and Family Enterprises. New York: Oxford University Press.

Mouer, R., \& Kawanishi, H. (2005). A Sociology of Work in Japan. Cambridge, New York: Cambridge University Press.

Nakagawa, K. (1983). Japanese Management: An Interdisciplinary Approach. In Orientation Seminars on Japan, no.12 (pp.1-7). Tokyo: The Japan Foundation Office for the Japanese Studies Center,.

Nakane, C. (1972). Japanese Society. Berkeley: University of California Press.

Nakane, C. (1990). Tokugawa society. In C. Nakane, \& S. Oishi, Tokugawa Japan: The Social and Economic Antecedents of Modern Japan (pp. 213-240). Tokyo: University of Tokyo Press.

Nakane, C., \& Oishi, S. (1990). Tokugawa Japan: The Social and Economic Antecedents of Modern Japan. Tokyo: University of Tokyo Press.

Nakase, T. (1979). The Introduction of Scientific Management in Japan and its Characteristics. In K. Nakagawa, Labor and Management (Proceedings of the Fourth Fuji Conference) (pp. 171-202). Tokyo: University of Tokyo Press,.

Nakata, H. (2011). Carmakers back TPP talks decision. The Japan Times Online [online] November 13. Available at: <http://www.japantimes.co.jp/text/nb20111 113a3.html>.

Nemes, F. (2006). Szervezet és vezetés. Budapest: BCE KTI.

New York Stock Exchange Euronext. (2011). European Equities. Yearly Statistics: Euronext Fact Books [online] Feburary 1. Available at: <http://europeanequities. nyx.com> [Accessed December 14, 2011].

Newman, W. H. (1969). L'art de la gestion (Aministrative Action). Paris: Dunod.

Nielsen, R. P. (1988). Cooperative Strategy. Strategic Management Journal, 9 (5) pp.475-492.

Ogura, M. (2004). Delivering the Goods: Entrepreneurship and Innovation in a Japanese Corporation. Tokyo: The International House of Japan.

Ohmae, K. (1982). The Mind of the Strategist: the Art of Japanese Business. New York: McGraw-Hill.

Ohmae, K. (1989). Managing in a Borderless World. Harvard Business Review, 67 (3), pp.152-161.

Ohmae, K. (1995). Letter from Japan. Harvard Business Review, 73 (3), pp.154-163. 
Ohtaki, R., Umezu, H., \& Sugiura, M. (2010). Fundamentals of Human Capital Management for Asian Global Companies. Singapore: Marshall Cavendish

Ohtsu, M. (2002). Inside Japanese Business: A Narrative History, 1960-2000. Armonk and London: M.E. Sharpe.

Okabe, M. (2002). Cross Shareholdings in Japan: A New Unified Perspective of the Economic System. Cheltenham and Northampton: Edward Elgar.

Okuda, K. (1974). Managerial Evolution in Japan. Personnel Review, 3 (3), pp.52 - 58.

Olcott, G. (2009). Conflict and Change: Foreign Ownership and the Japanese Firm. New York: Cambridge University Press.

Olcott, G. (2011). A note in NBR's Japan Forum, November 13.

Ouchi, W. G. (1981). Theory Z: how American business can meet the Japanese challenge. Reading, Mass.: Addison-Wesley.

Ouchi, W. G., \& Jaeger, A. M. (1978). Type Z Organization: Stability in the Midst of Mobility. The Academy of Management Review, 3 (2), pp.305-314.

Ozsvald, É. (2007). A japán corporate governance új modellje (The new model of corporate governance in Japan). In I. Szerdahelyi, \& P. Wintermantel, Japanológiai körkép (An Overview of Japanese Studies in Hungary) (pp. 391408). Budapest: ELTE Eötvös Kiadó.

Palmer, D., Friedland, R., Devereaux Jennings, P., \& Powers, M. E. (1987). The Economics and Politics of Structure: The Multidivisional Form and the Large U.S. Corporation. Administrative Science Quarterly, 32 (1), pp.25-48.

Papp, I. (2003). Szolgáltatások a harmadik évezredben. Budapest: Aula.

Pascale, R. T., \& Athos, A. G. (1981). The art of Japanese management: applications for American executives. New York: Simon and Schuster.

Perlow, L. A. (1997). Finding Time: How Corporations, Individuals, and Families Can Benefit from New Work Practices. Ithaca and London: ILR Press.

Pindur, W., Rogers, S. E., \& Kim, P. S. (1995). The history of management: a global perspective. Journal of Management History, 1 (1), pp.59-77.

Podolny, J. M. (2009). The Buck Stops (and Starts) at Business School. Harvard Business Review, 87 (6), pp.62-67.

Poór, J. (1996). Bérezés-ösztönzés menedzsment nemzetközi vállalatoknál (Compensation Management in Multinational Firms). Munkaügyi Szemle, 40, (7-8), pp.38-42. 
Poór, J. (2005). A menedzsment tanácsadás fejlödési tendenciái. Budapest: Akadémiai Kiadó.

Porter, M. E. (1980). Competitive Strategy: Techniques for Analysing Industries and Competitors. New York: Free Press.

Porter, M. E. (1985). Competitive Advantage: Creating and Sustaining Superior Performance. New York: Free Press.

Porter, M. E., \& Kramer, M. R. (2006). Strategy \& Society: The Link Between Competitive Advantage and Corporate Social Responsibility. Harvard Business Review, 84 (12), pp.78-92.

Porter, M. E., Takeuchi, H., \& Sakakibara, M. (2000). Can Japan compete? Houndmills, Basingstoke, Hampshire: Macmillan.

Powell, W. W., \& DiMaggio, P. J. (1991). The New Institutionalism in Organizational Analysis. Chicago: University of Chicago Press.

Prahalad, C. K., \& Hamel, G. (1990). The Core Competence of the Corporation. Harvard Business Review, 68 (3), pp.79-91.

Pucik, V. (1984). White-collar human resource management in large Japanese manufacturing firms. Human Resource Management, 23 (3), pp.257-276.

Pucik, V., \& Hatvany, N. (1982). Management Practices in Japanand Their Impact on Business Strategy (Working Paper No.317). The University of Michigan: Division of Research, Graduate School of Business Administration.

Pudelko, M. (2006). Decision-Making in Japanese Companies. In R. Haak, The Chnaging Structure of Labour in Japan (pp.58-77). Basingstoke: Palgrave Macmillan.

Pugh, D. S., Hickson, D. J., Hinings, C. R., \& Turner, C. (1969). The Context of Organization Structures. Administrative Science Quarterly, 14 (1), pp.91-114.

Putnam, A. O. (1985). A redesign for engineering. Harvard Business Review, 63 (3), pp.139-144.

Pyle, K. B. (1996). The Making of Modern Japan. Lexington, Massachusetts: D. C. Heath and Company.

Rappaport, A., \& Sirower, M. L. (1999). Stock or Cash? Harvard Business Review, 77 (6), pp.147-158.

Rebick, M., \& Takenaka, A. (2006). The Changing Japanese Family. London and New York: Routledge. 
Roach, S. S. (1996). The Hollow Ring of the Productivity Revival. Harvard Business Review, 74 (6), pp.81-89.

Robbins, S. P. (1991). Management. Englewood Cliffs: Prentice Hall.

Roe, M. J. (1994). The Political Roots of American Corporate Finance. Princeton, New Jersey: Princeton University Press.

Roethlisberger, F. J. (1977). The elusive phenomena: an autobiographical account of my work in the field of organizational behavior at the Harvard Business School. Boston, Mass.: Harvard University Press.

Roethlisberger, F. J., \& Dickson, W. J. (1939). Management and the worker: an account of a research program conducted by the Western Electric Company, Hawthorne works, Chicago. Cambridge, Mass.: Harvard University Press.

Román, Z. (1972). Progress and planning in industry: Proceedings of the International Conference on Industrial Economics: Budapest, 14-17 april, 1970. Budapest: Akadémiai Kiadó.

Román, Z. (2003). A versenyképesség kulcsa : A termelékenység. Munkaügyi Szemle, 47, (6), pp.28-32.

Rozman, G. (2002). Can Confucianism Survive in an Age of Universalism and Globalization? Pacific Affairs, 75 (1) pp.11-37.

Saito, T., \& Vaszkun, B. (2010). What is the Lifetime of the 'Lifetime Employment'? Empirical Research from Japan. Journal of Asia Pacific Studies, 1 (3), pp.591614.

Sajtos, L., \& Mitev, A. (2007). SPSS Kutatási és adatelemzési kézikönyv. Budapest: Alinea.

Sako, M. (1992). Prices, Quality and Trust: Inter-Firm Relations in Britain \& Japan. Cambridge: Cambridge University Press.

Sako, M. (1998). Does Trust Iimprove Business Performance? In R. M. Kramer, Organizational Trust: A Reader (pp.267-292). Oxford: Oxford University Press.

Sakudo, Y. (1990). The management practices of family business. In C. Nakane, \& S. Oishi, Tokugawa Japan: The Social and Economic Antecedents of Modern Japan (pp. 147-166). Tokyo: University of Tokyo Press.

Sato, T. (1990). Tokugawa villages and agriculture. In C. Nakane, \& S. Oishi, Tokugawa Japan: The Social and Economic Antecedents of Modern Japan (pp. 37-80). Tokyo: University of Tokyo Press. 
Schaede, U. (2008). Choose and Focus: Japanese Business Strategies for the 21st Century. Ithaca: Cornell University Press.

Schor, J. B. (1992). The Overworked American. New York: Basic Books.

Schreyogg, G. (1980). Contingency and Choice in Organization Theory. Organization Studies, 1 (4), pp.305-326.

Schulz, F. (2006). Recruitment in Japan. In R. Haak, The Changing Structure of Labour in Japan (pp. 169-179). Basingstoke: Palgrave Macmillan.

Schwarz, J. E., \& Volgy, T. J. (1985). The myth of America's economic decline. Harvard Business Review, 63 (5), pp.98-107.

Selznick, P. (1957). Leadership in administration; a sociological interpretation. Evanston, Ill.: Row, Peterson.

Sheard, P. (1986). Intercoporate shareholdings and structural adjustment in Japan. Canberra, Australia: Research School of Pacific Studies, Australian National University.

Shinpo, H. (2008). Historical development of Japanese companies: corporate governance and foreign investment. [S.1.]: CreateSpace.

Sibbet, D. (1997). 75 Years of Management Ideas and Practice 1922-1997. Harvard Business Review, Supplement, 75 (5), pp.2-12.

Silverman, D. (1970). The theory of organisations: a sociological framework. London: Heinemann Educational.

Simon, H. A. (1947). Administrative behavior: a study of decision-making processes in administrative organization. New York: Macmillan.

Simpson, J. R., \& Schoenbaum, T. J. (2011). Japan has viable options on the TPP conundrum: Why not use one? The Japan Times Online [online] November 3. Available at: 〈http://www.japantimes.co.jp/text/eo20111103a1.html〉.

Skaggs, B. C., \& Leicht, K. T. (2005). Management Paradigm Change in the United States: A Professional Autonomy Perspective. In L. A. Keister, Entrepreneurship (pp. 123-150). Kidlington, Oxford: Elsevier.

Smith, A. (1937). The wealth of the nations. London: Everyman's Library.

Sugimoto, Y. (2003). An introduction to Japanese society. Cambridge and New York: Cambridge University Press.

Szabó, K. (1999). Hálózatok hiperversenyben: Vállalatok szétesése molekuláris egységekre és összekapcsolódásuk. Vezetéstudomány, 30 (1), pp.15-25. 
Szabó, K., \& Kocsis, É. (2002). Digitális paradicsom vagy falanszter?: A személyes tömegtermelés. Budapest: Aula.

Szentpéteri, I. (1974). Az igazgatástudomány szervezéselméleti alapjai. Budapest: Akadémiai Kiadó.

Szintay, I. (2004). The changing tendencies of economic organizations, where are the borders? Theory methodology practice, 1, (2), pp.51-58.

Tadokoro, M. (1999). The end of Japanese egalitarianism. Bulletin del Committee on Intellectual Communication, (3) p.60-72.

Tari, E. (1995). Adalékok a vállalati stratégia elméletének és gyakorlatának korai fejlődéstörténetéhez. Vezetéstudomány, 26, (12), pp.14-22.

Tari, E. (2002). Konszernek kialakulása és fejlődése. In R. Bühner, M. Dobák, \& E. Tari, Vállalatcsoportok : Konszern szervezetek, holding-struktúrák (pp. 45-64). Budapest: Aula.

Taylor, F. W. (1911). The Principles of Scientific Management. New York; London: Harper \& Brothers.

Taylor, F. W. (1983). Üzemvezetés - A tudományos vezetés alapjai. Budapest: Közgazdasági és Jogi Könyvkiadó.

Théret, B. (2000). Theoretical problems in international comparisons: Towards a reciprocal improvement of societal analysis and régulation theory by methodic structuralism. In M. Maurice, \& A. Sorge, Embedding Organizations: Societal Analysis of Actors, Organizations and Socio-Economic Context (pp. 101-116). Amsterdam and Philadelphia: John Benjamins.

Thomann, B. (2008). Le salarié et l'entreprise dans le Japon contemporain: Formes, genèse et mutations d'une relation de dépendance (1868-1999). Paris: Les Indes savantes.

Tokunaga, S. (1983). Marxist interpretation of Japanese industrial relations, with special reference to large private enterprises. In T. Shirai, Contemporary Industrial Relations in Japan (pp. 313-329). Madison: University of Wisconsin Press.

Totman, C. (2006). Japán története. Budapest: Osiris.

Tsuneyoshi, R. (2001). The Japanese Model of Schooling. New York and London: RoutledgeFalmer.

Tsurumi, Y. (1987). The U.S. Trade Deficit with Japan. World Policy Journal, 4 (2), pp.207-230. 
Tsutsui, W. M. (2001). Manufacturing Ideology: Scientific Management in TwentiethCentury Japan. Princeton and Oxford: Princeton University Press.

Turner, C. E. (1932). Test Room Studies in Employee Effectiveness. Read before the Industrial Hygiene Section of the American Public Health Association at the 61st Annual Meeting in, Washington, D. C. Available at: <http://ajph.aphapubli cations.org/cgi/reprint/23/6/577.pdf>.

Tushman, M. L., \& Romanelli, E. (1985). Organizational evolution: A metamorphosis model of convergence and reorientation. In B. M. Staw, \& L. L. Cummings, Research in organizational behavior, vol. 7. (pp. 171-222). Greenwich, CT: JAI Press.

U.S. Dept. of Commerce, Bureau of the Census. (1975). Historical Statistics of the United States: Colonial Times to 1970, Part 1. Washington, D.C.: U.S. Government Printing Office.

Umezu, H. (2009). Human Capital Management (MBA class lecture). Waseda University, Tokyo, Japan. December 15.

Urista, S. (2011). Cause and Effect (note on the NBR's Japan Forum). October 26.

van de Ven, A. H., \& Poole, M. S. (1995). Explaining Development and Change in Organizations. The Academy of Management Review, 20 (3), pp.510-540.

Varga, Gy. (1972). A japán business: Irányitás és vezetés. Budapest: Kossuth.

Vaszkun, B. (2010). Crises and Employment In Japan: Maintaining Stable Employment in a Crisis Context. SOUTH-EAST EUROPE (International Relations Quarterly), 1(3). Available at: 〈www.japss.org/JAPSDec2010.html>

Vecsenyi, J. (1992a). Amerika panaszkodik. Figyelö, 36 (Febr. 27), - p. 27.

Vecsenyi, J. (1992b). Újkeletủ amerikanizmusok : Levelek Tulsából. Figyelő, 36 (June $18),-$ p. 25.

Veresné, S. M. (1993). Szervezetelemzés és fejlesztés szakértői rendszerrel. Vezetéstudomány, 24, (3-4), pp.61-72.

Vogel, E. F. (1979). Japan as number one: lessons for America. Cambridge, Mass.: Harvard University Press.

Vogel, S. K. (2006). Japan remodeled: how government and industry are reforming Japanese capitalism. Ithaca: Cornell University Press.

Voordeckers, W., Van Gils, A., \& Van den Heuvel, J. (2007). Board Composition in Small and Medium-Sized Family Firms. Journal of Small Business Management, 45 (1), pp.137-156. 
Voszka, É. (1991). Tulajdonosok és menedzserek. Európa Fórum, Vol 1, (2), pp.104115.

Voszka, É. (2011). Erős állam : A verseny feltétele vagy torzítója? Külgazdaság, 55, (5-6), pp.3-30.

Waring, S. P. (1991). Taylorism Transformed: Scientific Management Theory Since 1945. North Carollina: The University of North Carolina Press.

Washburn, N. T. (2009). Why Profit Shouldn't Be Your Top Goal. Harvard Business Review, 87, (12), p.23.

Webber, A. M. (1990). A New Separation. Harvard Business Review, 68 (1), pp.209210.

Weber, M. (1930). The Protestant Ethic and the Spirit of Capitalism. London: G. Allen \& Unwin, Ltd.

Weber, M. (1947). The Theory of Social and Economic Organization, trans. by A.M. Henderson and T. Parsons. New York: Free Press.

Weiss, A. (1984). Simple truths of Japanese manufacturing. Harvard Business Review, 62 (4), pp.119-125.

Wernerfelt, B. (1984). A Resource-based View of the Firm. Strategic Management Journal, 5 (2), pp.171-180.

West, G. B. (2007). Innovation and Growth: Size Matters. Harvard Business Review, 85 (2), pp.34-35.

Whyte, W. F. (1948). Human Relations in the Restaurant Industry. New York: McGraw-Hill Book Co.

Williamson, O. E. (1970). Corporate control and business behavior: an inquiry into the effects of organization form on enterprise behavior. Englewood Cliffs, NJ: Prentice-Hall.

Williamson, O. E. (1975). Markets and hierarchies, analysis and antitrust implications: a study in the economics of internal organization. New York: Free Press.

Williamson, O. E. (1985). The economic institutions of capitalism: firms, markets, relational contracting. New York: Free Press.

Williamson, O. E. (1996). The mechanisms of governance. New York: Oxford University Press.

Wissema, J. G., van der Pol, H. W., \& Messer, H. M. (1980). Strategic Management Archetypes. Strategic Management Journal, 1 (1), pp.37-47. 
Witzel, M. (. (2005). The Encyclopedia of the History of American Management. Bristol: Thoemmes Continuum.

Wolff, E. N. (2007). Recent Trends in Household Wealth in the United States: Rising Debt and the Middle-Class Squeeze. Annandale-on-Hudson, New York: The Levy Economics Institute of Bard College.

Womack, J. P., Jones, D. T., \& Roos, D. (1990). The machine that changed the world: based on the Massachusetts Institute of Technology 5-million dollar 5-year study on the future of the automobile. New York: Rawson Associates.

Wood, S. (1979). A Reappraisal of the Contingency Approach to Organization. Journal of Management Studies, 16 (3), pp.334-354.

Woodward, J. M. (1965). Industrial organization: theory and practice. London: Oxford University Press.

Wren, D. A. (1994). The Evolution of Management Thought. New York: John Wiley \& Sons, Inc.

Wren, D. A. (2005). The History of Management Thought. New York: John Wiley \& Sons, Inc.

Wriston, W. B. (1990). The State of American Management. Harvard Business Review, 68 (1), pp.78-83.

Yaziji, M. (2008). Time to Rethink Capitalism? Harvard Business Review, 86 (11), pp.27-28.

Yoshimori, M. (1995). Whose Company Is It? The Concept of the Corporation in Japan and the West. Long Range Planning, 28 (4), pp.33-44.

Yoshino, M. Y. (1968). Japan's Managerial System: Tradition and Innovation. Cambridge, Mass.: MIT Press.

Zaleznik, A. (1992). Managers and Leaders: Are They Different? Harvard Business Review, 70 (2), pp.126-135.

Zhu, Z. (2009). Understanding East Asia's Economic "Miracles". Ann Arbor, Michigan: Association for Asian Studies. 


\section{List of the author's relevant publications:}

\section{Publications in Hungarian}

Marosi, M. \& Vaszkun, B. (2009). A japán menedzsment kialakulása és fejlődése. In: Szöveggyüjtemény a Vezetéselmélet és módszertan c. tárgyhoz (textbook for Management Theories and Methods), Corvinus University of Budapest, Institute of Management

Vaszkun, B. (2008). Kína a nemzetközi üzleti gazdaságtan tükrében (China from an International Business Perspective). In: Czakó, E. (ed): Fejezetek a nemzetközi üzleti gazdaságtanból (Chapters from International Business). Working paper, Corvinus University of Budapest, Institute of Operations Management

\section{$\underline{\text { Publications in foreign languages }}$}

Vaszkun, B. \& Tsutsui, W. (2012). A Modern History of Japanese Management Thought. Journal of Management History (18) 4 (pp. 1-17)

Vaszkun, B. (2011). Taylor and After: Paradigms in the History of Management. Conference paper: "Scientific Management" and Management Science Today, University of Szeged, Hungary, November 5.

Vaszkun, B. (2011). La défense japonaise dans un contexte de multidisciplinarité. In: Renaud, P., Maár, J. \& Sandu, T., Ouest-Est: Dynamiques centre-périphérie entre les deux moitiés du continent (77-82). Paris : L'Harmattan. ISBN : 978-2296-13972-5

Saito, T. \& Vaszkun, B. (2010). What is the Lifetime of the "Lifetime Employment"? Empirical Research from Japan. Journal of Asia-Pacific Studies (1) 3: 591-614 www.japss.org/JAPSDec2010.html

Vaszkun, B. (2010). Crises and Employment in Japan: Maintaining Stable Employment in a Crisis Context. South-East Europe - International Relations Quarterly (1) 3. http://dke.equal.hu/page/vol.asp?strVol=GIXBRT (pp. 1-12) 